\title{
THE CONTEMPORARY COMMON:
}

Reinvigorating the Public Realm Through Enhancing

Topophilic Relationships

\author{
by \\ Daniel Carey \\ B.Arch. Sci., Ryerson University, 2016
}

\author{
A thesis \\ presented to Ryerson University \\ in partial fulfillment of the \\ requirements for the degree of \\ Master of Architecture \\ In the Program of \\ Architecture
}

Toronto, Ontario, Canada. 2018

CDaniel Carey, 2018 

"People come to where people are."

- Scandinavian Proverb

iii | Page 



\section{AUTHOR'S DECLARATION}

I hereby declare that I am the sole author of this thesis. This is a true copy of the thesis, including any required final revisions, as accepted by my examiners.

I authorize Ryerson University to lend this thesis to other institutions or individuals for the purpose of scholarly research.

I further authorize Ryerson University to reproduce this thesis by photocopying or by other means, in total or in part, at the request of other institutions or individuals for the purpose of scholarly research.

I understand that my thesis may be made electronically available to the public.

Daniel Carey 



\section{The Contemporary Common:}

Reinvigorating the Public Realm Through Enhancing Topophilic Relationships

Master of Architecture 2018

Daniel Carey

Program of Architecture, Ryerson University

\section{ABSTRACT}

Urban neighbourhoods are experiencing an increase in density, placing greater importance on a vibrant and invigorated public realm. By focusing on enhancing place-based relationships, the quality of public spaces can be rejuvenated, improving social relations while creating an enhanced sense of community.

The contemporary common is a multi-faceted public space that functions as a unifying platform for social inclusion, collective culture, and civic inculcation. This is accomplished through the use of topophilic design, a place-based design methodology that focuses on the creation of interventions that facilitate the definition of place.

These ideas are tested through the establishment of a community hub within St. James Town. The common has the potential to revitalize the public realm, attempting to enable culturally-rich spaces. Creating this identity for Toronto's public parks can improve civic formation, ultimately establishing neighbourhoods resilient to the current carceral archipelago of Toronto's urban green spaces. 



\section{ACKNOWLEDGEMENTS}

The following design research thesis project would not have been possible without several individuals who have left their mark on this work in varying degrees.

I'd like to begin by thanking my family, for without their endless support and encouragement I would not be the person I am today nor accomplish what I have. My parents and grandparents have always been by my side, since day one, motivating me and pushing me to achieve my best. I would also like to thank my Uncle Doug. Without his endless support and editorial eye for detail, I would not be able to produce this document.

To my friends and colleagues, for their constant support, encouragement, and enthusiasm; who kept me balanced, overjoyed and confident; for our friendship and experiences which I will never forget and always be thankful for.

A special thank you to my thesis supervisor, June Komisar, for her guidance, enthusiasm, and insightful mentorship. Her dedication over the last year has helped guide my thesis to a level of excellence I didn't know I was capable of. I'd also like to acknowledge my second reader, Scott Sorli, and his ability to encourage me to push beyond the surface which helped focus my thesis in a tremendous way. Finally, l'd like to thank my program representative and research supervisor, Jenn McArthur, for her encouragement and support, in both my thesis and academic endeavours. 



\section{DEDICATION}

To my parents, Joe and Deb: for their love, endless support, and unwavering encouragement.

In loving memory of Bert Redman and Joseph Lawrence Carey. 
1.0 Introduction 1

1.1 Scales of Focus 6

1.1.1 The Neighbourhood Scale 6

$\begin{array}{ll}1.1 .2 & \text { The Building Scale }\end{array}$

$\begin{array}{ll}\text { 1.1.3 The Human Scale } & 7\end{array}$

2.0 Research Themes and Methodology 9

2.1 Environmental Considerations 11

2.2 The Anthropocene 12

2.3 Urban Resiliency 14

PART 1: THE PUBLIC GRADIENT

3.0 The Public Realm 17

3.1 Public Space $\quad 21$

3.2 Civic Space 23

3.3 Civic Sustainability and Urban Development 24

4.0 Defining the Contemporary Common 27

4.1 The Origins 29

4.2 Common Assets 30

4.3 Cooperative Management 30

4.4 Tragedy of the Commons 31

4.5 Modern Implementation and Renaissance 32

4.6 Mobilizing Principles of the Commons 33

4.7 Socio-Cultural Resonances 33

$\begin{array}{lll}4.8 & \text { Outcomes } & 36\end{array}$

4.9 The Resiliency of the Commons 37

PART 2: DESIGN METHODOLOGY

5.0 Biophilic Design: The Natural Context 41

5.1 Origins and Development 43

5.2 First Principles - The Biophilia Hypothesis 44

5.3 Design Elements $\quad 45$

5.4 Biophilic Urbanism 46

$\begin{array}{lll}5.5 & \text { Outcomes } & 47\end{array}$ 


\section{TABLE OF CONTENTS}

6.0 The Topophilic Dimension 49

6.1 Place-Based Relationships $\quad 51$

6.2 The Spirit of Place 52

6.3 Placelessness $\quad 55$

$\begin{array}{ll}\text { 7.0 Precedents } & 57\end{array}$

7.1 Public Landscape Parks $\quad 59$

$\begin{array}{ll}7.2 & \text { Linear Parks } \\ 7.3 & 61\end{array}$

$\begin{array}{lll}7.3 & \text { Institutional Buildings } & 63\end{array}$

$\begin{array}{lll}7.4 & \text { Place-Based Relationships } & 65\end{array}$

$\begin{array}{lll}7.5 & \text { Markets } & 67\end{array}$

PART 3: DESIGN PROPOSAL

8.0 An Introduction to St. James Town 73

8.1 Early Years and Development 76

$\begin{array}{lll}8.2 & \text { Present Conditions } & 77\end{array}$

$\begin{array}{lll}8.3 & \text { The Future } & 91\end{array}$

$\begin{array}{ll}\text { 8.4 Analysis and Interest } & 93\end{array}$

9.0 Design Project Proposal $\quad 97$

9.1 Design Inspiration $\quad 99$

$\begin{array}{ll}9.2 \text { Defining the Scope } & 102\end{array}$

9.3 Design Elements 105

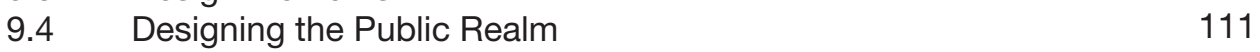

9.5 The Ontario Street Pedestrian Promenade and Commercial Hub 117

9.6 The Commons - A Public Market 139

9.7 Public Infrastructure 153

9.8 Playground Design 155

$\begin{array}{ll}10.0 \text { Conclusion } & 157\end{array}$

$\begin{array}{lr}\text { Appendix A: Model Photos } & 163\end{array}$

Bibliography 169

$\begin{array}{ll}\text { Lexicon } & 177\end{array}$ 
Figure 1 Thorncrown Chapel, E. Fay Jones, 1980

Source: Retrieved from https://www.archdaily.com/533664/ad-classics-thorncrown-chapele-fay-jones/553952d4e58ece9fb6000177-ad-classics-thorncrown-chapel-e-fayjones-photo, accessed September 14, 2017.

Figure 2 World map highlighting concentration of populations around urban centres

Source: $\quad$ Daniel Carey, 2018.

Figure 3 Thesis diagram, researrch themes, and design parameters

Source: $\quad$ Daniel Carey, 2018.

Figure 4 Scales of focus

Source: $\quad$ Daniel Carey, 2018.

Figure 5 Satallite photograph of Earth highlighting shipping routes, 2017

Source: Retrieved from http://www.hd-freeimages.com/free-hd-blue-world-earthwallpapers-download/, accessed March 23, 2018.

Figure 6 Six primary environmental considerations

Source: $\quad$ Daniel Carey, 2018. 


\section{LIST OF FIGURES}

Figure 7

Source: Retrieved from http://blogs.ucdavis.edu/sustainability/category/land/, accessed March 23, 2018.

Figure 8 Manhattan comparison, 400 years ago vs. today

Source: $\quad$ Retrieved from http://bustler.net/news/2448/2012-buckminster-fuller-challenge-en tries-published-to-idea-index-1-0, accessed October 1, 2017.

Figure 9 Illustration depicting extensive urban development

Source: Retrieved from https://avopix.com/premium-photo/103895273-shutter stock, accessed March 28, 2018.

Figure 10 Photograph of Nathan Phillips Square

Source: $\quad$ Daniel Carey, October 17, 2017.

Figure 11 Degrees of ownership/access of urban spaces

Source: $\quad$ Daniel Carey, 2018.

Figure 12 St. Peter's Square, Vatican City

Source: Retrieved http://thecatholictalks.com/artspeaks_post.asp?id=6, accessed March 28, 2018. 
Figure 13 Central Park, New York City

Source: Retrieved from https://www.snappingnewyork.com/blog, accessed on September 21, 2018.

Figure 14 London City Hall

Source: $\quad$ Retrieved from http://www.cityhalllabour.org, accessed February 12, 2018.

Figure 15 Toronto City Hall and Nathan Phillips Square

Source: https://www.videoblocks.com/video/toronto-tourism-sign-city-hall-panamtimelapse-low-angle-xpuyyjy, accessed February 12, 2018.

Figure 16 Placelessness

Source: Retrieved from https://futureinreachdesign.wordpress.com/2014/05/25/placeless ness/, accessed on September 14, 2017.

Figure 17 Critical Regionalism precedent, Saynatsato Town Hall Alvar Alto

Source: Retrieved from https://coisasdaarquitetura.wordpress.

com/2010/05/29/regionalismo-critico/, accessed March 28, 2018.

Figure 18 Central Park, New York City

Source: Retrieved from https://www.homeexchange.com/en/listing/247275, accessed March 14, 2018.

Figure 19 Concentric model of a village: (I) village, (II) fields and meadows, (III) common pastures and woods (Rosener $1985,56)$

Source: Retrieved from http://wealthofthecommons.org/essay/com mons-\%E2\%80\%93-historical-concept-property-rights, accessed on January 18, 2018.

Figure 20 The Red Lion Hotel, Yorkville, 1885

Source: Retrieved from http://wholemap.com/historic/toronto.php?neighbour hood=yorkville, accessed on September 21, 2017. 
Figure 21 Diagram of the tragedy of the common

Source: $\quad$ Daniel Carey, 2018.

Figure 22 Sherbourne Common, Waterfront Toronto, Toronto

Source: Retrieved from https://www.water-technology.net/projects/sher bourne-common-stormwater-toronto-canada/, accessed March 28, 2018.

Figure 23 Thesis Diagram

Source: Daniel Carey, 2018.

Figure 24 Close-up of a polyphylia spiral aloe

Source: Retrieved from http://www.plants-wallpapers.com/plant,spiral-cactus, accessed on April 1, 2018.

Figure 25 Biophilia, Edward O. Wilson, 1986

Source: Retrieved from http://reach-unlimited.com/p/99499715/rewilding-theearth—starting—with-urban-spaces, accessed September 21, 2017.

Figure 26 Biophilic design components

Source: $\quad$ Daniel Carey, 2018.

Figure 27 Panorama of the Swiss Alps

Source: Daniel Carey, 2017.

Figure 28 Dimensions of biophilic design

Source: Daniel Carey, 2017.

Figure 29 Vancouver, Canada is an example of a city planned with Biophilic Urbanism principles

Source: Retrieved from https://www.fotocommunity.de/photo/vancouver-downtownwaterfront-and-sta-mike-leismann/3066440, accessed July 6, 2018.

Figure 30 Biophilic design network diagram

Source: Daniel Carey, 2018. 
Figure 31 Impacts of biophilic design

Source: $\quad$ Daniel Carey, 2018.

Figure 32 National September 11 Memorial, New York City

Source: https://nypost.com/2016/04/29/patriotism-was-banned-from-the-911memorial-a-long-time-ago/, accessed March 28, 2018.

Figure 33 Identity generation process, based on Claire Hintz's dimen sions of palce and environmentally responsible behaviour

Source: $\quad$ Daniel Carey, 2018.

Figure $34 \quad$ National September 11 Memorial, New York City

Source: Retrieved from https://paththroughhistory.lloveny.com/listings/9-11-Memorial-Muse um/31769/\#.WsLIgojwaUk, accessed March 28, 2018.

Figure 35 Experiential dimensions of the spirit of place

Source: $\quad$ Daniel Carey, 2018.

Figure $36 \quad$ Nested elements of the spirit of place

Source: $\quad$ Daniel Carey, 2018.

Figure 37 Principles of place-based design

Source: $\quad$ Daniel Carey, 2018.

Figure 38 Aerial view of suburan development

Source: Retrieved from https://futureinreachdesign.wordpress.com/2014/05/25/placeless ness/, accessed September 21, 2017.

Figure 39 Kowloon walled city skyline

Source: Retrieved from http://www.scmp.com/business/article/2063972/sti fling-hong-kongs-once-unstoppable-aspirations, accessed September 21, 2017.

Figure 40 Bucharest's homogeneous skyline

Source: Retrieved from https://www.botosaneanul.ro/stiri/vrei-sa-participi-la-hramul-bisericiiizvorul-tamaduirii-iata-programul-/, accessed March 14, 2018. 
Figure 41 Quai Branly Museum, living facade, Jean Nouvel

Source: Retrieved from https://www.timeout.com/paris/en/art/amazing-things-to-do-inquai-branly-this-year, accessed March 14, 2018.

Figure 42 Aerial render of Corktown Common

Source: Retrieved from http://urbantoronto.ca/database/projects/corktown-common, accessed on February 21, 2018.

Figure 43 Swooping canopy structure and snakc/washroom pavilion

Source: Retrieved from https://www.blogto.com/city/2013/08/corktown_common_sets_the_ standard_for_toronto_parks/, accessed on February 21, 2018.

Figure 44 Splash pad

Source: Retrieved from https://www.blogto.com/sports_play/2016/07/the_top_10_splash_ pads_in_toronto/, accessed on February 21, 2018.

Figure 45 Wetland elevated boardwalk

Source: Retrieved from https://www.blogto.com/city/2013/08/corktown_common_sets_the_ standard_for_toronto_parks/, accessed on February 21, 2018.

Figure 46 Viaduc de la Bastille

Source: Retrieved from https://suethomasnet.wordpress.com/2017/10/06/your-tips-for-digi talwellbeing/, accessed on February 21, 2018.

Figure $\mathbf{4 7}$ Viaduc de la Bastille

Source: Retrieved from https://worldinparis.com/promenade-plantee, accessed on February 21, 2018.

Figure 48 View of landscaped staircase connecting to grade below

Source: Retrieved from http://www.everintransit.com/paris-park-promenade-plantee/, accessed on February 21, 2018.

Figure 49 Recessed seating along walkway

Source: Retrieved from http://thesmallsabroad.com/2016/05/see-my-paris-promenadeplantee/, accessed on February 21, 2018. 
Figure $\mathbf{5 0}$ Expressive waterfall and staircase

Source: Retrieved from http://belairsud.blogspirit.com/archive/2015/week43/index.html, accessed February 21, 2018.

Figure 51 Iconic living wall using La Mur Végétal living wall system

Source: Retrieved from https://blog.groupemobilis.com/Ce-qui-va-changer-dans-I-urban isme-parisien-prochainement_a827.html, accessed on February 21, 2018.

Figure 52 Exterior expression of interior galleries

Source: Retrieved from http://initiative-tourisme-durable.fr/content/enqu\%C3\%AAte-sur-leterrain-le-mus\%C3\%A9e-du-quai-branly, accessed on February 21, 2018.

Figure 53 Aerial overview of Quai Branly Museum

Source: Retrieved from http://www.signature-saintgermain.com/en/terrace-of-quai-bran ly-museum-an-incredible-view/, accessed on February 21, 2018.

Figure 54 Trellis structure with vines beginning to take

Source: Retrieved from http://comeniusletstravel.blogspot.com/, accessed on February 21, 2018.

Figure 55 Exterior view of Gilles Clément's landscape

Source: Retrieved from https://www.aleou.fr/salle-seminaire/14041-musee-du-quai-branly.। html, accessed on February 21, 2018.

Figure 56 Exterior view of Thorncrown Chapel

Source: Retrieved from https://www.archdaily.com/533664/ad-classics-thorncrown-chapele-fay-jones, accessed on February 21, 2018.

Figure 57 Ornamental lamp fixtures

Source: Retrieved from https://www.archdaily.com/533664/ad-classics-thorncrown-chapele-fay-jones, accessed on February 21, 2018.

Figure 58 Regulating lines and design consistency between pews, columns, and lamps

Source: Retrieved from https://www.archdaily.com/533664/ad-classics-thorncrown-chapele-fay-jones, accessed on February 21, 2018. 
Figure 59 Interior view of the chapel's tree-like structure

Source: Retrieved from https://www.archdaily.com/533664/ad-classics-thorncrown-chapele-fay-jones, accessed on February 21, 2018.

Figure 60 Interior view highlighting the chapel's blurred interior-exterior relationship

Source: Retrieved from https://www.archdaily.com/533664/ad-classics-thorncrown-chapele-fay-jones, accessed on February 21, 2018.

Figure 61 Exterior view of Markthal

Source: Retrieved from https://archidialog.com/2011/12/05/mvrdv-le-corbusier-and-theultimate-inspirational-roof-terrace/, accessed on April 29, 2018.

Figure 62 Interior view of The Horn of Plenty from a vendor's second storey

Source: Retrieved from https://radioarchitettura.com/2016/04/08/mvrdv/, accessed on April 29, 2018.

Figure 63 Interior rendering highlighting the two-storey vendors

Source: Retrieved from https://dunedinstadium.wordpress.com/tag/social-hub/, accessed on April 29, 2018.

Figure 64 Aerial perspective of the completed Muttrah Fish Market

Source: Retrieved from https://www.dezeen.com/2018/01/02/snohetta-muttrah-fish-marketfeatures-a-slatted-canopy-architecture-arabic-calligraphy-oman/, accessed on April 29, 2018.

Figure 65 Intracate canopy structure and hexagonal relief pattern

Source: Retrieved from https://www.dezeen.com/2018/01/02/snohetta-muttrah-fish-marketfeatures-a-slatted-canopy-architecture-arabic-calligraphy-oman/, accessed on April 29, 2018.

Figure 66 Experiential photograph of the canopy's shading quality

Source: Retrieved from https://www.dezeen.com/2018/01/02/snohetta-muttrah-fish-marketfeatures-a-slatted-canopy-architecture-arabic-calligraphy-oman/, accessed on April 29, 2018. 
Figure 67 The demeterialization of the canopy to demarcate the market's entrance

Source: Retrieved from https://www.dezeen.com/2018/01/02/snohetta-muttrah-fish-marketfeatures-a-slatted-canopy-architecture-arabic-calligraphy-oman/, accessed on April 29, 2018.

Figure 68 The Muttrah Fish Market site plan, N.T.S

Source: Retrieved from https://www.dezeen.com/2018/01/02/snohetta-muttrah-fish-marketfeatures-a-slatted-canopy-architecture-arabic-calligraphy-oman/, accessed on April 29, 2018.

Figure 69 World's tallest mural, Sean Martindale, 2017

Source: Retrieved from http://towerrenewal.com/turning-heads-at-st-jamestown/, accessed on February 21, 2018.

Figure 70 St. James Town neighbourhood boundaries

Source: $\quad$ Daniel Carey, 2018.

Figure 71 Neighbourhood key plan

Source: $\quad$ Daniel Carey, 2018.

Figure 72 Historic map of St. James Town, 1855

Source: Retrieved from http://relativerealty.com/blog/, accessed on February 13, 2018.

Figure 73 Historic St. James Town Victorian homes, 1913

Source: Retrieved from http://urbantoronto.ca/news/2016/07/heritage-restoration-progress es-north-st-james-town, accessed on February 13, 2018.

Figure 74 St. James Town public pool and playground

Source: $\quad$ Daniel Carey, 2017

Figure 75 Aerial view of St. James Town's apartment towers

Source: Retrieved from http://deconstructedcity.blogspot.com/2010/07/st-james-town-andregent-park.html, accessed February 13, 2018. 
Figure 76 Historic master plan, St. James Town, 1959

Source: Retrieved from https://www.blogto.com/city/2014/04/st_james_town_and_the_ messy_politics_of_urban_renewal/, accessed on February 13, 2018.

Figure 77 Toronto Daily Star, 1961

Source: Retrieved from https://www.blogto.com/city/2014/04/st_james_town_and_the_ messy_politics_of_urban_renewal/, accessed on February 13, 2018.

Figure 78 St. James Town fire insurance map, n.d.

Source: Retrieved from https://www.blogto.com/city/2014/04/st_james_town_and_the_ messy_politics_of_urban_renewal/, accessed on February 13, 2018.

Figure 79 New Howard St. development proposal

Source: Retrieved from http://urbantoronto.ca/news/2013/02/lanterras-north-st-jamestown-proposal-resurfaces, accessed on February 13, 2018.

Figure 80 St. James Town playground and public pool

Source: $\quad$ Daniel Carey, 2018.

Figure 81 Existing pergola structure for market, St. James Avenue

Source: $\quad$ Daniel Carey, 2018.

Figure 82 St. James Town public pool

Source: $\quad$ Daniel Carey, 2018.

Figure 83 Existing storefronts along the Ontario Street Continuation

Source: $\quad$ Daniel Carey, 2018.

Figure 84 Neighbourhood gateways map, 1:2500

Source: $\quad$ Daniel Carey, 2018.

Figure 85 Development applications map, 1:2500

Source: Daniel Carey, 2018.

Figure 86 Pedestrian circulation map, 1:2500

Source: $\quad$ Daniel Carey, 2018. 
Figure 87 Vehicular circulation and parking map, 1:2500

Source: $\quad$ Daniel Carey, 2018.

Figure 88 Figure-ground map, 1:2500

Source: $\quad$ Daniel Carey, 2018.

Figure 89 Noli Plan, 1:2500

Source: Daniel Carey, 2018.

Figure 90 Building usage map, 1:2500

Source: $\quad$ Daniel Carey, 2018.

Figure 91 Property ownership map, 1:2500

Source: $\quad$ Daniel Carey, 2018.

Figure 92 Tower renewal, mid-century apartment tower neighbourhood

Source: Retrieved from http://urbantoronto.ca/news/2012/12/high-rise-community-up date-tower-renewal-and-u-t, accessed September 21, 2017.

Figure 93 Worlds tallest mural, Sean Martindale, 2017

Source: Retrieved from http://www.urbaneer.com/blog/a_mini_history_on_st._james_town, accessed on September 21, 2017.

Figure 94 Sustainable and vibrant neighbourhoods diagram

Source: Retrieved from http://Retrieved from http://www.urbaneer.com/blog/a_mini_history_l on_st._james_town, accessed on September 21, 2017.

Figure 95 Neighbourhood opportunities diagram

Source: $\quad$ Daniel Carey, 2018.

Figure 96 Neighbourhood connections and linkages diagram

Source: $\quad$ Daniel Carey, 2018.

Figure 97 Overlayed mapping matrix

Source: Daniel Carey, 2018. 
Figure 98 St. James Town axo, highlighting its 19 high-rise apartment towers Source: $\quad$ Daniel Carey, 2017.

Figure 99 View from St. James Avenue looking south.

Source: Daniel Carey, 2018.

Figure 100 St. James Town resident's daily flea market, Wellesley and Ontario Street, October 2017.

Source: Daniel Carey, 2017.

Figure 101 St. James Town resident's daily flea market, Wellesley and Ontario Street, November 2017.

Source: Daniel Carey, 2017.

Figure 102 St. James Town resident's daily flea market, Wellesley and Ontario Street, March 2018.

Source: Daniel Carey, 2018.

Figure 103 St. James Town resident's daily flea market, Wellesley and Ontario Street, April 2018.

Source: Daniel Carey, 2018.

Figure 104 St. James Town Common extents and influence (walking radius) Source: Daniel Carey, 2018.

Figure 105 Site plan highlighting the extents of the scope Source: Daniel Carey, 2018.

Figure 106 St. James Town Common primary circulation spine and ancillary paths

Source: Daniel Carey, 2018.

Figure 107 Systematic integration of design methodology, design scope, and design elements

Source: Daniell Carey, 2018. 
Figure 108 Design methodology, design scope, and design elements matrix Source: Daniel Carey, 2018.

Figure 109 Design methodology, design scope, and design elements matrix Source: Daniel Carey, 2018.

Figure 110 Program parti

Source: Daniel Carey, 2018.

Figure 111 St. James Town typical tower blocks

Source: Retrieved from http://urbantoronto.ca/news/2012/12/high-rise-community-up date-tower-renewal-and-u-t, accessed September 21, 2017.

Figure 112 Base geometry selection and directionality diagram Source: Daniel Carey, 2018.

Figure 113 Sizing base geometry diagram

Source: Daniel Carey, 2018.

Figure 114 Design elements axonometric

Source: Daniel Carey, 2018.

Figure 115 Ground floor plan

Source: Daniel Carey, 2018.

Figure 116 Site plan

Source: $\quad$ Daniel Carey, 2018.

Figure 117 Site section through the Ontario Street Pedestrian Promenade and large social gathering space

Source: Daniel Carey, 2018.

Figure 118 View from Wellesley St. looking north-west

Source: Daniel Carey, 2018. 
Figure 119 Existing conditions, looking north from Wellesley St. E.

Source: Daniel Carey, 2018.

Figure 120 View from St. James Avenue looking south

Source: Daniel Carey, 2018.

Figure 121 Existing conditions, looking south from St. James Avenue Source: Daniel Carey, 2018.

Figure 122 Public gradient section through the Ontario Street Pedestrian Promenade

Source: $\quad$ Daniel Carey, 2018.

Figure 123 Ground plan highlighting micro-business vendors and cafe Source: Daniel Carey, 2018.

Figure 124 Existing conditions pedestrian promenade, August 2018 Source: Daniel Carey, 2018.

Figure 125 A perspective looking north from the Ontario Street Pedestrian \ Promenade

Source: Daniel Carey, 2018.

Figure 126 Existing conditions, looking north from the Ontario Street Pedestrian Promenade

Source: Daniel Carey, 2018.

Figure 127 A perspective looking north from the vegetated forecourt and covered pathway

Source: Daniel Carey, 2018.

Figure 128 Existing conditions, looking north from the vegetated forecourt Source: Daniel Carey, 2018.

Figure 129 A perspective looking north from the revitalized storefronts Source: Daniel Carey, 2018. 
Figure 130 Existing conditions, looking north from the service road

Source: Daniel Carey, 2018.

Figure 131 A perspective looking west from the Food Basics, looking towards the renovated storefronts

Source: Daniel Carey, 2018.

Figure 132 Existing conditions, looking west from the Food Basics

Source: Daniel Carey, 2018.

Figure 133 Single-module market stall

Source: Daniel Carey, 2018.

Figure 134 Double-module market stall

Source: Daniel Carey, 2018.

Figure 135 Single-module vendor with movable seats/planters out front

Source: Daniel Carey, 2018.

Figure 136 Parking lot emergency exit pavilion

Source: Daniel Carey, 2018.

Figure 137 Double-module vendor with second storey outdoor space and movable seats/planters out front

Source: Daniel Carey, 2018.

Figure 138 Double-module outdoor seating pavilion with second storey outdoor space and movable seats/planters out front

Source: Daniel Carey, 2018.

Figure 139 A perspective looking south from the service road, looking towards the renovated storefronts

Source: Daniel Carey, 2018.

Figure 140 Existing conditions, looking south down the service road Source: Daniel Carey, 2018. 
Figure 141 Perspective looking east along the new retail corridor, just north of the recreational field

Source: Daniel Carey, 2018.

Figure 142 Existing conditions, looking east from north of the pool

Source: Daniel Carey, 2018.

Figure 143 Perspective looking south-west, towards the new vendors, with the recreational field in beyond

Source: Daniel Carey, 2018.

Figure 144 Existing conditions, looking south-west, towards the pool

Source: Daniel Carey, 2018.

Figure 145 Existing trees diagram

Source: Daniel Carey, 2018.

Figure 146 New trees diagram

Source: Daniel Carey, 2018.

Figure 147 Pathways diagram

Source: Daniel Carey, 2018.

Figure 148 Furniture diagram

Source: Daniel Carey, 2018.

Figure 149 Lighting diagram

Source: Daniel Carey, 2018.

Figure 150 Vendors diagram

Source: Daniel Carey, 2018.

Figure 151 Typical section through pathway highlighting landscaping strategies

Source: Daniel Carey, 2018. 
Figure 152 Jan Gehl's principles of fortyfying public space

Source: Daniel Carey, 2018.

Figure 153 Aerial view of St. James Town's existing conditions

Source: Retrieved from https://www.google.ca/maps/place/St.+James+Town,+Toronto,+ ON/@43.6683364,-79.3730346,377a,35y,343.47h/=!3m1!1e3!4m5!3m4!1s0x89d4c b51a3891935:0xa11c73fe81eacdd0!8m2!3d43.6708666!4d-79.3733064, accessed on July 21, 2017.

Figure 154 Section through the ampitheatre steps over the OSPP looking north Source: Daniel Carey, 2018.

Figure 155 Overall site axo and blow-up of Wellesley frontage

Source: $\quad$ Daniel Carey, 2018.

Figure 156 View from inside the cafe looking south towards an outdoor seating area, Wellesley beyond

Source: Daniel Carey, 2018.

Figure 157 Section through Wellesley amphitheatre seating, cafe, and elevated allotment garden

Source: Daniel Carey, 2018.

Figure 158 Ground plan highlighting micro-business vendors and cafe Source: Daniel Carey, 2018.

Figure 159 Site plan highlighting canopy and elevated allotment garden Source: Daniel Carey, 2018.

Figure 160 View from service road looking east towards the community kitchen, amphitheatre steps, and vegetated forecourt.

Source: Daniel Carey, 2018.

Figure 161 Existing conditions, looking north from the Ontario Street Pedestrian Promenade

Source: Daniel Carey, 2018. 
Figure 162 Aerial view of St. James Town's existing conditions

Source: $\quad$ Retrieved from https://www.google.ca/maps/place/St.+James+Town,+Toronto,+ ON/@43.6683364,-79.3730346,377a,35y,343.47h/=!3m1!1e3!4m5!3m4!1s0x89d4c b51a3891935:0xa11c73fe81eacdd0!8m2!3d43.6708666!4d-79.3733064, accessed on July $21,2017$.

Figure 163 Images of transecting pathways, dividing the open space Source: $\quad$ Daniel Carey, 2018.

Figure 164 Site plan highlighting the large social gathering space, adjacent pavilion, enclosed dog park, and OSPP

Source: $\quad$ Daniel Carey, 2018.

Figure 165 View from social gathering area looking south-east, rendered as a play field

Source: $\quad$ Daniel Carey, 2018.

Figure 166 View from social gathering area looking south-east, rendered as a skating rink in the winter

Source: $\quad$ Daniel Carey, 2018.

Figure 167 View from social gathering area looking south-east, rendered as a social gathering area for collective congregation

Source: $\quad$ Daniel Carey, 2018.

Figure 168 Proposed board struction of The Toronto Common Authority

Source: Daniel Carey, 2018.

Figure 169 Waterfront Toronto's development projects along Toronto's waterfront

Source: Retrieved from https://waterfrontoronto.ca/nbe/portal/waterfront/Home, accessed on March 28, 2018.

Figure 170 View of playground looking north-west

Source: $\quad$ Daniel Carey, 2018. 
Figure 171 Site plan highlighting splash pad and playground

Source: Daniel Carey, 2018.

Figure 172 Flea market, Ontario St. Promenade

Source: $\quad$ Daniel Carey, 2017.

Figure 173 The public market that initiated this thesis investigation

Source: Daniel Carey, 2018.

Figure 174 A collection of images highlighting the design portion of this thesis Source: Daniel Carey, 2018. 
Figure A.1 Collection of thesis models

Source: Daniel Carey, 2018.

Figure A.2 1:50 model of the Wellesley St. E. amphitheatre steps, elevated allotment garden, and hexagonal canopy

Source: Daniel Carey, 2018.

Figure A.3 Close-up image of the tree-like canopy support structure Source: Daniel Carey, 2018.

Figure A.4 A collection of 1:50 models of the various commercial vendors Source: Daniel Carey, 2018.

Figure A.5 1:50 model of the single-module commercial vendor Source: Daniel Carey, 2018.

Figure A.6 1:50 model of the double-module commercial vendor with elevated patio space

Source: Daniel Carey, 2018.

Figure A.7 1:50 model of the double-module outdoor seating pavilion Source: Daniel Carey, 2018.

Figure A.8 1:50 model of experimental canopy support structures: the wave Source: Daniel Carey, 2018.

Figure A.9 1:50 model of experimental canopy support structures: the orthogonal tree-canopy

Source: Daniel Carey, 2018.

Figure A.10 1:50 model of experimental canopy support structures: the twisted tree

Source: Daniel Carey, 2018.

Figure A.11 1:50 model of experimental canopy support structures: the tapered tree

Source: Daniel Carey, 2018. 


\footnotetext{
rowing up in the suburbs of Toronto and spending summers up north in the Muskokas, I was exposed 3 to the beauty of nature from a young age. In the summer, the world I was surrounded by was a stark contrast to the concrete jungle of downtown Toronto, and yet, its lure was equally irresistible. Traveling downtown was always an adventure. The city presented itself as an endless landscape of opportunity, differentiated from the natural landscape. As I grew older, I would come to learn that these two distinct places had more in common than I previously believed possible.
}

I had always been a curious and insightful child, constantly trying to figure out how things work. I would take objects apart and put them back together again in order to learn what they did and how they were assembled; there was not a remote control in my house that was not missing a piece or two from a failed reassembly! Whether it be with Lego ${ }^{\mathrm{TM}}, \mathrm{K}^{\prime} \mathrm{Nex}^{\mathrm{TM}}$, or Meccano ${ }^{\mathrm{TM}}$, I always had to have something in my hands to keep my mind occupied.

As I grew older, this fascination evolved to include buildings and design. I could never simply walk down the street, mindlessly wandering like the rest of my friends. I was constantly analyzing my surroundings, inquiring about why things were designed or constructed in such a way. I slowly developed an appreciation for architecture, design, and construction. My parents would always laugh at how I could just sit at a construction site and bask in the complex structures, materials, and machinery before me. 


\section{PREFACE}

I have been fortunate enough to have traveled quite extensively with my family, allowing me to experience the way of life of vastly different cultures from around the world. But one of the constants I have noticed is people's instinctive affinity for nature. The unique approaches each city takes to integrating nature into the urban fabric fascinates me. From Central Park and the High Line in New York City, to the Superkilen Park in Copenhagen, every approach was an entirely unique response to that city's specific context, the best of which have learned from the success and failures of others. As a result, successful urban spaces around the world provide the strategies that function as the foundation upon which this thesis is built.

It seems only natural then that when tasked with developing a topic for my Master of Architecture designresearch thesis project that I would challenge myself with the endeavour of integrating the natural experiences of my childhood into an architectural medium, in the hopes of evoking the same feelings of place and identity. This thesis provides me with the opportunity to unite two of my favourite environments to be in: the urban and the natural. Through engaging, navigating, and designing the public realm, my hope is to develop more than just an urban park - to produce a stratified approach to improving urban public spaces. 



\section{INTRODUCTION}

HOW ARCHITECTURE AND URBAN DESIGN CAN IMPROVE PROBLEMATIC STRESSES OF PUBLIC SPACE THROUGH THE CONTEMPORARY COMMON

"They travel long distances to stroll along the seashore, for reasons they can't put into words."

- Edward O. Wilson

$\mathbf{T}$ his thesis is a response to the problematic stresses on the urban public realm in Toronto's vertically densifying neighbourhoods, specifically looking at the impact on its urban green space. While Toronto has some beautiful parks, many of these spaces lack integration within the urban fabric - as if they are solely provided to be green bandages on a concrete jungle rather than social condensers that increase urban vitality. Through analysis and observation, it appears as if only a handful of these outdoor public green spaces are designed to function as an interface for play, recreation, and cultural formation. What is more common are generic spaces that do little to invigorate the public realm. 


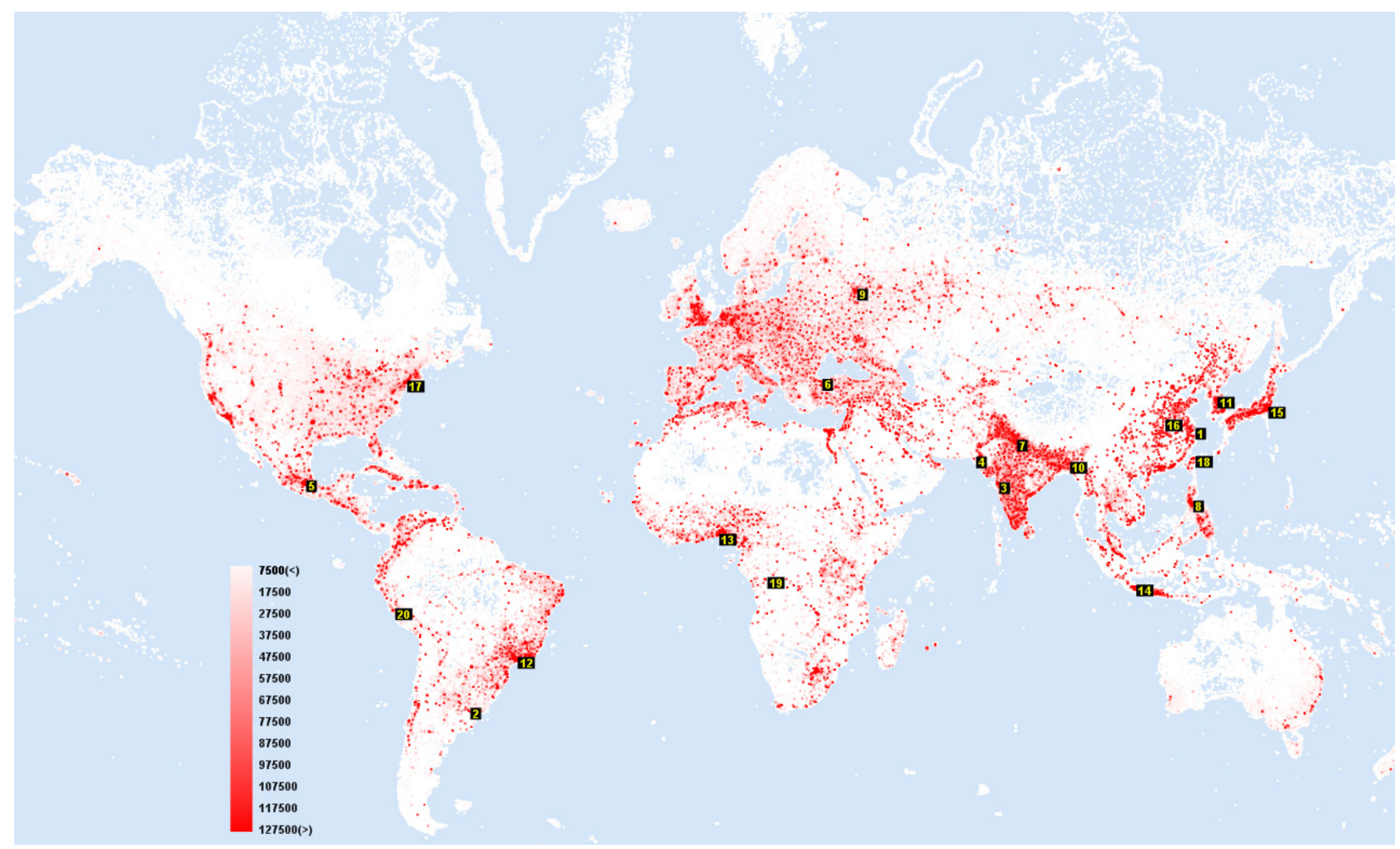

FIGURE 2

World map highlighting concentration of populations around urban centres

Jan Gehl, a Danish architect and professor, gave the concluding presentation at the 2010 Velo City Global Conference in Copenhagen. He discussed how by $2050,65 \%$ of the world's population will be living in cities, an increase by over $11 \%$ from the $54.5 \%$ that currently do (Gehl, 2011). This creates a series of challenges; however, one of the greatest stresses it creates is for the public realm. As the population and density of cities continue to increase, there will inevitably be more people sharing the same amount of space. Gehl, an expert on sustainable urbanism, discusses how the growth rate of mega-cities currently remove pedestrianism from the planning process. In his book, Life Between Buildings (2011), Gehl describes the declining quality of public life in urban public spaces because of unsustainable urban growth. He establishes that life between buildings is an intrinsic dimension of architecture, and yet, it is one that has been neglected. He additionally he outlines principles of urban design for cold climates to facilitate year-round activated public.

"Cultures and climates differ all over the world, but people are the same. They'll gather in public if you give them a good place to do it."

\section{- Jan Gehl (Velo City Global Conference in}

Copenhagen, 2010)

Beyond parks and urban green space, adequate consideration needs to be given to the ways in which buildings interact with the city's ground plane and its inhabitants. The public space surrounding buildings is an inherent extension of architecture, and therefore, a critical consideration in the design of any project. As Toronto continues to grow in density, the ratio of green space to inhabitants is dropping - there is a greater number of people 


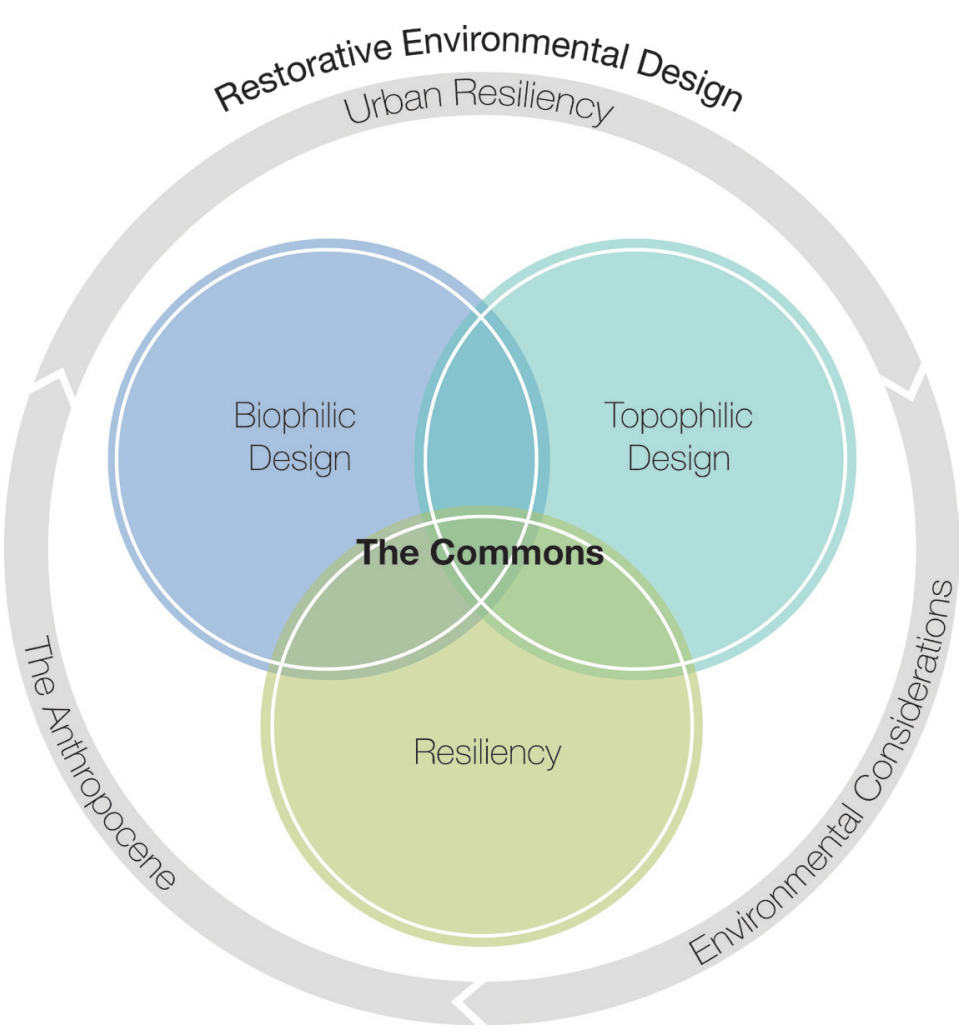

\section{FIGURE 3}

Thesis diagram, research themes and design parameters.

sharing a quantity of green space that is not growing at a proportional rate. The prevalence of the high-rise in the contemporary city is a significant contributing factor to this disparity. The notion of the high-rise stems from the idea that a building can function as a vertical city. This paradigm falls apart, however, when the user is removed from design. Urban vitality is compromised when the public realm is neglected, resulting in cities that are no longer responsive to the societal forces of change. The value of well-designed public spaces continues to rise as a result of this increased density.

The working hypothesis of this thesis is that the lacking societal attachment to buildings and places is one of the fundamental contributing factors to the destruction and decay of urban form. It will be argued that this has manifested itself in an apathetic public, which can be seen in the insufficient stewardship and responsibility exercised by users (Amin, 2008). As a response, urban planning and landscape urbanism practices are employed by this thesis to develop a stratified approach to place-based design. This is informed by international precedents that have demonstrated successful place-making and urban design, ranging from public landscape parks, civic spaces, institutional programs, and public marketplaces. Theprimaryoutcomeofthisthesisisthedevelopment of a methodology for reinvigorating underutilized public park space across Toronto. This is manifested through defining the contemporary common, a hybrid civic and public space that establishes the domain of the public through public ownership and the equitable distribution of resources. 
A driving ambition of this thesis is to improve social interaction and develop a design capable of obtaining a sense of place. It will be argued that this can be achieved through proposing a design framework that intends to the enhance the public realm through improving the user's connection with nature, within the modern-built environment.

This book is broken down into three parts: Part 1 - The Public Gradient, Part 2 - Design Methodology, and Part 3 - Project Proposal - The Contemporary Common. As a prelude, the first chapter establishes the research framework that structures this thesis (Figure 3 ). It explores three primary research themes that fall under the focus of Restorative Environmental Design: environmental justice, the Anthropocene, and architectural resiliency. These research themes establish the extents of this thesis, mandating a design that is informed by restorative environmental design practices.

Considering these research parameters, Part 1 begins with a critique of Toronto's public realm, describing the evolution of public space and its current shortcomings. Within The Public Gradient, the current state of Toronto's public realm is analyzed, differentiating the roles of public vs civic spaces. It investigates the role urban development plays on civic sustainability, focusing particularly on the lack of attachment between people and architecture within an urban environment. Part 1 presents the position that successful urban placemaking requires a redefinition of what public space should be. This revitalized public space is given the title of The Contemporary Common. The common functions as a vehicle to improve cultural and social agonism within this thesis, and is subsequently the primary design outcome. Social agonism is a concept developed by Michel Foucault that hypothesizes that there are potentially positive social benefits and outcomes as a result of social, political, and various other means of competition and conflict.

From this critique, Part 2 discusses relationships between people and their built environment, adopting the design parameters of Biophilic Design, with a focus on Topophilic Design, the outcome of which identifies place-based relationships as fundamental to the success of the common. Information from secondary sources provides the design methodology for this thesis, which is reinforced by several notable projects that exemplify the implementation of these practices.

Part 3 presents the subject and scope of the design project - an architectural, master planning and landscape architectural revitalization of St. James Town's primary public space and its potential role as a neighbourhood gateway. St. James Town is a neighbourhood which has been troubled by poor social relations, a lack of collective identity, and inadequate spaces for civic formation. A historical analysis of the neighbourhood, in addition to a critique of the existing park, is provided to situate the design decisions and master planning approach. The intervention proposed in this thesis leverages the critical mass of local residents to develop an enhanced sense of community. The St. James Town Common is a multi-faceted public space that is designed to activate the public realm. The design focuses on creating a commercial hub for the neighbourhood, leveraging community initiatives and retail space to drive pedestrian traffic. The primary design elements include a pedestrian promenade, a playground and splash pad, a multi-purpose gathering space and park 
Neighbourhood

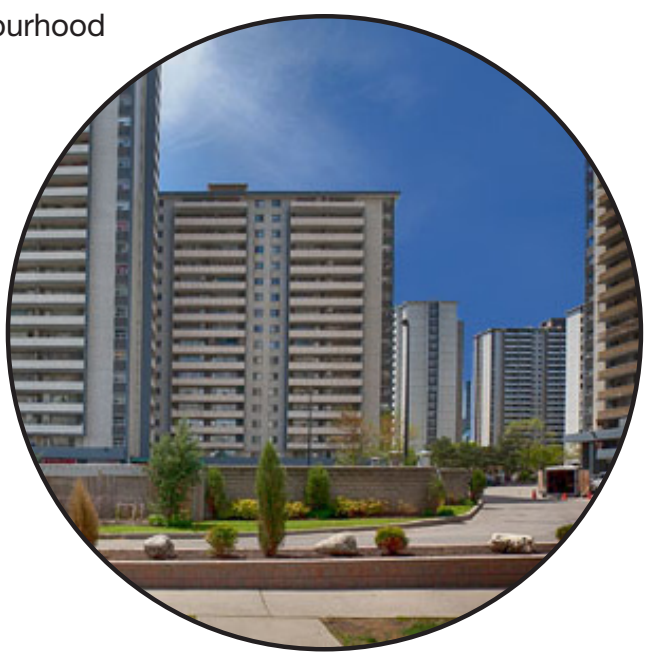

Building

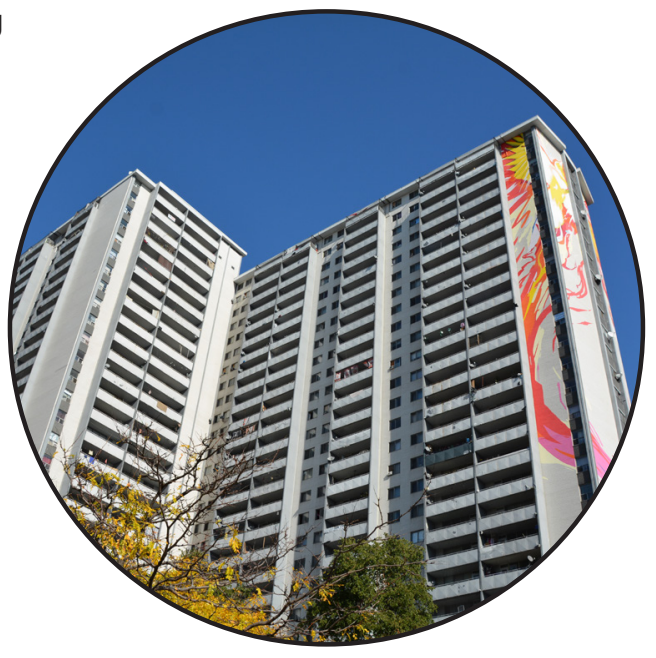

User

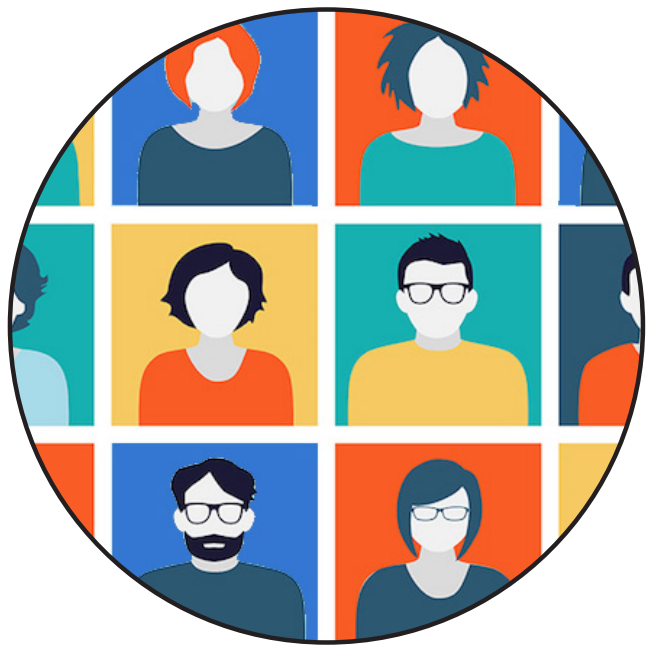

FIGURE 4

Scales of focus. pavilion, micro-commercial vendors, and an elevated park space. Together, they create a holistic design that responds to the identified opportunities in St. James Town. These interventions aim to improve place-based or topophilic relationships and enhance the identity of the St. James Town neighbourhood and surrounding community. The principles and strategies established by this thesis are intended to be applicable to the redevelopment of dense urban parks across North America and other Western countries.

\subsection{SCALES OF FOCUS}

This thesis argues that the relationship between humans and place is a fundamental relationship; one that is a requisite for the creation of resilient architecture. Therefore, it is important to begin with the understanding that this is an intrinsic human relationship that can be experienced at different scales and by varying means. It follows that any intervention must be considered concurrently at different scales. For this thesis, these topophilic relationships are investigated at three different scales: the neighbourhood, the building, and the human scale.

\subsubsection{THE NEIGHBOURHOOD SCALE}

The neighbourhood is a societal construct that has been discussed, theorized, and designed for millennia (Figure 4 - Top). While the industry of urban planning was only officially established as a practice in the mid-19th Century, urban planning practices can be seen from the ancient world, including the Minoan, Mesopotamian, and Egyptian civilizations dating back to 3,000 BC (Beatley, 2016). The understanding of the fundamental elements which 
a neighbourhood must possess in order to activate its citizens has continued to evolve ever since. The utopian ideal cities designed in the early 20th Century provide an interesting point of departure. Drawing influence from Thomas More's 16th Century utopian city arrangement and Sir Ebenezer Howard's Garden City movement, both of which limit the size of cities while connecting these small nodes together, the network of neighbourhoods that comprise the Greater Toronto Area can be compared and analyzed. This analysis reveals key relationships as well as regions that are currently suffering the greatest from unsuccessful urban design. Additionally, neighbourhoods that exemplify Biophilic Urbanism - the application of Biophilic Design at an urban scale - are scrutinized. These critical design elements - such as parks and civic spaces, landscape architecture, street design, and the public realm and its relationship to its users, as well as these interventions' role in the broader urban context - helped focus the scope of this thesis.

\subsubsection{THE BUILDING SCALE}

This thesis explores the roles that individual buildings play within the greater network of a neighbourhood (Figure 4 - Middle). Through the use of precedent analysis, specific projects that exemplify Biophilic Design are explored. As Biophilic Design hypothesizes the increase of health, productivity, and wellness when it is a preliminary driver of design rather than an afterthought, it is critical to compare and contrast built projects that took varying approaches to design. These approaches include implementing environmental features, natural shapes, forms, patterns, and processes, as well as focusing on the quality of light and space, developing place-based relationships, and drawing from evolved human-nature relationships (Kellert, et al., 2008). Additionally, as the end outcome of this design research thesis project is the design of a large-scale urban park that will incorporate surrounding buildings, the analysis of built projects will clarify the successes and challenges of the practical implementation of Biophilic Design.

\subsubsection{THE HUMAN SCALE}

The human scale plays a vital role in this thesis, as people are the end users and subsequently function as the ultimate agents of change (Figure 4 - Bottom). As much as architects, designers, and city planners believe they know what's best for people, they are unable to mandate or predict the ways in which people interact with, and experience their projects. In order to avoid being excessively prescriptive, this thesis is rooted in an in-depth investigation of ongoing activities in the public realm of St. James Town as a means of understanding existing patterns of operation and use. Additionally, this thesis is sensitive to the impact of architecture on the end user, building upon research about design interventions that have demonstrated a significant impact.

Overall, the exploration of scale is primarily explored through first-person observations, analysis, research, and precedent analysis, as well as through close readings of the writings of established scholars and practitioners of Biophilic Design and its associated subtopics. 
"Humans have wandered the Earth for thousands of years but never has our capacity to alter the

Earth's ecosystem at a larger scale been more prominent than it is today."

- Kat Lahr, Parallelism Of Cyclicality 


\section{RESEARCH THEMES AND METHODOLOGY}

"A great building must begin with the immeasurable, must go through measurable means when it is being designed, and in the end must be unmeasured."

- Louis Kahn

FIGURE 5

Satallite photograph of Earth highlighting shipping routes, 2017.
$T_{0}$ e approach for this thesis stems from the Restorative Environmental Design movement. Restorative environmental design is a two-pronged approach to design. It mandates [1] a low-environmental-impact strategy that minimizes and mitigates adverse impacts on the natural environment. It goes further to additionally require [2] a positive environmental impact, or Biophilic approach to design, fostering beneficial contact between people and nature through building and landscape design. Initially coined by Kellert (2005), this movement plays a fundamental role in focusing this thesis. Within this theme emerges three more explicit areas of research this thesis focuses on: environmental considerations, the Anthropocene, and architectural resiliency. 


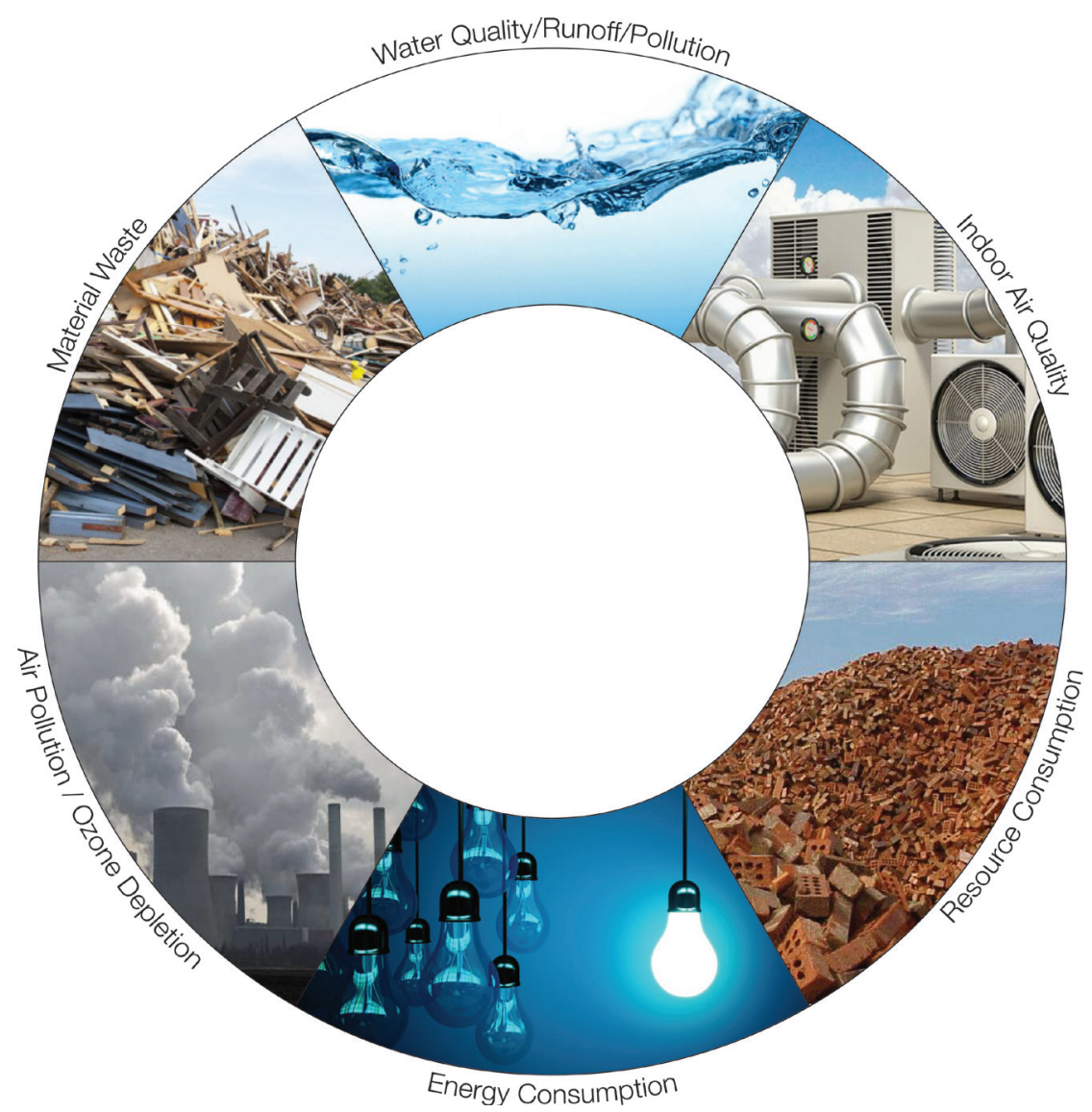

FIGURE 6

Six primary environmental considerations

\subsection{ENVIRONMENTAL CONSIDERATIONS}

A fundamental component of Restorative Environmental Design is an understanding of the environmental impacts of a design. This is informed by Environmental Justice, a concept which considers each design decision's lifecycle impact on the environment. The world has seen an unprecedented acceleration of global changes to the environment - in just the last century: rising sea levels, warming oceanic temperatures, and an increased frequency of natural disasters-all of which validate climate change on a global scale (Feireiss \& Feireiss, 2009). The disassociation between people and architecture, and more troublesome, between people and nature, has resulted in the lack of comprehension of their impacts on each other (Feireiss \& Feireiss, 2009). In the last century, policy regarding urban development has trended towards a capitalist and consumerist mindset rather than focusing on the long-term ramifications of design decisions on user engagement, enjoyment, and well-being. The buildings architects conceive play a vital role in these changes. According to the United Nations Environmental Programme - Sustainable Buildings and Climate Initiative, $40 \%$ of national (US) energy consumption is attributed to building operation (2014). From the energy they consume on a daily basis, to the amount of raw materials and resources they consume in their construction and operation, a slight change in design can have a drastic effect on the global environment. As a result, the six primary environmental concerns this thesis focuses on are outlined in Figure 6. 


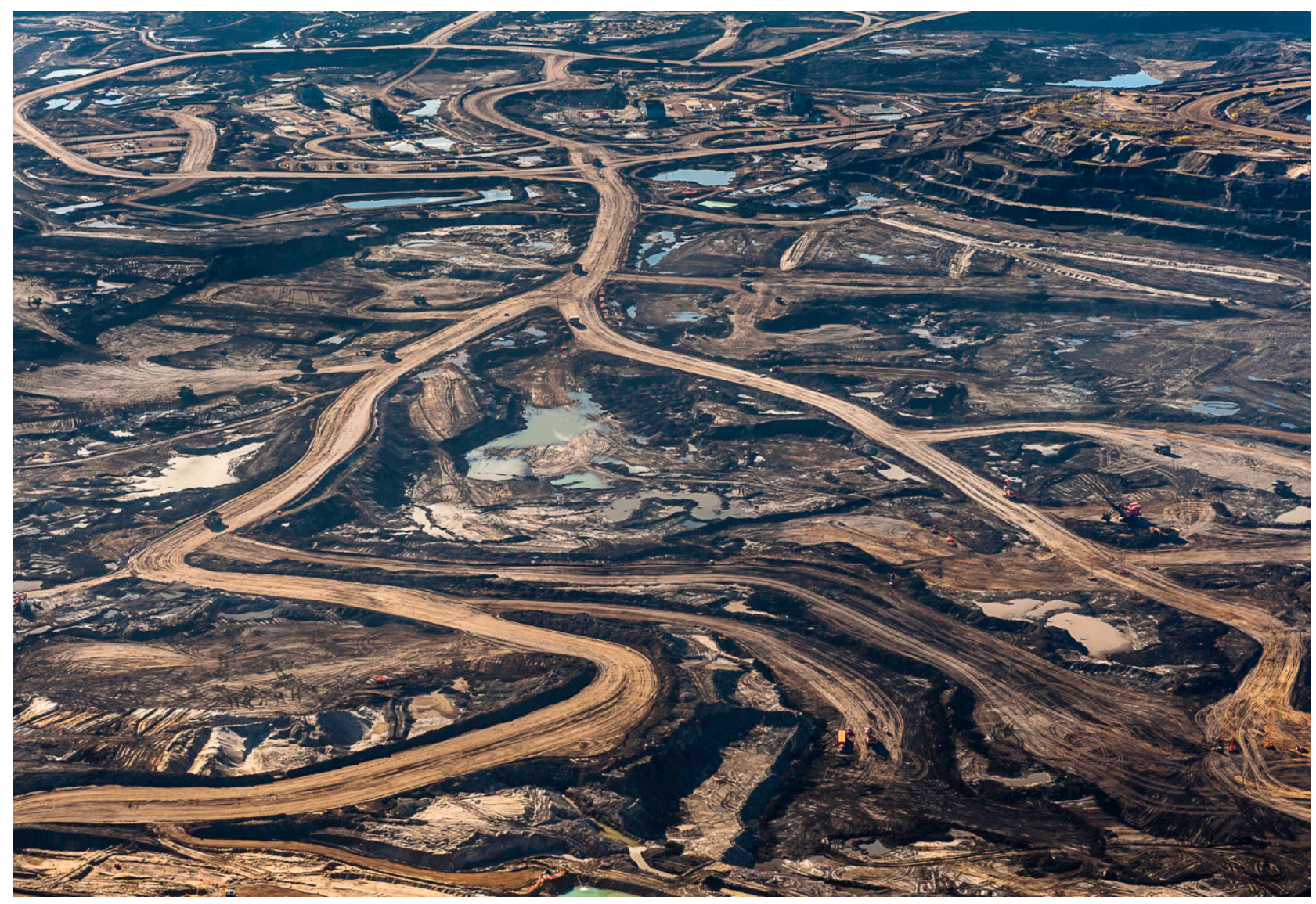

FIGURE 7

Alberta oil sands.

\subsection{THE ANTHROPOCENE}

The Anthropocene is a period of time that was initiated when humans began having a substantial impact on Earth's land use, its resources, ecosystems, biodiversity, climate, and geology (Nixon, 2001). It is widely agreed that this impact began approximately 12,000 to 15,000 years ago (Kellert, 2005). Moreover, this impact is increasing exponentially as the global population continues to grow and consume at an alarming rate. This has placed increased pressure on the energy, manufacturing, food, and transportation industries to meet unprecedented demands, culminating in an increased production of greenhouse gases (Figure 7). As a result, more heat is being trapped within the Earth's atmosphere, and ultimately accelerating climate change.
An additional critical influence is humanity's impact on biodiversity. The human race, experts believe, has substantially accelerated the global rate of species extinction. This increase has been argued quite extensively, but ranges between 100 and 1,000 times the natural rate, further illustrating humankind's impact on biodiversity and their ecosystems (Gore, 2013). It is through the Anthropocene that the concept of 'natural' - understood as resources that have not been influenced by human interference - is no longer an accurate description of any of Earth's resources. If nature is to be understood as raw resources or territory which is unadulterated by human influence, then there is no place on Earth which has yet to be impacted in some way, shape, or form, by human 


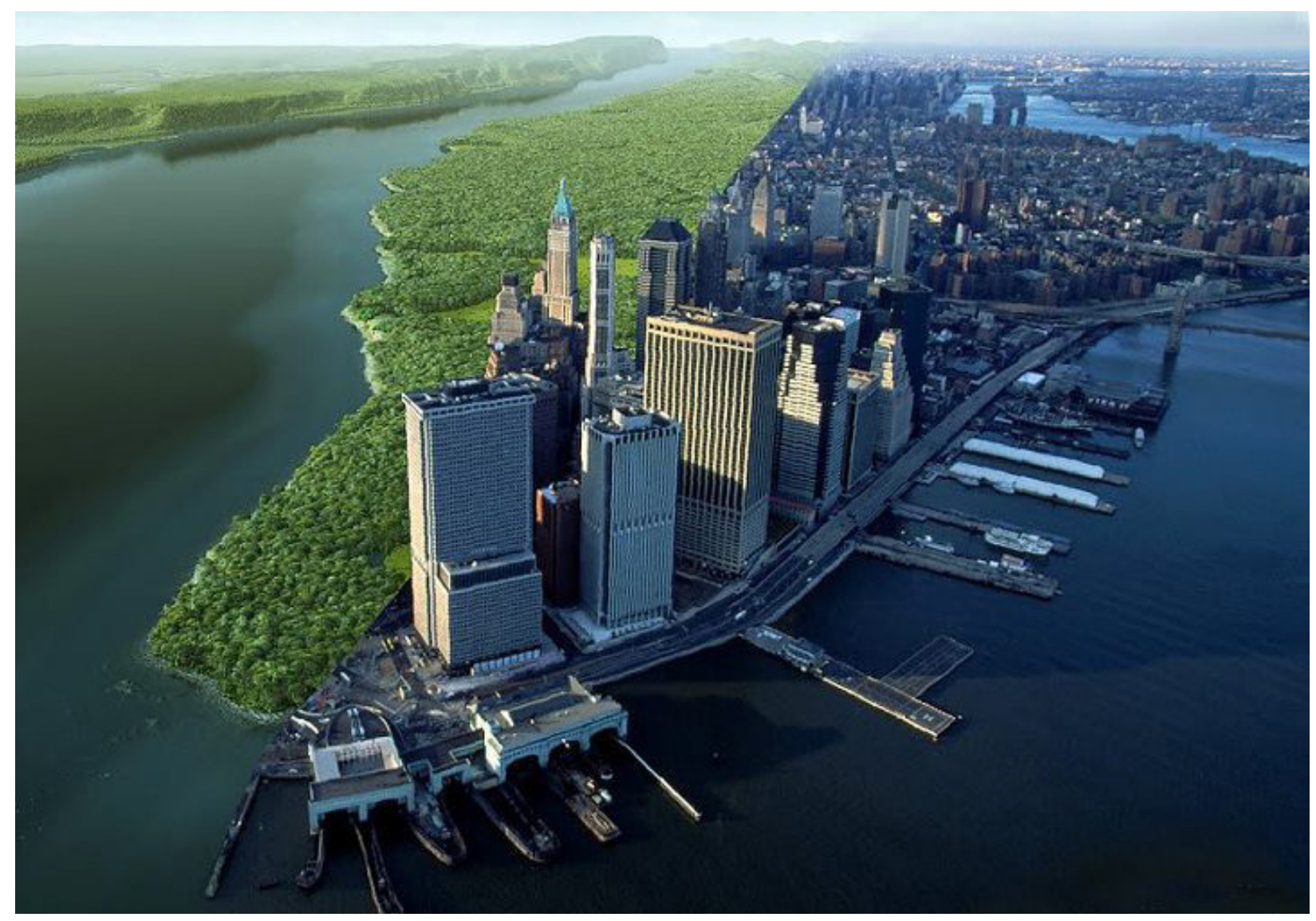

FIGURE 8

Manhattan comparison, 400 years ago vs. today.

activities. A mindfulness of the Anthropocene and environmental considerations is a necessary response to this impact-a response that constructs an overarching framework to provide structure for this thesis, and acts as a constant reminder to each decision's impact on a grander-scale.

Architecture - and the planning of cities, neighbourhoods, and buildings - should promote a more intimate connection between people and their environment (both built and organic) in order to increase overall well-being (Browning, et al., 2014). Architecture and other contrived environments create potential settings for experiential expressions of environmental justice. The built form is the medium through which humanity can begin to overcome the degradation of natural resources that has accelerated through the Anthropocene while positively influencing urban development. By focusing on enhancing place-based relationships within the urban environment, the intention is that the public will exercise an enhanced level of stewardship and advocacy towards their built and environmental contexts. It is only through such conscientious design that urban metropolises can begin to evoke the same sense of vitality and connection to place experienced when immersed within natural environments. 


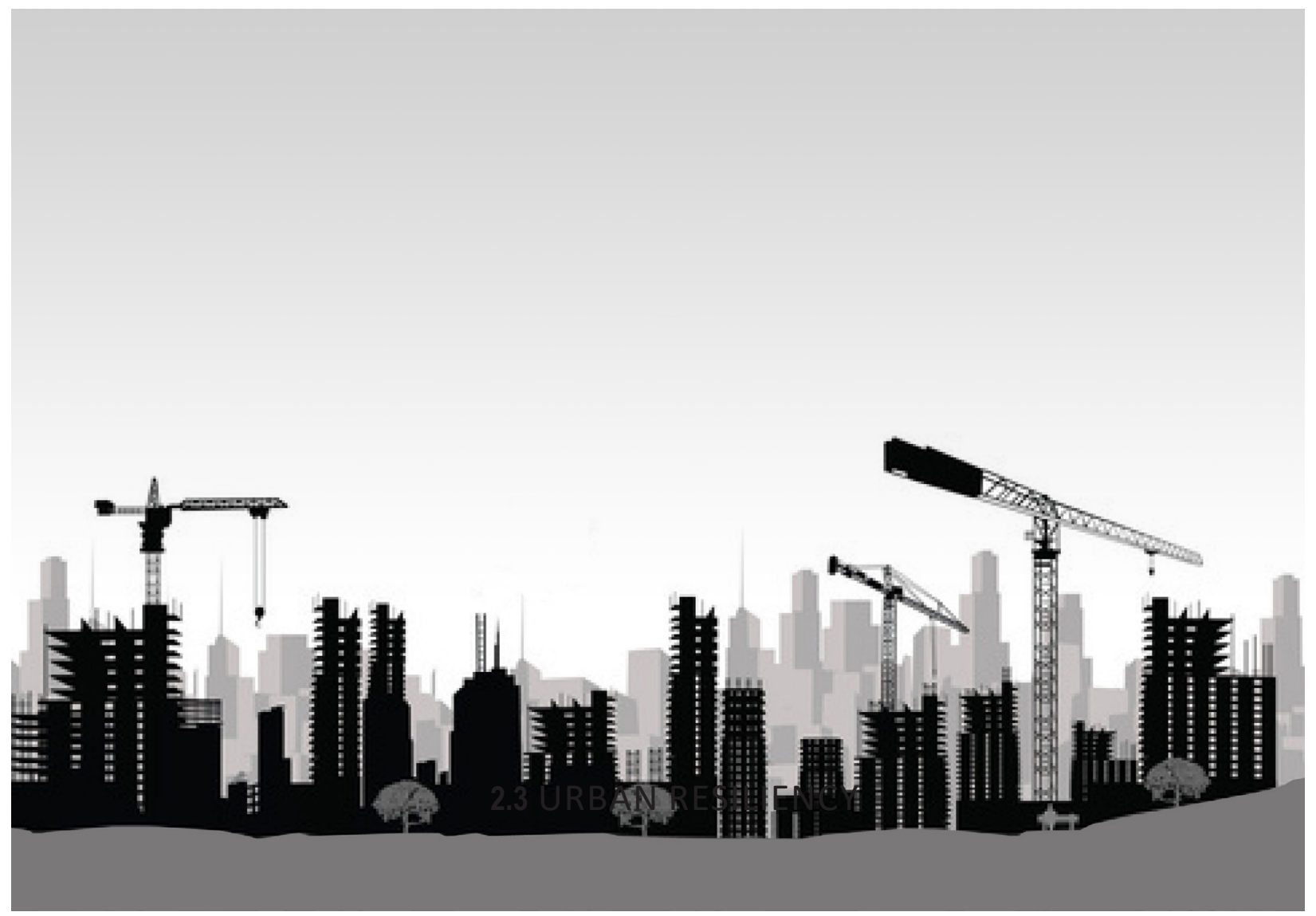

FIGURE 9

Illustration depicting extensive urban development

\subsection{URBAN RESILIENCY}

Through the lens of this thesis, urban resiliency is viewed as the capacity of urban architecture to withstand extreme forces of change. One aspect of resilient design is the creation of stronger connections between architecture and its users. Urban environments are constantly undergoing changes: shifting societal demands, politicallydriven infrastructure projects, and developerdriven urban growth and construction. Buildings are subsequently being commodified, viewed simply as assets rather than integral components of urban life (Karmanov \& Hamel, 2008). While there are numerous reasons that contribute to the premature destruction of viable buildings, the influence of developers and the quest for increased capital is a significant contributing factor, arguably affirming the claim that current urban metropolises are succumbing to the capitalist forces of change.

Improving the resiliency of design can be accomplished through a restorative environmental design approach - applying Biophilic Design principles at the scale of the individual user, building, and urban environment. This promotes urban vitality and can ultimately produce stronger connections with users. Focusing on enhancing topophilic relationships results in an architecture that is embraced by its users, rather than one that is begrudgingly occupied. When this strategy is adopted, architecture has the capacity to stand resilient to the pressures that shape the city. 

THE PUBLIC GRADIENT 


\section{$\Sigma$

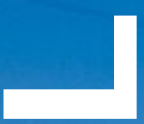

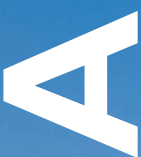 \\ II

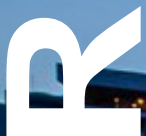

ETRER

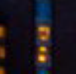

?
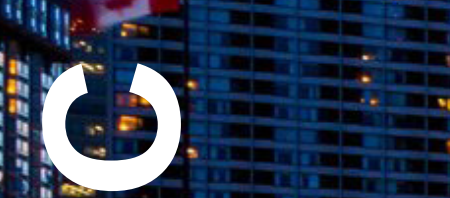

$4: 0$

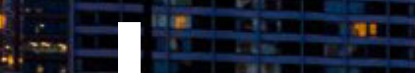

-

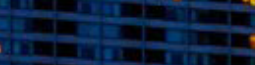

"The square is a treasure precisely because it doesn't masquerade as an outdoor museum.

It's a living place, jammed with people, changeable, democratic, urbane."
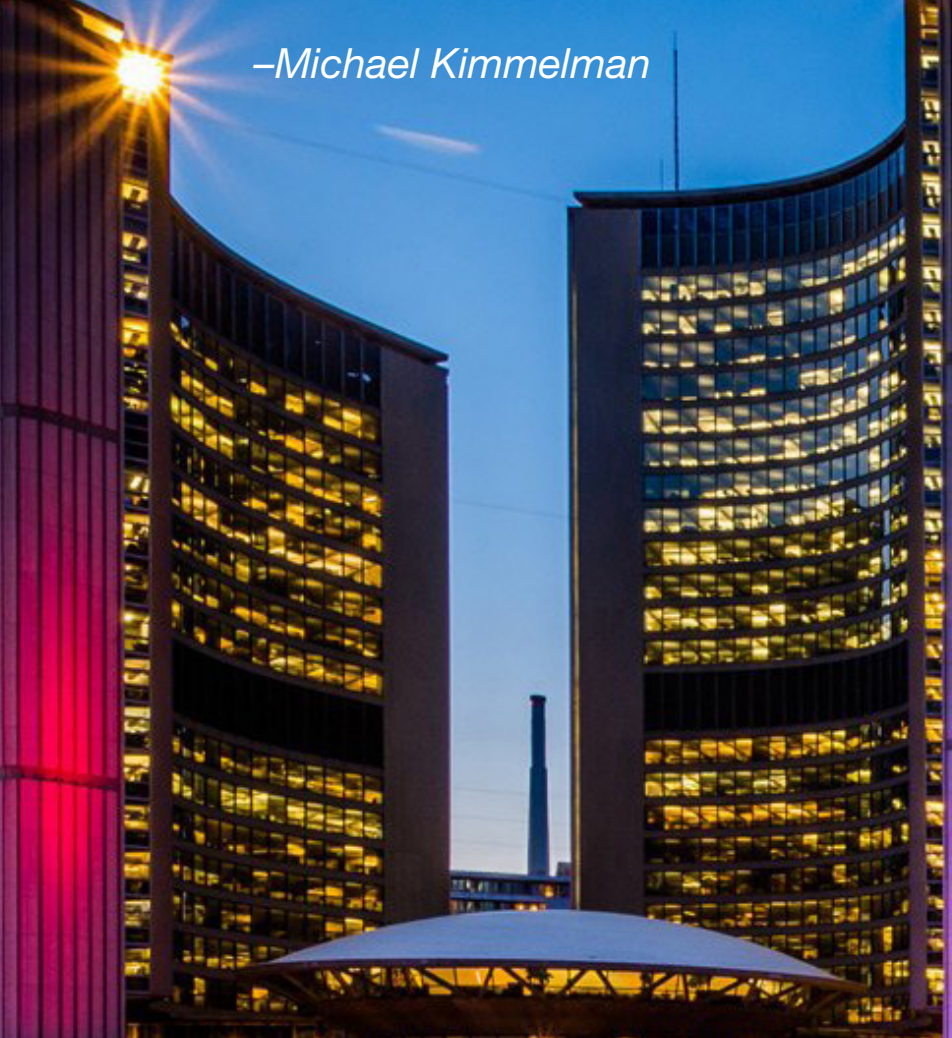

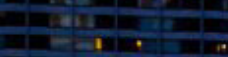

$\frac{-12}{2}$

\section{Ga}

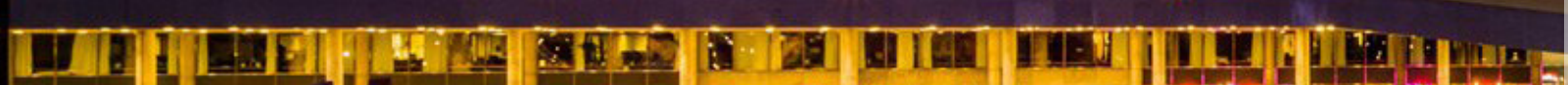

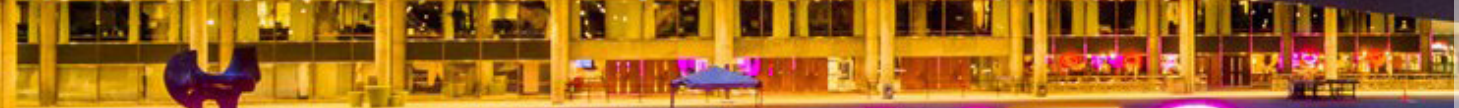
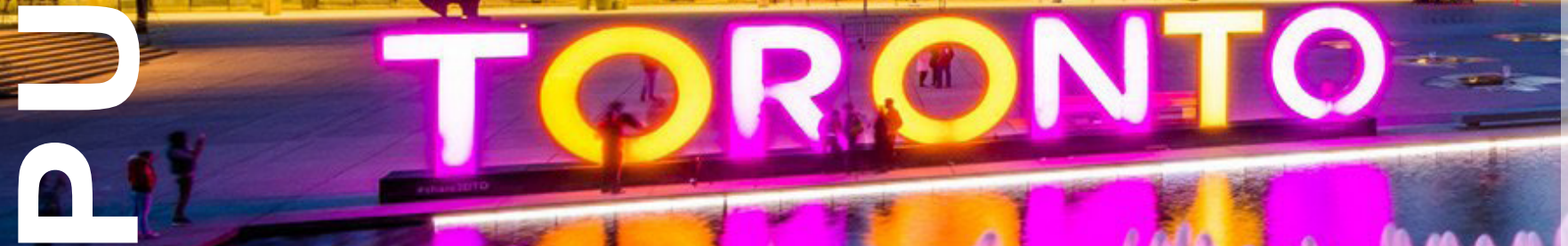

\section{4}

42
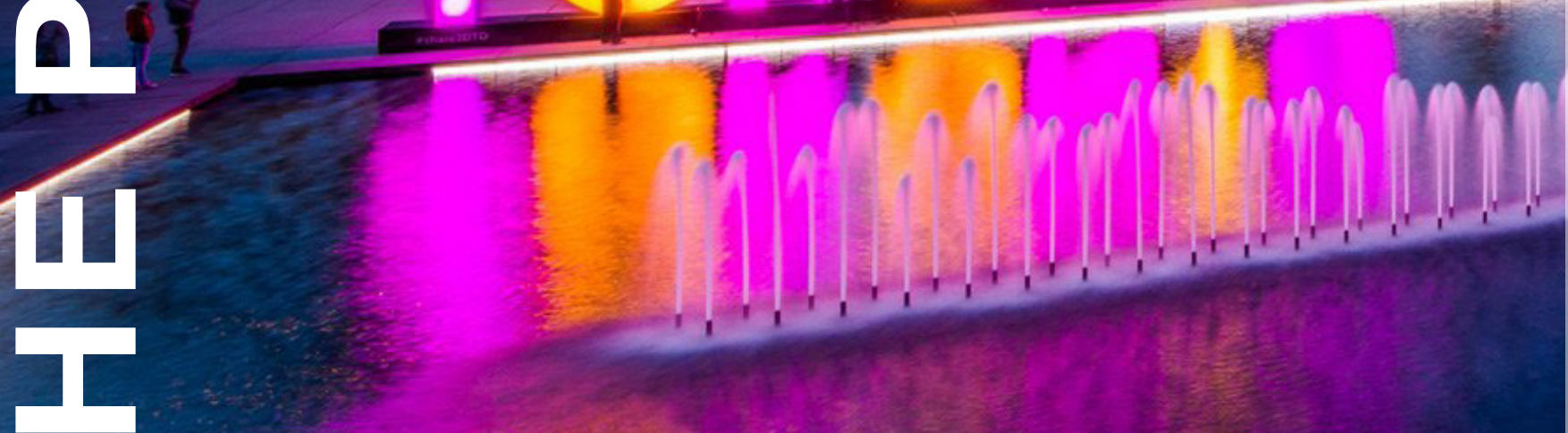


\section{THE PUBLIC REALM}

"Cultures and climates differ all over the world, but people are the same. They will gather in public if you give them a good place to do it."

\section{- Jan Gehl}

U rbanists have long held the view that the physical and social dynamics of the public realm plays a central role in the formation of publics and public culture (Amin, 2008). The understanding that architecture has a profound influence on social behaviour is a pivotal concept for this thesis. A city's streets, parks, squares, and other shared spaces have been seen as symbols of collective well-being and possibility; expressions of the success and ambition of urban visionaries and pioneers. They are the sites of public happenstance, and contribute to the formation of civic culture, while functioning as significant spaces for political debate and freethinking. While urban commentators and practitioners have varied in their views on its precise formation and boundaries, they have generally not questioned the assumption that a strong relationship exists between urban public space, civic culture, and political formation (Jacobs, 1961). While there is no denying that this relationship exists, the challenge today revolves around the condition of this relationship. The contemporary urban realm is fragmented; disrupted due to the disjointed carceral archipelago of public spaces within the urban environment, resembling Foucault's prison of islands. 
Private Restaurant Patios Toronto's Waterfront, ON

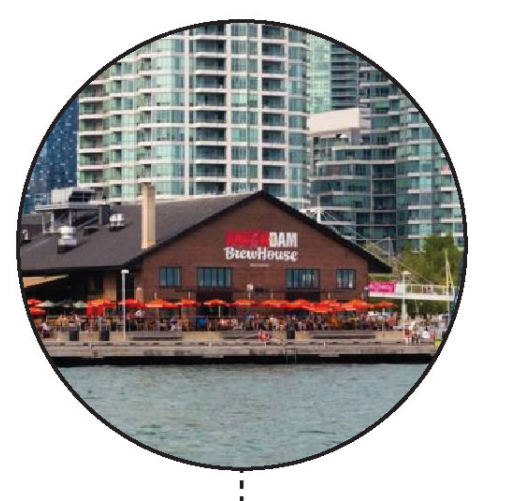

Semi-Private Front Yard Cabbage Town, ON

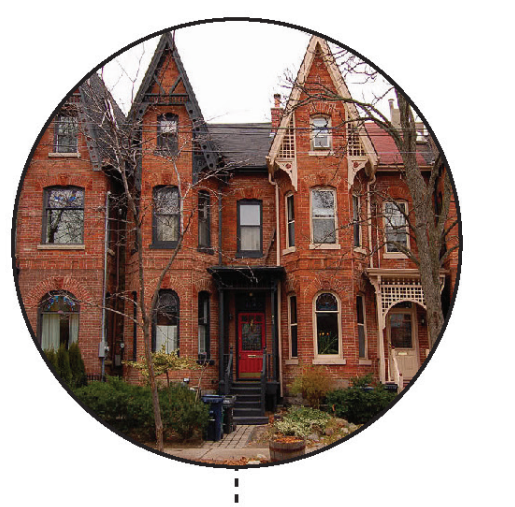

Semi-Public POPS (Plaza) Shops at Don Mills, Toronto, ON

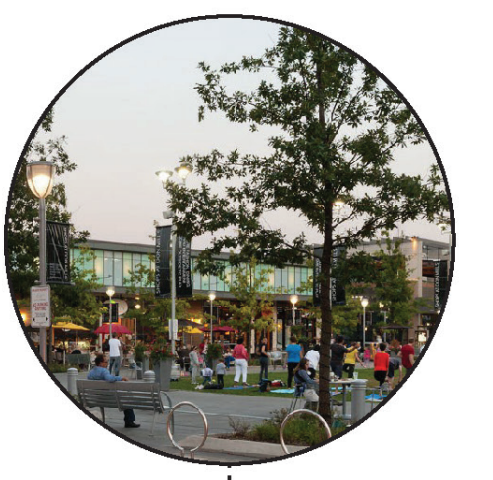

FIGURE 11

Degrees of ownership/access of urban spaces 
Public Streets and Sidewalks St. James Town, ON

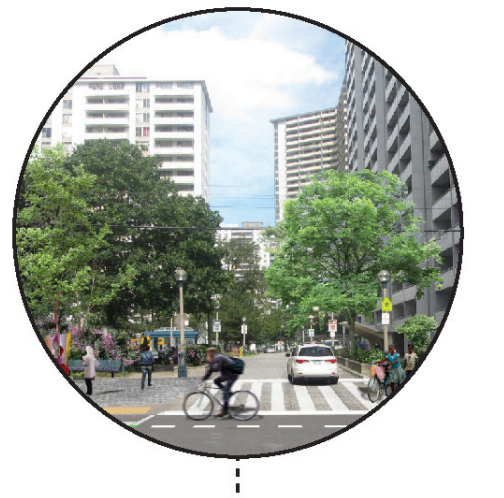

Civic Nathan Philips Square Toronto, ON

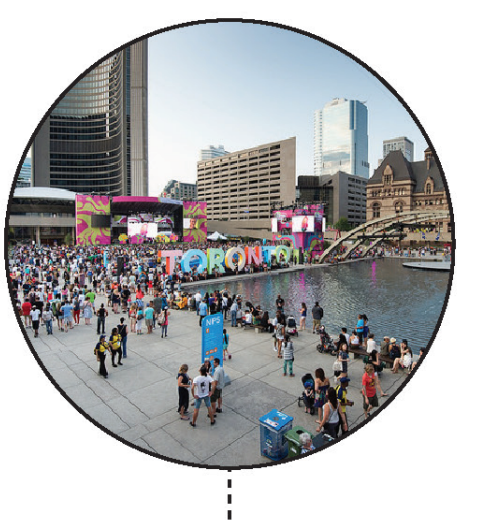

Common Corktown Common Toronto, ON

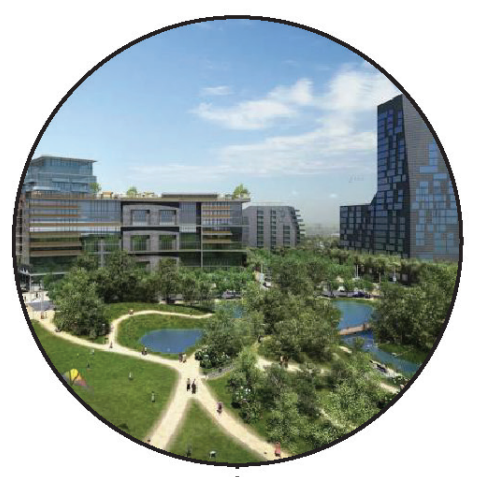




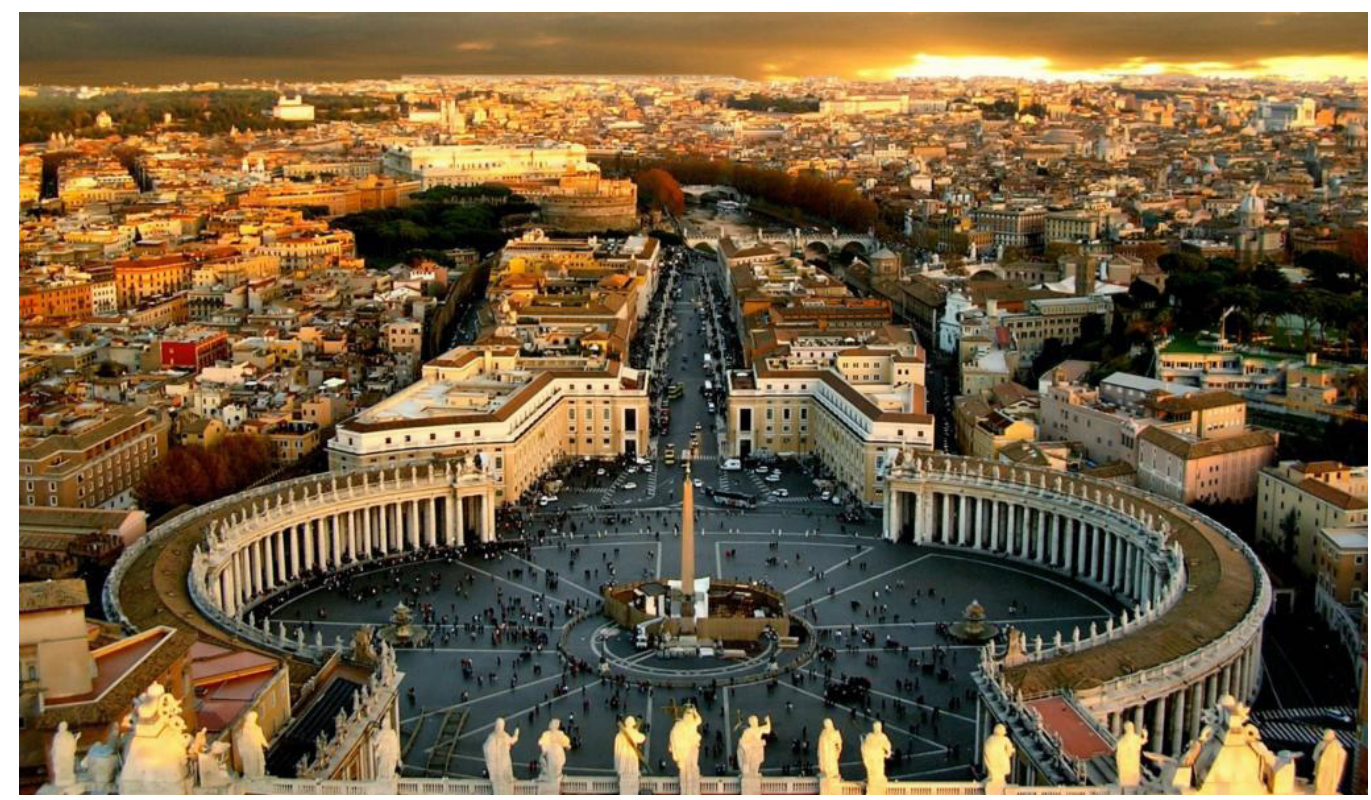

FIGURE 12

St. Peter's Square, Vatican City

\subsection{PUBLIC SPACE}

Public space can be understood as the space around, between, and within buildings which are publicly accessible. This includes streets, squares, parks, and open spaces. There is naturally a gradient of to the degree of "publicness" of these spaces (Figure 11). The role of public spaces has evolved beyond their traditional roles as spaces for commerce, leisure, civic inculcation, and political participation. This can be seen in the current age of urban sprawl, the diverse usage of public spaces, and the frequenting of socially-loaded civic spaces for political and cultural demonstration (Figure 12). While society has evolved immensely over the last several centuries, a city's most prominent public spaces continue to function as the public's fundamental stage from which their cultural and political voices could be heard. This is evident in Toronto's Dundas Square, Nathan Phillips Square, and Maple Leaf Square (also referred to as "Jurassic Park").
From classical times - starting in Italy and Greece and, through the Renaissance, into France and England - the public spaces in European cities directly influenced the formation and development of cultural and political practices, and subsequently, civic establishment (Amin, 2008). While they contribute to the unique place-definition and identity of a community, public squares and plazas significantly benefit the economy by increasing land values. This can be seen additionally in North America in the real estate surrounding New York's Central Park, Times Square, Prospect Park or High Line (Beatley, 2016). Amin (2008) argues that public space was primarily established to provide a platform for the social body of citizens. He references a quote that states,

"When public spaces are successful [...] they will increase opportunities to participate in communal activity. This fellowship in the open nurtures the growth of public life, which is stunted by the social isolation of ghettos and suburbs".

- Carr, et al. (Public Space, 1993, p. 344) 


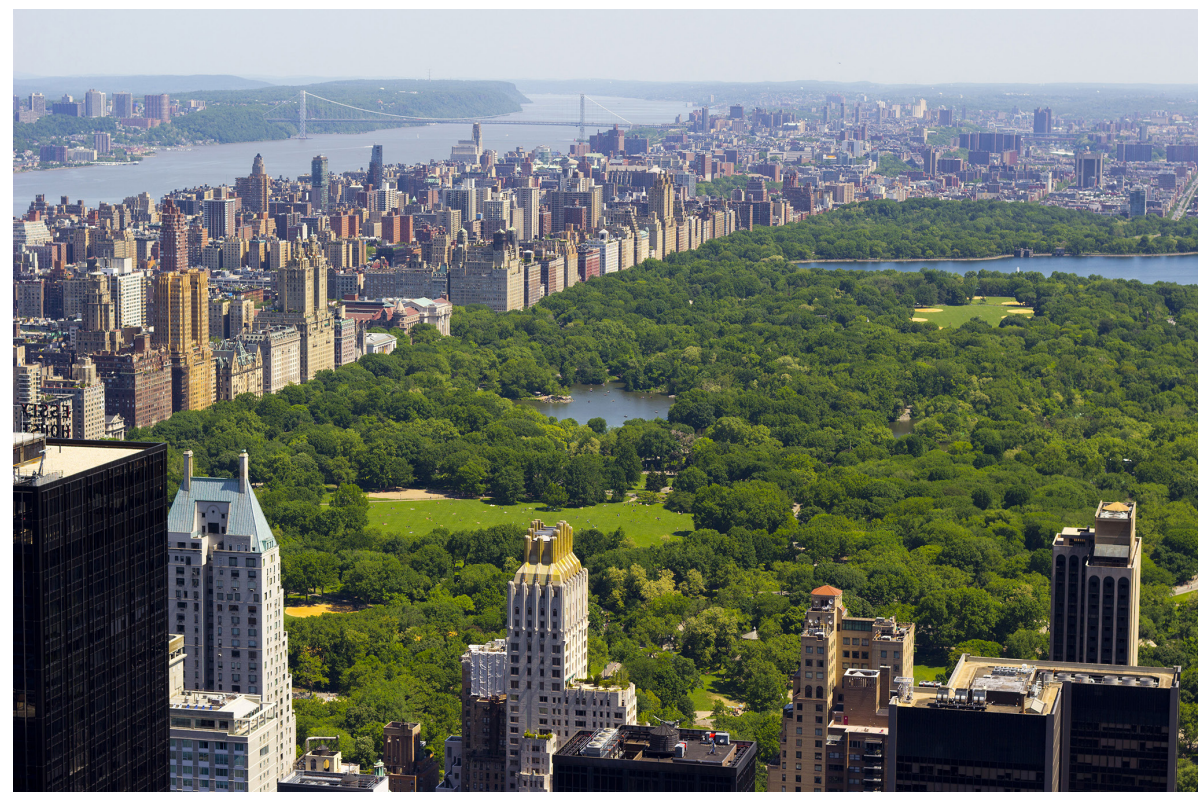

FIGURE 13

Central Park, New York City

The practice of urban planning has evolved in an attempt to manage public space in order to build social vitality and civic stewardship through the spontaneous interaction of strangers. Its foundation is rooted in the intimate connection between citizens, civic virtue, and urban public space. According to Carr, et al, this relationship relies on the:

“...free and unfettered mingling of humans in open and well-managed public space, encourages forbearance towards others, pleasure in the urban experience, respect for the shared common, and an interest in civic and political life".

- Carr, et al. (Public Space, 1993, p. 344)

As Toronto's downtown core continues to densify due to the influx of condominium developments - and more recently rental apartment buildings under construction - increasing land values are jeopardizing the accessibility and quantity of public spaces to make way for private interests. This can be seen in a new trend emerging in the urban environment known as POPS, or Privately-Owned
Public Spaces. While these micro-parks/parkettes are adding a significant amount of park space into the downtown core (adding over a million squarefeet of open space in Toronto's downtown core since 2000 (Noble, 2015)), they lack any means connectivity to one another as they are implemented on an individual, project-by-project basis.

Toronto has recently established The Urban Design Guidelines for POPS in 2014 in response to this lacking connectivity, but there are still numerous concerns regarding their operation and management. For instance, the owner of a space has the right to hire a private security contractor to monitor the POPS, a regulatory concern for the accessibility of the general population (Sharma, 2017). This has drawn the comparison by urban commentators that POPS are creating carceral archipelagos out of public space - spaces which are viewed as prisons consisting of a series of islands (Amin, 2008). The privatization of a public amenity not only goes beyond just public space, but extends further into the realm of civic space. 


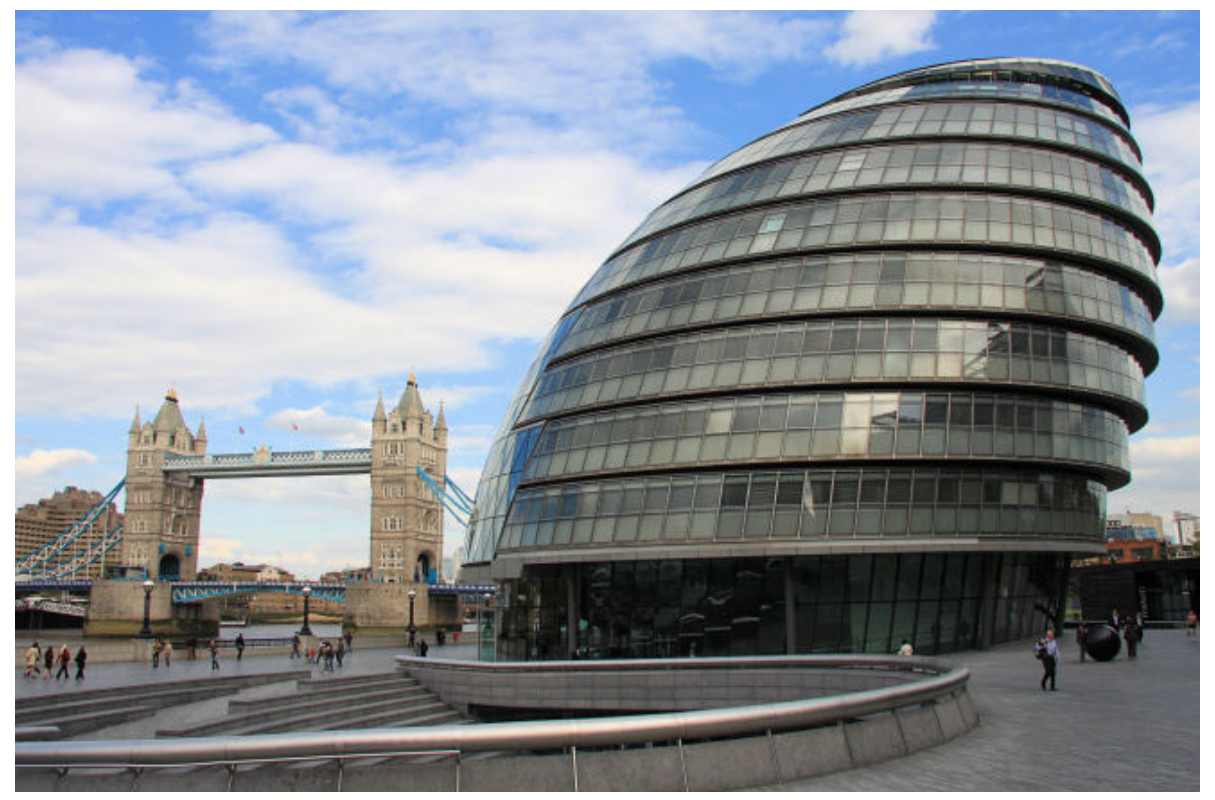

FIGURE 14

London City Hall

\subsection{CIVIC SPACE}

Civic spaces are public spaces which operate as a means of cultural and political inculcation. They are an extension of the community that function as a platform for community engagement. They are the thresholds between the public and societal institutions; the essential building blocks of the community. Their successful implementation is pivotal to the connection between the public and their neighbourhoods (Project for Public Spaces). Great civic spaces contribute to community health through social, economic, cultural, or environmental endeavours, ultimately creating a forum through which the voice of the community can be heard. Beyond fostering the development of civic identity, civic spaces have the ability to drive economic growth. This can be seen in the more than 1.5 million visitors who visit Nathan Philips Square and the variety of community and special events which it hosts (City of Toronto, 2018).
While civic spaces have the potential to invigorate the public realm, their success depends on their equitable management. This has been an issue in recent years as the influence of civic spaces continues to be restricted by the growing control of the private sector. This is made clear in the precedent established by the city of London's new City Hall (Figure 14). The land it sits on was sold to a private company from China, who has the right to remove protesters and demonstrators from the private property (Garrett, 2015). This stands in stark contrast to Toronto's City Hall and the iconic Nathan Philips Square in its forecourt, which was designed to be a platform for the unrestricted dissemination of social, political, and cultural ideas (Figure 15). While this civic space is a great success, the current state of the greater public realm in Toronto is in peril due to the lack of unified planning and the increasing responsibility of the private sector's role in the operation, management, and overall success of Toronto's public spaces. 


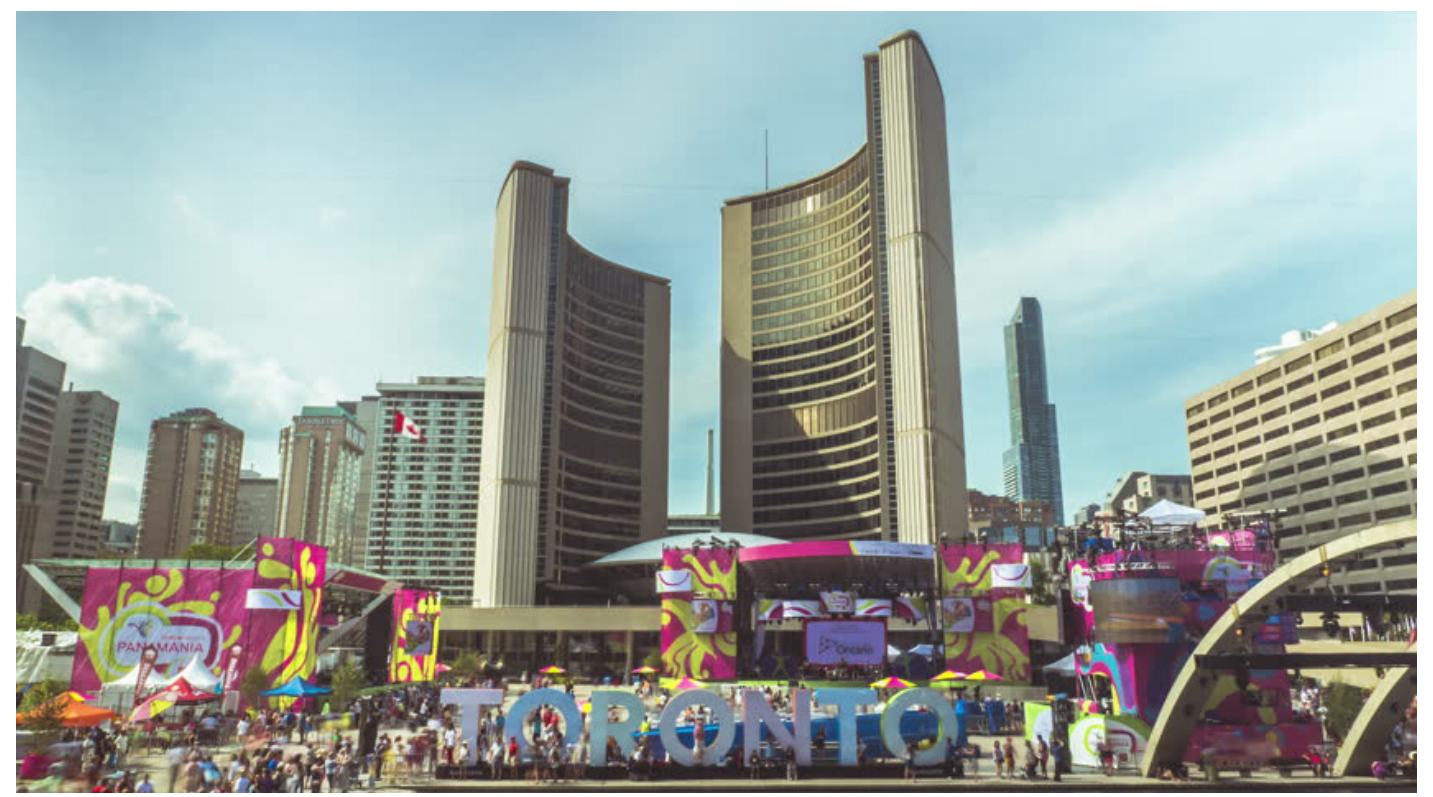

FIGURE 15

Toronto City Hall and Nathan Philips Square

\subsection{CIVIC SUSTAINABILITY AND URBAN DEVELOPMENT}

One of the greatest challenges of this century is the resiliency of urban architecture, the built form, and the public realm which connect them. The world is experiencing change at an unprecedented rate, putting pressure on the built world to adapt to the dynamic nature of the urban environment. This challenge is compounded due to the disconnect between architecture and the contextual factors that shape it. Architecture and the urban environment ideally operate in a constant feedback loop, having a continuous influence on one another through their symbiotic relationship; however, the hegemony of economic and social actors has been negatively influencing the development of the urban environment. This can be seen in the precarious relationship between people and their built environment (Kaplan \& Kaplan, 1989). Stephen and Rachel Kaplan compare the built environment to its ecological counterpart. They discuss its inability to evoke the same affinity humans possess towards nature. This separation is manifested in the placelessness experienced in numerous urban environments. Placelessness is the antithesis of place-based design; the divorce between design and its connection to the ecology of place (Kellert, et al., 2008). The outcome of placelessness is a lack of advocacy and attachment towards architecture (Figure 16). This can be seen in the growing trend of Urban Decay, the decline of vitality and built form within an urban environment (Beatley, 2011). This results in buildings being torn down prematurely, and even manifests itself in the design phase, where buildings are no longer designed for longevity (Feireiss \& Feireiss, 2009). This narrow-minded and human-centred view is deteriorating the quality of architecture while jeopardizing the stability of sustainable incentives (Beatley \& Newman, 2013). Until the intrinsic relationship between people and the built world can be reconnected through the public realm, people will not be able to have as strong of a connection with their urban context (Frampton, 1998). 


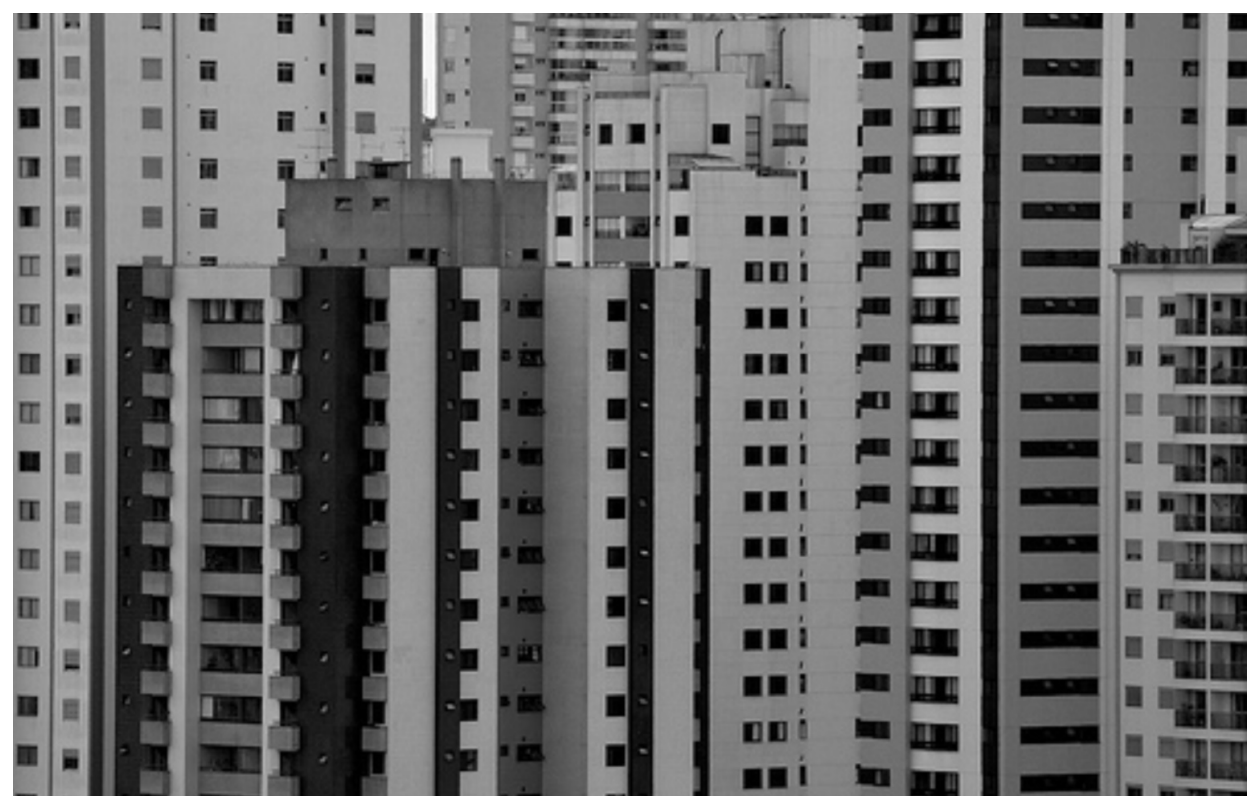

FIGURE 16

Placelessness

Research suggests that the current built environment increasingly isolates people from the beneficial experience of natural systems, processes, and materials (Beatley, 2016). This has been attributed to societal trends, such as urbanization, developerled design, and the evolution of urban lifestyles (Beatley, 2016). The predominant approach to the design of the modern urban environment has mindlessly encouraged the immense transformation and dilapidation of natural systems, further isolating humans from the biological world. This misguided development has resulted in unprecedented loss of biodiversity, widespread chemical pollution and contamination of the air, soil, and water, as well as extensive atmospheric degradation, all accelerated due to humanity's alienation from nature (Kellert, et al., 2008). The consequences that actions today have on the future stability of the environment have been ignored for years. This can be observed in unsustainable global population growth, changes in manufacturing, ever-growing transportation networks, unsustainable fuel/energy/building material choices, as well as the increase of consumerism and the excessive consumption of resources that have resulted in its wake. While the effects of these changes have only manifested in the last two centuries due to global urbanization, they are not an inevitable by-product of it; rather, they demonstrate serious flaws in design strategies, among other outcomes that this thesis is not concerned with. As only design can be addressed here, it cannot solve the problem in its entirety; however, it can play a pivotal role in improving the current state of the public realm in cities through the adoption of a radically different paradigm for urban development.

Sustainable design has become a strategy to mitigate climate change and other previously mentioned problems; however, some of the current approaches to sustainability fail to reconnect people with the biological world - a fundamental aspect of sustainable development (Beatley, 2016). The prevailing approach to sustainability focuses almost exclusively on the low-environmentalimpact objectives of avoiding and minimizing harm 


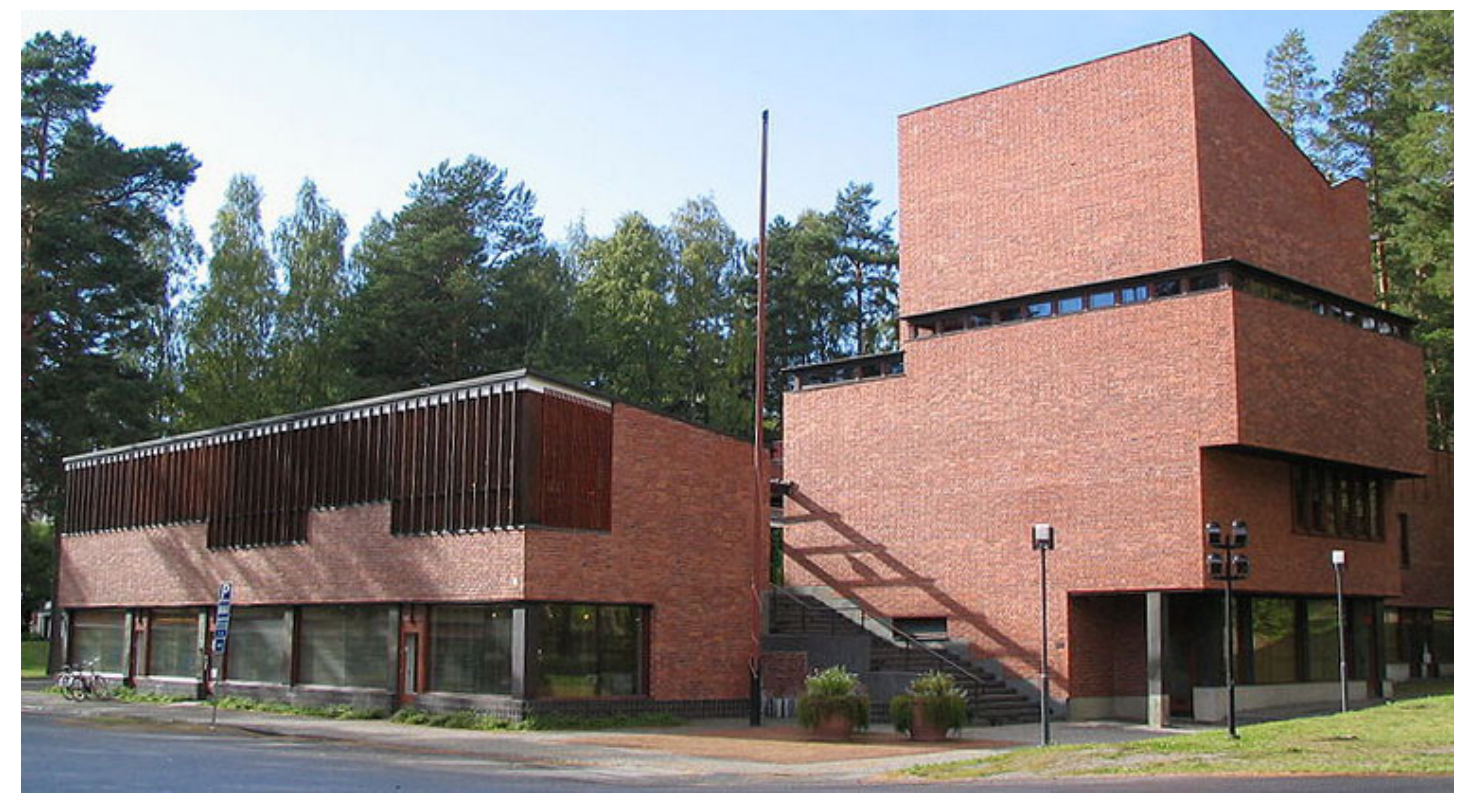

FIGURE 17

Critical Regionalism precedent, Saynatsato Town Hall - Alvar Aalto

to natural systems (Wheeler \& Beatley, 2014). This approach ignores the importance of achieving longterm sustainability through restoring and enhancing people's positive relationship to their environment, specifically in the built context. It has manifested itself in the marginalization of the pedestrian realm within urban environments in order to privilege the motorized personal vehicle. This has resulted in a diminishment of vibrant public space and a lack of easy public access to nature (Beatley \& Newman, 2013). Specifically, this is most apparent in the paucity of well-designed public parks within Toronto's downtown core. Vancouver and New York City, in contrast, both have sizable and successful public spaces in Stanley Park and Central Park and the High Line that function as anchors for ancillary parks, public programming, and additional urban development.

Without positive benefits and associated societal attachment to buildings and places, people rarely exercise responsibility or stewardship to keep them in existence, resulting in buildings which are left to wither, and cities which are no longer resilient to the societal forces of change. Accordingly, it is critical to establish that the concept of sustainability is as much about retaining existing buildings (for cultural and embodied energy reasons) as it is about constructing new low-impact efficient designs. The public realm, therefore, requires interventions which place the priority back onto public and civic space (Figure 17). This will increase the public's wellbeing, develop a sense of community, civic identity, and culture in neighbourhoods, drive economic growth, give purpose to open spaces, and provide a desperately-needed sense of character and architectural diversity within an urban environment (Gehl, 2011). 
"A commons is not just a resource but also

the community of people managing

and protecting it."

- David Bollier
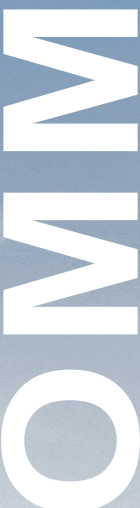

(5)

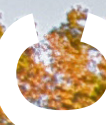

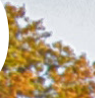

$4-3.5 \times \frac{1}{2}$

th

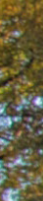

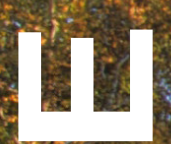

1.t.

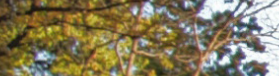

5. No\% 5 .
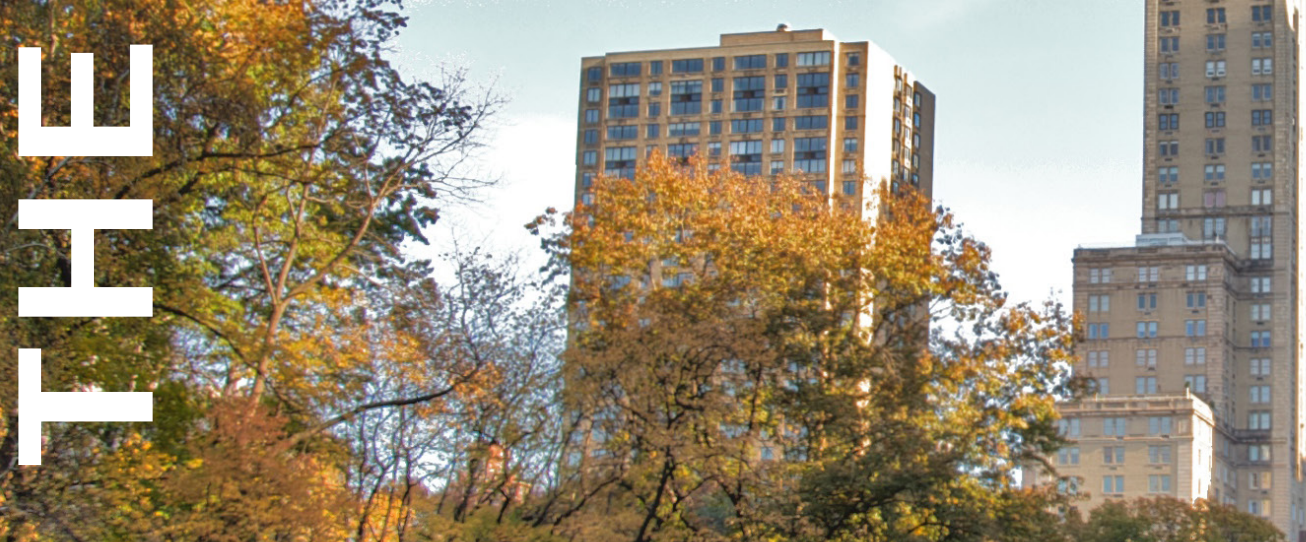

(14)

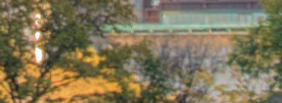

(1)

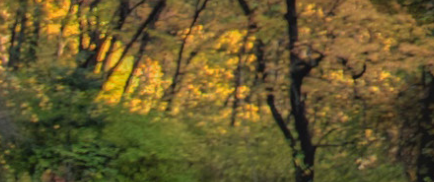

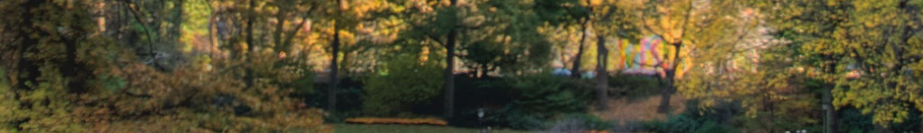

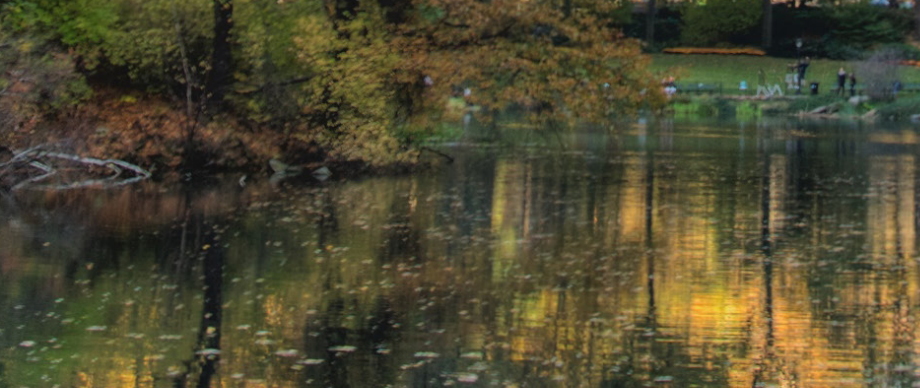

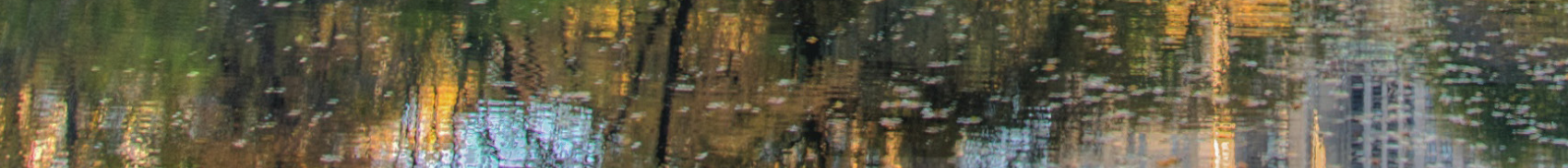

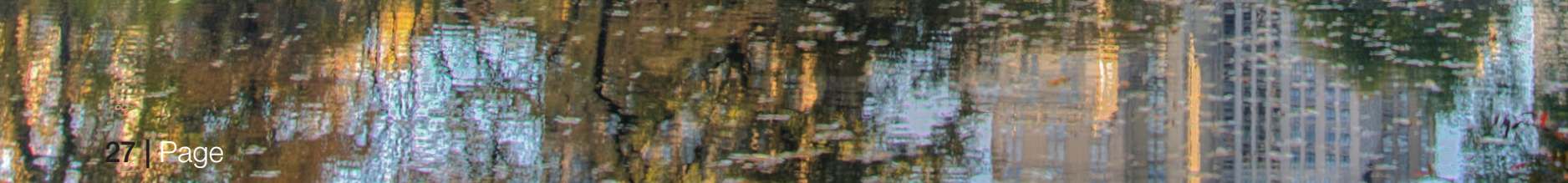




\section{O4 DEFINING THE CONTEMPORARY COMMON}

"Collective will supplants individual whim"

- Samuel P. Huntington

$T$ he contemporary common is a social and political entity through whom resources are publicly owned, shared, and protected. But it goes beyond functioning solely as a political construct. It is a civic space in which the public has established a unified and regulated domain over, promoting common asset security, collective culture, and civic engagement. The common is aptly named, derived from its role in holding common assets that the community has a shared and equal access to, and rights over, offering an affirmative vision of a more equitable, eco-friendly society. While originally established in medieval England, the common continues to challenge the competitive, mechanistic, and profit-centric mindset that has ruled Western civilization since the onset of the Industrial Revolution (Monbiot, 2015). The common responds to the typically restricted access to public resources, where the state or private interests usually try to capitalize on this access through ownership. The common operates through a shared public ownership, creating accessible resources that are owned and managed by the community in an attempt to increase public stewardship. The implementation of a common establishes a geo-centric view; an environmental awareness and holistic world view that seeks to combat the over-commercialization of culture and public space, which has created generic public spaces devoid of an identity. 


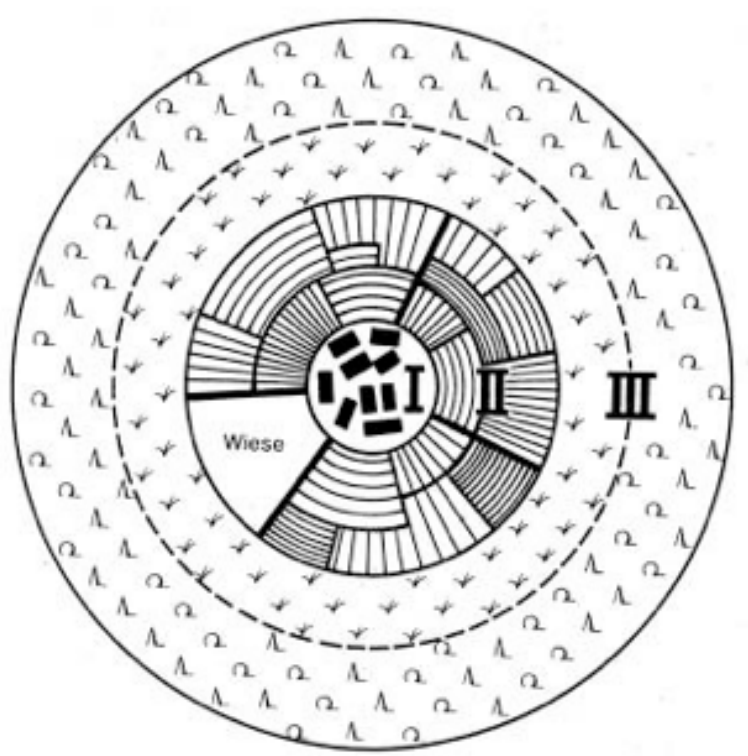

FIGURE 19

Concentric model of a village: (I) village, (II) fields and meadows, (III) common pastures and woods (Rosener 1985, 56)

\subsection{THE ORIGINS}

The common originated in medieval England as an integral component of the manorial and feudalism system of land ownership (Monbiot, 2015). This social system was responsible for the distribution of land from the Crown to nobility in exchange for military services. The nobility would house peasants (or commoners) on the land, who were legally obliged to live on their lord's land. They would pay him homage through providing labour services and were responsible to pay a share of the yield of the land in exchange for military protection (provided by the nobility). In essence, feudalism granted rights of land use to varying social classes. The most common right was the right to pasture, which allowed tenants to pasture livestock on common land (Figure 19).

The term, common, has since evolved to become encompassing of resources that a population or community has rights or access to, with respect to a defined region or piece of land. In more recent times, commons were allocated to farmers who required a place of rest when traveling from their farms and pastures to the marketplace. They were established on the outskirts of city, as livestock was not permitted within city limits. Space was allocated for refuge for both the farmers, in terms of an inn or lodge, and livestock, with a pasture for them to graze. This can be seen in the historic town of Yorkville which was originally a post for farmers awaiting market in the former city of York (Figure 20)(Toronto Neighbourhood Guide, 2018). 


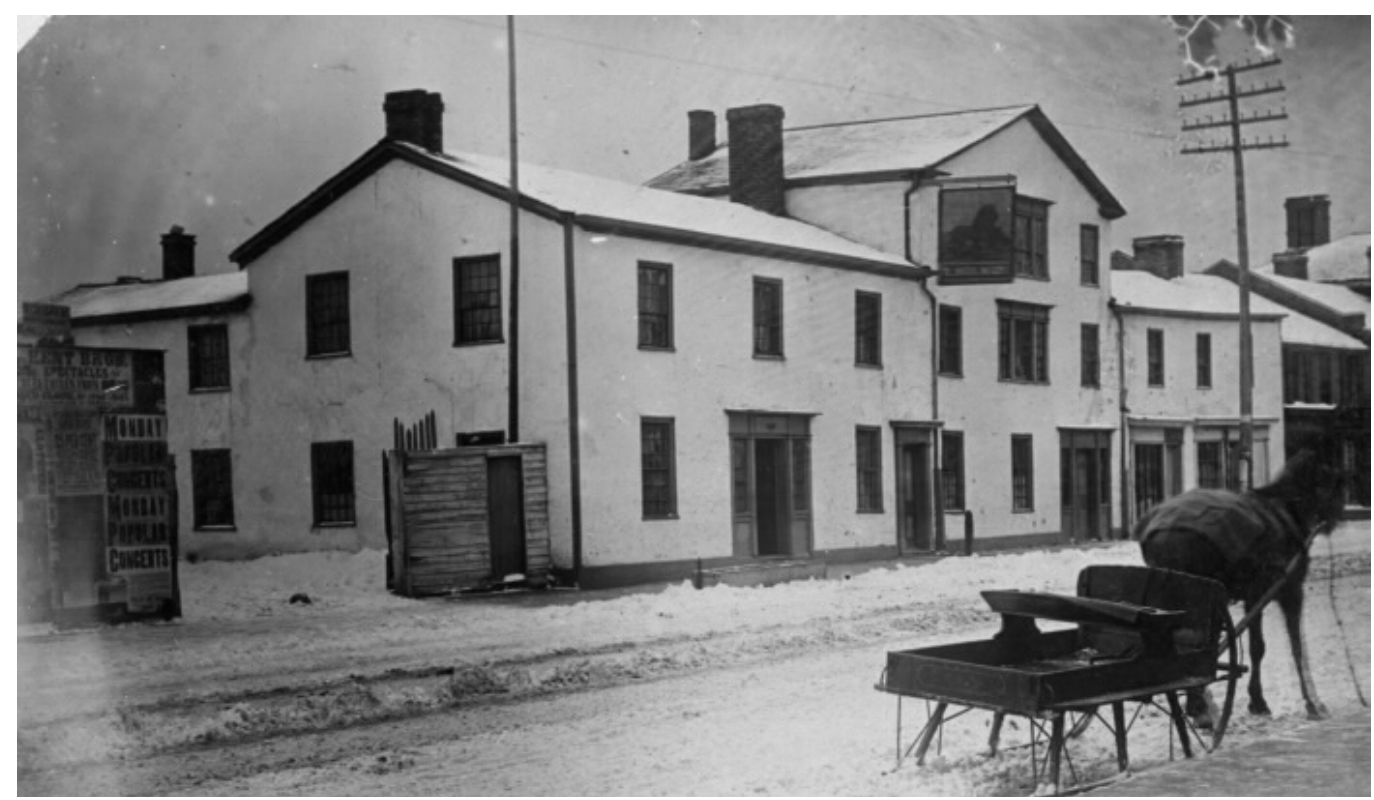

FIGURE 20

The Red Lion Hotel, Yorkville 1885

\subsection{COMMON ASSETS}

For the purpose of this thesis, common assets can be understood as any component of the common which has a recognized societal value. While previously understood as tangible, natural resources, the definition has been broadened to include intangible assets, including knowledge, software, and more abstract resources, such as air or radio waves. The identification of resources as common assets is the first step in establishing the common, resulting from questioning their management, equitable distribution, and the status of their abundance. Resources are subsequently categorized as either limited access or openaccess resources, with the latter being more vulnerable to exploitation (Monbiot, 2015).

\subsection{COOPERATIVE MANAGEMENT}

The distinctive feature that differentiates the common from traditional public space is its means of cooperative ownership, operation, and management. The common is owned and operated, in part, by each member of the community. Due to its users having a vested interest in its successful functioning, they are more likely to exhibit stewardship and due diligence in their actions. This form of cooperative establishes an informal institution which is capable of holding rights and managing resources and assets. The cooperative management of the common relies on the premise that the actions of the collective enables each individual to enjoy its use. While the land rights were previously held solely by landowners, commoners held limited-use rights for access to the resources the land offered/yielded. Today, this ownership would be held by the government and managed by a designated public entity. Funding would be provided by municipal, provincial, and federal taxes. 
Common A (10 acres)

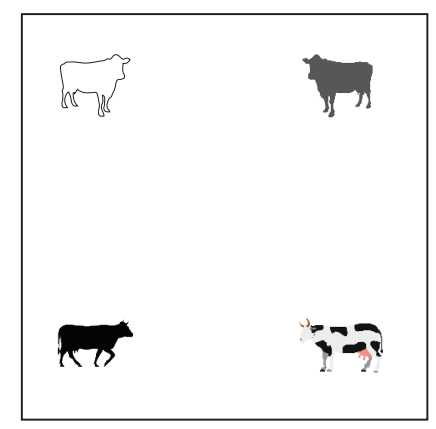

Total: 4 cattle

(2.5 acres each)
Common B (10 acres)

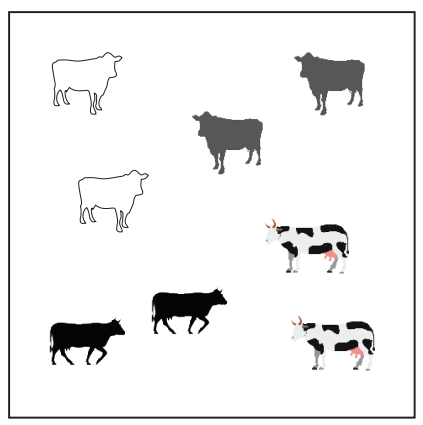

Total: 8 cattle

(1.25 acres each)

Carrying Capacity
Common C (10 acres)

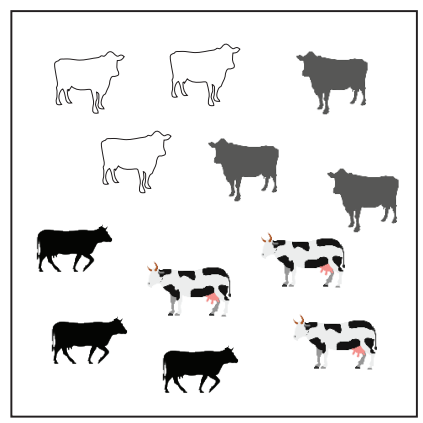

Total: 12 cattle

(0.83 acres each)

Tipping Point

FIGURE 21

Diagram of the tragedy of the commons

\subsection{TRAGEDY OF THE COMMONS}

The Tragedy of the Common is a theory posited by William Foster Lloyd in the 18th Century that analyzes some of the failures of the common (Hardin, 1968). It discusses the decline of the majority of medieval common land in England, which was lost due to enclosure and privatization (Monbiot, 2015). Enclosure refers to the transfer of ownerships from the public collective, established by the common, back to the sole ownership of the lords of the land. Enclosure ended the ancient system of arable farming in open fields through both the transfer of ownership, as well as through the physical enclosure of previously common land (fencing). The practice of the common was further eradicated with the practice of land being deeded to a singular or collective owner. This was accomplished through the purchase of land rights and all common rights. The influx of enclosure and the privatization of once commonly-held land has been argued as the inciting incident which initiated the British Agricultural Revolution and a major contributor to the growth of capitalism (Monbiot, 2015). The Tragedy of the Common by Garrett Hardin (1968) describes the abuse of commonlyheld resources due to greed and the lack of stewardship that exists when something is not held in sole proprietorship (Figure 21).

"Without a complex knowledge of one's place, and without the faithfulness to one's place on which such knowledge depends, it is inevitable that the place will be used carelessly and eventually destroyed".

- Wendell Berry (The Regional Motive, 1972, 69) 


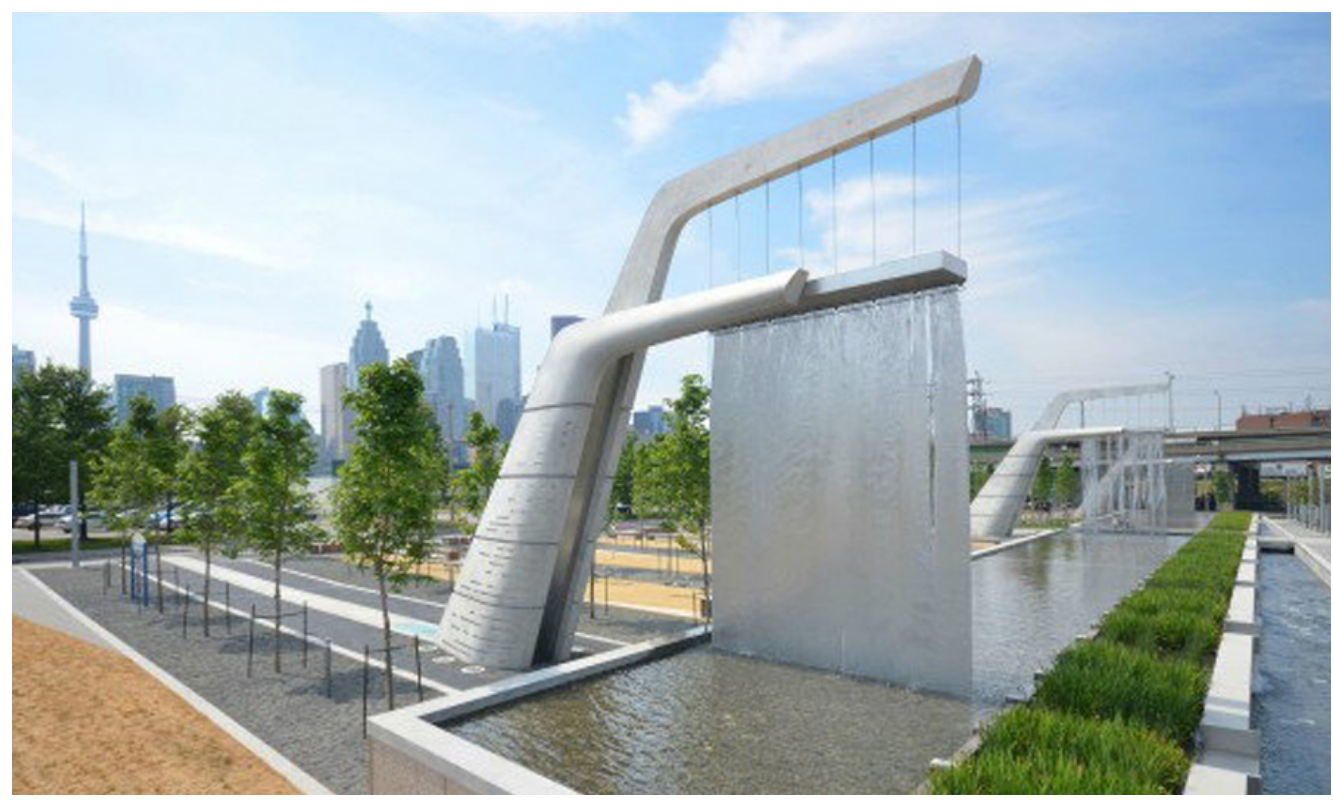

FIGURE 22

Sherbourne Common, Waterfront Toronto, Toronto

\subsection{MODERN IMPLEMENTATION AND RENAISSANCE}

While previously viewed as a tangible entity, the concept of the common has created a resurgent social and political movement, whereby the ideology behind the common is applied to various societal sectors, including economics, social justice, and politics. Its principles of public ownership, as an attempt to fortify collective interest, are being employed as a countervailing force to keep excesses of the market and government in check (Harvey, 2011). The contemporary common functions as tool of resistance for the community; a means of establishing domain and defining the authority of the public within an increasingly privatized world.

Even though the feudal and manorial social structures of medieval England are not in existence today, the concept of the common has the potential to challenge detrimental societal structures of the modern world, as noted by the Nobel Memorial Prize winner for Economic Sciences, Elinor Ostrom. Her work focused on analyzing the situations where the common operated successfully. She concluded that common can be successfully maintained and exercised through the implementation of mechanisms of authority and the development of a collective understanding and appreciation (Ostrom, 2015). Managing common assets requires developing rules, values, and traditions. Whether it be through community initiatives or acts of defiance, the common is a means of restructuring government agency to meet the needs of the public, rather than the needs of corporate conglomerates. The common is not just about a collection of commonly-held assets; it is about the uniting of a community to manage and protect their domain, ultimately building deeper connections with each other in the process. Toronto has seen two new commons constructed in recent years, Sherbourne Common (2009) (Figure 22) and Corktown Common (2013). These two commons were constructed by Waterfront Toronto, a public entity responsible for Toronto's waterfront redevelopment. 


\subsection{MOBILIZING PRINCIPLES OF THE CONTEMPORARY COMMON}

When looking at the contemporary common, there are four key mobilizing principles required for its successful implementation, which have been adapted from Ash Amin's Collective Culture (2008): socio-spatial multiplicity, social solidarity, conviviality, and sustained maintenance.

Socio-Spatial Multiplicity is the diversity of uses that the common must facilitate in order to resonate with its users. When the common contains diverse and flexible public spaces, each develops its own rhythms of use and regulation. This functions as a means of urban inclusion, responding to the unique needs of its users as heightened civic space.

Social Solidarity is a unifying platform for the dissemination of ideas, beliefs, and values (education, protest, pleasure, recreation, etc.). Due to the collective ownership of the common, it is inherently an expression of the public. This display of social and cultural values and ideals can be accomplished through public art and the narrative created by the tectonics of the built form, landscaping, and material selections.
Conviviality is the atmosphere created by the common. Developing from multiplicity, conviviality is the resultant of multicultural mingling, and is experienced through the interaction of people with the common. Promoting this quality, the circulatory patterns of the common establishes an improved vitality over conventional public spaces. It can be elevated through the established design narrative (material and colour palette, landscaping, nodes of interaction, programmatic/circulatory overlap, etc.).

Sustained Maintenance is the backbone upon which the success of the common depends. As noted in Garrett Hardin's Tragedy of the Common (1968), one of the fundamental oversights of the medieval common was the lack of maintenance. When something is held in common ownership, if it is abused, neglected, or mistreated by any individuals, its value to the collective diminishes. Public spaces, civic spaces, and the common function as part of the delicate life-supporting role of urban infrastructure, subsequently requiring regular upkeep and updating as urban practices evolve.

\subsection{SOCIO-CULTURAL RESONANCES}

There are clear distinctions between public spaces, civic spaces, and the common. As a result, they each have varying impacts on their users. The common's impact on its users is described in the following sequence, also adapted from Ash Amin's Collective Culture (2008): sensory surplus, ordering of space, territorialization, emergence, public projection, collective delineation, and emplacement.
Due to the socio-spatial multiplicity of the contemporary common and the variegated spaces within, the first resonance is Sensory Surplus. As the common is a moment of pause from the rest of the city, its contrast results in a sense of awe and bewilderment experienced in situations that place individuals and groups in relation to the space and others around them. The common can evoke these feelings by being open, crowded, diverse, incomplete, improvised, and disorderly or lightly 


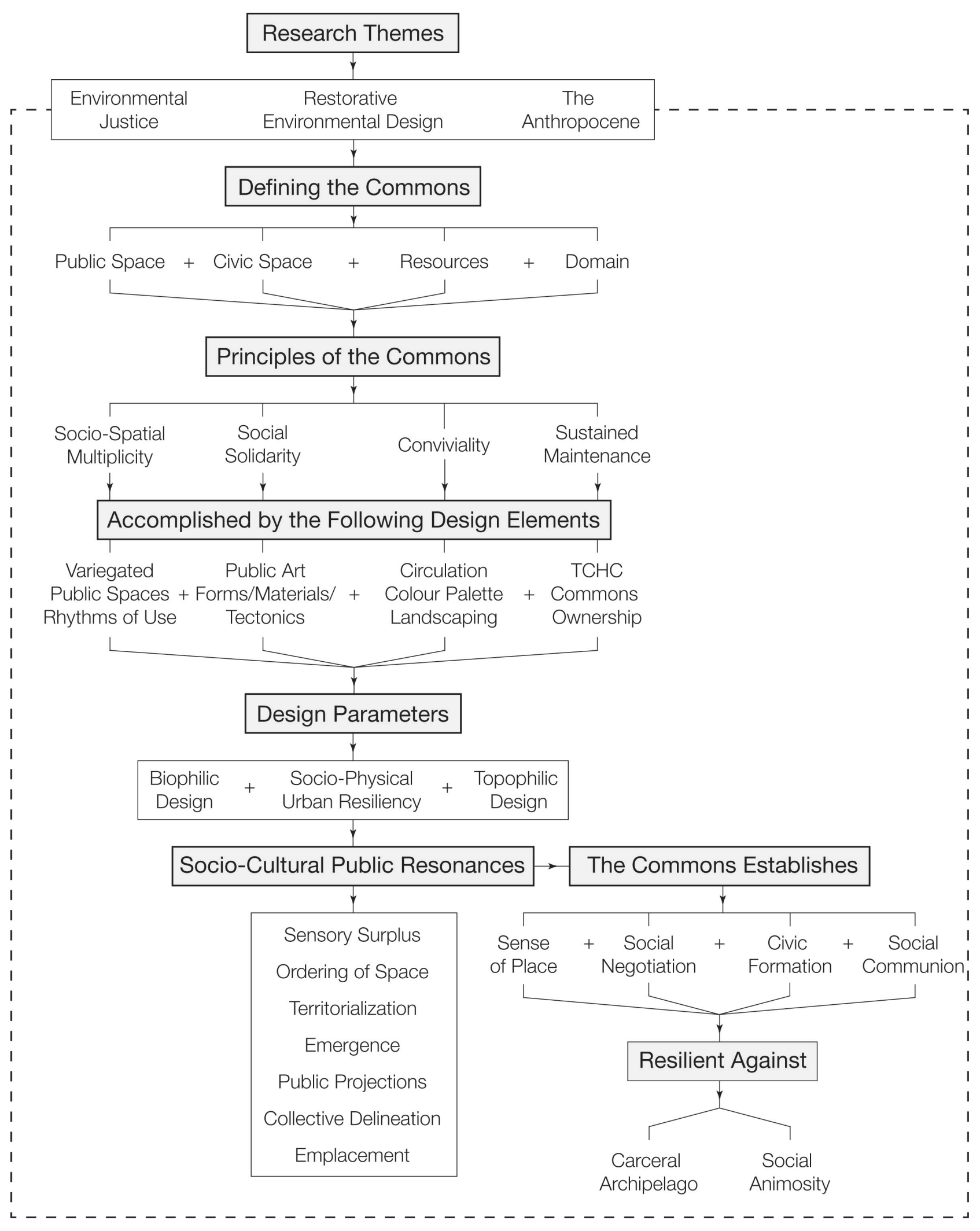

FIGURE 23

Thesis diagram 
regulated. One such example is the Manhattan experience. As one travels north along 7th Avenue from Times Square in downtown Manhattan, one traverses through the hustle and bustle of the urban core before being abruptly stopped by the wall of green that is New York's Central Park. While not all parks can operate at this same scale, the common creates a sensory surplus through contrast with its surrounding environment.

As users circulate through the common, they instinctively begin Ordering the Space. This tool of social regulation, assurance, and delegation is a means of cultural and public orientation. It embodies the dynamics of deliberation and social interaction as people move through the common. Users habituate the common, making the space their own.

Territorialization is the process whereby users establish a repetition of spatial demarcation based on daily patterns of usage and orientation. The way people and things move through public spaces is not random but a highly, yet subconsciously, choreographed rhythm. This transforms typical public space in a way which allows users to make sense of the space, define their place within it, and ultimately traverse through it. The common functions as a vehicle for the domestication of public or civic space.

The next social resonance is the process of Emergence. The interaction of people in public space is simultaneously a process of ordering and disruption. The unpredictability of the common influences and alters people's personal habits, patterns of movement, and routine preferences.
This creates a sense of unanticipated novelty, subsequently creating new rhythms and routines.

There is an intentional Public Projection of social, cultural, and political values onto the common. It functions as a testing ground where current modes of public culture can both be formed, articulated, influenced and disseminated. The iconography of the common, from the quality of spatial design and architectural expression to the consumption of public art and advertising, coalesce to facilitate urban culture.

The cultural projection of the public onto the common is reciprocated by its inverse: Collective Delineation. This is the process whereby the common influences social practices, framing, testing, and evaluating the pulse of public culture. The atmosphere, its aesthetic quality, and the physical environment subtly and subconsciously shape the performances of social life within the common.

Lastly, the temporality of the common is best understood as Emplacement; the physical embodiment of time as seen in the relationship between the positioning of people and things within the common and the relative time of day/year. The vitality of the common is achieved through its dynamic quality - no two visits will ever be the same. The common is constantly evolving, shifting as a result of the perpetual variability of its use, role within society, and the people who use it. 


\subsection{OUTCOMES}

'This thesis seeks accomplish five desired outcomes through the implementation of the common, extrapolated from Ash Amin Collective Culture (2008): evoking a sense of place, social negotiation, civic formation, positively influencing social justice, and creation social communion.

[1] The primary intention of the common is its ability to develop a Sense of Place. This is a result of the inherent connection it creates between its built and unbuilt qualities and the users who interact with it.

[2] The second, and most impactful outcome of the common is Social Negotiation. Through the diversity of opportunities and experiences of the common, the public can become united through their differences. The common embraces the perpetuity of uniqueness, while creating a ordered space for public interaction.

[3] The third outcome of the common is Civic Formation. The common is a tool for the securitization of public and civic spaces. Its purpose remains to create a space accessible to the people; a space for civic and political participation. The common returns the value once placed upon the public square by providing a space designed for public congregation and the dissemination of ideas. When successful, the common operates as a space for collective well-being, expression, aspiration, public encounter, and possibility.

[4] Social Justice is the fourth outcome of the formation of the common. As it functions as a space suited for everyone, it promotes equitable relations between the individual and society. It responds to the current times, characterized by state withdrawal, capital mobility, transnational entities, and the movement of the market away from the needs of the local collective. Within social justice lies the concept of social well-being. "Urban wellbeing is inextricably tied to the nature of the work/ livelihood/survival opportunities offered within a city." (Amin, 2006, p.16). The common is a space where people can freely express themselves and gather for political action. It is pragmatically a civic space, no different from Nathan Philips Square. The fundamental difference, however, lies in collective ownership - where residents can subsequently feel a sense of responsibility for the space. While not explicitly designed for it, these spaces function as a physical platform for public commentary and participatory politics in contemporary times. This gives a voice to under-represented or emergent communities, allowing for the spontaneity created among empowered citizens. In essence, the social dynamics of the community within the common can operate as the measuring stick for participatory politics, most notably through community events which unite the neighbourhood (events, rallies, protests, etc.).

[5] The establishment of the contemporary common creates the opportunity for Social Communion by providing a place of refuge, where its occupants can escape the stresses of the daily grind. The common is a place where the public can unite, where they can come together to relax, learn, and recreate; a public forum for collective public expression. This thesis speculates that the desire to improve social interactions is one of the fundamental inspirations for the City Beautiful movement, 
Garden City movement, urban renaissance, new urbanism movements. The desire to improve social interactions is present today in the resurgence of micro-housing, pedestrian-oriented design, shared urban assets, integrated communities, and cities with diverse public spaces (Harvey, 2011). Through accomplishing the outcomes mentioned above, the common can contribute towards the resiliency of the public realm. This thesis seeks to combat the crippling effects of two societal forces: the carceral archipelago of urban public spaces and the social animosity which can develop between people.

\subsection{THE RESILIENCY OF THE COMMONS}

Carceral Archipelago is a term coined by Michael Foucault in his book, Discipline and Punish (1975). It describes the use of barriers and boundaries in order to gain control. What was once accessible to the masses, public space has now been transformed into defendable spaces - enclosed by walls, fences, security and constant surveillance. This can particularly be seen in condominium parks. These Privately-Owned Public Spaces (POPS) provide public space, but only for a limited population. This control over what is normally a public amenity is reminiscent of George Orwell's 1984, and its omnipresent government surveillance and public manipulation. In Ash Amin's Collective Culture and Urban Public Space, he describes how privately-owned public spaces are enabling the transformation of urban parks into carceral archipelagos (Amin, 2008). The common attempts to combat this through its collective ownership, preventing any private entity from exploiting public space and transforming it into a privatized commodity, restricted to the social elite and financially inept.

By providing spaces that accommodate and celebrate the diversity of its users, the contemporary common can promote social negotiation - the recognition that there will inevitably be differences between people, but instead of discriminating because of them, these differences are accepted out of a deep respect and concern for the other. To this point, Bonnie Honig writes,

"To affirm the perpetuity of the contest is not to celebrate a world without points of stabilization; it is to affirm the reality of perpetual contest, even within an ordered setting, and to identify the affirmative dimension of contestation."

- Bonnie Honig (Political Theory and the Displacement of Politics, 1993, p. 15) 



\section{PART 2: \\ DESIGN METHODOLOGY}




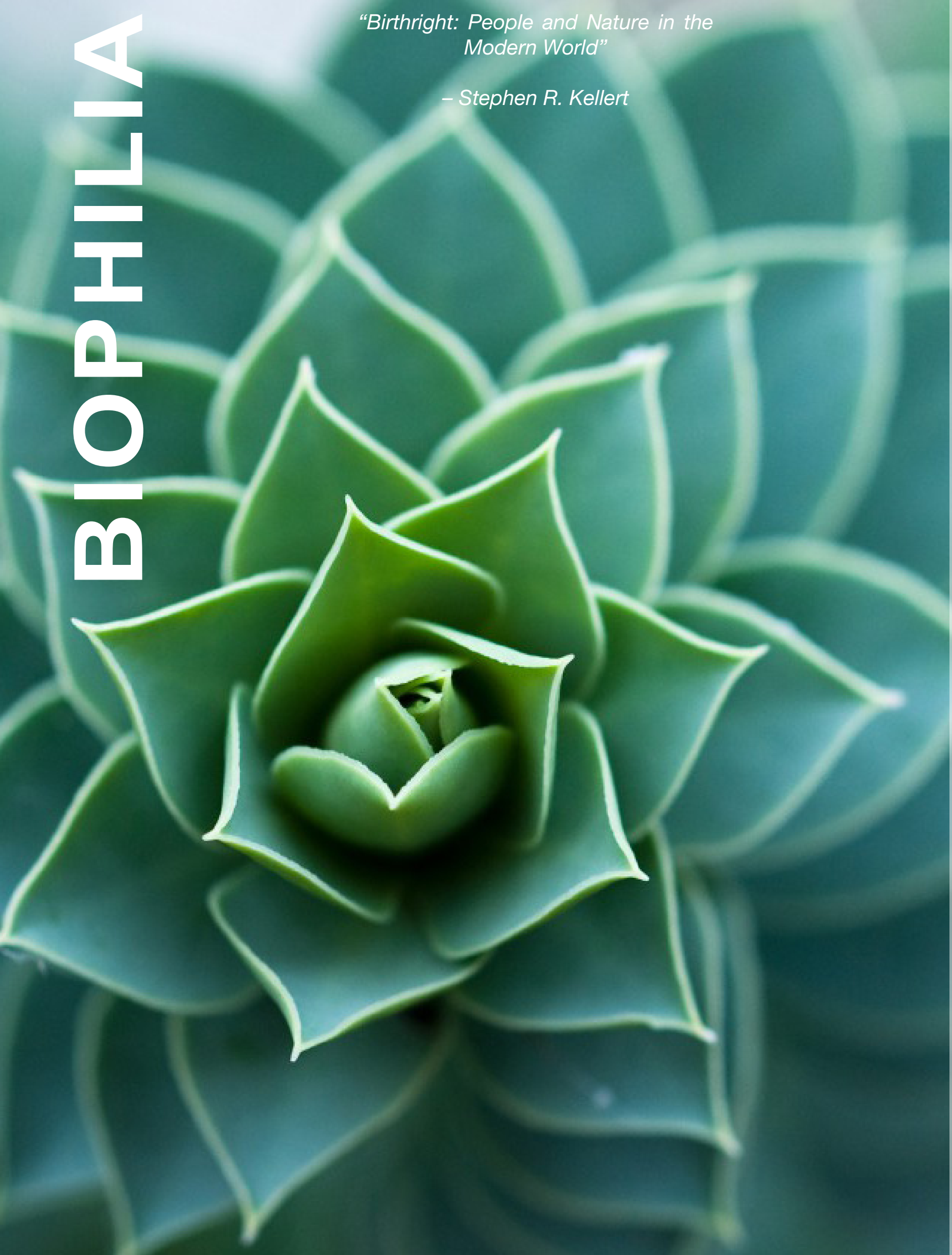

41 | Page 


\section{BIOPHILIC DESIGN: THE NATURAL CONTEXT}

"[Biophilia] ... the connections that human beings subconsciously seek with the rest of life."

- Edward O. Wilson

$\mathbf{P}$ art 2 addresses the design parameters that this thesis operates within, providing the structure and methodology to inform design decisions. This chapter explores Biophilic Design, a strategy for implementing a restorative environmental design methodology. Biophilic Design focuses on the traditional concept of sustainability, but addresses it from a bottom-up position. Instead of considering the impact humans have on the natural context, it first addresses the impact the environment has on people, and how, in turn, people can positively influence their context (Beatley, 2011). It is an innovative way of designing the places where people live, work, and learn through the lens of environmental justice.

Biophilic Design establishes the biological realm as a fundamental design component. This emerges as a result of developing concerns regarding the contemporary condition of the urban environment. Biophilic Design is a theory, philosophy, and design approach that was developed out of an understanding that the human race has evolved congruent to nature, subsequently developing an ineffable connection with it (Wilson, 1986). Biophilic Design advocates for the seamless integration of organic elements within architecture, as it results in the improvement of people's health, well-being, and vitality (Kaplan, 1995). 


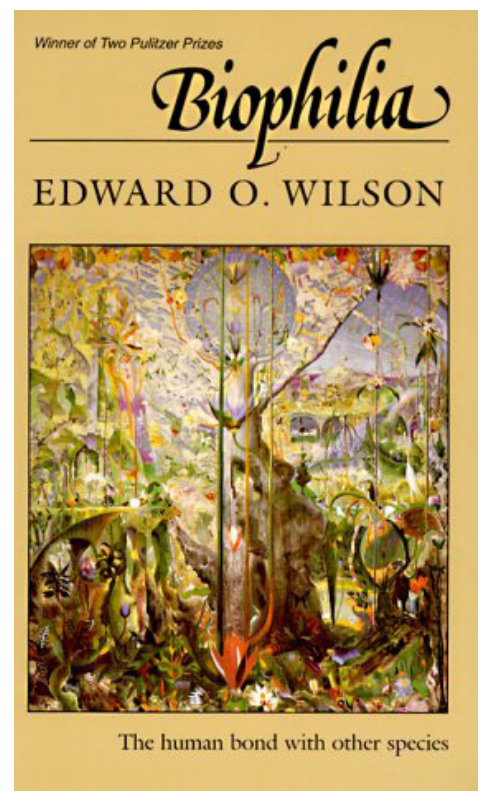

FIGURE 25

Biophilia, Edward O. Wilson, 1986

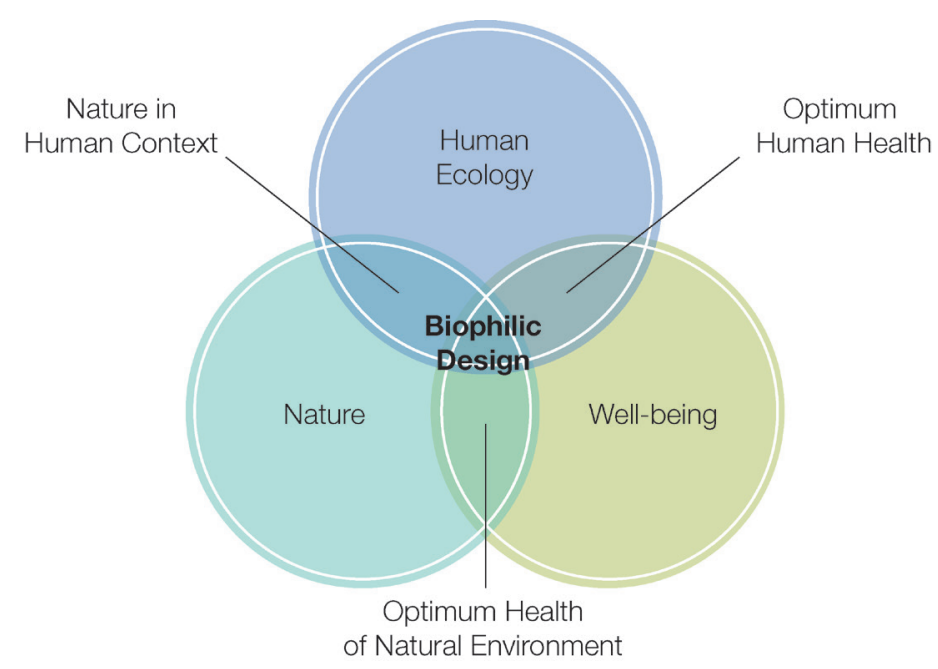

FIGURE 26

Biophilic design components

\subsection{ORIGINS AND DEVELOPMENT}

It has been demonstrated that a person's proximity to nature directly affects that person's mental and physical health, and overall well-being (Egorov, et al., 2016; Gillis \& Gatersleben, 2015; Heerwagen, 2000). Conversely, if people are deprived of nature, this too has a negative effect, resulting in sensory deprivation, disassociation, and placelessness (Kellert, et al., 2008). The human condition predisposes people to require a deep and intrinsic connection with nature, yet visionaries have often designed cities and suburbs in ways that both degrade the environment and alienate its citizens from nature (Hayes and Burman, 2015). The recent movement towards green architecture has trended towards reducing the ecological impact of the built environment. This, however, is often limited in its concern to the more measurable and verifiable aspects of environmental design, such as minimizing the use of energy, water and materials (Heerwagen, 2000). The growing popularity of energy rating systems, such as Leadership in
Energy and Environmental Design (LEED), has oversimplified sustainable practices down to a series of checklists. This has resulted in a disconnect between development stakeholders while reducing the architectural impact on sustainability. The value of architecture is diminished as a result, while concurrently producing buildings which are socially unsustainable (Byrd \& Rasheed, 2016). Generally speaking, this is because they fail to address the interconnectivity of factors that influence sustainability. The myopic urban development of Western cities (since the 1800s) is the resultant of a mindset that privileges a number of other factors, including immediate economic gains, over longterm sustainable development. This corruptive mindset emerges out of a false dichotomy that tends to consider cities and nature as polar opposites, when in reality, due the multiplicity of factors that influence cities, they should be viewed as interconnected ecosystems (Beatley \& Newman, 2013). 


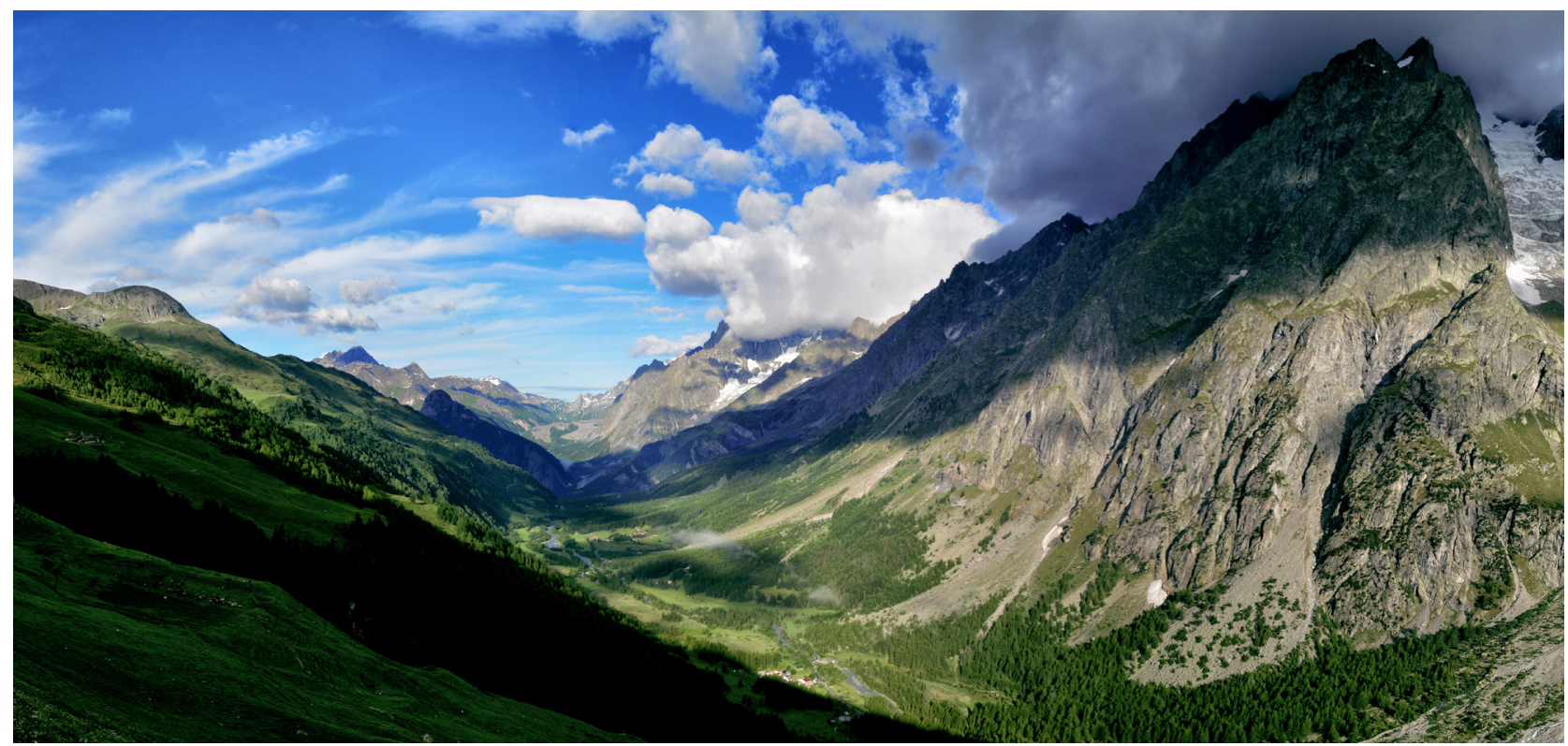

FIGURE 27

Panorama of the Swiss Alps

\subsection{FIRST PRINCIPLES - THE BIOPHILIA HYPOTHESIS}

Biophilic Design is an extension of The Biophilia Hypothesis that was developed by Edward $\mathrm{O}$. Wilson in 1984 in his seminal discourse, Biophilia (Figure 25). It is a theory and design philosophy which advocates for living things [bio], and people's inherent affinity towards nature [philia] (Wilson, 1984). It is a movement towards developing healthy and productive habitats, extending the theory and practice of green buildings into a new dimension: Biophilic Design places the human connection with nature and the establishment of a sense of place as its primary function (Figure 26). It can play a critical role in fostering environmental consciousness through the broad reintroduction of nature into human habitats (Figure 27). The aspiration of Biophilic Design is for citizens to become more cognizant of their connection with nature and the role they play in its prolonged preservation.
Biophilic Design is meant to establish the missing connection between the built world, its users, and the environment. It is a low-environmentalimpact strategy that minimizes and mitigates adverse impacts on the natural environment while contributing to a positive environmental impact. The outcome is a form of sustainable design that complies with four key conditions established by Kellert, et al. (2008):

\section{Promotes natural elements that stimulate or increase human health and productivity}

\section{Emphasizes the siting and context of a project}

$$
\begin{aligned}
& \text { 3. Advocates for the interconnectivity of } \\
& \text { interventions }
\end{aligned}
$$

\section{Stimulates human engagement with nature through a network of natural interventions.}




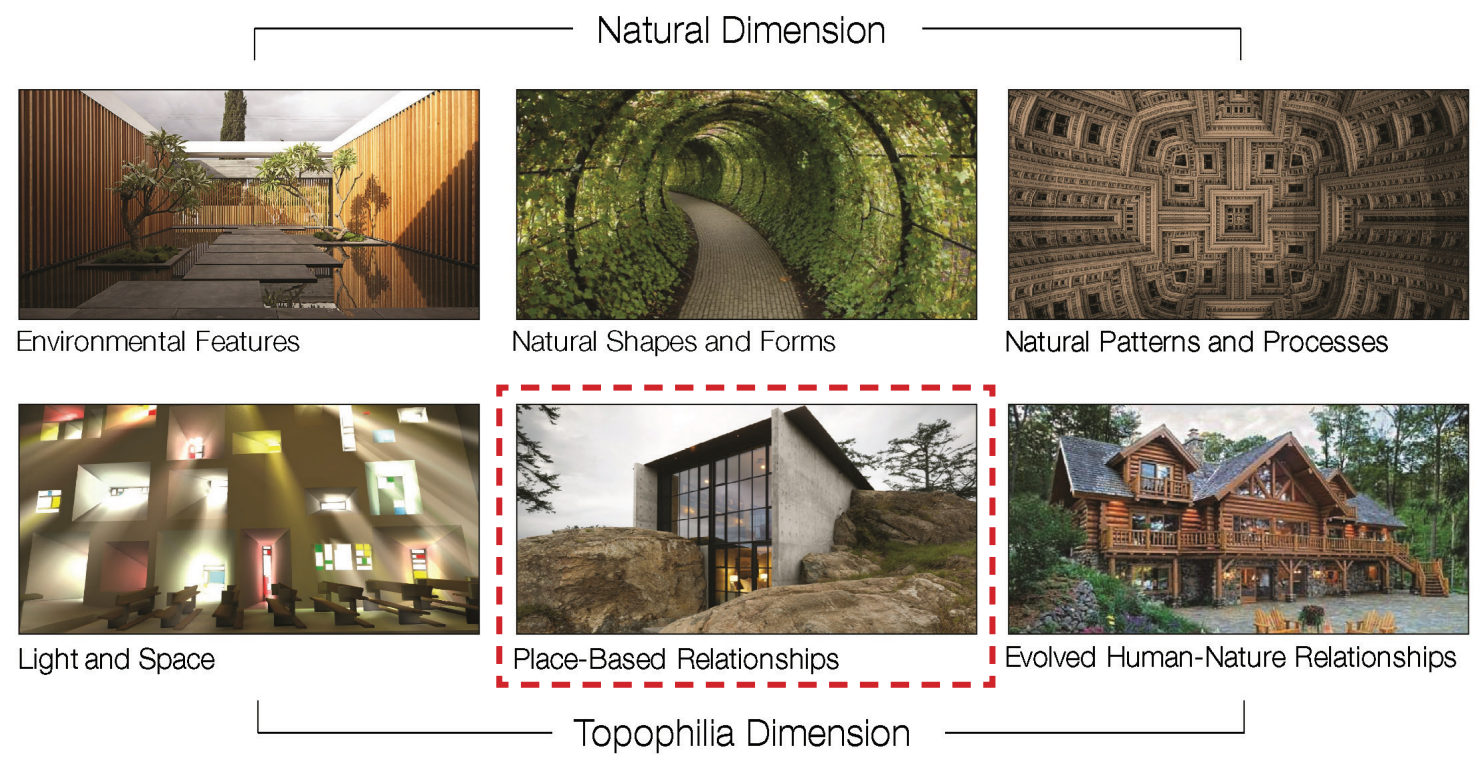

FIGURE 28

Dimensions of biophilic design

\subsection{DESIGN ELEMENTS}

Biophilic Design functions as a design tool kit, developing numerous design elements that provide specific results. These design elements have been categorized into two dimensions: the natural dimension and the topophilic, each comprising of three aspects, as defined by Kellert, et al. (2008) (Figure 28):

The Natural Dimension

1. Environmental Features

2. Natural Shapes and Forms

3. Natural Patterns and Processes

\section{The Topophilic Dimension}

1. Light and Space

2. Place-Based Relationships

3. Evolved Human-Nature Relationships

This thesis focuses on the Topophilic Dimension, specifically addressing place-based relationships while utilizing the other five aspects as design tools.
The conditions stipulated by Biophilic Design are most commonly accomplished by the following methods, established by (Browning, et al., 2014):

- Creating visual connections to nature

- Implementing non-visual stimuli

- Establishing stochastic and ephemeral connections

- Incorporating thermal control

- Including water elements

- Integrating dynamic lighting qualities

- Connecting with natural processes

- Utilizing patterns found in nature

- Framing views towards natural surroundings

- Using natural materials

- Establishing a sense of complexity and order 


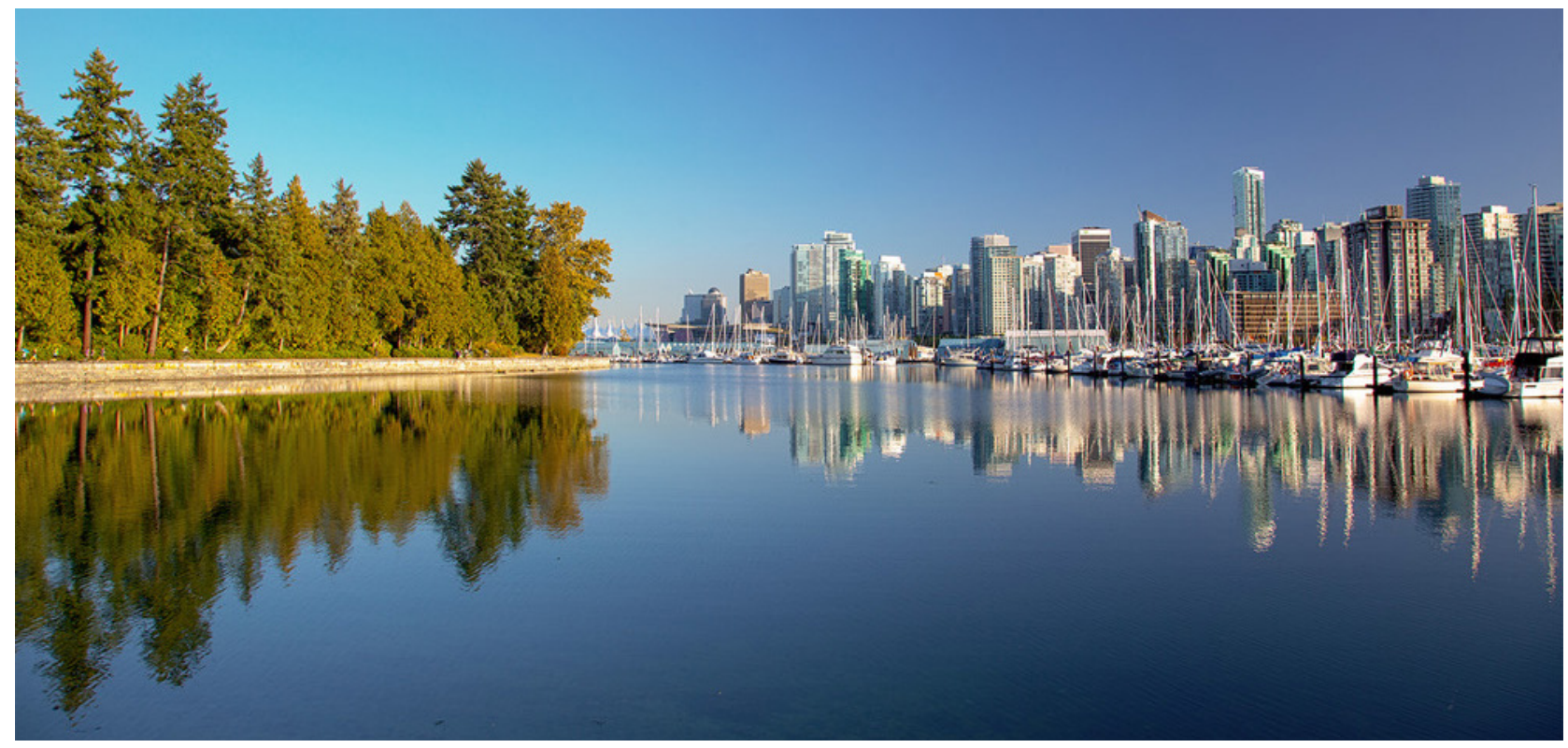

FIGURE 29

Vancouver, Canada is an example of a city planned with Biophilic Urbanism principles

\subsection{BIOPHILIC URBANISM}

Biophilic Urbanism is the systematic application of Biophilic Design interventions at an urban scale (Beatley, 2011). It is a concept that emerged due to the necessity for Biophilic Design elements and interventions to be methodically integrated into the urban fabric at a city scale, rather than standing as solitary interventions. As it is concerned with design at an urban scale, elements range in scale from building, street, city block, neighbourhood, community, and entire regions. According to Beatley (2011), a city exemplifies biophilic urbanism if it:

- Functions within its own ecological limitations

- Is designed to function analogous to nature

- Strives to attain a circular metabolism

- Establishes local/regional sustainable lifestyles

- Emphasizes a high quality of community life
Biophilic urbanism responds to a crucial flaw within the conventional approach to the development of urban public green space, resulting in the disconnect between them. As previously discussed, a significant challenge to the systematic design of urban public green space across a neighbourhood or city is the establishment of a unified objective, or a cohesive design narrative. This is further complicated by the influx of POPS, each of which is generally developed on an individual basis. Biophilic urbanism provides the foundation for legislation and policy to develop a methodology and parametric framework that the design of all new urban public green spaces should comply with. This can be seen in the master planning of sustainable cities, such as Vancouver, Copenhagen, and Melbourne (Figure 29). 


\subsection{OUTCOMES}

The intention behind Biophilic Design is the promotion of specific benefits for people and the environment. The following is a list of demonstrated benefits for inhabitants established by places that follow Biophilic Design principles (Kellert, et al., 2008):

- Contact with nature has been found to enhance healing and recovery from illness and major surgical procedures.

- People living in proximity to open spaces report fewer health and social problems.

- Office spaces with natural lighting and ventilation result in increased worker performance, lower stress, and greater motivation.

- Contact with nature improves cognitive functions.

- Contact with nature promotes healthy childhood maturation and development.

- The human brain responds to sensory patterns and cues emanated by the natural environment.

- Communities with higher-quality natural environments reveal more positive outlooks towards nature, improved quality of life, greater neighbourliness, and a stronger sense of place.

o Consistent across poor urban areas, affluent areas, and suburban neighbourhoods.
The objective of Biophilic Design is to improve air quality, reduce stress, promote activity, increase well-being, and encourage social cohesion. Biophilic Design seeks to foster a positive relationship with nature, furthering Ebenezer Howard's Garden City concepts through the focus on a new dimension of design: human interaction.

By better understanding the impact nature has on a person's health, well-being, productivity, and performance, architects can better design buildings and spaces that are more resilient. Judith Heerwagen has devoted her academic career to developing an intimate understanding of the social benefits and physiological impacts of biophilic and sustainable design. Her work concludes that building design and the additional effort to include sustainable interventions has a significant impact on human health, well-being, and worker performance (Heerwagen, 2000; Heerwagen, 2006). Rachel and Steven Kaplan have also investigated the impacts of nature and Biophilic Design, with a specific focus on the psychological effects of being immersed in nature. Their work has concluded that "experience in natural environments can not only help mitigate stress; it can also prevent it through aiding in the recovery of this essential resource" (Kaplan, 1995). Additionally, numerous studies have been conducted outlining the health impacts urban green spaces have on people, including improved mental health, reduced cardiovascular morbidity and mortality, obesity and risk of Type 2 diabetes, and improved pregnancy outcomes (Egorov, et al., 2016). Ultimately, Biophilic Design has the greatest potential to become successful through the development of a built environment which advocates for the seamless integration of nature. 


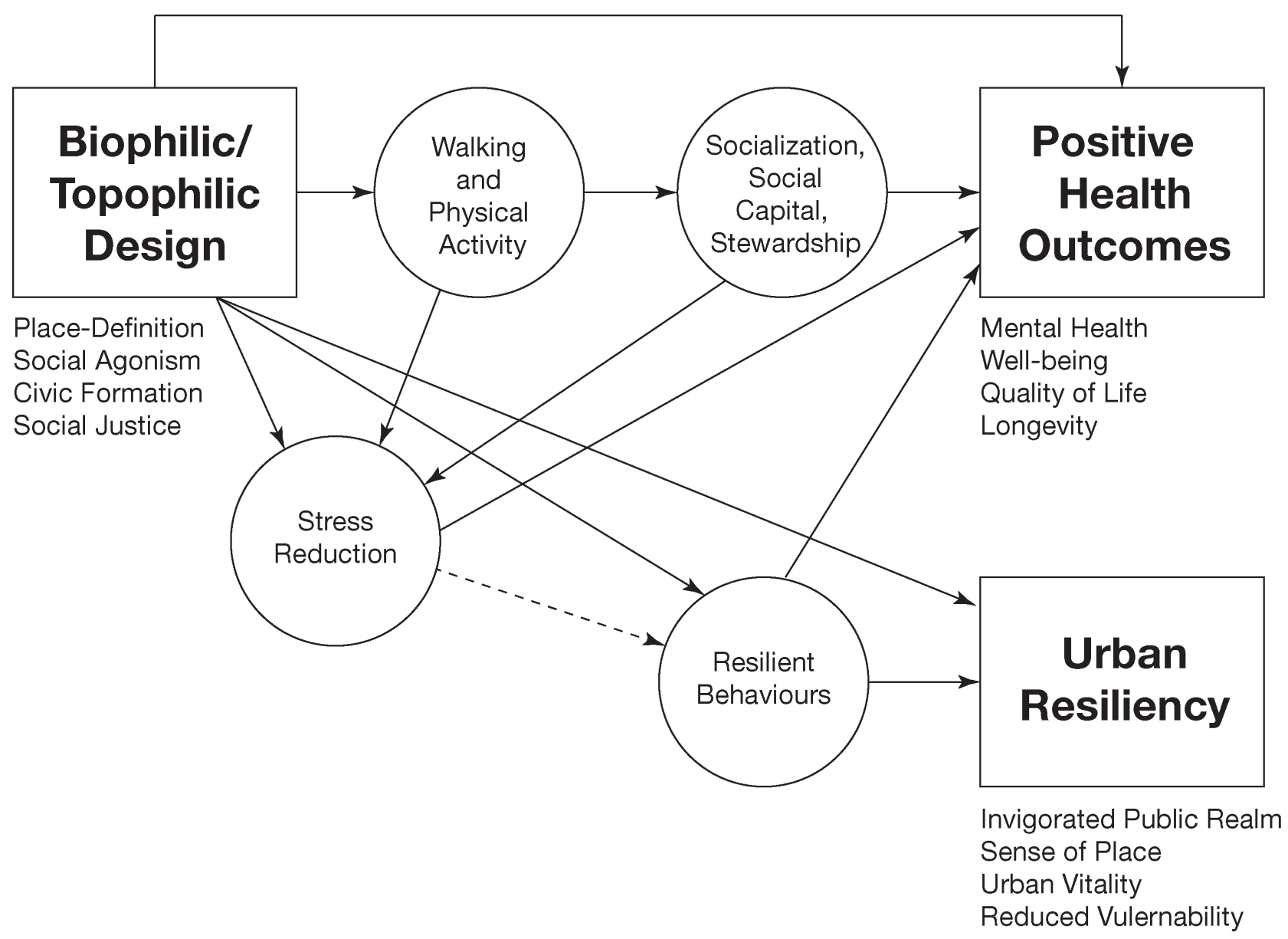

FIGURE 30

Biophilic design network diagram

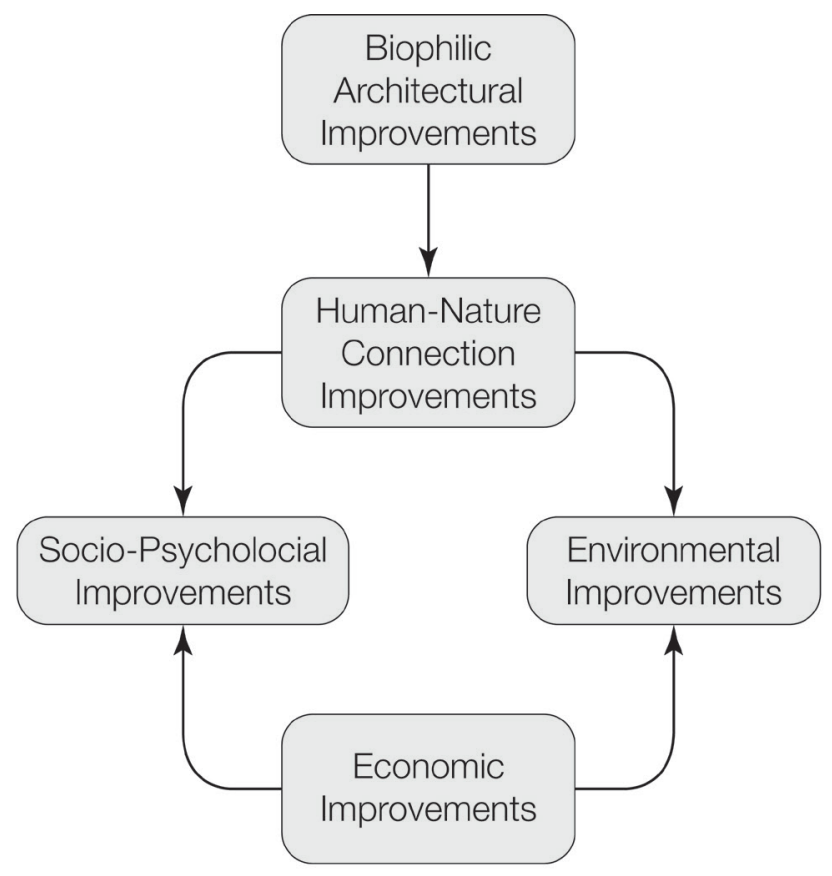

FIGURE 31

Impacts of biophilic design 


\section{THE TOPOPHILIC DIMENSION}

"Public spaces allow for shared experiences that can give rise to the mutual respect - however grudging - that is the basis of a thriving metropolitan culture.

- Raymond Gastil and Zoe Ryan (2004, p. 9)

$\mathrm{T}$ he term, topophilia, describes the "love of place". The study of such empathies posits that place-based relationships are a direct outcome of humankind's biological affinity for the natural environment, and is stimulated by design interventions that elevate or reinforce the connection between the built environment and its natural counterpart (Tuan, 1974). It is rooted in humans' natural tendencies; an inherent need to establish territorial control. This domain is manifested through controlling resources, attaining safety, and achieving security (Kellert, et al., 2008). Today, it is most commonly experienced in locational familiarity, or the yearning for home, which is a fundamental aspect of everyday human life. In order to develop this connection, it requires the successful synergy of culture and ecology; architecture and nature; form and function.

One of the fundamental components of Biophilic Design is the topophilic dimension. Topophilic design is a framework that focuses on all aspects of design that contribute to a user's attachment to, and definition of, place (Kellert, et al., 2008). The establishment of a sense of identity created by topophilic interventions fosters positive and sustained connections between people and their habitats. This is accomplished by developing a seamless connection between the natural and man-made realms; between building and its site; between architecture and place. This applies to all types of places, whether they be physical, emotional, historical, cultural, or any combination thereof. By embracing this biologically-encoded relationship, this thesis asserts that cities, neighbourhoods, and buildings can become more resilient through the definition of place and its associated benefits. 


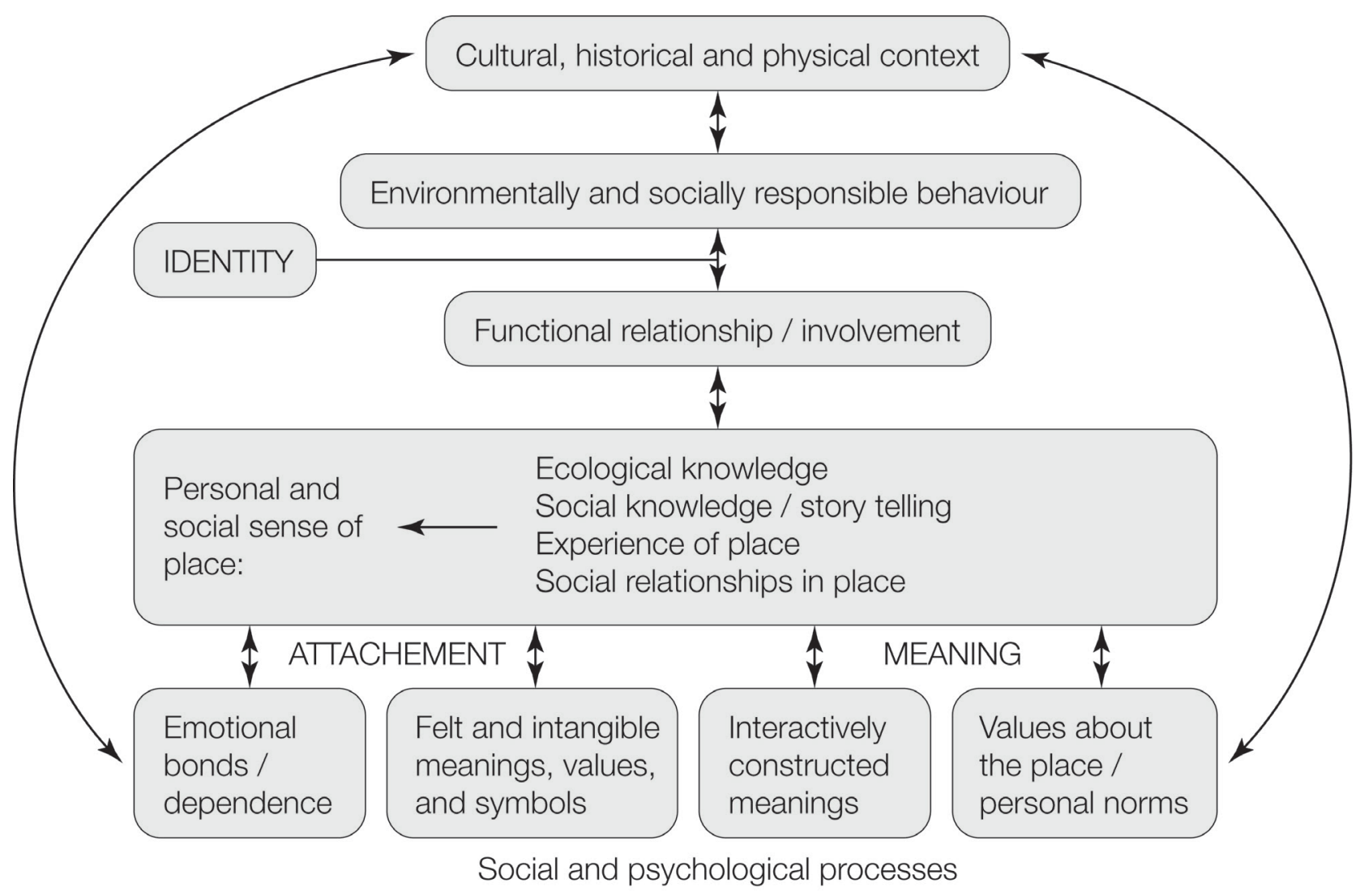

FIGURE 33

Identity generation process, based on Claire Hintz's Dimensions of Place and Environmentally Responsible Behaviour

\subsection{PLACE-BASED RELATIONSHIPS}

Stephen Kellert, Judith Heerwagen, and Martin Mador propose a series of attributes that describe placebased relationships in their collective text, Biophilic Design: The Theory, Science, and Practice of Bringing Buildings to Life. Place-based relationships "refers to the successful marriage of culture with ecology in a geographical context"(Kellert, et al., 2008, p. 12). They posit that these relationships must be established in order to create an intervention that embraces, celebrates, and defines the unique spirit of a place. Figure 33 descibes the process of generating an identity, based on Claire Hintz's Dimensions of Place and Environmentally Responsible Behaviour. It descibes the role attachment and meaning play in developing an emotional bonds between people and their habitats. These relationships include:

- Geographic connection to place

- Historic connection to place

- Cultural connection to place

- Ecological connection to place

- Indigenous materials

- Landscape orientation
- Form defining landscape features

- Landscape ecology

- Integration of culture and ecology

- Spirit of Place

- Avoiding Placelessness 


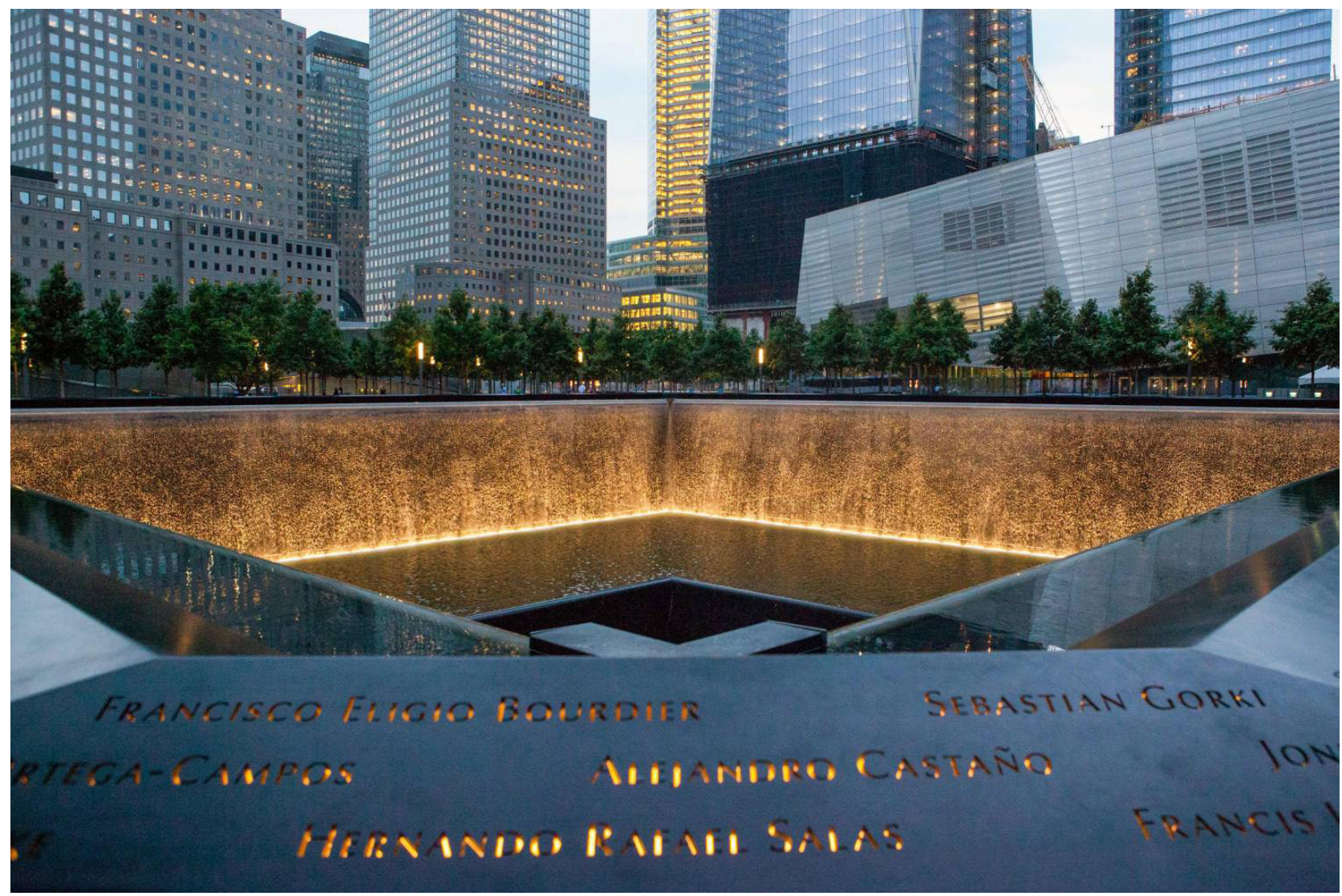

\section{FIGURE 34}

National September 11 Memorial, New York City

\subsection{THE SPIRIT OF PLACE}

The Spirit of Place, or the Genius Loci, was a common notion in the 1800 s, originally associated with the belief of a sacred character of certain spaces. One origin of this sentiment was the ancient Roman religion and its belief that parts of this world are occupied by gods. These gods were entrusted with the protection of the unique spirit of a place, with genius loci being the Latin term for these spiritual guardians of place (Norberg-Schulz, 1991). With respect to architecture, its contemporary use has been increasingly secularized. Spirit of Place can be understood as the physical and spiritual elements that give meaning and value to place (Bianco, 2008). The term, genius loci, is now interpreted as "the enhanced, or recognized connection between a person and the world" (Tuan, 1974, p. 142). In a broader sense, it describes the unique and distinctive atmospheric quality, or spirit of place, that makes a location distinctive (Figure 34). It is comprised of the social, cultural, geographic, demographic, and environmental contexts that shape and define place.

"People want to experience the sensory, emotional, and spiritual satisfactions that can be obtained only from an intimate interplay, indeed from an identification with the places in which [they] live. This interplay and identification generates the spirit of the place. The environment acquires the attributes of place through the fusion of the natural and human order."

- René Dubos (Wooing of the Earth, 1980, p. 110) 


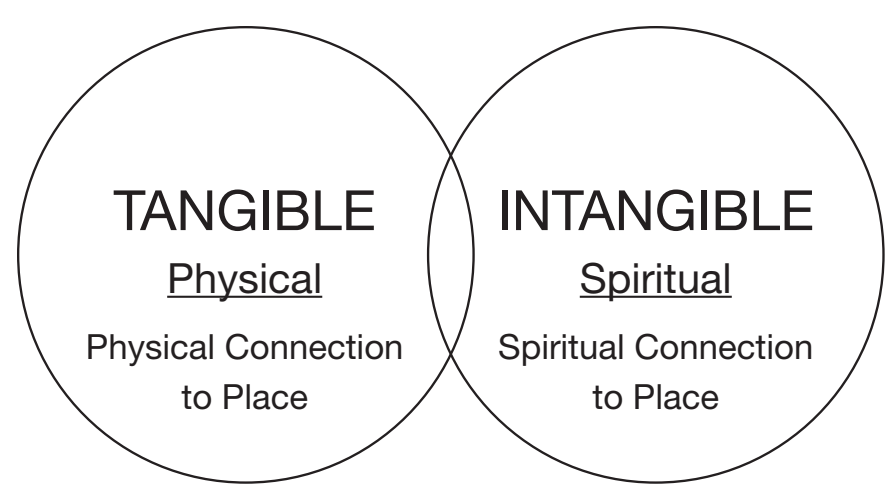

FIGURE 35

Experiential dimensions of the spirit of place

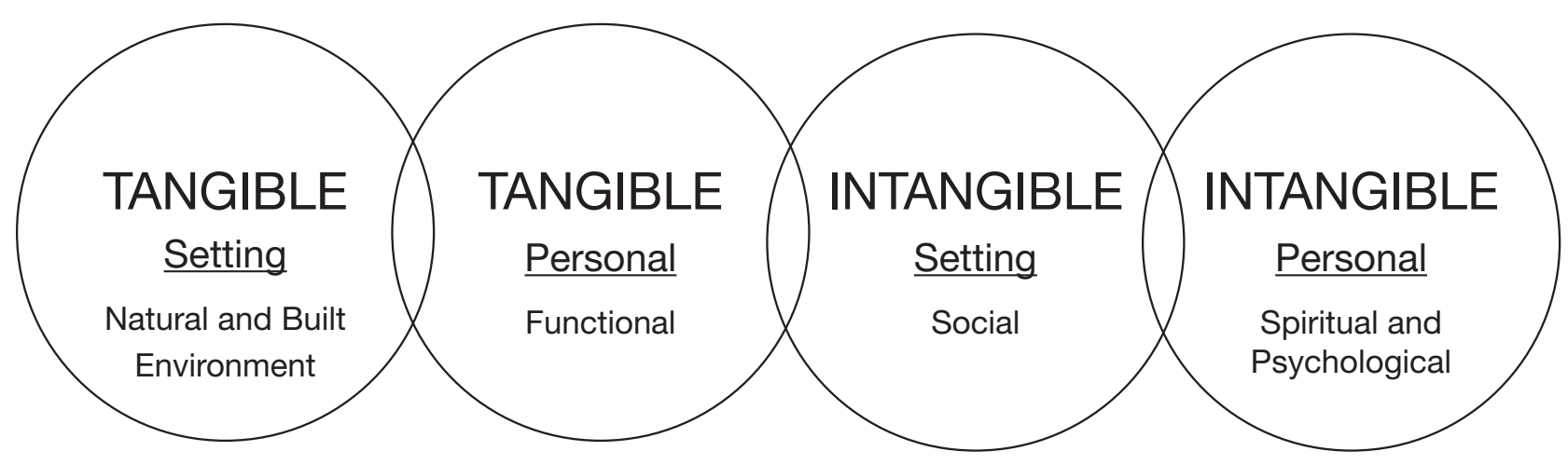

FIGURE 36

Nested elements of the spirit of place

Yi-Fu Tuan describes how the spirit of place can be divided into two categories: tangible and intangible (Figure 35 and 36)(1974). Tangible elements that contribute to the definition of place include: buildings, sites, landscapes, pathways, or objects. The physical connection to a place stems from the primitive and fundamental desire for home and shelter. This is often embodied in the priority of the physical hearth as the centre of a dwelling, referencing man's historic need for shelter and warmth (Tuan, 1974). Intangible elements include memories, narratives, written documents, rituals, festivals, traditional knowledge, values, and fragrances. These elements create a spiritual hearth, providing spiritual shelter, safety, emotional refuge, relief, rest, and a sense of belonging.
There are numerous disciplines concerned with the ways that humans interact with their surrounding environment, and their subsequent relationships that develop, including: environmental psychology, phenomenology, anthropology, biology, ecopsychology, and geography (Bianco, 2008).

"Topophilia is not the strongest of human emotions. When it is compelling, we can be sure that the place or environment has been the carrier of emotionallycharged events or perceived as a symbol".

- Yi-Fu Tuan (Topophilia, 1974, p. 93)

The genius loci is a fundamental aspect of placemaking and the greater phenomenology discourse. Phenomenology is the systematic reflection on, and study of, the structures of consciousness. This topic is explored by Christian Norberg-Schulz 


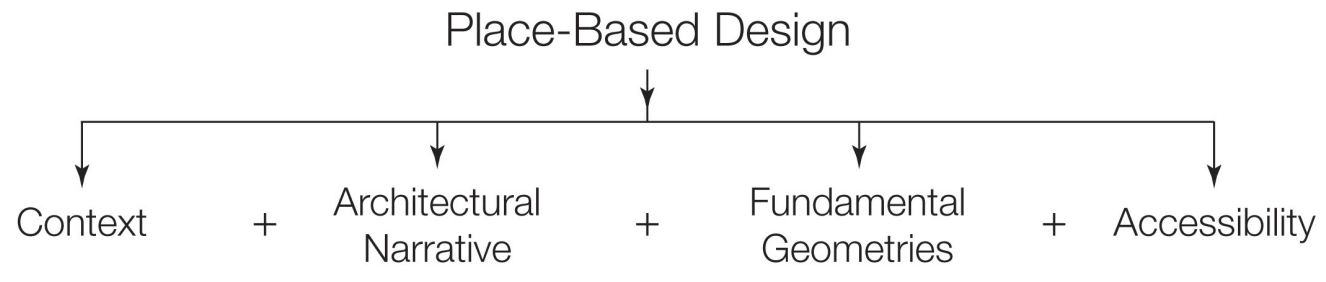

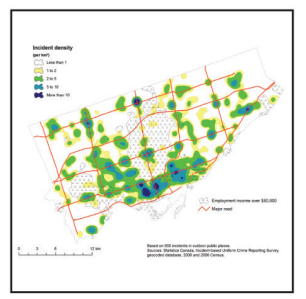

Site Conditions/ Factors/Influences

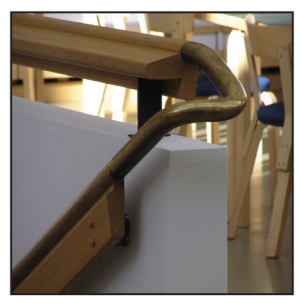

Design

Nattarive

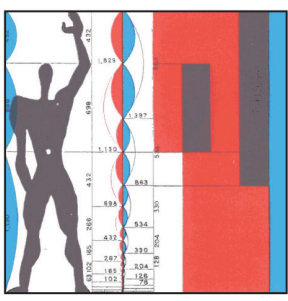

Regulating

Geometric

Principles

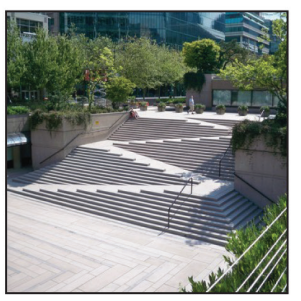

Removing

Barriers to

Entry

\section{FIGURE 37}

Principles of place-based design

in his seminal discourse, Genius Loci: Towards a Phenomenology of Architecture. The Norwegian architect contrasts pre-modern buildings against their modern counterparts to illustrate the placelessness of the international style. Rooted in an Heideggerian approach, Schulz (1991) discusses how architecture's duty is to concretize the genius loci, stating:

"The spaces where life is occurs are places... A place is a space that has a distinct character. Since ancient times the genius loci, or spirit of place, has been recognized as the concrete reality man has to face and come to terms with in his daily life. Architecture means to visualize the genius loci and the task of the architect is to create meaningful places, whereby he helps man to dwell."

- Christian Noberg-Schulz (Genius Loci: Towards a Phenomenology of Architecture, 1994, p. 5)

The role of architecture, therefore, is arguably to analyze these numerous place-based relationships and human interaction patterns and design an environment that stimulates and/or improves them. In order to do so, Yi-Fu Tuan (1974) put forward four principals of place-based design from academic and industry expert's theories (Figure 37). This thesis focuses on the following place-based design principals:

- Context: the surrounding environmental factors that give each space its unique character, Designing with Nature, Ian McHarg (1969)

- Architectural Narrative: developing a coherent design language to create a simplistic beauty and authenticity, A Pattern Language, Christopher Alexander (1977)

- Fundamental Geometries: utilizing the essential elements of design including basic geometries, scale, balance, proportion, and [as]symmetry, Sacred Geometry, Robert Lawlor (1982)

- Accessibility: designing spaces that are physically and emotionally accessible, Accessible Architecture, Philipp Meuser (2012). 


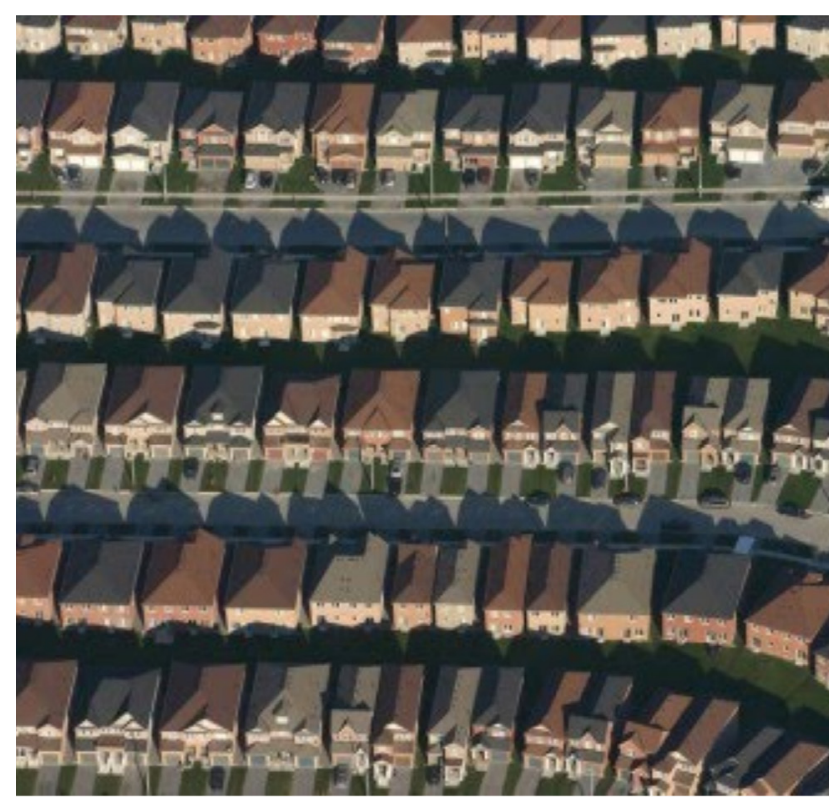

FIGURE 38

Aerial view of suburban development

There are numerous organizations, agencies, and communities that have been established to develop, maintain, and preserve the spirit of place in architecture, and other iconic sites, including:

- The Environmental Design Research Association (EDRA)

- Architectural \& Environmental Phenomenology (EAP)

- Academy for Neuroscience and Architecture (AFNA)

- The Centre of Health Design: Evidencebased Design Accreditation and Certification (EDAC)

- International Council on Monuments and Sites (ICOMOS): Declaration on the Safeguard of the Spirit of Place, Paris, 2008

- International Centre for the Study of Preservation and Restoration of Cultural Property (ICCROM): Cultural Heritage in Postwar Recovery, Rome, 2008

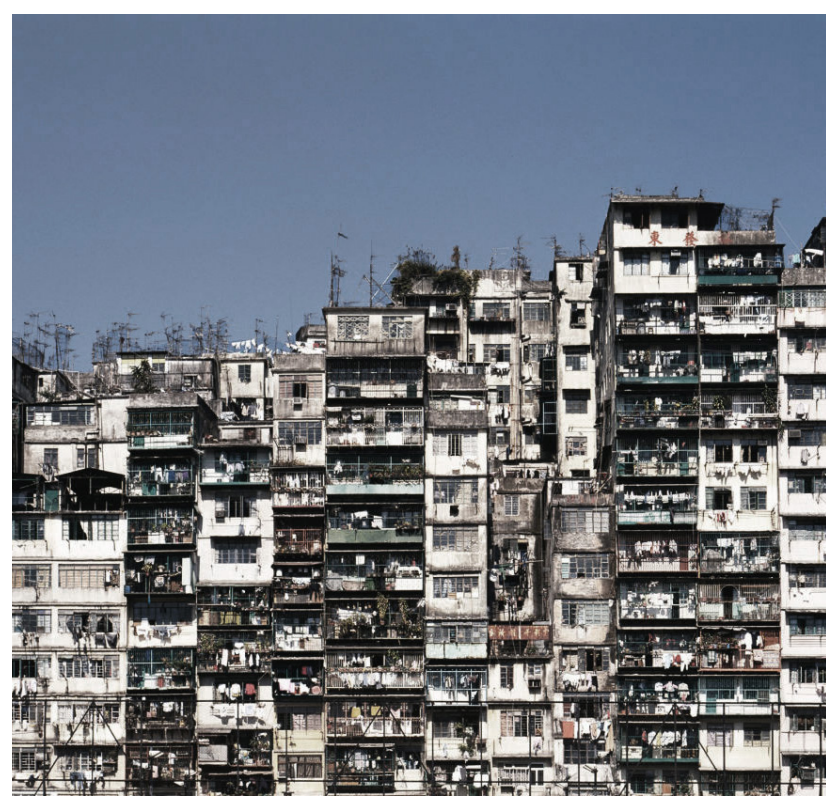

\section{FIGURE 39}

Kowloon walled city skyline

\subsection{PLACELESSNESS}

Placeless is the antithesis of place-based design and the genius loci. It is the resulting divorce of design from connection to the culture or ecology of place.

"This corrosive separation of the built environment from its biocultural context has resulted in the decline of human-nature relationships and environmental sustainability".

- Kellert, et al. (2008, p. 13).

Kellert provides examples, such as the homogeneity of suburban residential dwellings (Figure 38 and 39 ), in order to illustrate placeless design and its lack of regard for its context.

Kenneth Frampton's concept of Critical Regionalism, was developed as an effort to counter the placelessness and lack of identity of contemporary urban environments (Frampton, 1998). It explores the loss of regional culture to 


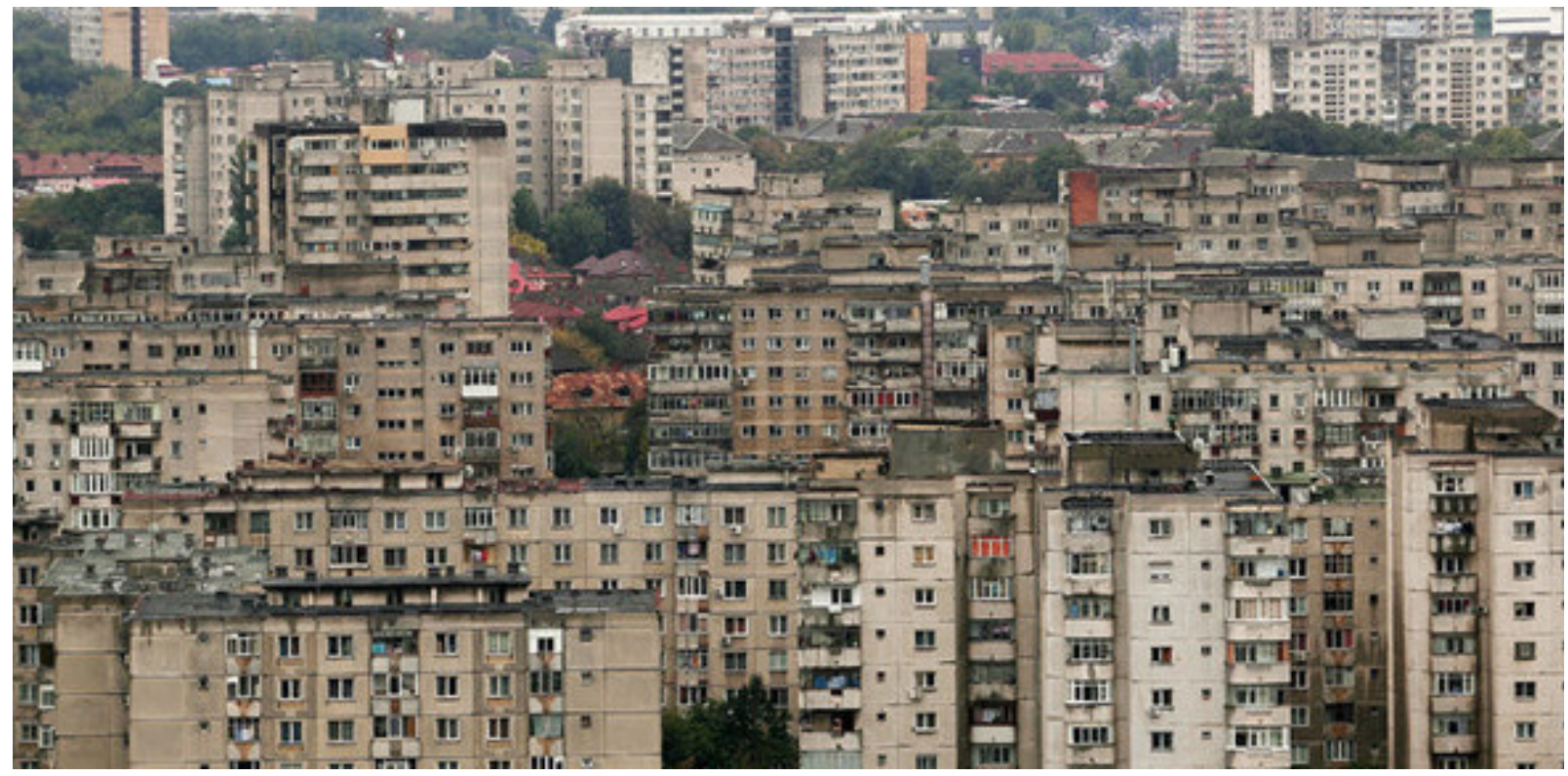

FIGURE 40

Bucharest's homogeneous skyline

the hegemony of global development (Figure 40). In Towards a Critical Regionalism, Frampton provides "Six Points Towards an Architecture of Resistance" in which he discusses the condition of contemporary, technocratic culture and its societal evolution towards a civilization of universality. Its critique centres on architecture's focus on the production of visual images and iconic forms, which is ironically contrasted by a decline of craftsmanship in design and construction that previously created them. The creation of superficial images, rather than well-designed and functional spaces, it argues, has culminated in an overall loss of the sense of place. Critical regionalism incorporates numerous elements of place in order to create an architecture of resistance: identity, past, history, culture, and values. The Columbia University Professor of Architecture develops a framework for regionalism which focuses on the relationship of a building to its site and its sociological context.
Modern architecture is characterized by the separation of design from place, resulting in placelessness. Through critical regionalism, or an emphasis on place-based design, architecture regains its ability to connect with its users. These concepts are employed as a strategy to enhance human connection with architecture and the urban environment. 


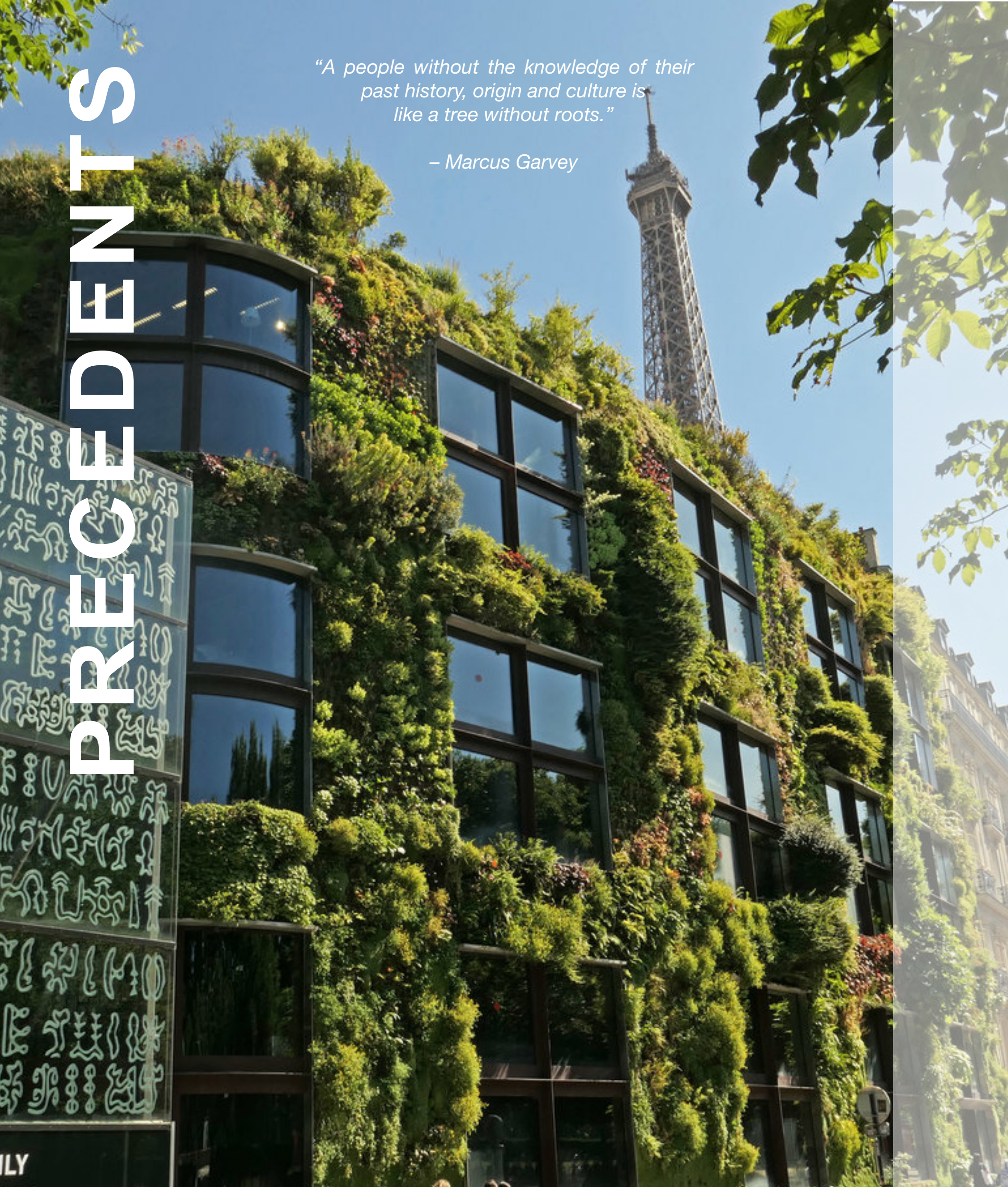




\section{PRECEDENTS}

"The great challenge of the twenty-first century is to raise people everywhere to a decent standard of living while preserving as much of the rest of life as possible."

- Edward O. Wilson

W hile Biophilic Design is both a theory and design philosophy, its success relies on its integration into the built form. This chapter focuses on precedents in an effort to identify the qualities and strategies that are most impactful, and can subsequently be integrated into the design portion of this thesis. The following section is divided into five parts: Public Landscape Parks, Linear Parks, Institutional Programs, Place-Based Relationships, and Markets. The two park projects were selected based on the way they invigorate the public realm and function as recreational anchors within an highly urban context. The institutional project was selected due to its seamless integration of nature within a fully functioning building. A project that developed significant place-base relationships was selected due to its ability to foster a symbiotic relationship between people, architecture, and the environment. Lastly, two market projects were selected for their innovation and vision in extending the limits of market architecture as well as their responses to the contextual relationships that influenced their design. 


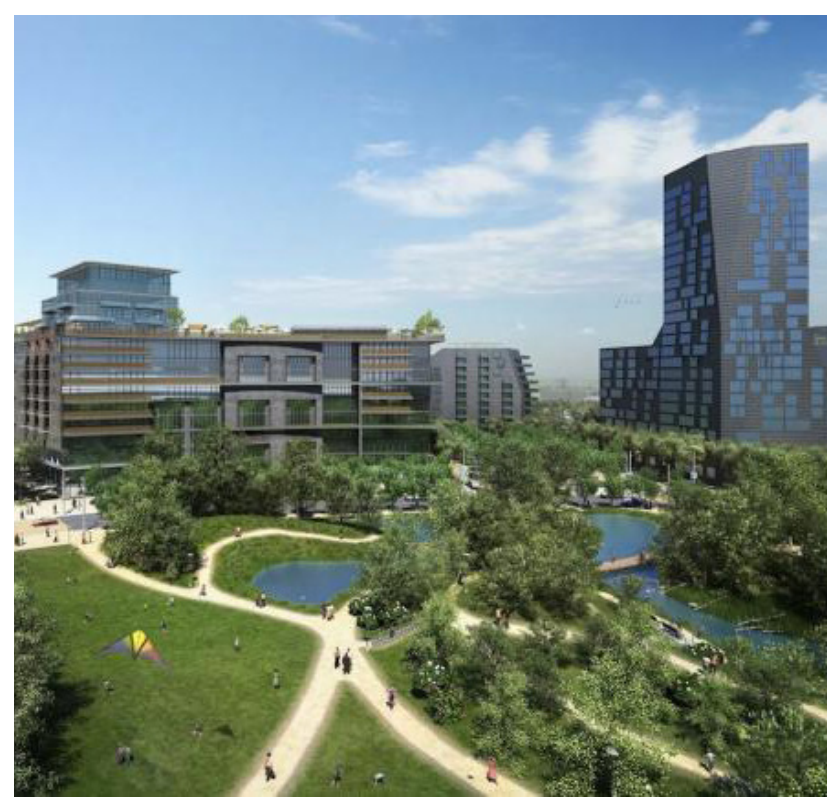

FIGURE 42

Aerial render of Corktown Common

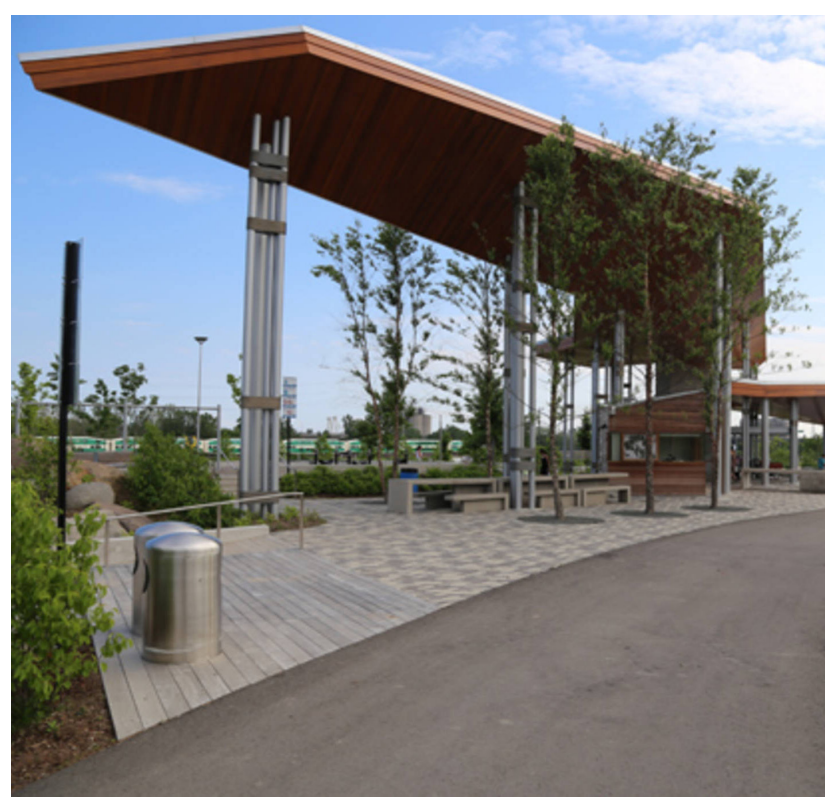

FIGURE 43

Swooping canopy structure and snack/washroom pavilion

\subsection{PUBLIC LANDSCAPE PARKS}

\section{Corktown Common}

Maryann Thompson Architects [Architect], Michael Van Valkenburgh [Landscape Architect]

Corktown Common park is an 18-acre open, vibrant and dynamic park that serves the local community, Greater Toronto Area, and numerous visitors to the city. The park's construction began in September, 2010 as part of the new athletes' village for the Pan Am Games. It is situated on the south-eastern portion of the new neighbourhood, running the length of the Don River, from King Street to the north to the rail corridor in the south. The area was once the William Davies hog abattoir. But now, the park offers an urban oasis with green space overlooking the Don River, and a view of the downtown skyline and Lake Ontario.

Completed in 2013, the development transformed a previously abandoned post-industrial site into a new multi-functional park. It offers "a dynamic, year-round, re-naturalized public park, animated by a wide variety of programming and a beautiful multi-functional pavilion.... the park will renew the site while addressing vital infrastructure, taking full advantage of the robust topography" (Urban Toronto, 2014). The landscape architecture firm Michael Van Valkenburgh Associates, integrated smaller playgrounds and innovative landscape features into the contours (Figure 45). The design incorporates a Floor Protection Landform (FPL) and capitalizes on the unique landscape to provide an observation area towards the Toronto skyline to the west, as well as Lake Ontario to the south, emphasizing a sense of scale and grandeur.

The park is of particular interest due to the way its designers navigated the design process. The extensive scale of the FPL created a means of organization for the park, both physically and programmatically, identifying two distinct halves. Additionally, Van Valkenburgh Associates implicitly employed interactive learning in the design of their play spaces, from the naturalized playground 


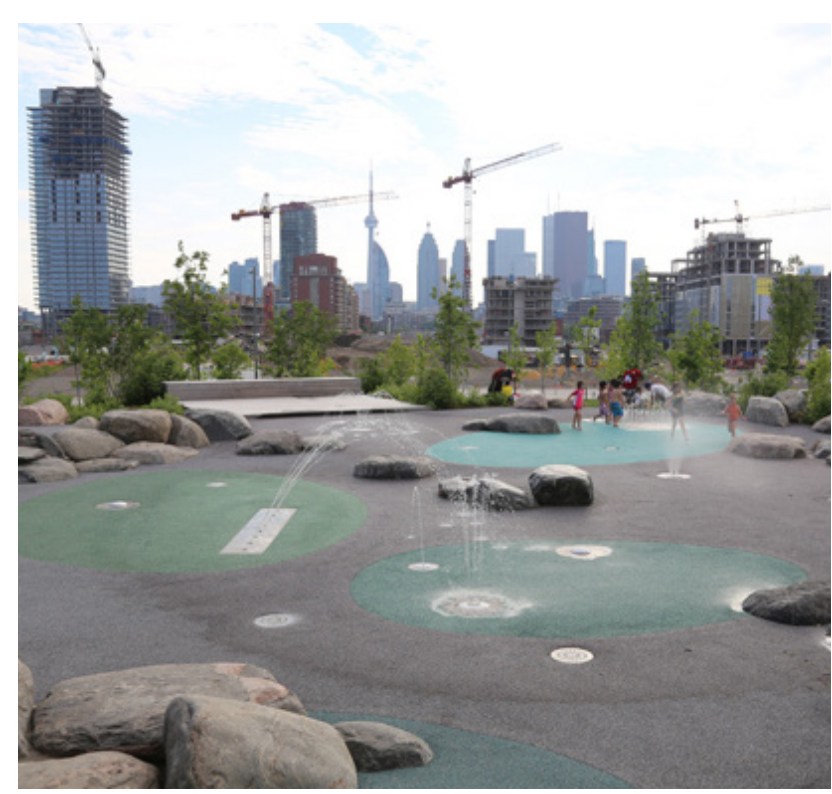

FIGURE 44

Splash pad

to the multi-purpose recreation field. The heavily landscaped playgrounds utilize natural elements for play, in contrast to conventional playgrounds, which rely almost exclusively on synthetic materials.

The urban prairie grassland contrasts an upland meadow on the upper slope, while the lowland wet meadow at the base of the landform adds ecological and experiential diversity. A meandering boardwalk moves both around and over the wetland, allowing users varying degrees of interaction with the landscape (Figure 45). The wet meadow serves more than merely an aesthetic role. It is a critical element in a park-wide ecological storm water recycling system. Winding paths, multi-use bike trails, and a wood-planked boardwalk allow visitors to traverse this unique urban landscape. Following the Don River, the park provides new access under the Bala railway corridor to provide direct access to the Don River Trail and the river's edge.

The 8.9-acre western, city-side of the FPL is defined by a dynamic, terraced topography that

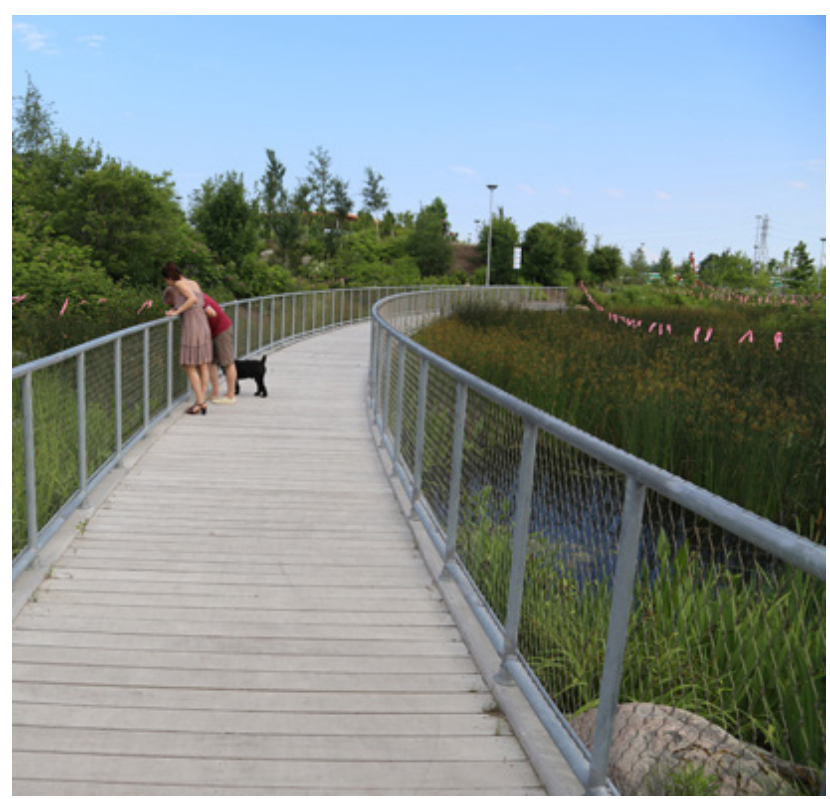

FIGURE 45

Wetland elevated boardwalk

creates variegated and dynamic spaces for a wide range of passive and active play. The landscape not only houses a variety of unique play structures, but is designed in such a way to be an interactive landscape. Local flora work in concert with the topography, articulating the boundaries of each space while framing views of the surrounding urban infrastructure. Corktown Common creates numerous spaces, ranging from introspective moments of contemplation to elevated landscapes, with sweeping views over the Toronto waterfront, allowing visitors to be immersed into its landscapes.

The park was built by Waterfront Toronto, a new public entity that has received government funding from each of its three levels, and also operates under a semi-autonomous mandate, shielding it from the bureaucracy of city politics. This means of public infrastructure has created a precedent for the development of public space in Toronto that focuses on social vitality and creating vibrant spaces for recreation rather than the commodification of public space. 


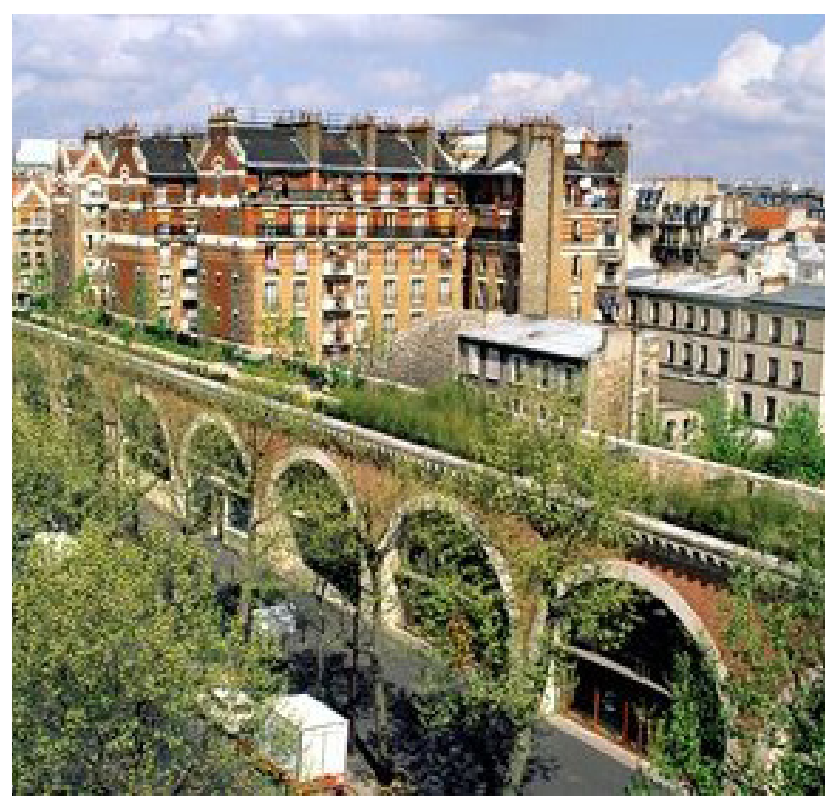

FIGURE 46

Viaduc de la Bastille

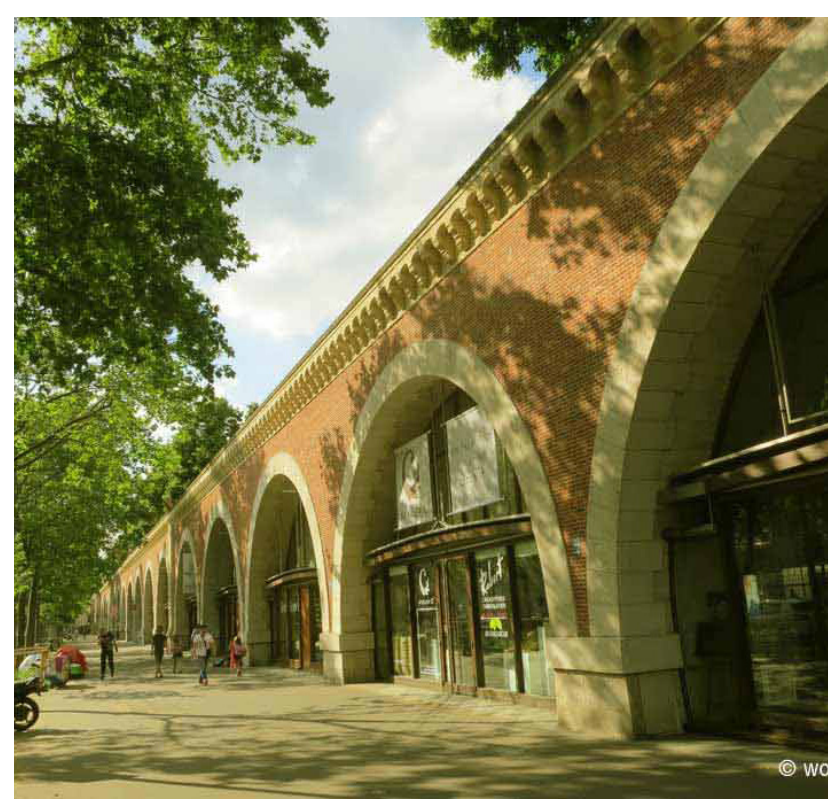

FIGURE 47

Viaduc de la Bastille

7.2 LINEAR PARKS

\section{La Promenade Plantée}

Philippe Mathieux [Architect] and Jacques Vergely [Landscape Architect]

The Promenade Plantée, or 'La Coulée Verte', is a $4.7 \mathrm{~km}$ elevated, linear park built primarily on top of an obsolete viaduct. It varies in width, from narrow passages to large swaths of gardens and meadows, as it meanders through the southeast region of Paris. Soaring 10 metres above the street, it is the inspiration for New York City's High Line and many other similar projects around the world.

As the region of the 12th arrondissement of Paris, France was being revitalized in the 1980s, the Vincennes railway line lay dormant for over a decade. As the Reuilly area's development initiated in 1986, it began by re-purposing the existing infrastructure. The old rail depot was converted into a group of park areas and plans were proposed to re-purpose the remainder of the abandoned line in 1983. The elevated walkway was designed by landscape architect, Jacques Vergely and architect, Philippe Mathieux. Construction began in 1988, and continued into the mid-2000s. The Promenade Plantée was the first and only elevated park in the world for over three decades

As the park is an elevated pathway, one its most critical relationships is between the upper walkway and the spaces underneath. The success of the walkway can be seen in one of the area's most unique segments: a portion of the railway that was constructed above an ancient viaduct (Figure 46). Below the park space is 'Viaduc des Arts', a series of 45 brick archways that have been re-purposed into artisan studios, galleries, showrooms, and cafés (Figure 47). Furthermore, numerous vertical circulation nodes were created along the path to allow pedestrian access. What could normally be dismissed as a functional requirement, the designers took the opportunity to create intricately designed staircases, ramps, paths, and elevators, to maintain its accessibility to all (Figure 48). 


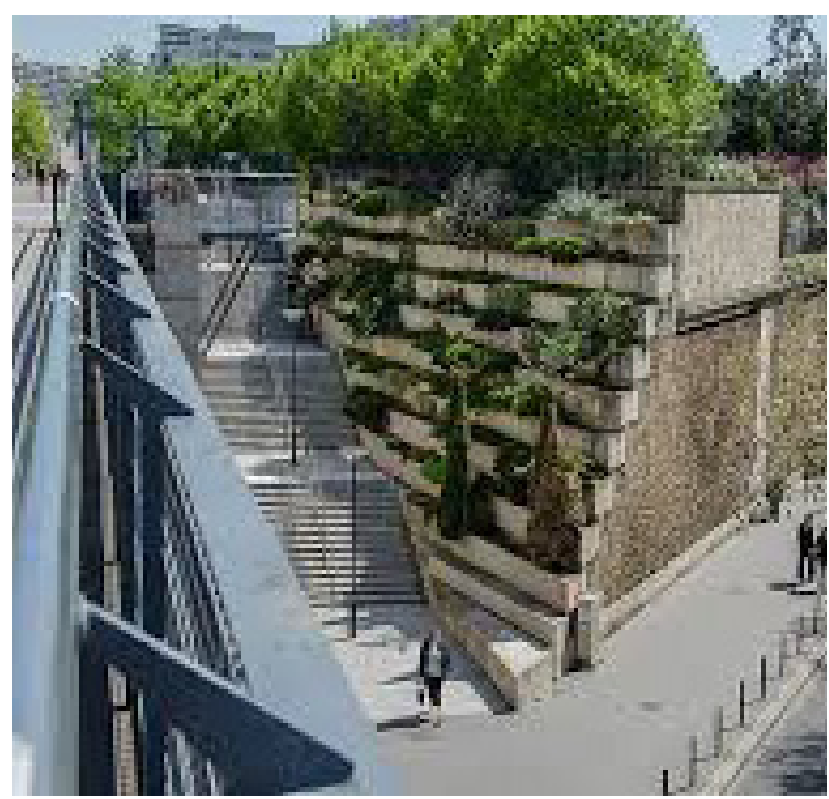

FIGURE 48

View of landscaped staircase connecting to grade below

This project is a testament to the capacity of architecture and development as initiators of growth. While the project cost only $\$ 25$ million to construct, it revitalized the region through the introduction of nearly $300,000 \mathrm{ft}^{2}$ of commercial and office spaces. Furthermore, its success initiated both the restoration of numerous historic buildings as well as the redevelopment of 25 adjacent lots.

This project is of particular interest to this thesis due to its unique features as a linear park. Firstly, as an elevated pathway, the circulation nodes it creates at the moments where it connects down to the ground plane is quite unique. Mathieux employs low-sloped stairs as the primary means of gently connecting to the ground plane. This creates interesting relationships as the park traverses across, over, and under varying park spaces. Its accessibility ultimately places the pedestrian as the primary driver of design. The integration of its seating draws people off the path and positions them within the planters themselves (Figure 49). This further enhances the relationship between users

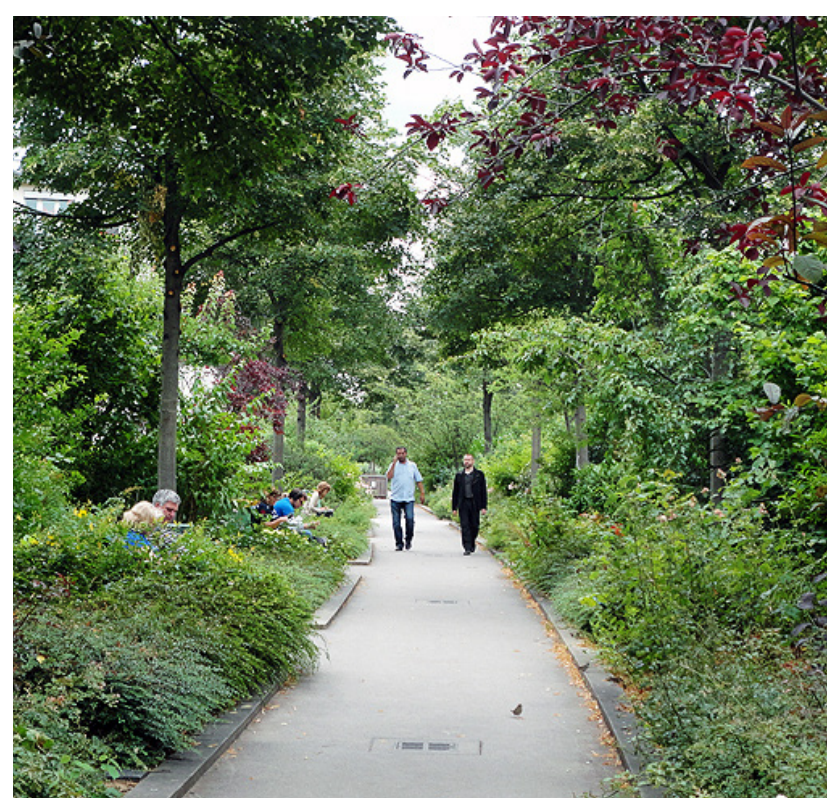

\section{FIGURE 49}

Recessed seating along walkway

and nature as the designers use the tree canopy as a means of shelter and shading. Lastly, due to the length of the linear park, there are a variety of types of arbours and trellis structures to augment the natural plant growth, as well as numerous water features to engage with the dynamic landscape. Overall, The Promenade Plantée is a primary example of both biophilic and topophilic design through its utilization of public green space as a design vehicle to connect people with nature.

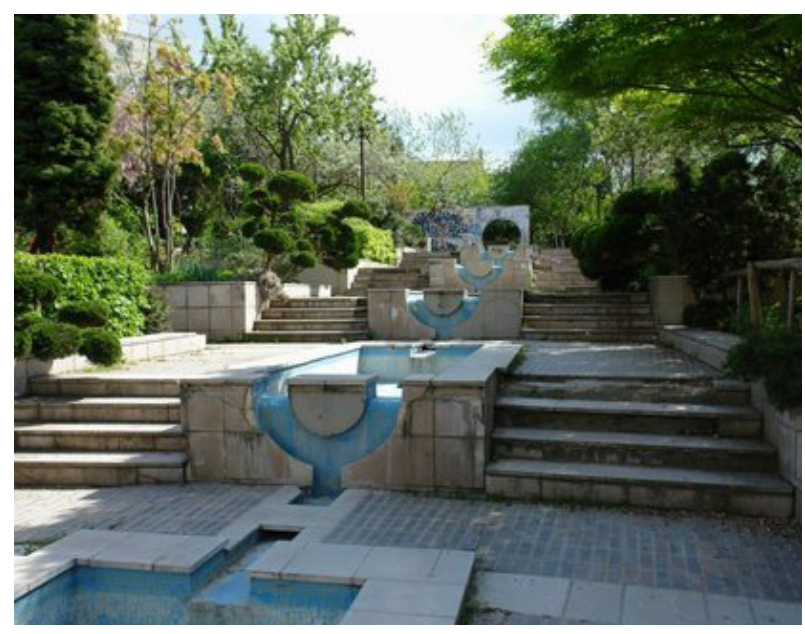

FIGURE 50

Expressive waterfall and staircase 


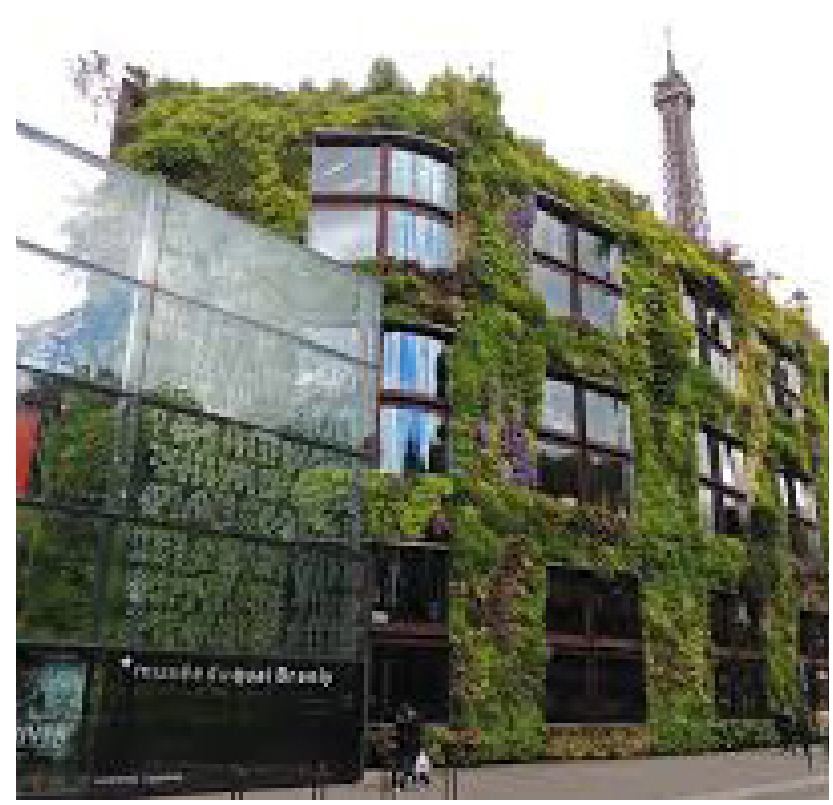

FIGURE 51

Iconic living wall using Le Mur Végétal living wall system

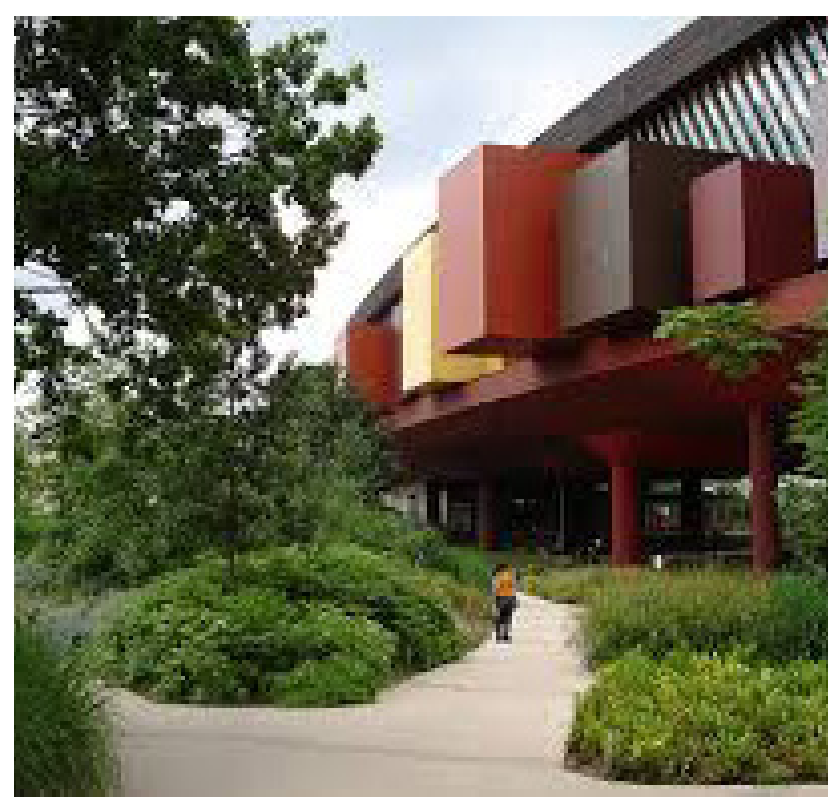

FIGURE 52

Exterior expression of interior galleries

\subsection{INSITUTIONAL PARKS}

\section{Quai Branly Museum}

Jean Nouvel [Architect] and Dr. Patrick Blanc [Green-wall Designer] Gilles Clément [Landscape Architect]

The Quai Branly Museum is one of Paris' most significant museums, curating a collection of over 450,000 objects. The iconic building was completed in 2006, and hosts one of the first largescale living walls on a public building in the world. The Le Mur Végétal system was created by Patrick Blanc, working with landscape architect Gilles Clément (Figure 51). Architect Jean Nouvel cleverly employs both nature and architecture to soften its street presence while creating an iconic façade. The museum embodies "a singular architecture for singular objects," as Nouvel phrased it, in order to embody the institution's mission statement: "to build bridges between cultures, to incite curiosity, and to meet the expectations of different audiences" (Musée Du Quai Branly Jacques Chirac, 2017).
The primary challenge of this project is the collection it housed. Nouvel's response to the museum's collection (art and artifacts collected during the colonial period) is a curved form punctuated by the museums numerous galleries (Figures 52 and 53). This is further emphasized by the contrast created in its siting within an immense landscape as noteworthy as the building itself. Nouvel creates a sense of enticement through the articulation of individual galleries onto the building's façade. The innovation of the museum is further enhanced by its living wall, only allowing users to view curated moments within. This experience is heightened by the users' procession to the building through Gilles Clément's undulating garden, which creates the appearance of an undomesticated landscape (Figures 52, 53, and 55). As with many of Nouvel's projects, this exploratory circulation continues within the doors of the museum. Each of the four continent exhibits are united in one central space where users are free to move and circulate as they please. The lack of imposed hierarchy allows for 


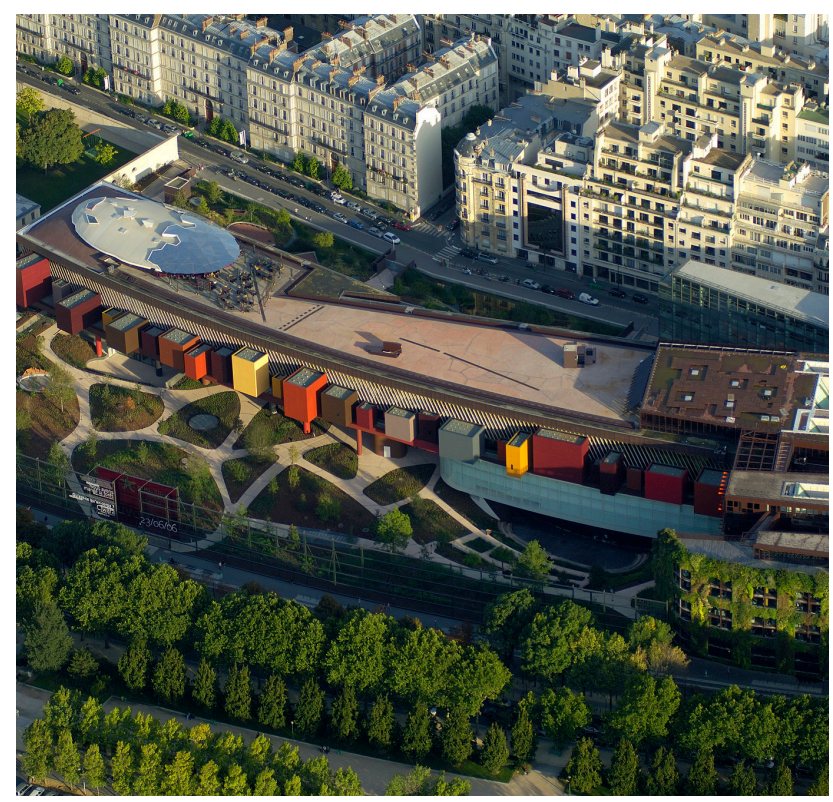

FIGURE 53

Aerial overview of Quai Branly Museum

unrestricted movement throughout the building's interior galleries. As a result, experiencing the museum is as much of a journey and work of art as the artifacts it displays.

Consciously or subconsciously, Nouvel employs numerous Biophilic Design principles throughout his design for the Quai Branly Museum. The relationship between the building's tectonic expression and materiality in relation to its interior configuration of spaces and circulation, echoes the symbiotic relationship of natural systems. The incorporation of vegetation as a building material provokes user interest, while stimulating their biologically-encoded affinity for nature an element that was adopted by this thesis. The sinuous form of the building adaptively responds to the forces and pressures which shape it, a similar response seen in plant life. The siting of the building within a vibrant ecosystem identifies the designers' comprehension of landscape ecology and establishes a vivacious spirit of place (Figure

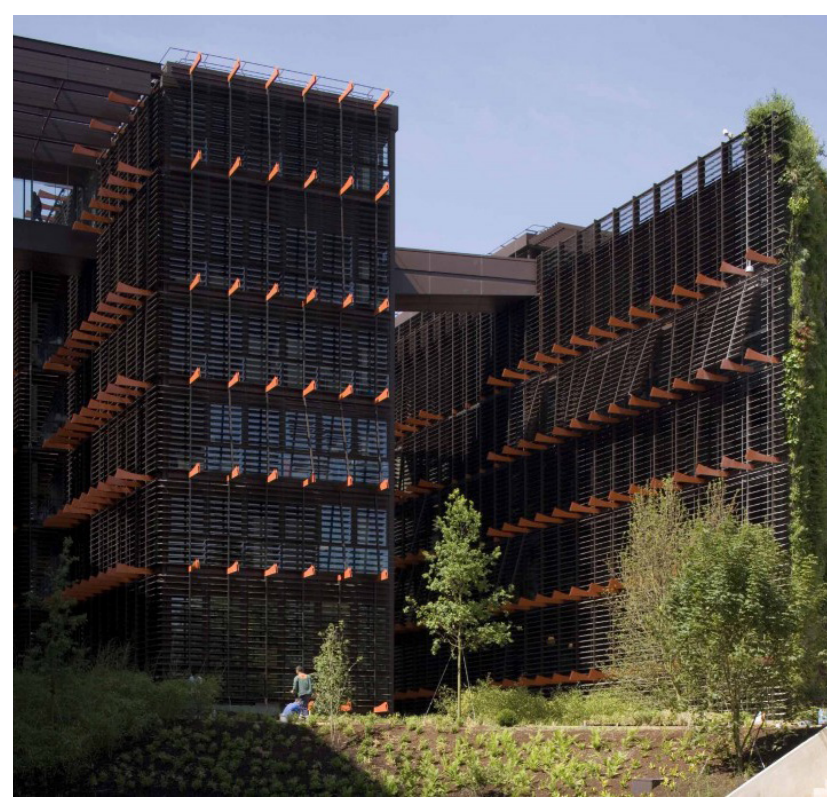

FIGURE 54

Trellis structure with vines beginning to take

55). Additionally, Nouvel's play on curiosity and enticement reflects the human need for exploration and discovery. The Quai Branly Museum functions as the pinnacle of holistic design, developing an intimate connection between users, architecture, and a curated environment.

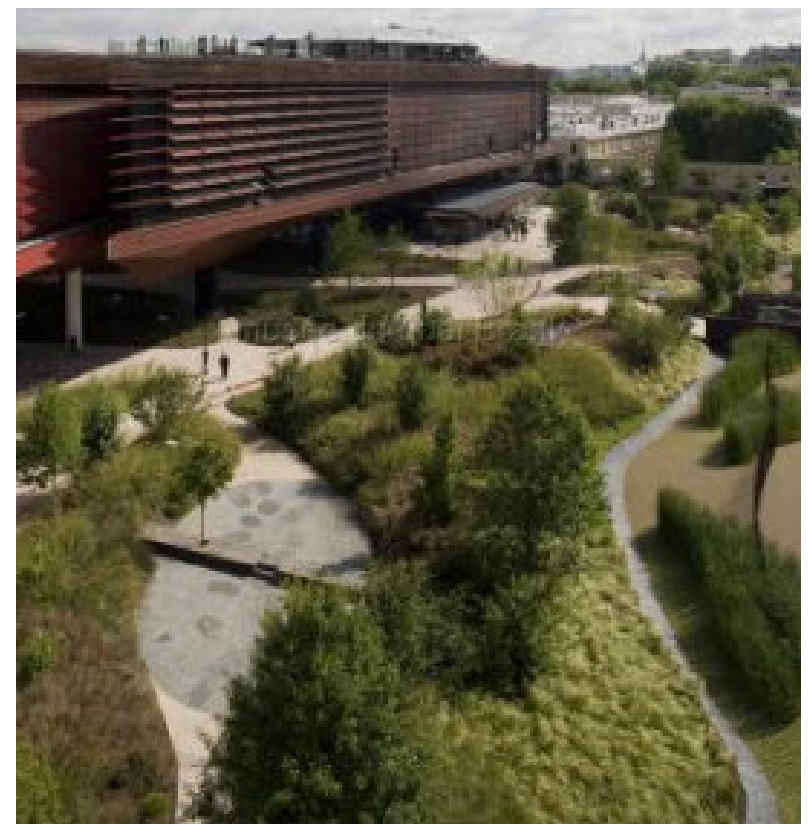

FIGURE 55

Exterior view of Gilles Clément's landscape 


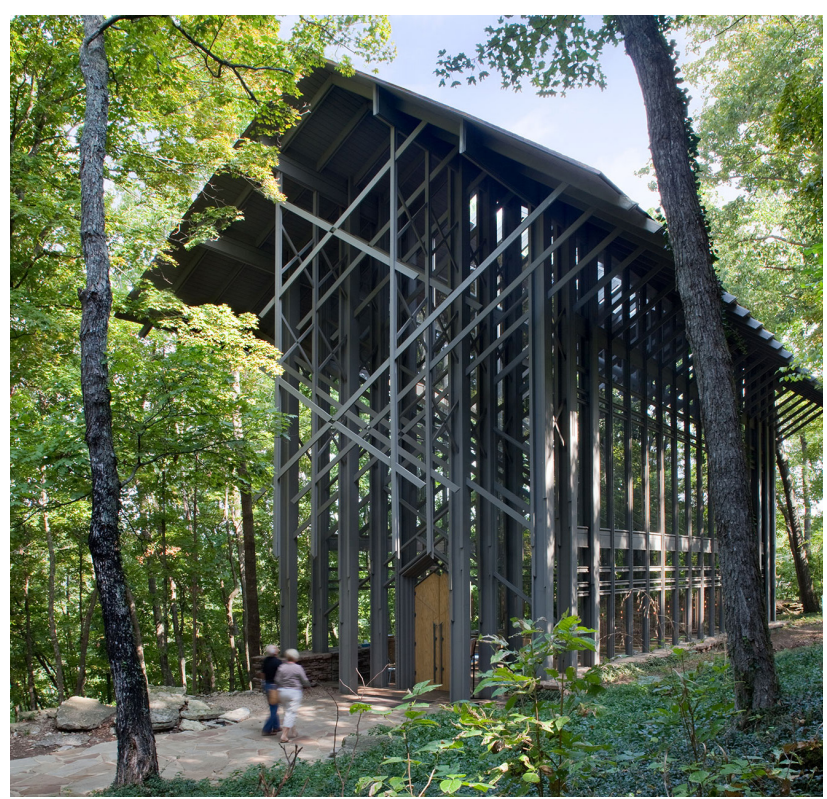

FIGURE 56

Exterior view of Thorncrown Chapel

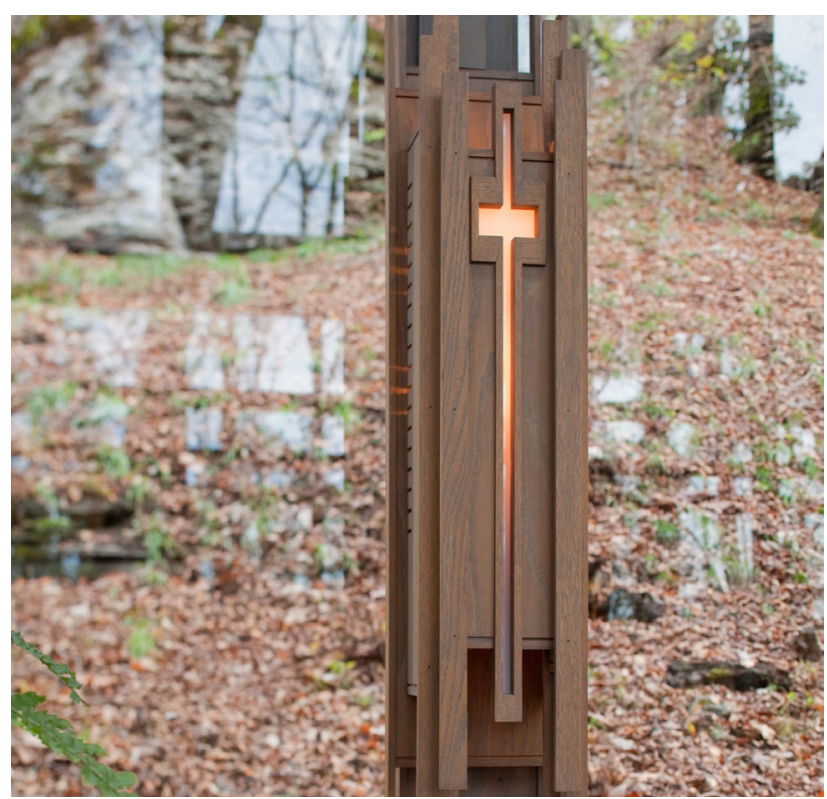

FIGURE 57

Ornamental lamp light fixtures

\subsection{PLACE-BASED RELATIONSHIPS}

\section{Thorncrown Chapel}

Euine Fay Jones [Architect] Jim and Doug Reed [Design and Construction]

The Thorncrown Chapel is a non-denominational place of reflection and spiritual contemplation nestled within Arkansas' Ozark Mountains in Eureka Springs. This project was conceived of by Jim Reed, who envisioned a minimalist glass chapel which would strike awe into its visitors through its intimate connection with its surrounding natural context. The dream was brought to life by Architect Euine Fay Jones, the former Dean at the University of Arkansas' School of Architecture. This humble chapel seamlessly integrates itself into its environment. Its large, expansive, glazed walls and ceiling blurs the lines between the built and the natural, the interior and the exterior, while its repetitive tree-like structure creates a forestwithin-a-forest illusion (Figure 56). It was the 2006 recipient of the Twenty-five Year Award, selected by the American Institute of Architects.
"This award showcases buildings that set a precedent; a building that has stood the test of time for 25-35 years, and continues to set standards of excellence for its architectural design and significance ... Thorncrown Chapel stands among the preeminent examples of spiritual architecture in the 20th Century"

- AIA CEO, Robert Ivy, 2005

The project is chosen as a precedent for its craftsmanship and the meticulousness of design, exercised by Fay Jones. The structure of the building is comprised of a repetitive wood column and truss system, designed to emulate a biomimetic forest. The roof structure further evokes the canopy of the forest with its large skylight, allowing daylight to filter down onto the chapel's guests. It is no surprise that Fay Jones was close friends with Frank Lloyd Wright, as both demonstrate a robust understanding of form, ornamentation, and order, derived from their intimate relationship with nature. Their affinity for nature is further expressed through their detail- 


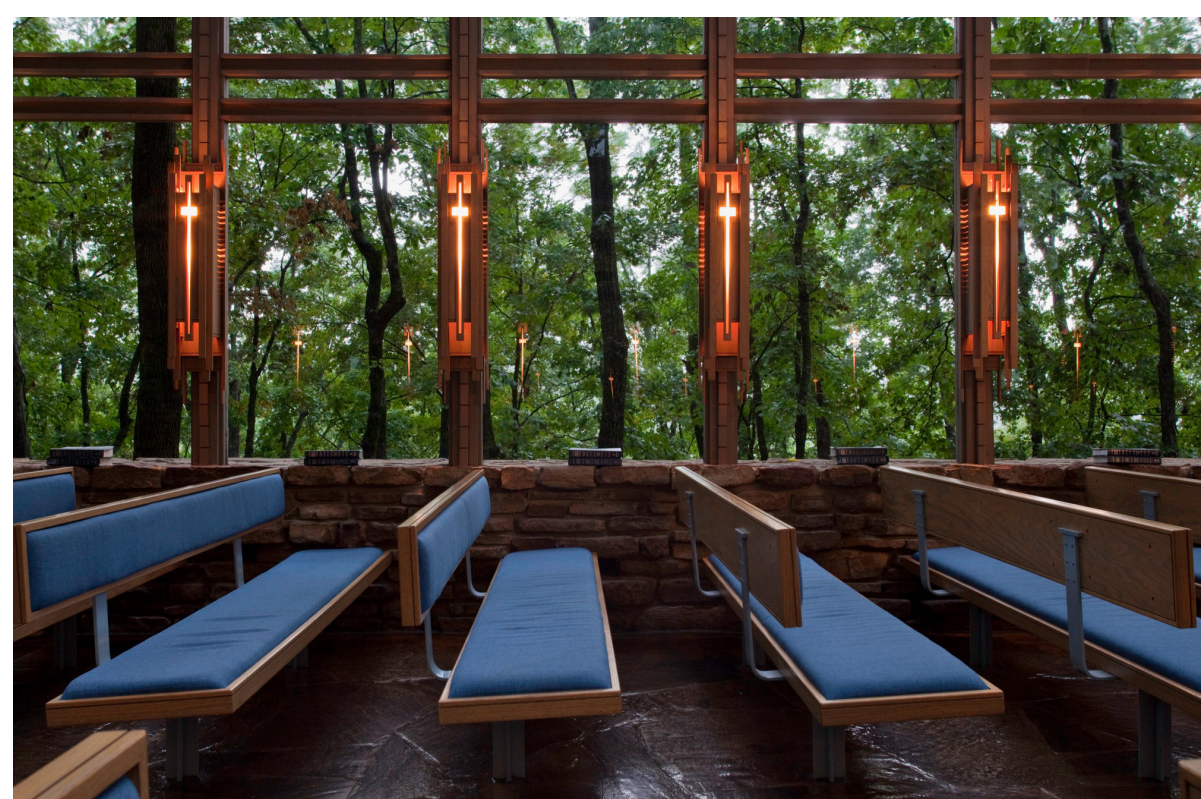

FIGURE 58

Regulating lines and design consistency between pews, columns, and lamps

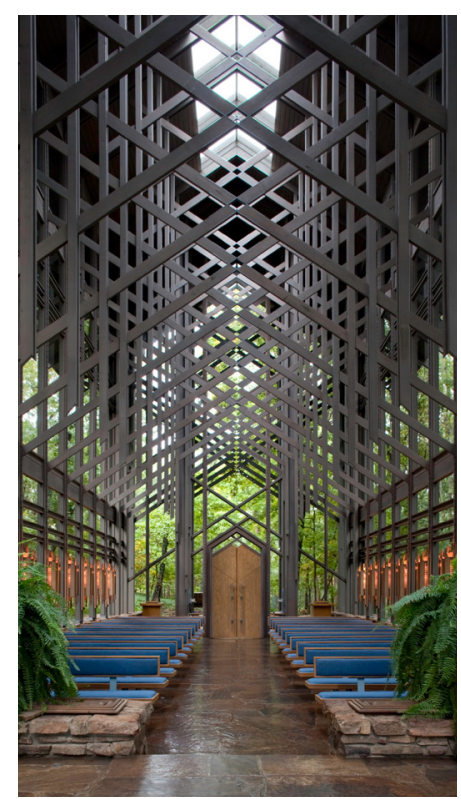

FIGURE 59

Interior view: tree-like structure oriented design which often extends beyond the traditional limits of architecture. This level of precision was applied to Fay Jones' consideration for the chapel's structure and materiality. Every member was carefully sized so that it could be carried by no more than two people (ArchDaily, 2014). The chapel's structure is constructed solely of $2 \times 4 s, 2 \times 6 s$, and $2 \times 12 s$ of Southern pine. This mentality stemmed from his intention to have as minimal a footprint on the site as possible. It was further applied to the material selection of the project. The entire chapel is constructed of wood and glass in an attempt to appear as if the structure emerged from the ground. The only steel found in the project is a series of ornamented cross lanterns which adorn each of the chapel's columns (Figure 57).

Thorncrown Chapel's significance for this thesis lies in the ability of its craftsmanship to connect people, through architecture, to nature. This is most specifically experienced in the synergy between design elements. Each of its components work harmoniously with one another to create a unified design. This can be seen where the treelike structure touches the ground and how this demarcates the spacing of the pews, while hosting an ornamented cross lantern (Figure 58). It is also apparent in the way the Fay Jones designed the structure with numerous small members so that they mimic intersecting branches (Figures 59 and $60)$. This project demonstrates how when every element of a design works together, architecture is capable of evoking a sense of place, wonder, and awe.

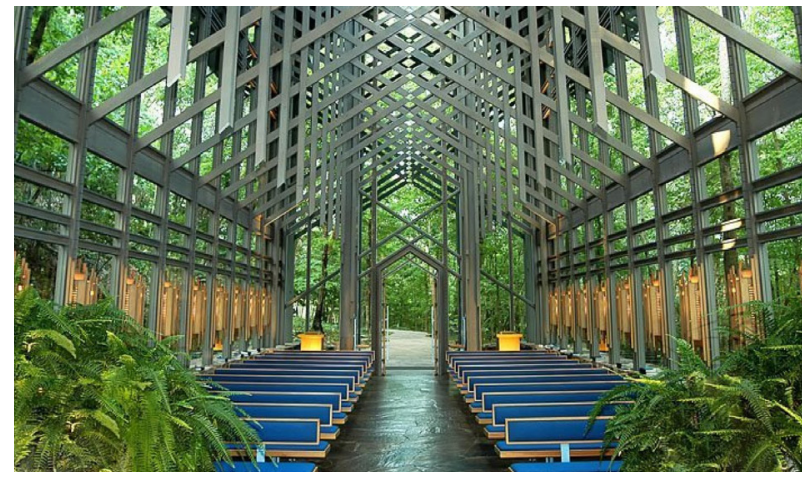

\section{FIGURE 60}

Interior view highlighting the chapel's blurred interiorexterior relationship 


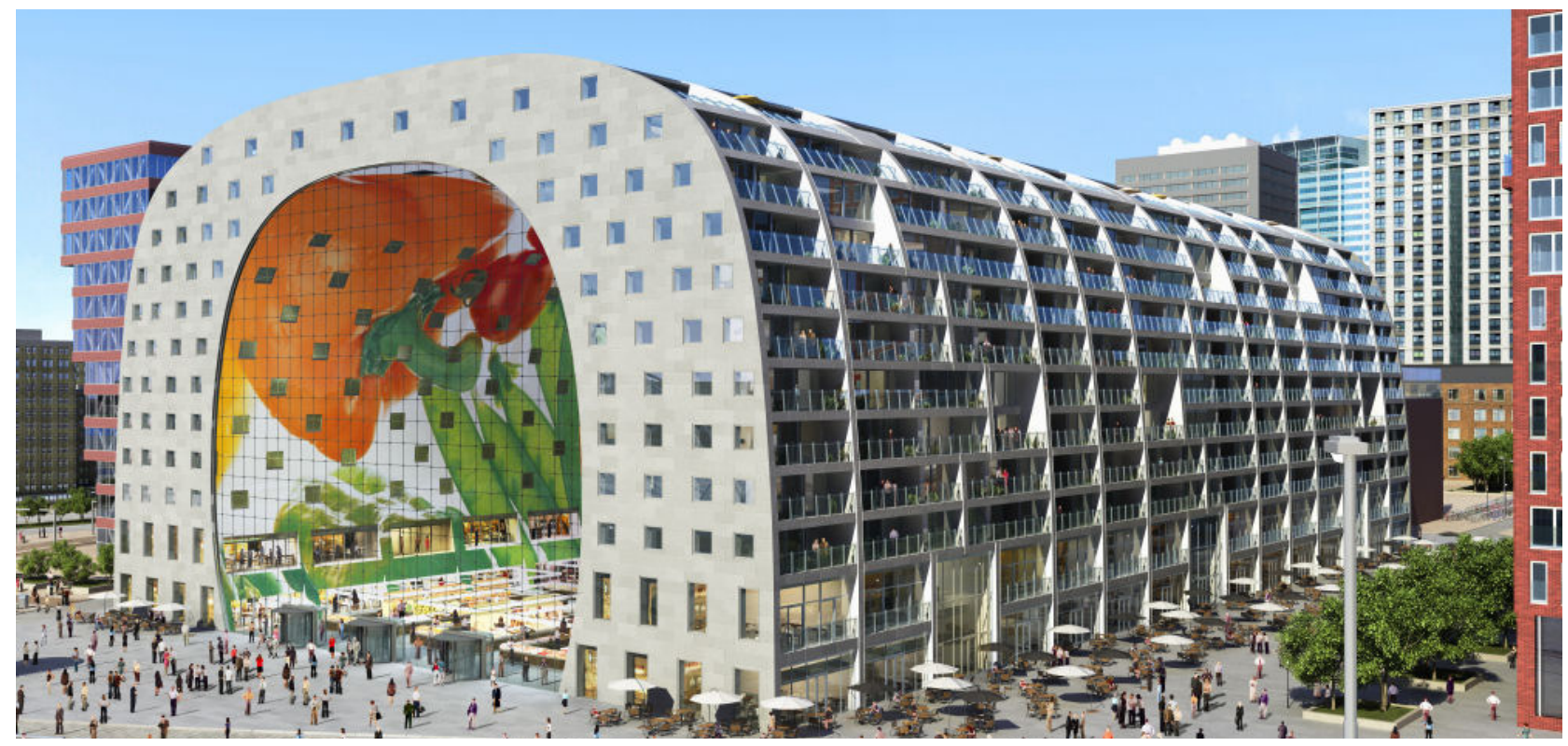

FIGURE 61

Exterior view of Markthal

7.5 MARKETS

\section{Markthal Rotterdam}

MVRDV [Architect], Arno Coenen and Iris Roskam [Artist], Provast [Developer]

The city of Rotterdam has seen tremendous transformation since its near-demolition in the World War II. Adding its own unique contribution to this redevelopment is MVRDV's, Markthal (Dutch for Market Hall). Completed in 2014, this 10-storey, elongated archway is comprised of apartments that wrap around the market hall (Figure 61). These apartments boast some of the best views in the city, both inwards, towards the hall, as well as from patios that overlook Rotterdam. Running longer than the length of a football field, an 11,000 squaremetre mural, The Horn of Plenty, covers the inside of the market hall (Figure 62). It depicts a vibrant cornucopia of produce that can be purchased within, as well as flora and fauna reminiscent of 17th-Century Dutch still-life paintings (Design Curial, 2014). Due to its size, it is recognized as Europe's largest piece of art (Design Curial, 2014).
While the new market hall has garnered international attention for its bold form and expression, its program emerges as a result of policy changes and a growing housing crisis in the city. The country's most historic market, the Binnenrotte, was in jeopardy after a new law was passed that banned the sale of meat and fish in open-air vendors. Architects MVRDV's innovative design solution fuses these two challenges into one of Rotterdam's most iconic pieces of architecture.

The hall hosts over 100 market stalls and is open seven days a week. The hall, constructed for a cost of $\$ 270$ million (CAD), is situated in a large square in Laurens Quarter, Rotterdam's pre-war centre. The new complex replaced a derelict post-war school, which was relocated to an empty lot nearby. At $40 \mathrm{~m}$ tall, $120 \mathrm{~m}$ long and $70 \mathrm{~m}$ wide, MVRDV's market hall has a defining presence on Rotterdam's rejuvenated skyline. As a result, it has become a tourist hot spot, attracting seven million visitors a year (Design Curial, 2014). 


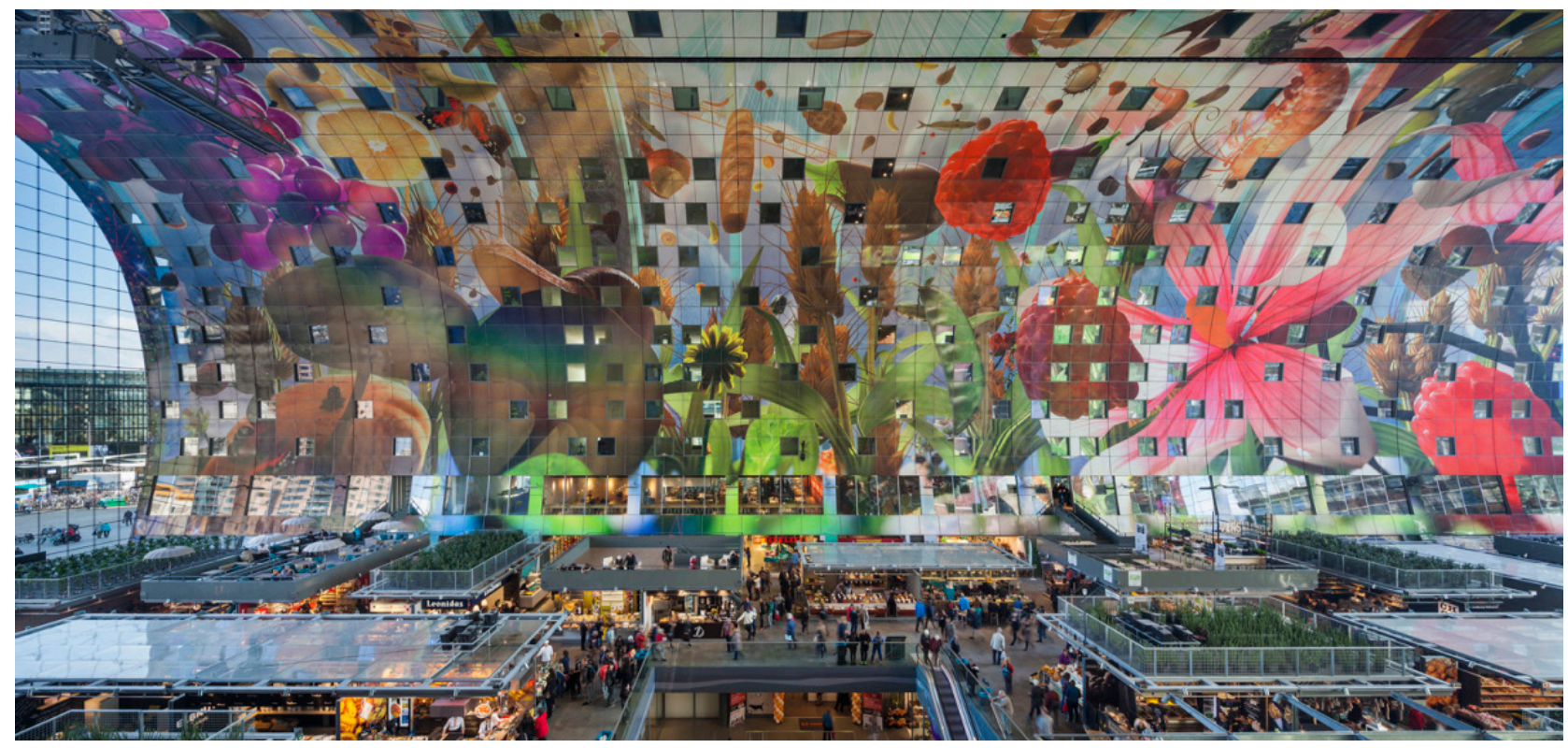

FIGURE 62

Interior view of The Horn of Plenty from a vendor's second-storey

The Markthal is a noteworthy precedent for this thesis due to the innovative design of its market stalls. These two-storey vendors engage with market-goers on the ground floor, while providing seating areas, growing spaces, and other programs on the upper levels (Figure 63). Due to the $25 \mathrm{~m}$ glazed façades (with an east-west orientation), the market hall receives enough daylight for vendors to have micro-gardens on their second floors. The design of these stalls demonstrates the multifaceted potential simple architectural interventions can have. What would normally be a simple, generic market stall has been elevated to connect people together and connect them with the building itself. By elevating users, the market stalls provide a new perspective for users

The Markthal is one of Rotterdam's most prominent pieces of architecture, alongside Rem Koolhaas' Vertical City, and Benthem Crouwel Architects' overhaul of Rotterdam Centraal station. It unites two programs which respond to the public's need for a commercial hub and affordable housing, while functioning as an icon for the city. Its vibrant colour palette and simple form are inspired by nature, consistent across contemporary Dutch architecture. Provast, the developer of the project, describes the hall as' "The food Walhalla of the Netherlands", or the "Dutch hall of fame," identifying its value as a definition of the future of Dutch architecture (Design Curial, 2014).

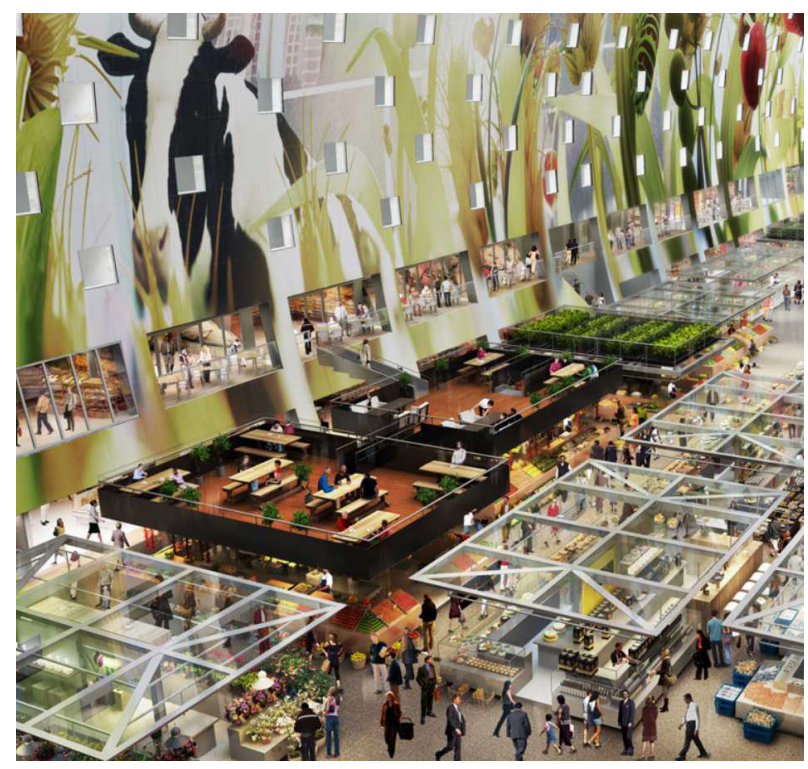

FIGURE 63

Interior rendering, highlighting the two-storey vendors 


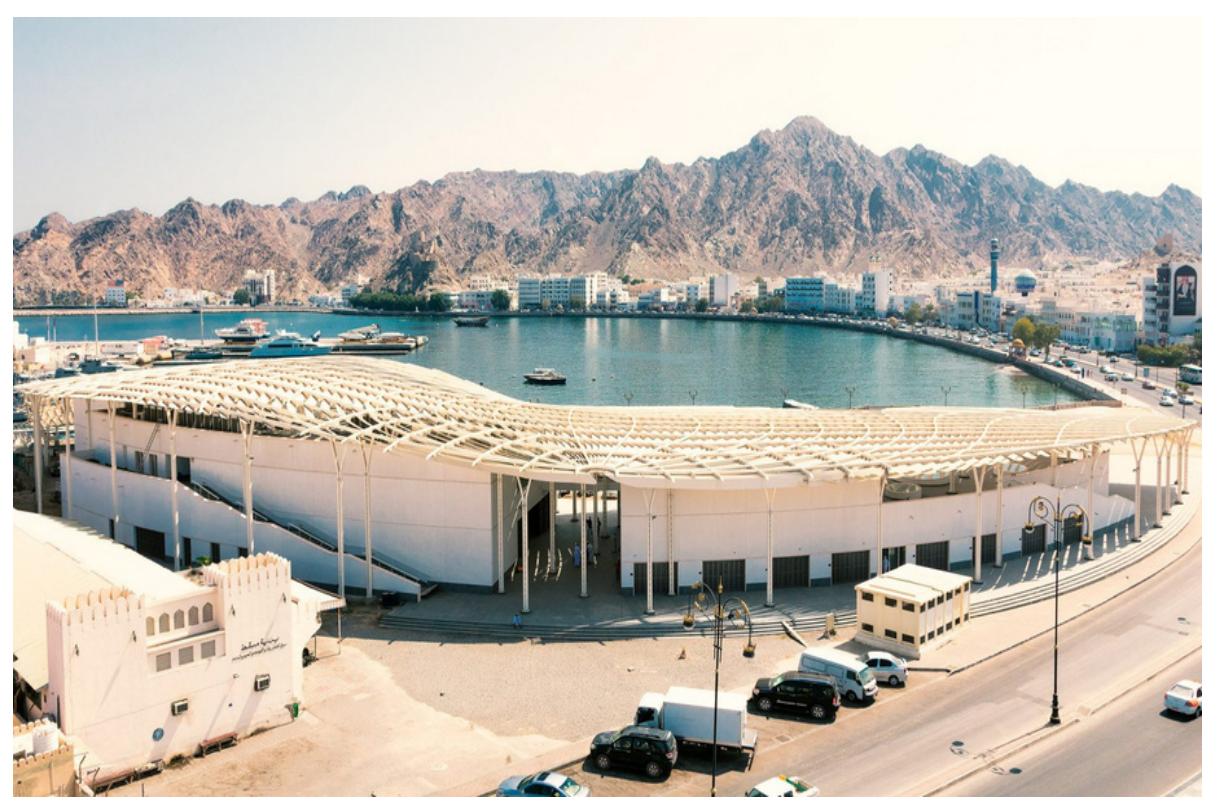

FIGURE 64

Aerial perspective of the completed Muttrah Fish Market

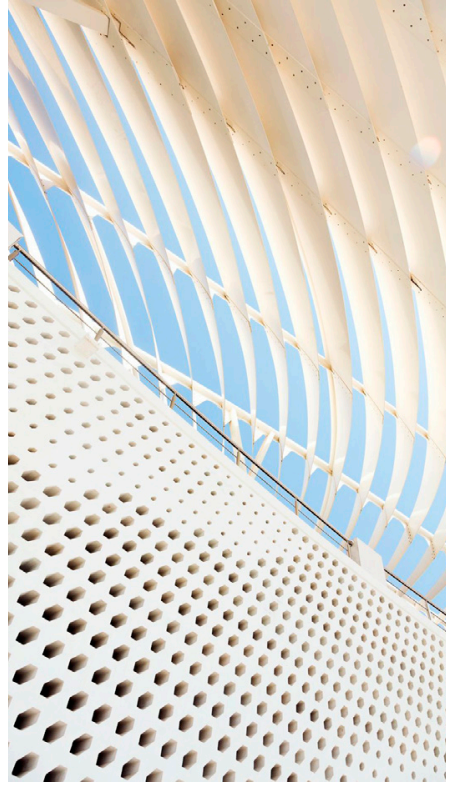

FIGURE 65

intracate canopy structure and hexagonal relief pattern

\section{Muttrah Fish Market Snøhetta [Architect]}

Situated along the Gulf of Oman, Muttrah has traditionally been Oman's centre for commerce due to its prominent sea port. It is now further distinguished thanks to the new Muttrah Fish Market, designed by Snøhetta (Figure 64). This new landmark is a focal point for the local community, and a tourist attraction for visitors.

The design of the new fish market pays homage to Oman's past while defining its place in the future. The city of Muttrah has a historic reputation as a lively port, supporting a long history of fishtrading and commercial activities. The new market, completed in 2017, continues the fish-trading tradition through its program, as it acts as a hub for the industry. At the same time, its bold design and articulated canopy invigorates the country's growing tourism industry.
"Merging tradition with innovation, the 4.000 square-meter fish market is designed to sympathetically unite the old and the new. The generous space creates a public meeting space where local fishermen and worldly tourists from all over the world meet under the same roof."

- Snøhetta (2017)

The expressive roof canopy's sweeping form mimics the buildings swooping waterfront siting (Figure 68). The entrance is engaged and articulated through the dematerialization of the canopy (Figure 67). The market itself stands as a unifying element, connecting the city, the mountains, and the waterfront.

"The new market enhances the public setting by forming a dynamically shaded canopy, organizing the spaces beneath it."

- Snøhetta (2017)

This precedent is of particular interest due to the way the architects use a structural framework as an interface between the built form and the public realm. Both the positioning of the staircase and the 


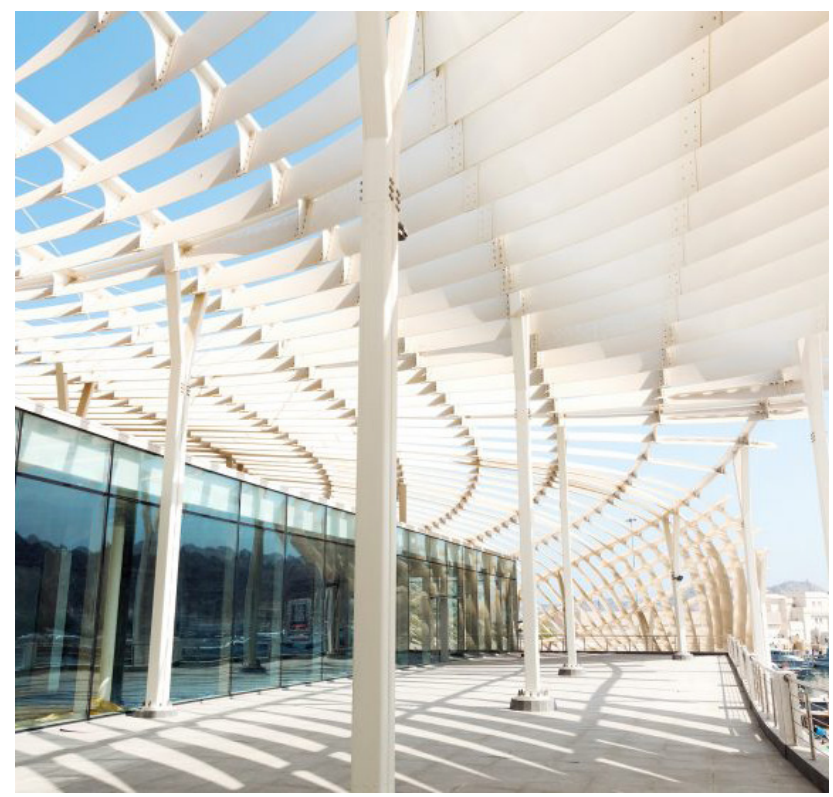

FIGURE 66

Experiential photograph of the canopy's shading quality

degree of opening within the canopy are conceived of in a such a way as to enhance the relationship between public and private space, opening up entirely to invite users to enter. The sinuous flow of Arabic calligraphy translates into the canopy's fin articulation, creating a playful movement that engages the market's surrounding boardwalk (Snøhetta, 2017). Furthermore, this rhythmic movement carries forward in the overall form of the canopy and its implementation as a way-finding strategy. The nature of the canopy structure is the significant take away from this project. Moreover, while the vertical fins of the canopy are designed for shading, it leaves room for innovation in the application of a canopy in a northern climate - one which requires shelter from the elements (rain, snow, etc.) as well.

The playfulness of the design is carried throughout the interior of the building as well. The heavy mass of the building's solid walls is broken up by hexagonal apertures, creating the appearance of a delicate building, while increasing the daylighting within

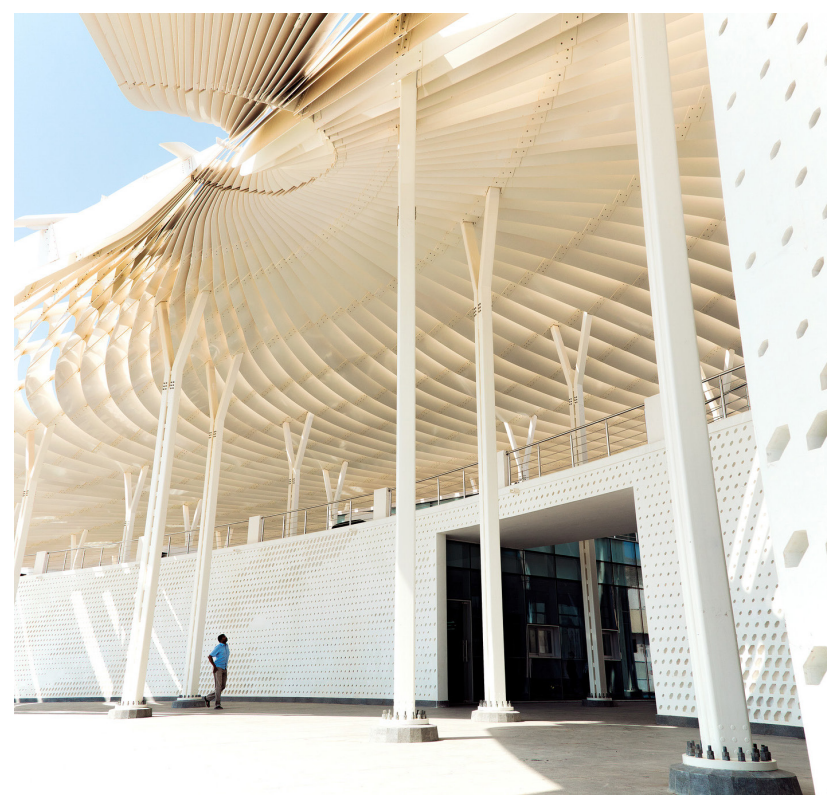

FIGURE 67

The demeterialization of the canopy

(Figure 65). Every gesture made in the design of the Muttrah Fish Market relates back to its context, creating a holistic project which emerges from its surroundings rather than one which is placed within it.

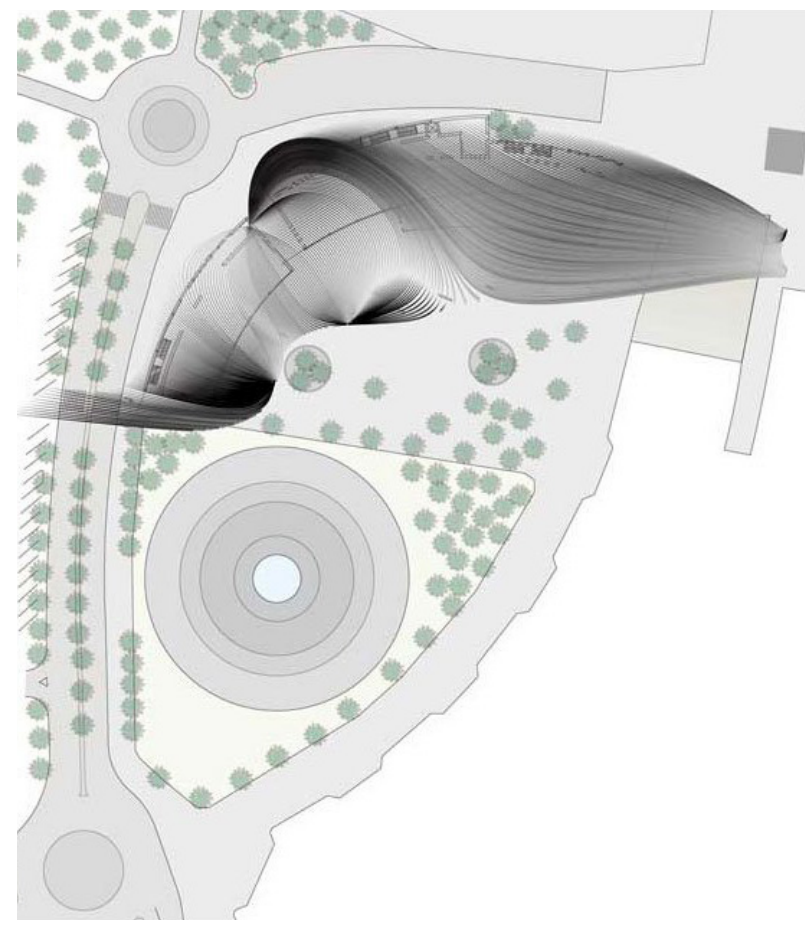

FIGURE 68

The Muttrah Fish Market site plan, N.T.S 



\section{PART 3: \\ DESIGN PROPOSAL}

THE CONTEMPORARY COMMON 


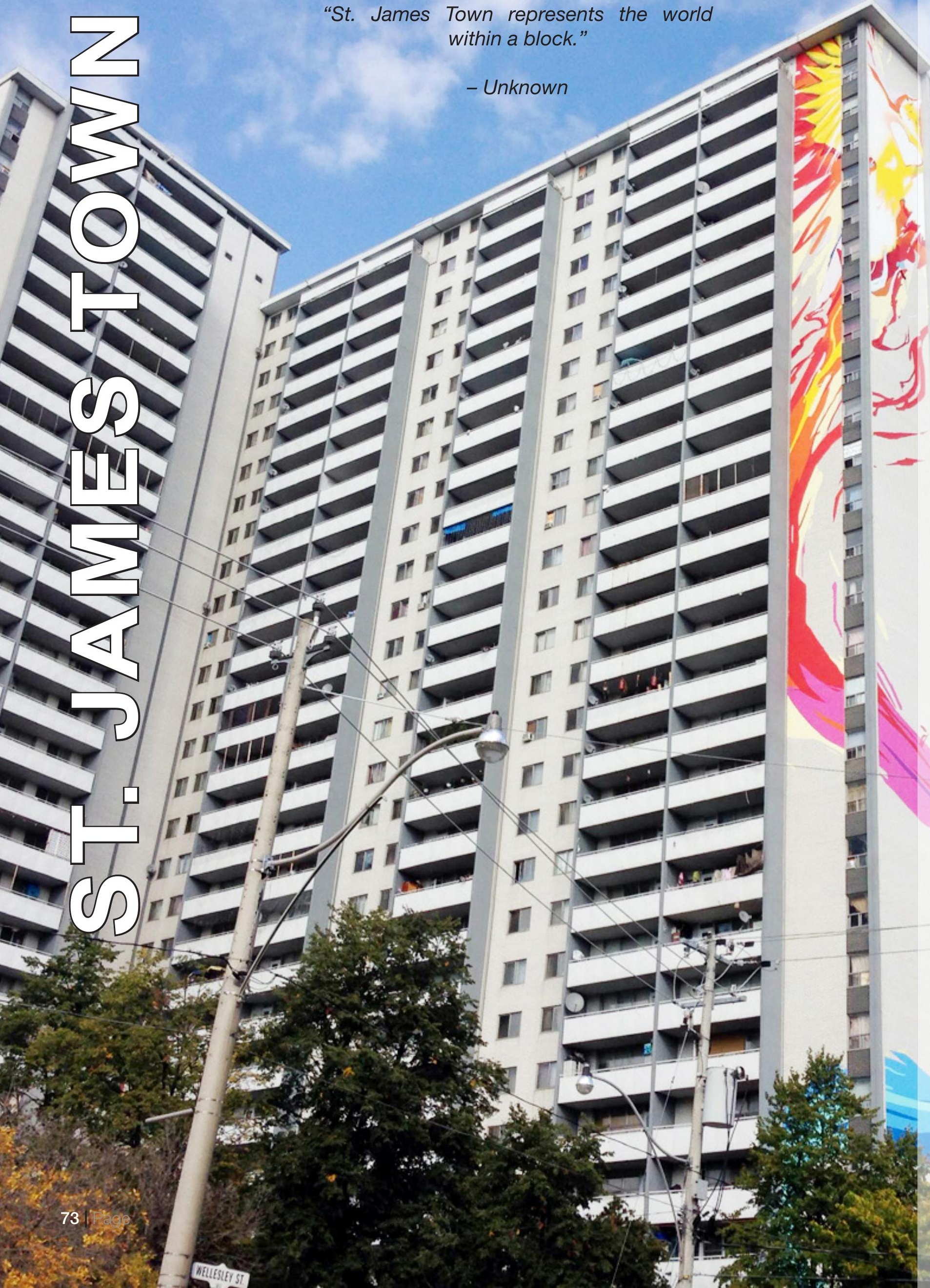




\section{AN INTRODUCTION TO ST. JAMES TOWN}

"The materials of city planning are: sky, space, trees, steel and cement; in that order and that hierarchy."

- Le Corbusier

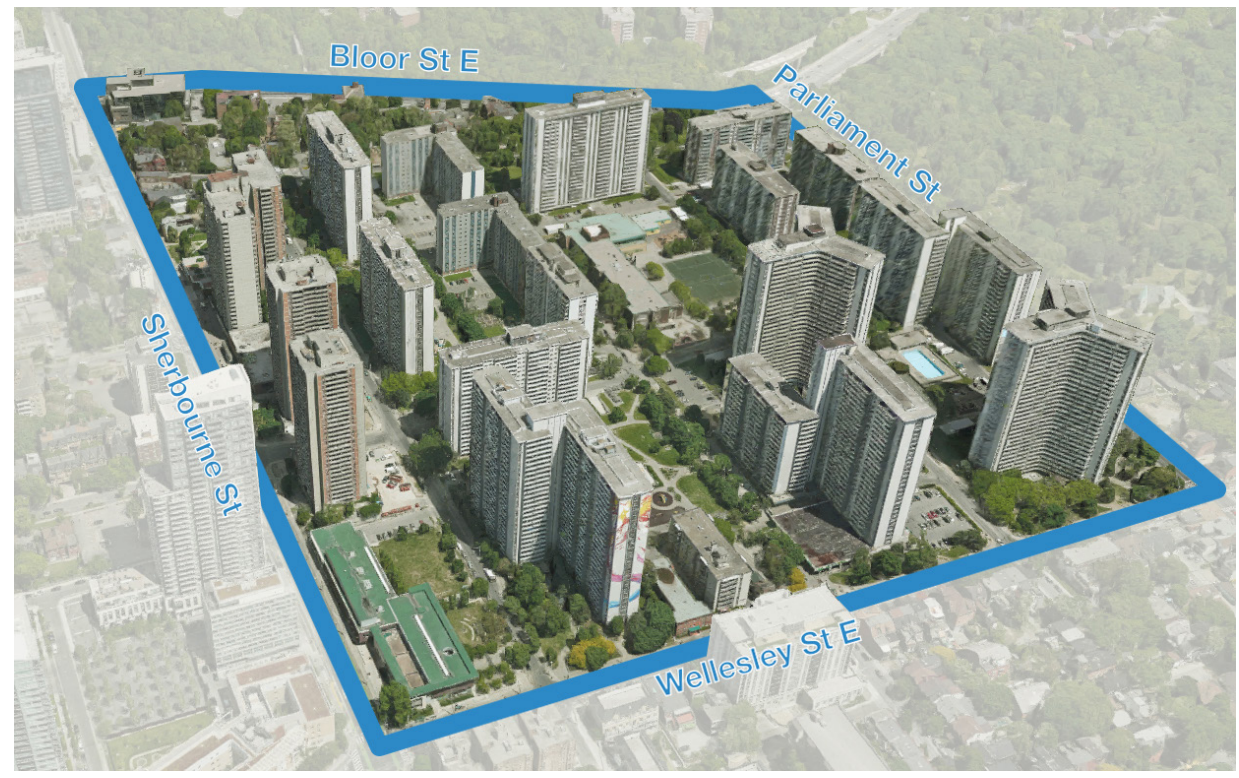

FIGURE 70

St. James Town neighbourhood boundaries

t. James Town is a dynamic neighbourhood in the northeast corner of
Toronto's downtown area. It is only a city block in area, being bound by Bloor Street to the north, Parliament Street to the east, Wellesley Street E to the south, and Sherbourne Street to the west. With a density 18 times that of other portions of the City of Toronto, it is one of the densest neighbourhoods in Canada (Canada, 2011). As it is home to a large number of immigrant and refugee populations, it has garnered the reputation as "the world within a block". 


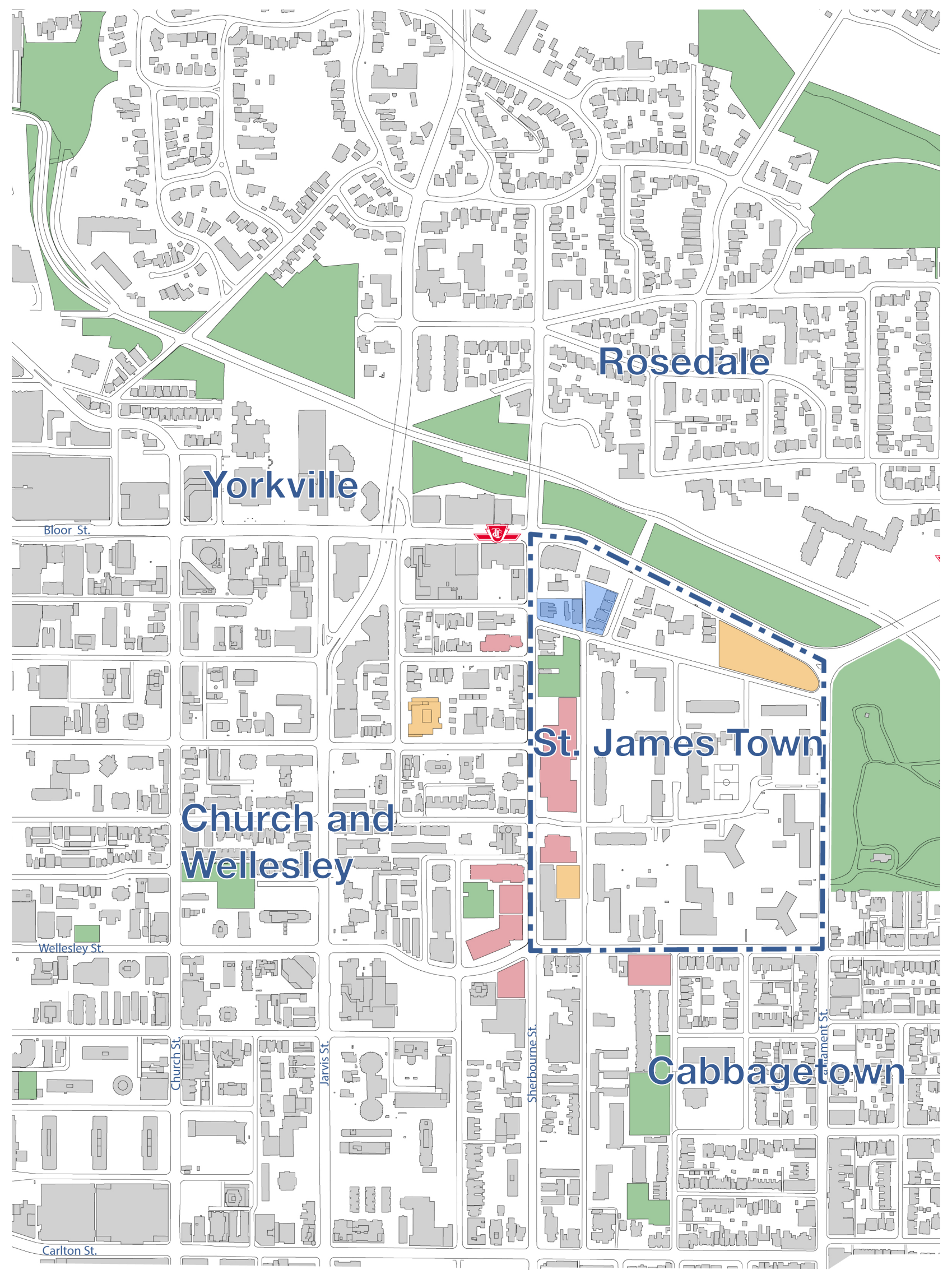

FIGURE 71

Neighbourhood key plan 


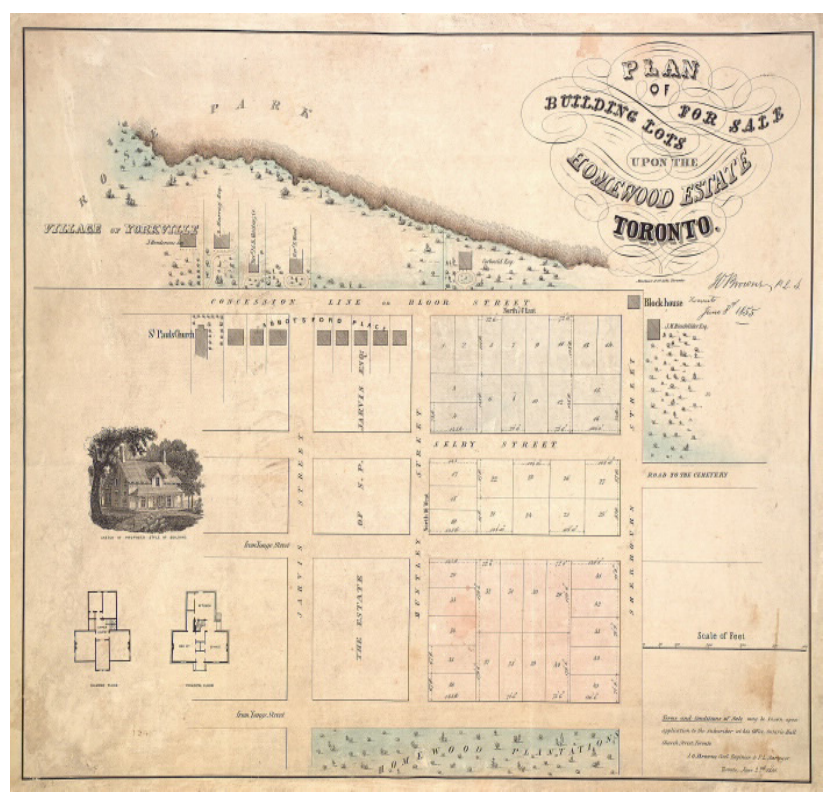

FIGURE 72

Historic map of St. James Town, 1855

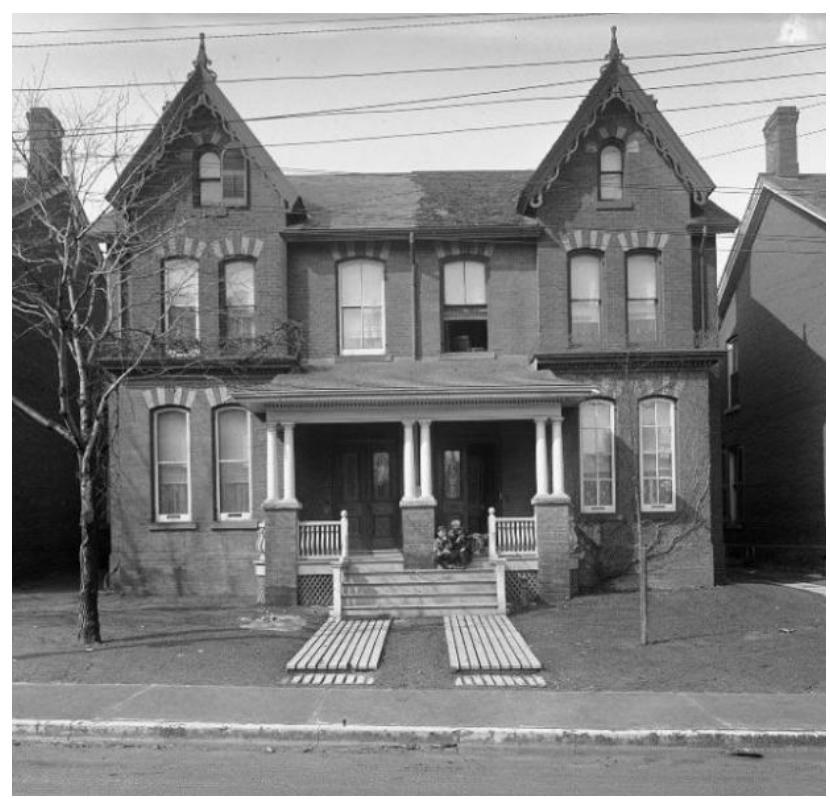

FIGURE 73

Historic St. James Town Victorian Homes, 1913

\subsection{EARLY YEARS AND DEVELOPMENT}

This unique neighbourhood has an interesting history of growth and development. In the late 19th, and early 20th Century, the block was part of Cabbagetown and was home to rows of Victorian homes. In 1953, the City of Toronto began re-zoning the downtown core, resulting in the demolition of St. James Town and the vast majority of its Victorian homes (Figures 72 and 73). By the end of the decade, St. James Town was home to the City of Toronto's first high-rise (City Living, 2014). The neighbourhood was entirely remodeled, designed after Le Corbusier's concept for Towers in the Park. Corbusier theorized that the removal of the existing urban fabric was necessary in order to construct the ideal neighbourhood of towers which sat in a vast public open space. Each tower was subsequently named after Canadian cities, almost as an ironic homage to some of the history it destroyed.
With this new building paradigm came a rebranding of the community. It was classified as a new community tailored for single men and women as well as young couples without children. It was developed for an emerging social class, focusing particularly on young couples looking to purchase their first home (Ley, 1996). Its population grew rapidly, with a density that is currently 18 times higher than the rest of the City of Toronto. Its vast open green space attracted new residents; however, its lack of public amenities, such as parks, playgrounds, and local daycare centres, made it less appealing to this desired social class. The younger demographic the neighbourhood was targeting was further turned off by the nonexistent street life, subsequently elected to move to the new suburbs of Toronto, namely Scarborough, Etobicoke, and North York. 


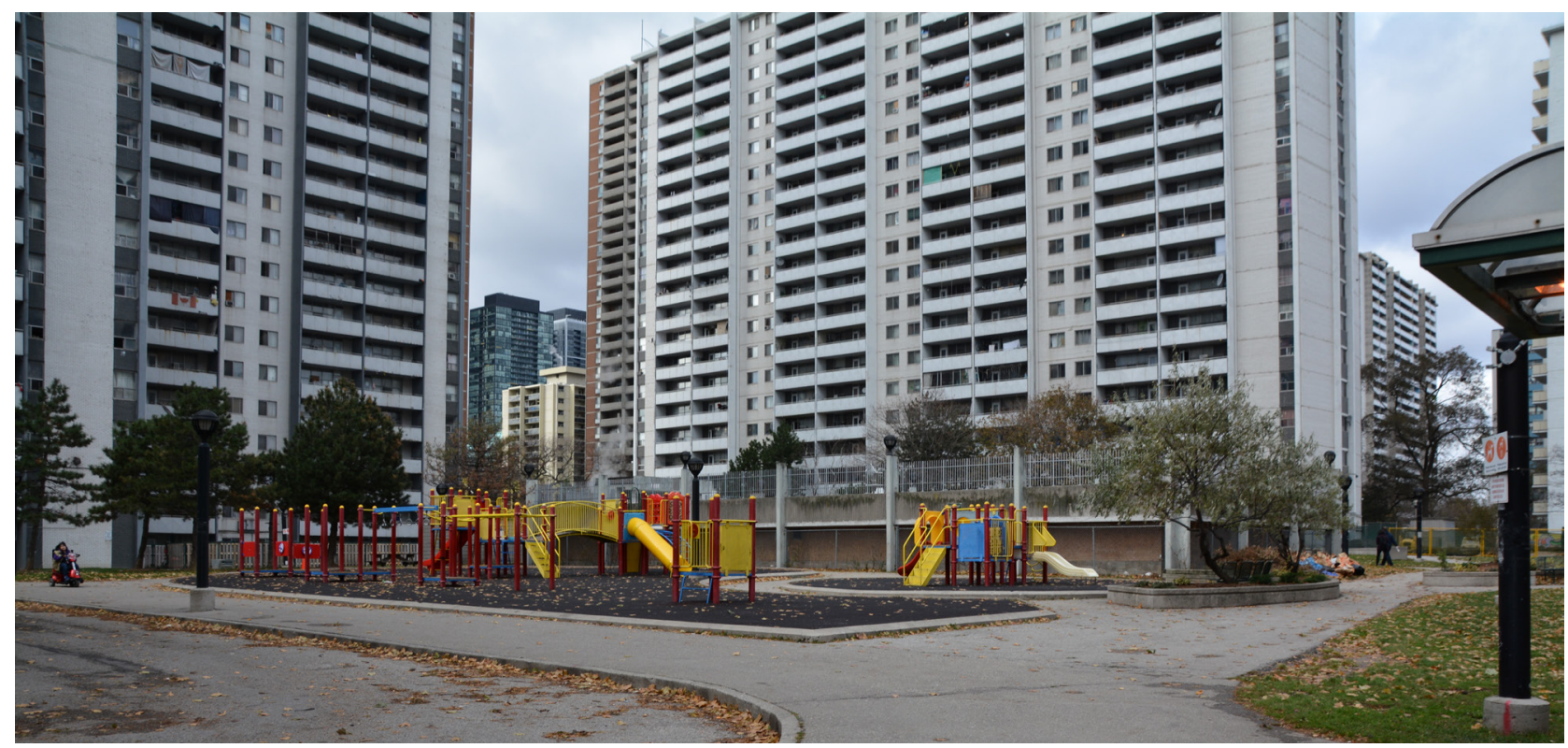

FIGURE 74

St. James Town public pool and playground

As a result of the area's declining appeal to residents, there was a steep influx of immigrants into the area due to its cheap rent (Dhungana, 2011). The area saw some development in 1997 as the St. James Town 2000: A Community Action Plan proposal was approved by City Council. This implemented the development of a multi-service community centre, facilitated improvements to existing parks, and initiated the maintenance and repair of St. James Town's residential buildings.

\subsection{PRESENT CONDITIONS}

Today, the neighbourhood is home to 19 high-rise apartment towers (4 of which are public housing), ranging in heights from 14 to 32 storeys, as well as 4 low-rise apartment buildings. The neighbourhood has more than 7,000 units, and houses more than 17,000 residents; however, many residents believe the actual population is closer to 25,000 (City Living, 2014). Of this population, $64 \%$ of residents are immigrants (Canada, 2011). The neighbourhood is known for its diverse immigrant population, coming from a large number of ethno-racial communities, including Filipino, Tamil, Chinese, Pakistani, Korean, Bangladeshi, Indian, Nepali, Ethiopian, Somali, and various Eastern European communities. St James Town is concurrently one of the most economicallydeprived neighbourhoods in Toronto. According to the 2011 Canadian Census, the average household income of the neighbourhood was only $\$ 22,341$, which is approximately $52 \%$ of Ontario's and $34 \%$ of Toronto's average household income (Canada, 2011). This results in a lack of unit ownership, with 


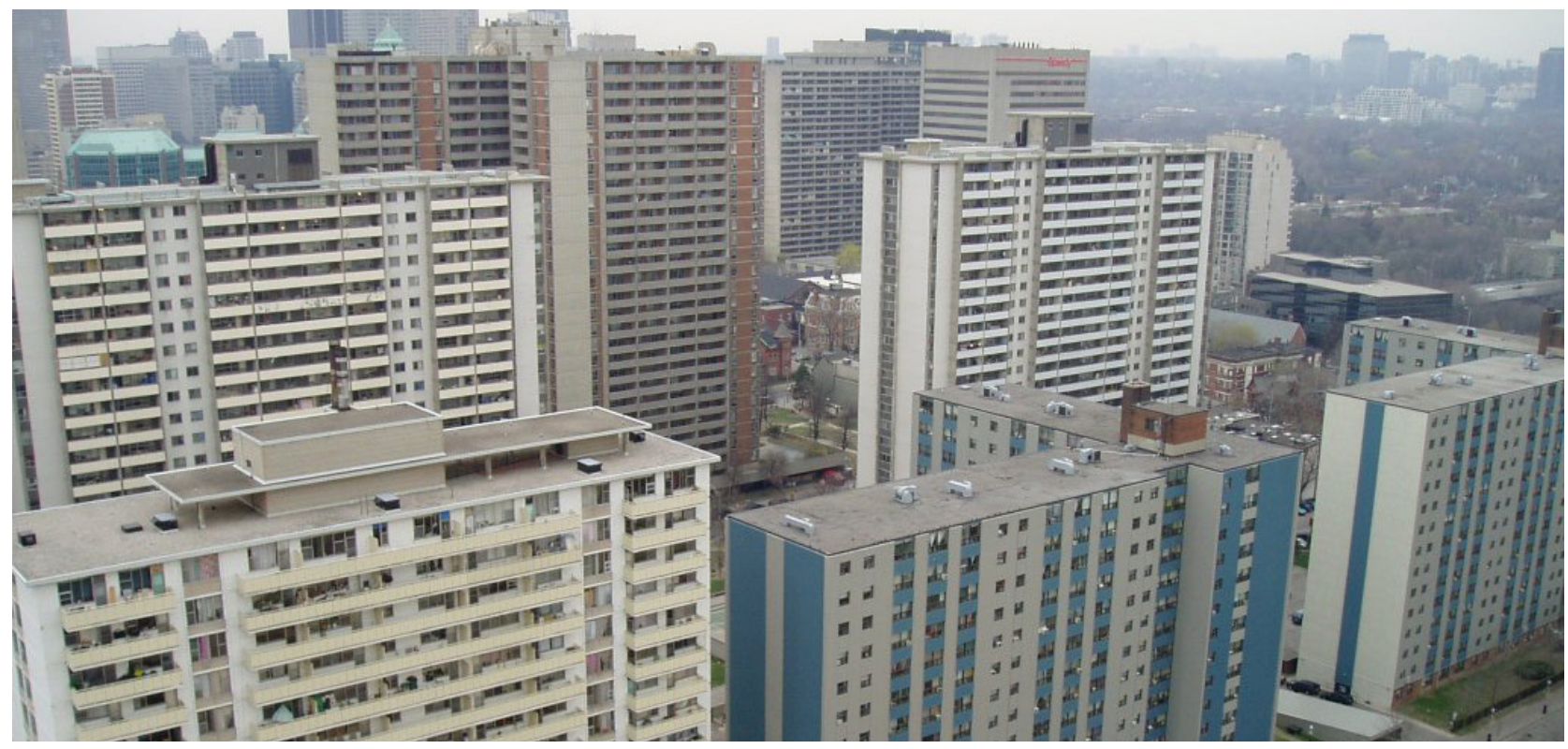

FIGURE 75

Aerial view of St. James Town's apartment towers

the vast majority of residents renting. Furthermore, there is a high turnover of residents as the neighbourhood is predominately home to newlylanded immigrants who move out once establishing themselves.

The neighbourhood's residents have numerous concerns regarding the current state of the public realm and the resident's built environment.

"Wellesley Institute's St. James Town Initiative has been researching the relationship between built environment and resident health and well-being in St. James Town for several years. This research has found strong evidence that St. James Town suffers from overcrowding, lack of green and public spaces, poor building and neighbourhood maintenance, and a general lack of resources for serving the large and diverse population. These neighbourhood factors are well known to impact health and well-being"
Additional concerns stem from the poor maintenance of the neighbourhood. Almost all of the neighbourhood's 19 high-rise rental apartment towers were constructed in the 1960s, all of which are in need of major repairs. A report by United Way in 2011, "Vertical Poverty", revealed that not only is poverty associated with poor housing conditions, but it is becoming more concentrated in high-rise buildings. A more recent report by the United Way, The Opportunity Equation in the Greater Toronto Area: An Update on Neighbourhood Income, Inequality, and Polarization, suggests that St. James Town's neighbourhood conditions are likely to be common in other low-income neighbourhoods in Toronto.

"In Toronto, an unusually large number of high-rise apartments poke above the flat landscape many miles from downtown... this is a type of high-density suburban development far more progressive and able to deal with the future than the endless sprawl of the U.S."

- Richard Buckminster Fuller (remarks after visit, 1968) 


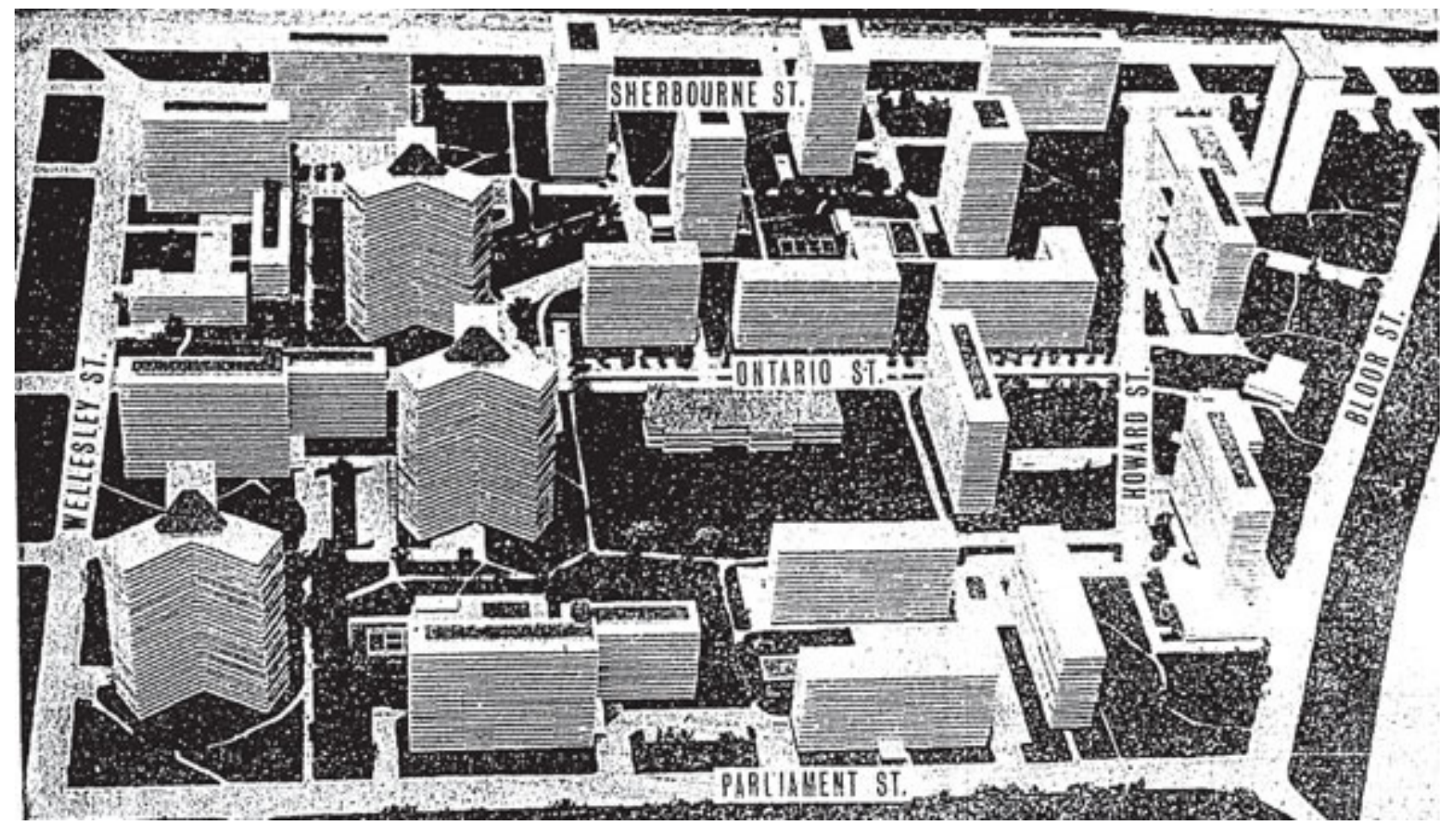

FIGURE 76

Historic master plan, St. James Town, 1959

\section{Toronto Daily Star ${ }_{3}^{3}$ METRO NEW}

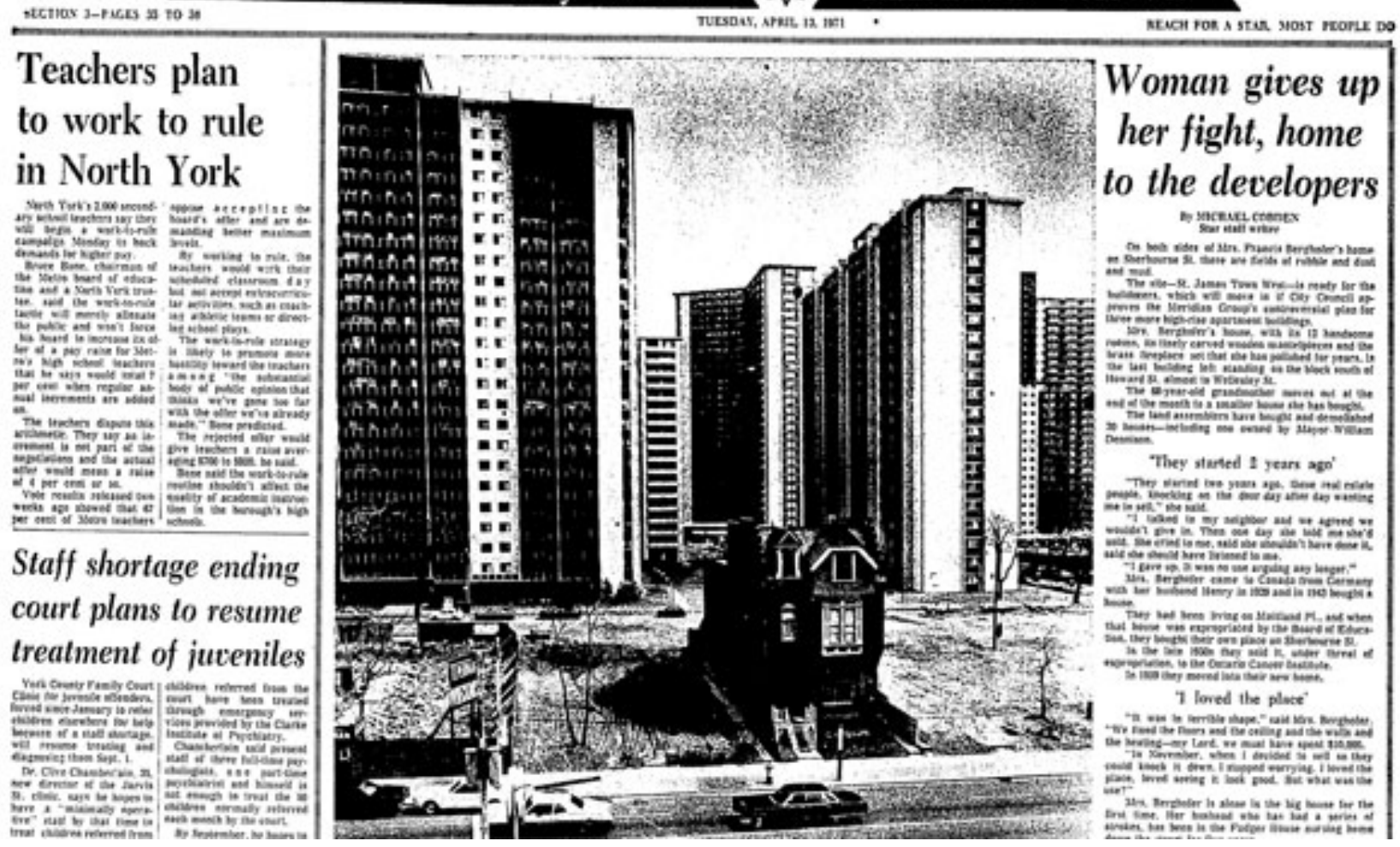

FIGURE 77

Toronto Daily Star, 1961 


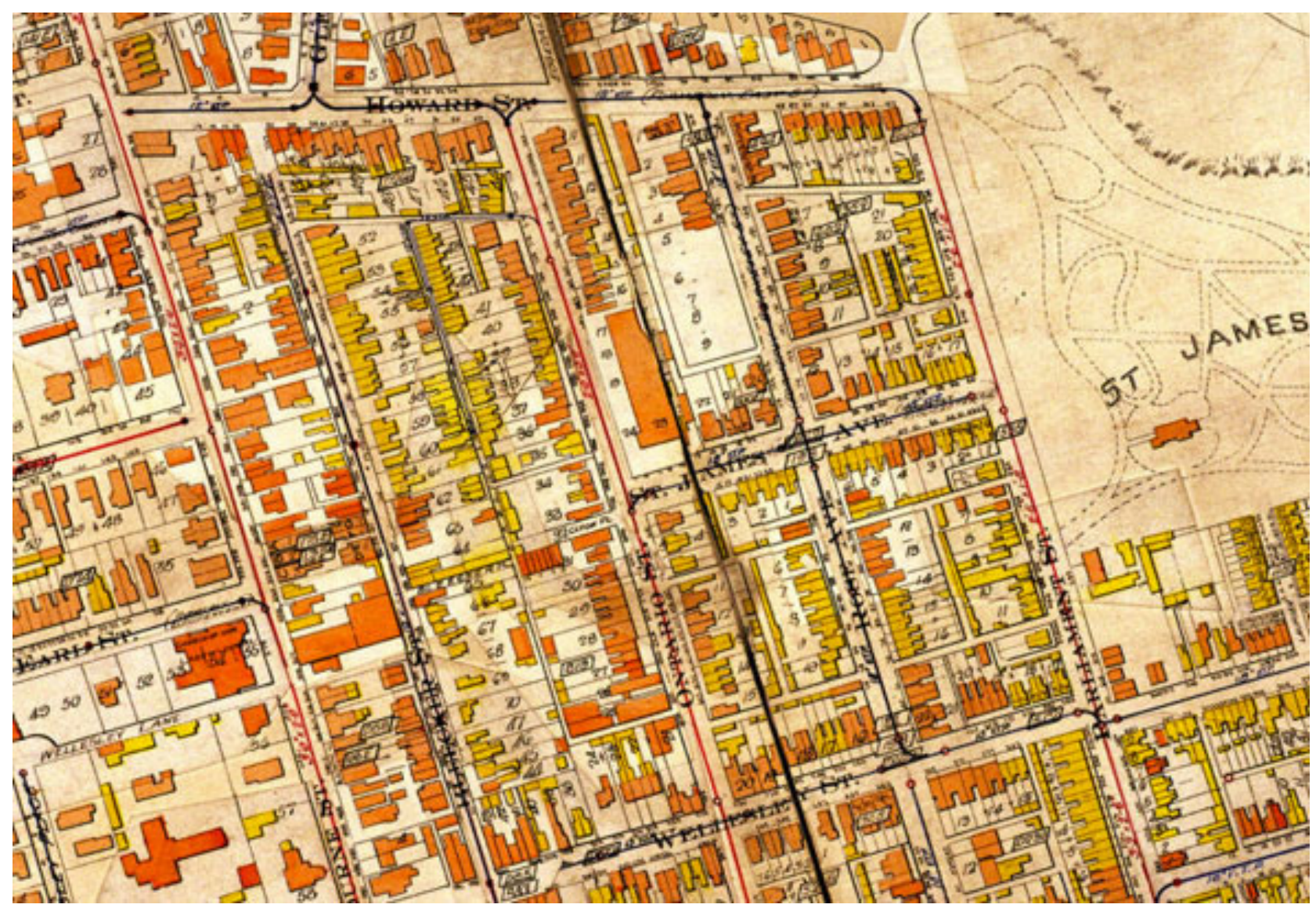

FIGURE 78

St. James Town fire insurance map, n.d.
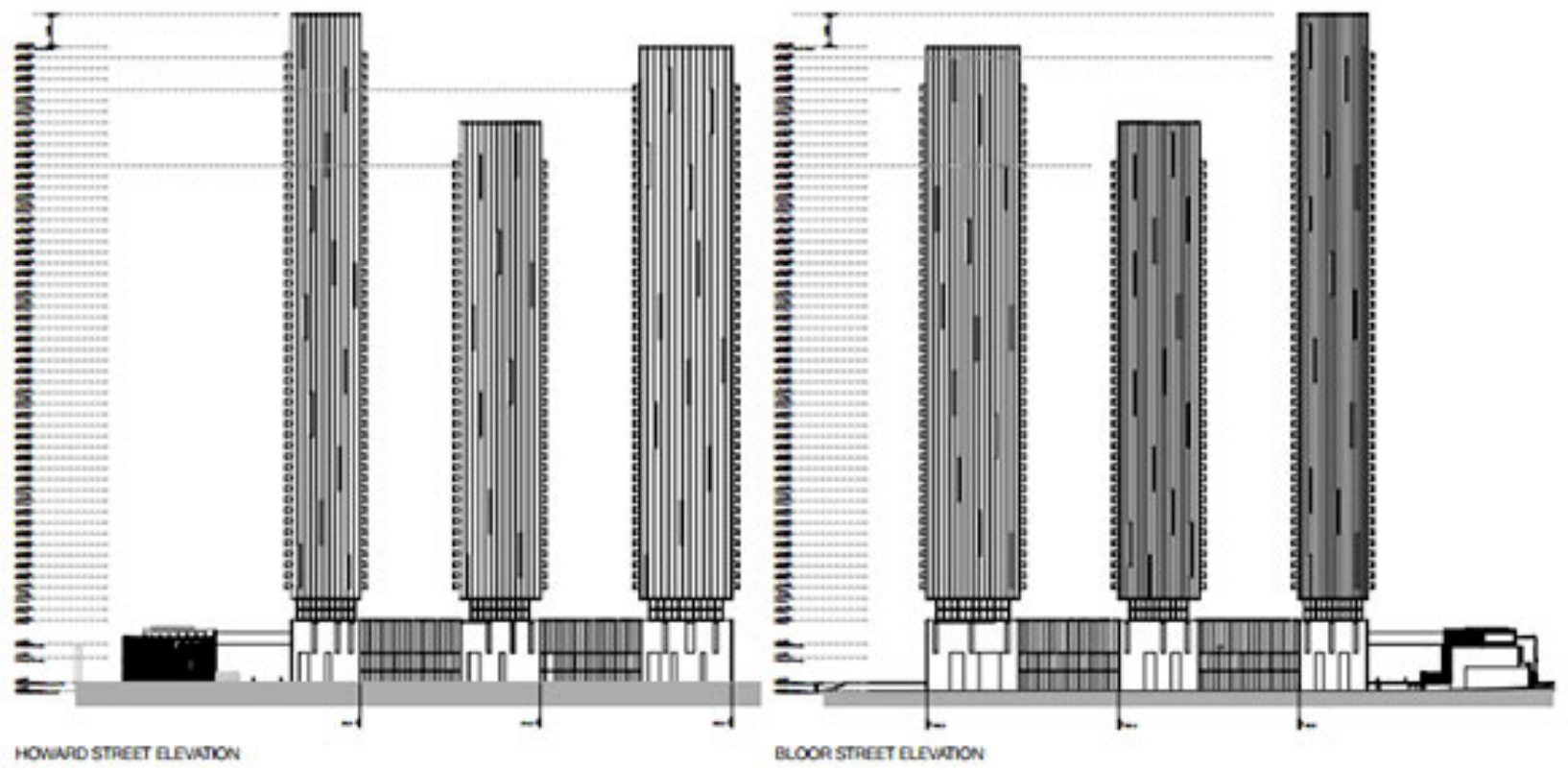

FIGURE 79

New Howard St. development proposal 


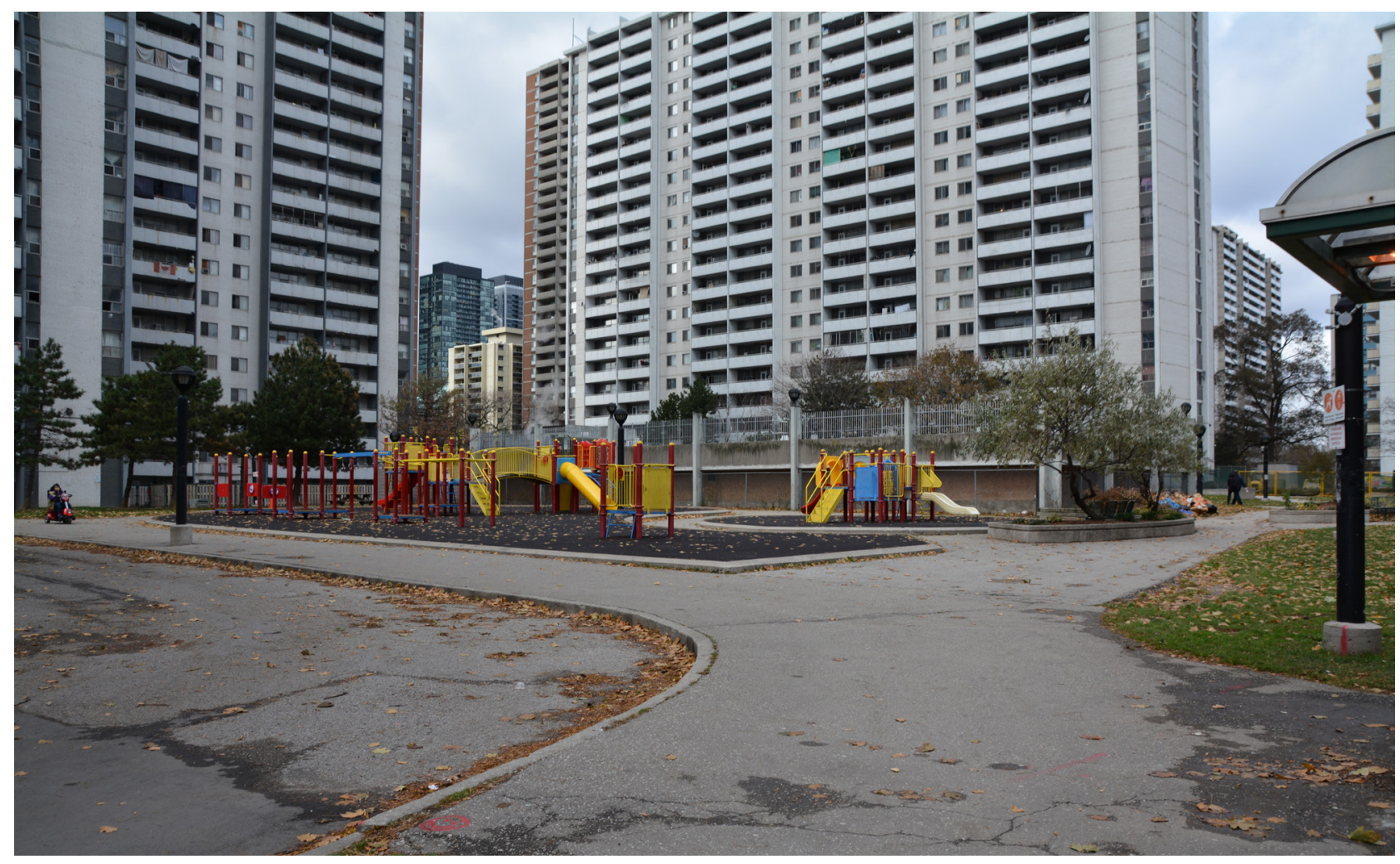

FIGURE 80

St. James Town playground and public pool

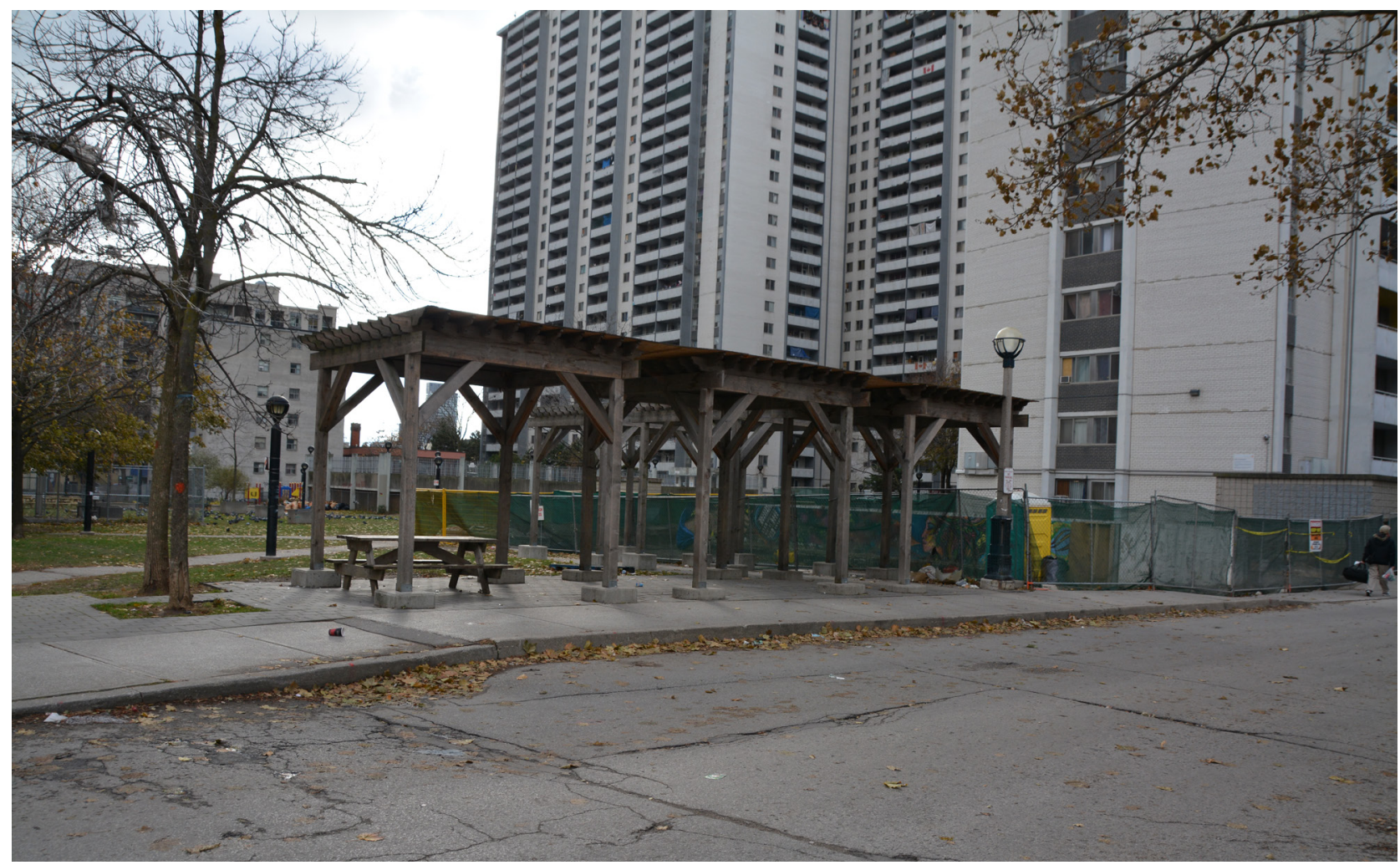

\section{FIGURE 81}

Existing pergola structure for market, St. James Avenue 


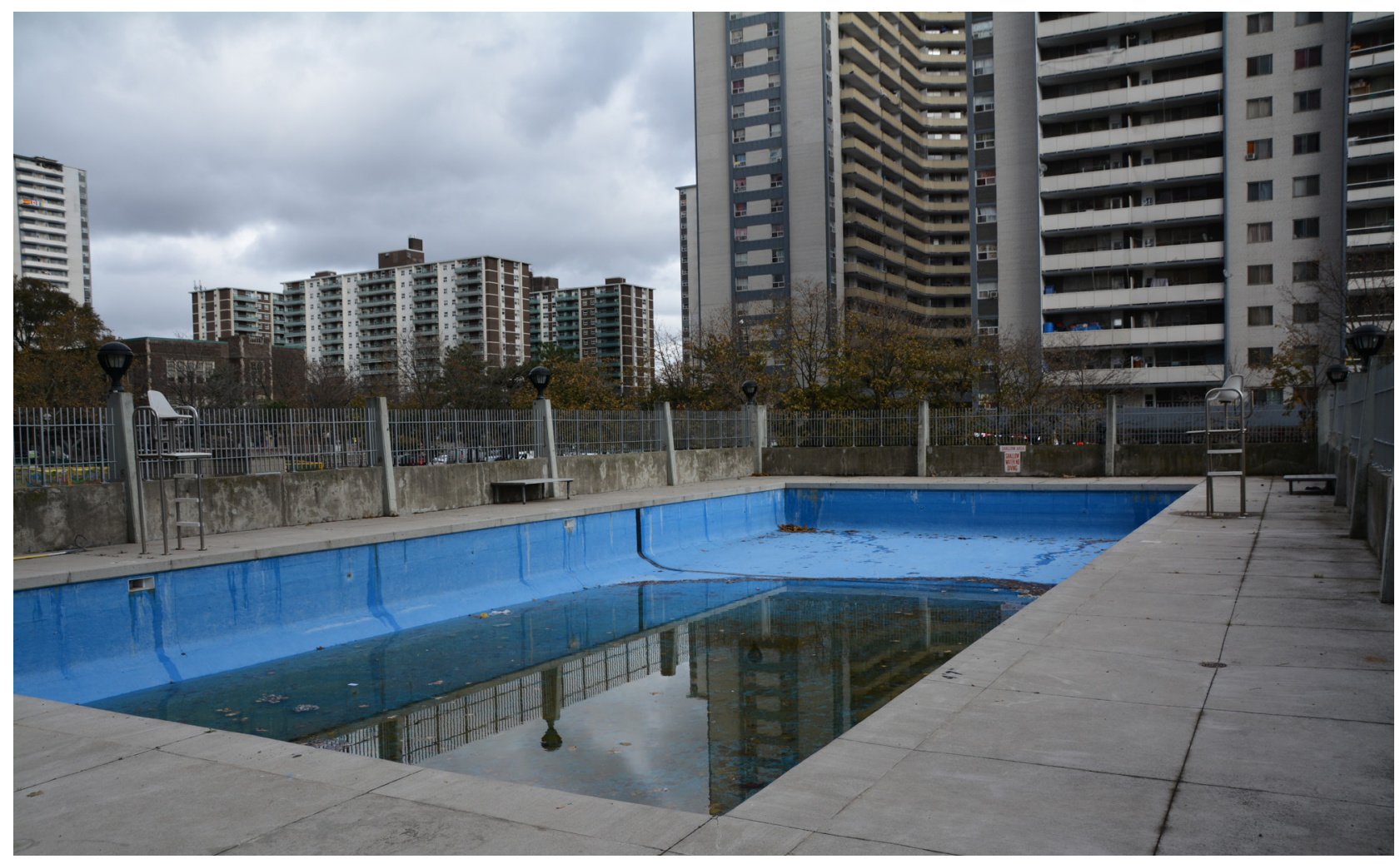

FIGURE 82

St. James Town public pool

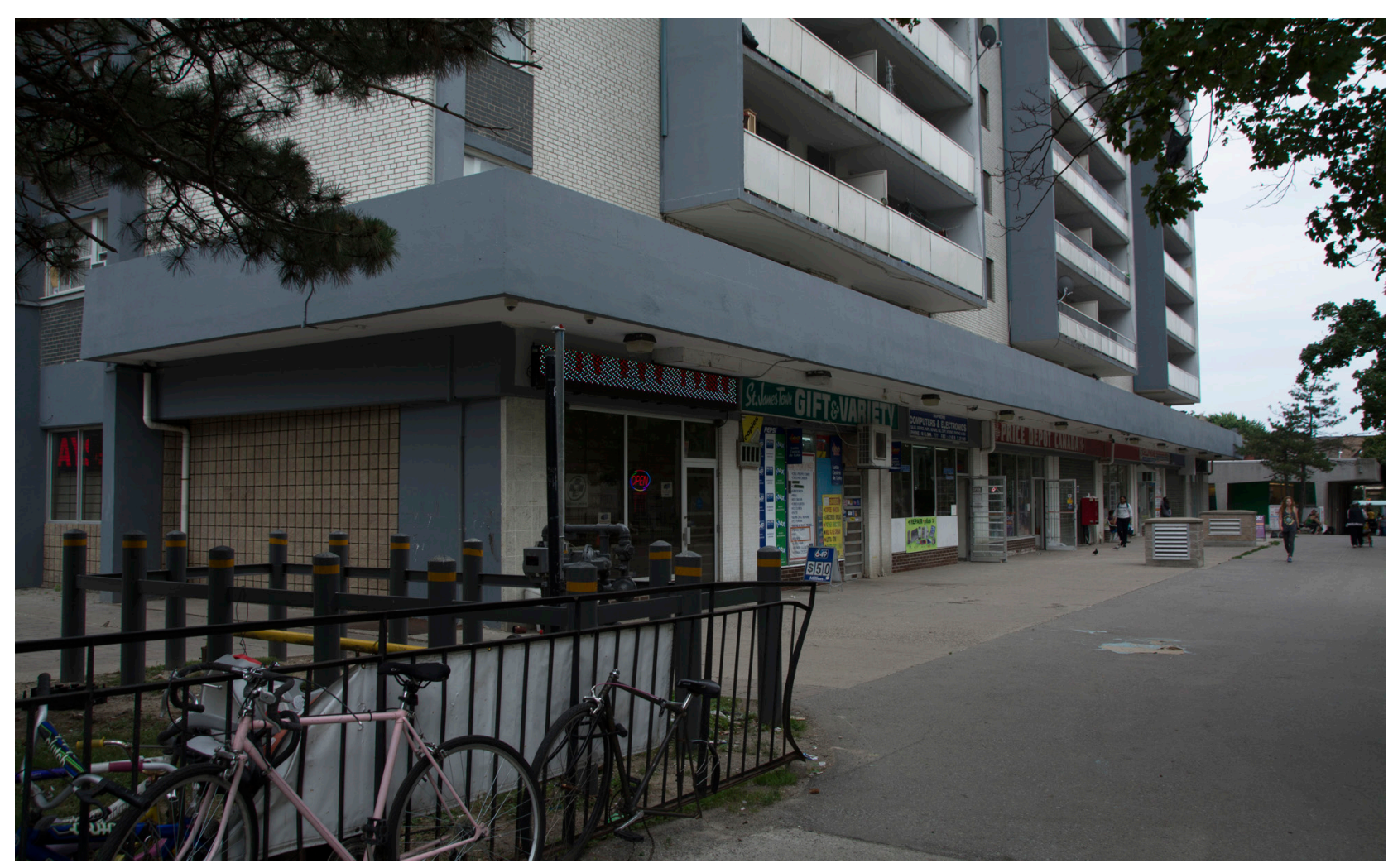

FIGURE 83

Existing storefronts along the Ontario Street continuation 


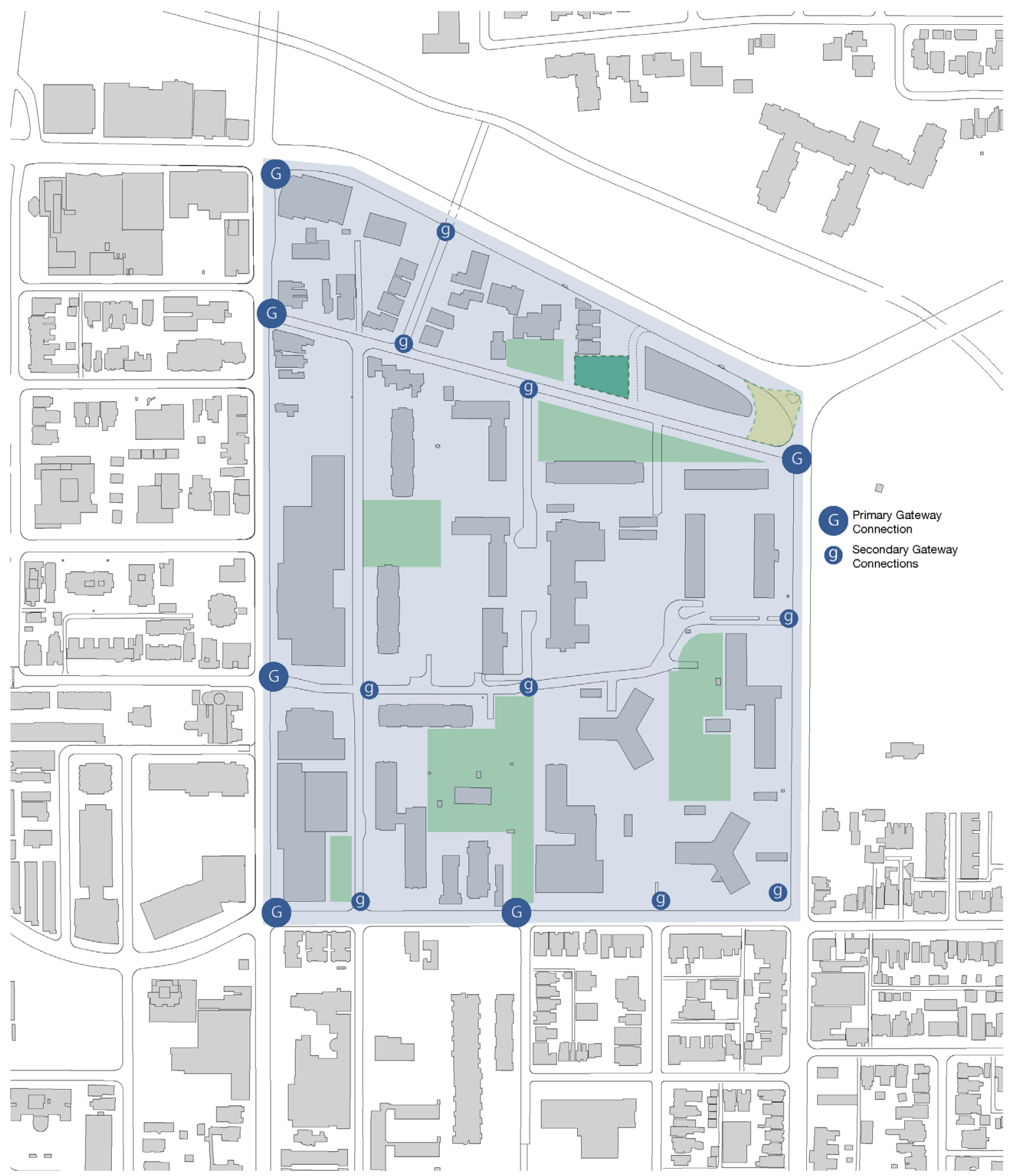

FIGURE 84

Neighbourhood gateways map, 1:2500

St. James Town's primary gateways are located along its western and southern boarders due to Bloor Street and Parliament Street transecting it from the adjacent cemetary to the east and Rosedale Valley to the north. The southern gateway which lies at the end of Ontario Street appears to be the most notable pedestrian gateway due to the large public space beyond, the pedestrian street which connects to St. James Avenue, and the fact that it hosts one of the neighbourhood's primary food grocers, Food Basics. 


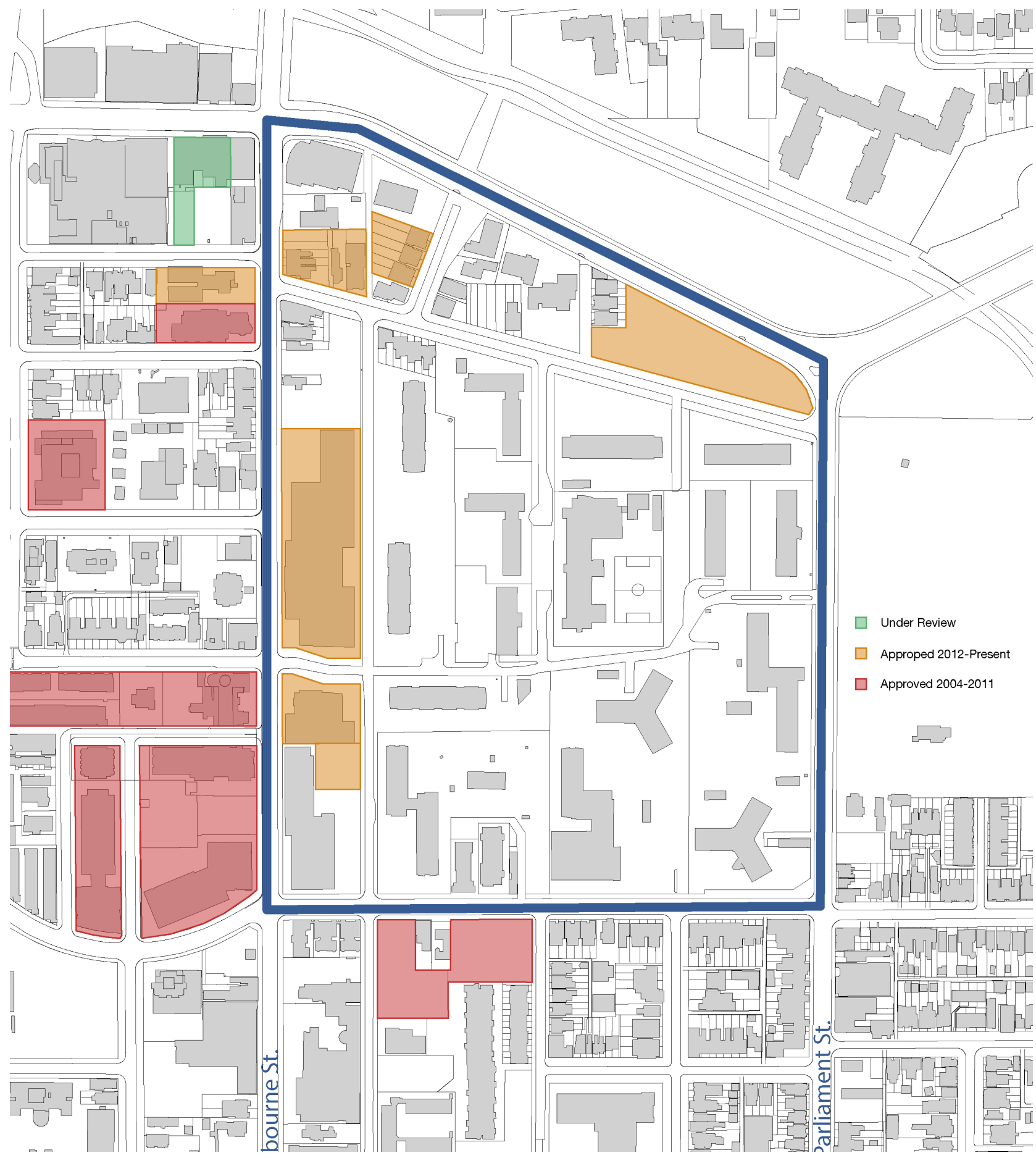

FIGURE 85

Development applications map, 1:2500

Much of St. James Town has gone untouched since it was developed in the 1960s; however, in the last 5 years there has been a surge of development. The new tower, just north of the St. James Town community centre and public library, is complete, and the adjacent podium renovation is nearing completion. The development of the large grassland at the intersection of Parliament and Bloor Streets has begun, and construction of three towers ranging from 46 to 56 stories is expected to start in the spring. $58 \%$ of the 1241 new units are one-bedroom units. 


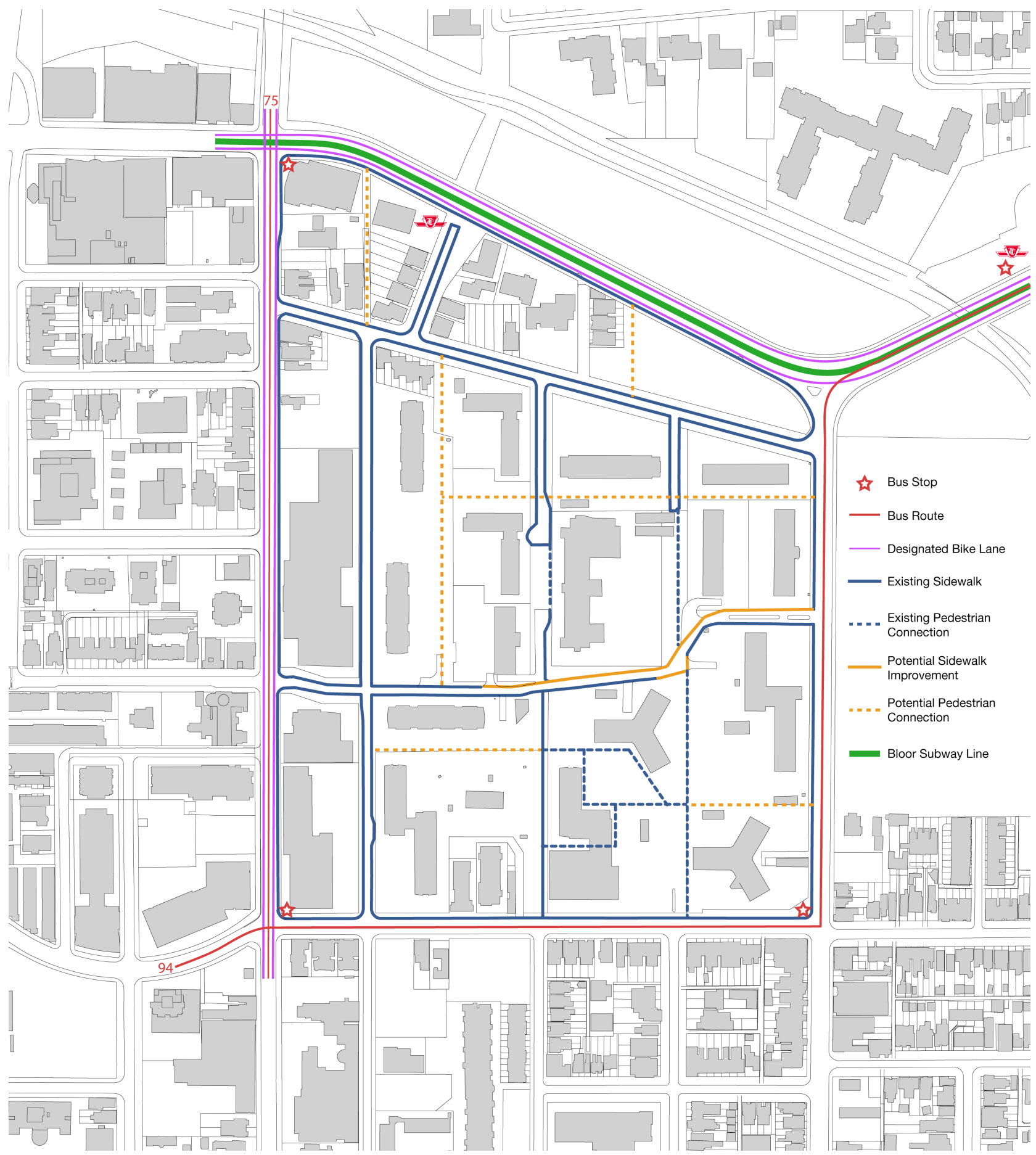

FIGURE 86

Pedestrian circulation map, 1:2500

Due to the neighbourhood's "Tower in the Park" design, moving through the neighbourhood is predominantly done by foot rather than vehicle. This is a result of the low income of residents, many of whom cannot afford the cost of having a car within the city. While there are numerous sidewalks throughout the neighbourhood, there is a need for future pedestrian circulation improvements. With the new development towards the northern and western boundaries, the open movement of people within St. James Town could become compromised if nothing is done. 


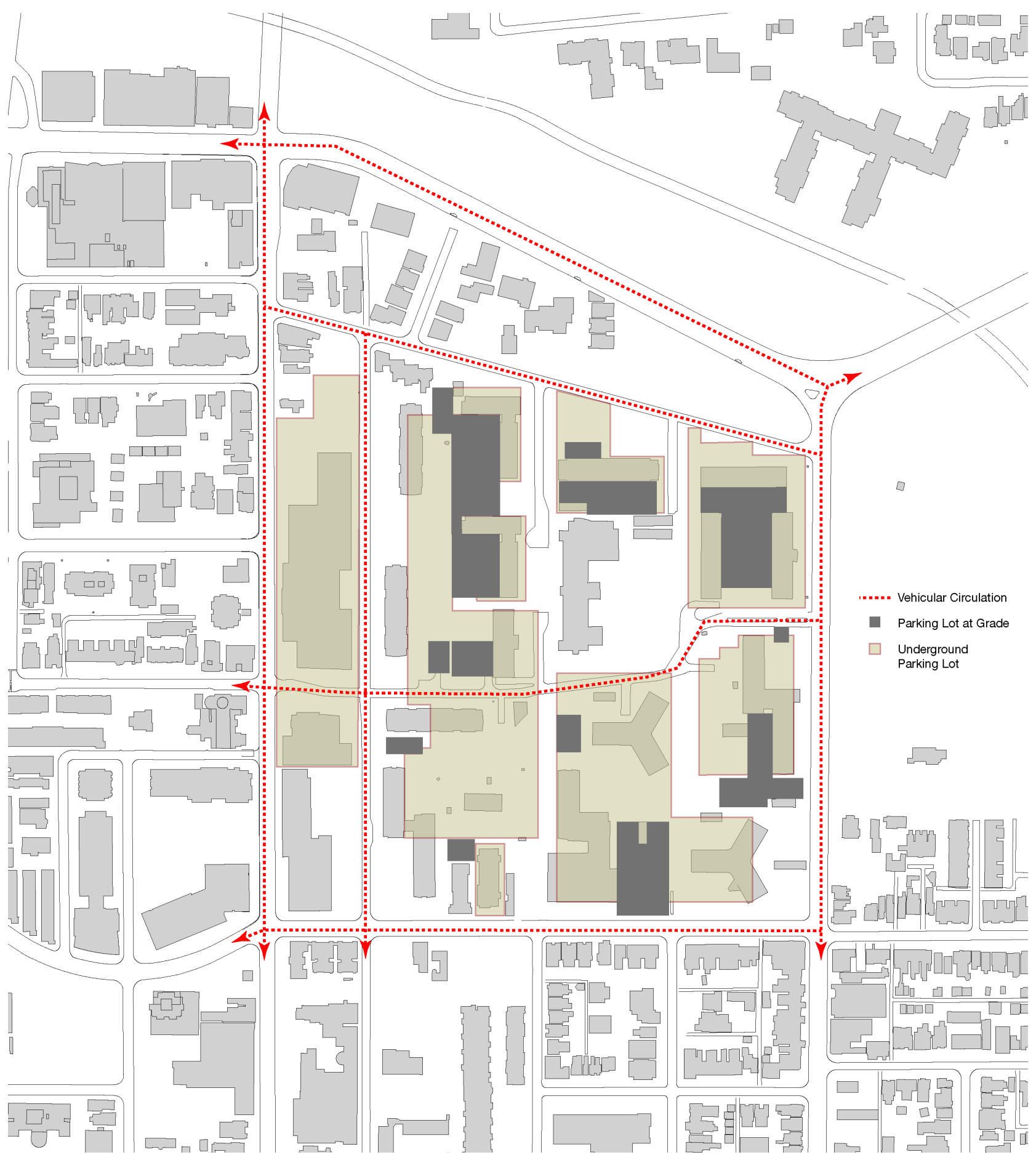

FIGURE 87

Vehicular circulation and parking map, 1:2500

As previously mentioned, this neighbourhood was designed to facilitate a walkable community. As a result, there are few vehicular thoroughfares. While the neighbourhood was designed to privilege the pedestrian over the motorized vehicle, there are numerous unused underground private parking lots which cover $53 \%$ of the neighbourhood (Canada, 2011). This large amount of vacant underground and parking space at grade has the potential to be revitalized, and better suited to the walkable community that this neighbourhood was designed to be. 


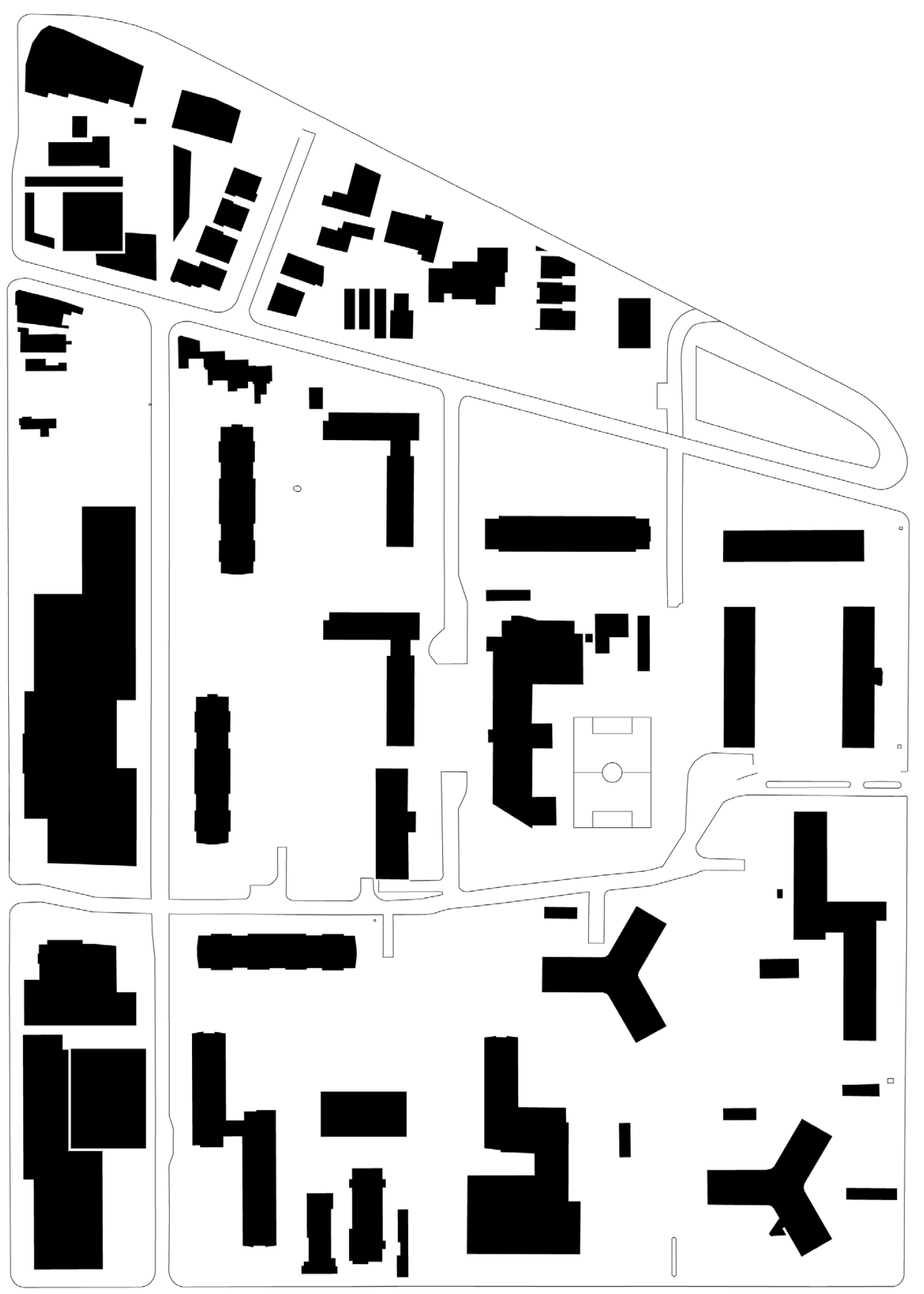

FIGURE 88

Figure-ground map, 1:2500

The figure-ground for the St. James Town neighbourhood illustrates the vast open spaces between buildings due to the minimal footprints of the high-rise towers. As Le Corbusier envisioned, there are large open areas, periodically interrupted by soaring towers with small footprints. This creates the potential for a vibrant and dynamic pedestrian realm; however, as Corbusier's visions has been tested repetitively in cities around the world, there have been proven shortcomings to high-density living including an increased incidence of poverty (Barnes, 2011). 


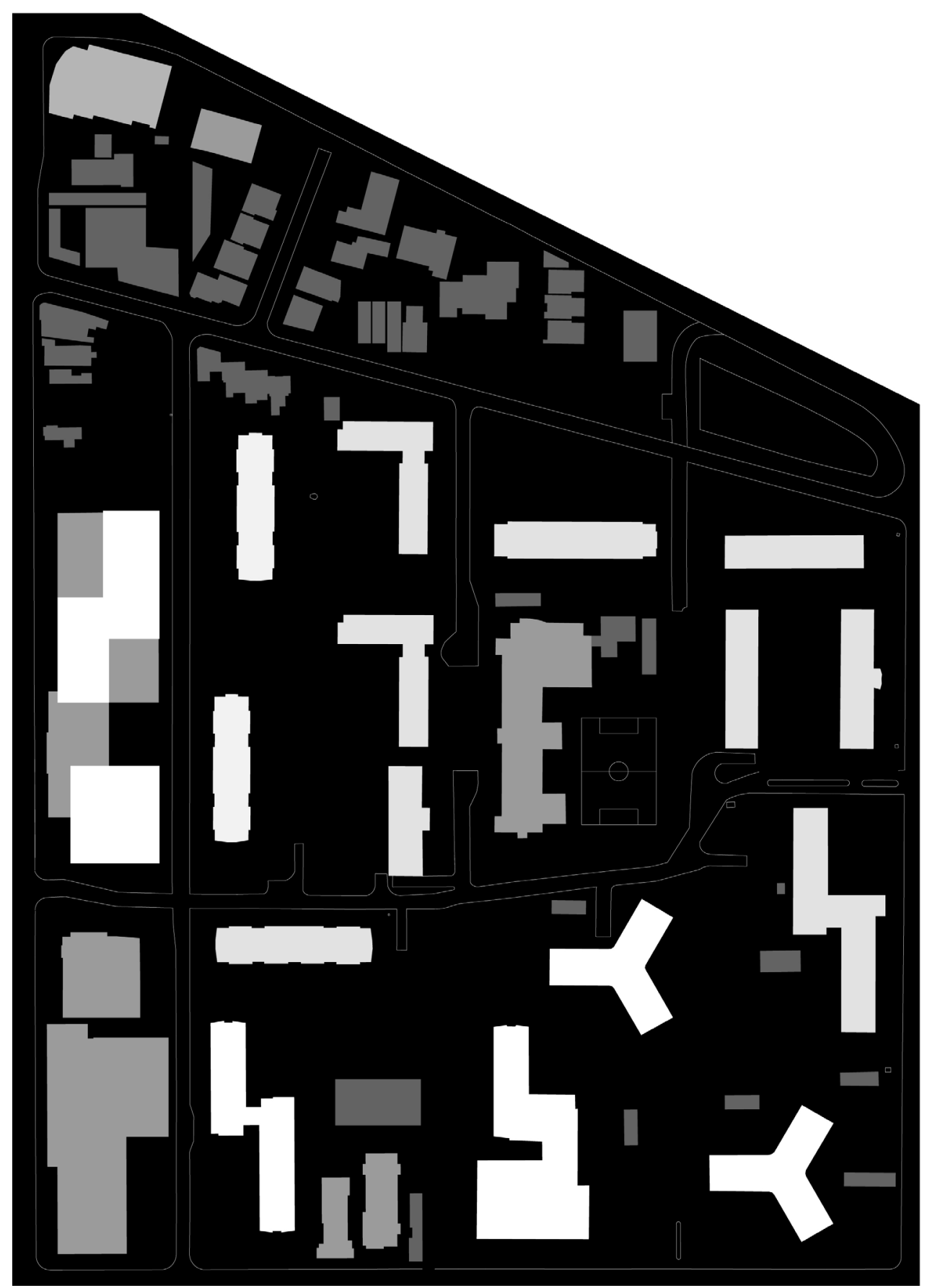

FIGURE 89

Noli Plan, 1:2500

The inverted figure-ground diagram further emphasizes the extent of the public realm and the sheer magnitude of open space within such a small community. This neighbourhood contrasts the rest of the city which elected to adopt the tower-andpodium typology as the primary building form, as it creates a definitive street presence, subsequently highlighting vehicular circulation paths. The lack of success of the tower-in-the-park design can be seen in the new development along Sherbourne Street which opted to return to the tower-and podium typology. 


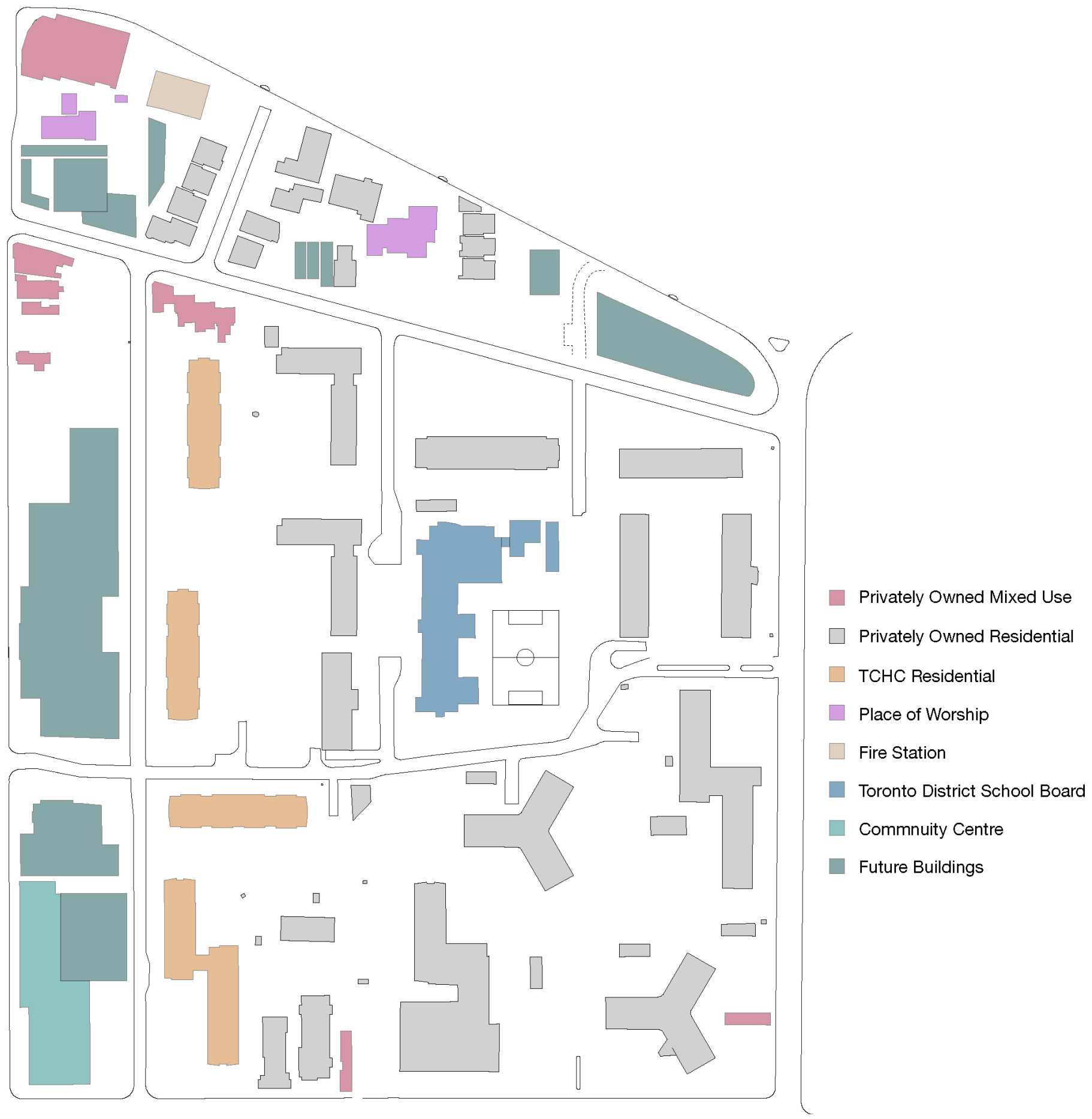

FIGURE 90

Building usage map, 1:2500

This diagram highlights one of the fundamental flaws of the neighbourhood: the majority of the neighbourhood is comprised of high-rise apartment towers and is severely lacking in public amenities. Furthermore, the consolidation of residential towers towards the core creates the illusion of an impenetrable wall. This can discourage visitors from wandering through the community. There is potential to convert first couple of floors of these towers into commercial space, as outlined by the Tower Renewal Guidelines (Kesik and Saleff, 2009). 


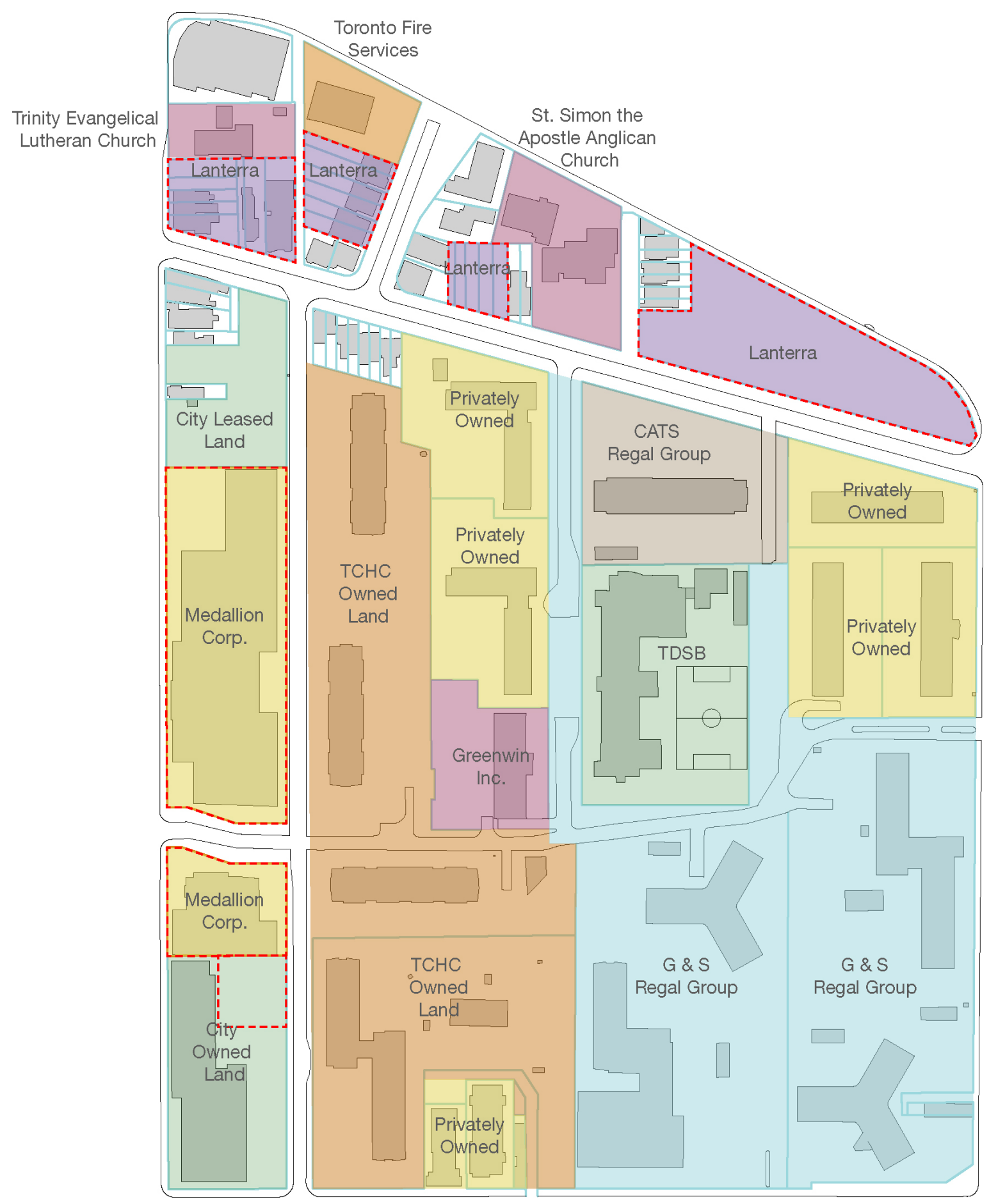

FIGURE 91

Property ownership map, 1:2500

The majority of the neighbourhood is privatelyowned high-rise residential towers. This has been identified as a critical flaw for the neighbourhood which has resulted in decades of deferred maintenance. This is due to the lack of regulatory policies that would otherwise require private land developers and owners to maintain their properties. There does, however, lie potential in the Toronto Community Housing owned land, as this is a public entity whose board is comprised of three city councilors, mayor representatives, and nine residents. 


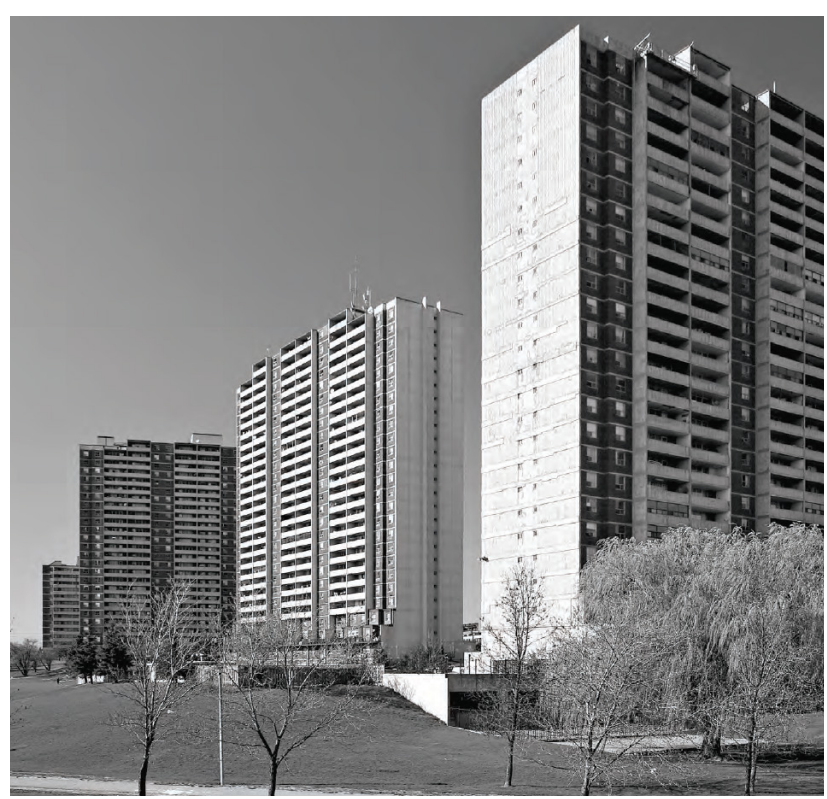

FIGURE 92

Tower renewal, mid-century apartment tower neighbourhood

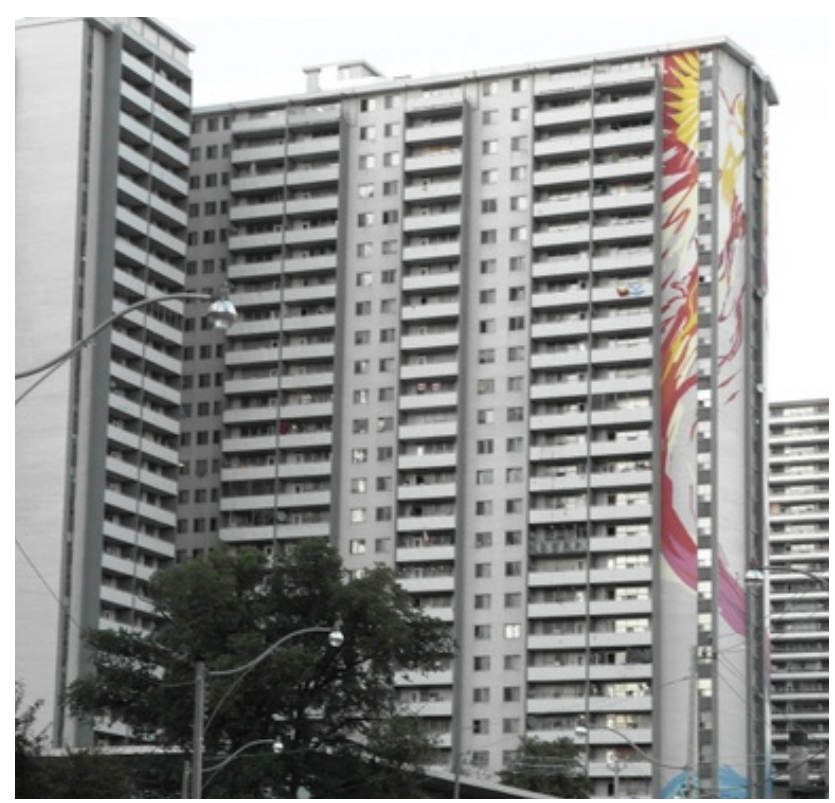

FIGURE 93

Worlds tallest mural, Sean Martindale, 2017

\subsection{THE FUTURE}

The neighbourhood of St. James Town has seen little development in the last half century, however, that is beginning to change. New development is underway along Sherbourne Street with a new 36-storey tower, and the rejuvenation of the commercial podium spanning between St. James Avenue and Howard Street, including several new townhouses. Additionally, there is a major development spanning numerous properties on the north side Howard Street, which has recently begun construction. The plan includes four high-rise towers which range from 46 to 56 storeys in height, along with some low-rise buildings, adding more than 1800 condo units to the area. The success of this redevelopment, however, predicates itself on the demolition of four heritage buildings. Additional concern is being generated due to the population increase the project proposes. More specifically, introducing more density to the neighbourhood may simply compound the issues without first addressing the underlying problems.
When looking at St. James Town's repertoire of high-rise buildings, it is important understand the context behind them. The Tower Renewal Guidelines by Kesik and Saleff (2009), out of the University of Toronto's Faculty of Architecture, Landscape, and Design, highlights four critical challenges Canadian cities with towers built in the same era as those in St. James Town are faced with: environmental sustainability, aging, the under-serviced communities they are a part of, and their overall neglect.

The towers of St. James Town and numerous others across Canada are currently in their sixth decade. While they were designed in an era of growth and optimism, constructed in a relatively high-quality manner, their current state is in decline. Towers pose one of the most wasteful and ecologically irresponsible building types in Toronto. 


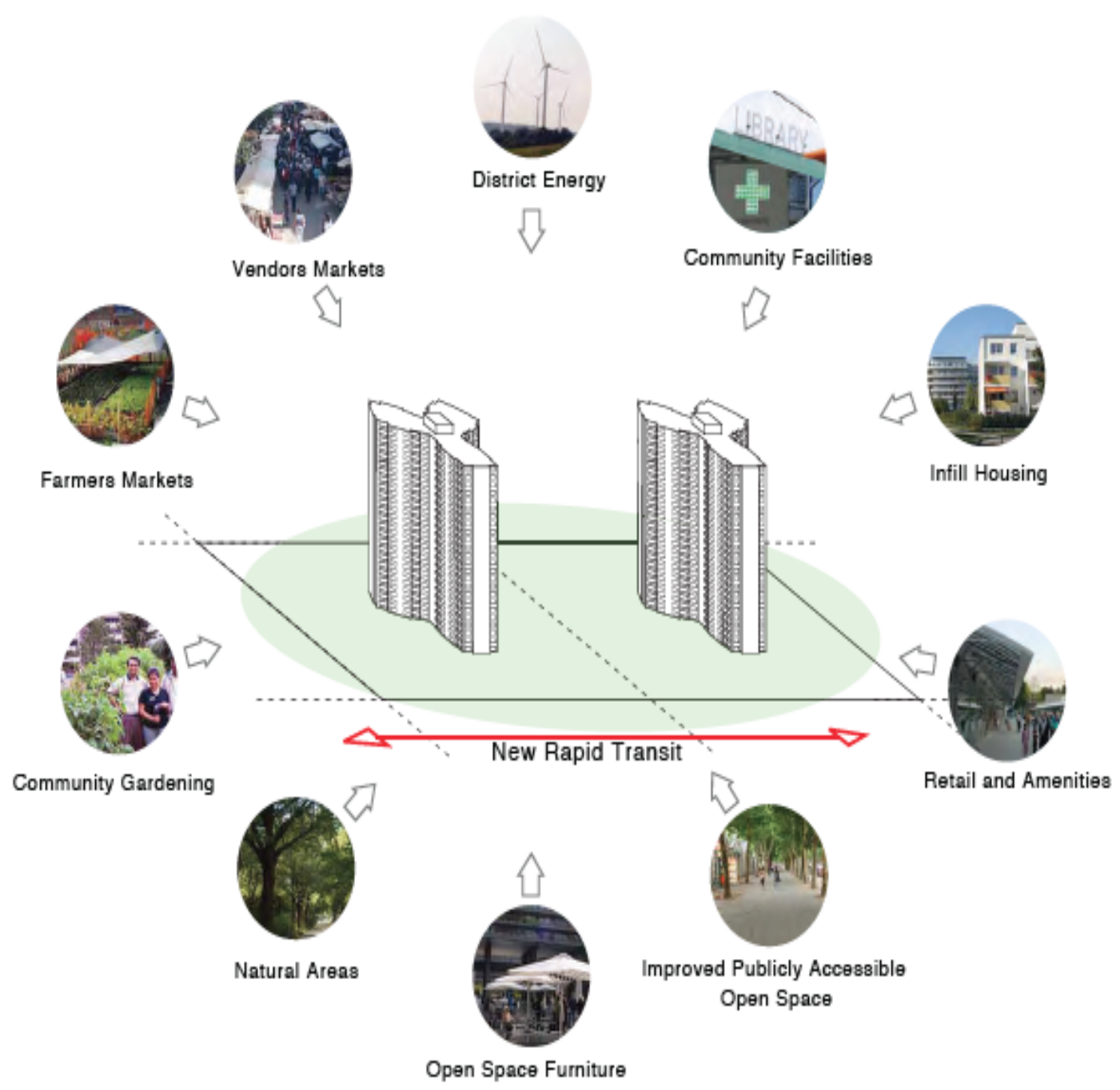

FIGURE 94

Sustainable and vibrant neighbourhoods diagram

The deterioration of Toronto's mid-century towers has become more and more apparent in recent years, identifying the increasing environmental impact these towers have. This is most evident in the amount of energy they consume due to their lack of insulation, resulting in a $20 \%$ increase in energy demand per household when compared to a contemporary single, detached house (Kesik \& Saleff, 2009). This is due to the era in which they were constructed. Energy was previously a cheap resource, and there wasn't the mindfulness for sustainable construction that has become a priority today.
St. James Town and many similar apartment neighbourhoods house the densest communities in Canada. Yet, these neighbourhoods are disjointed, with many lacking essential services and amenities, including retail, childcare, healthcare, or adequate food access and security. Furthermore, most of these communities rely heavily on public transit, yet in many places, there is poor service. This has resulted in plummeting land values and rent rates, making these communities popular for new Canadians. These low costs have resulted in "chronic neglect, disinvestment, and growing poverty" (Kesik \& Saleff, 2009). 


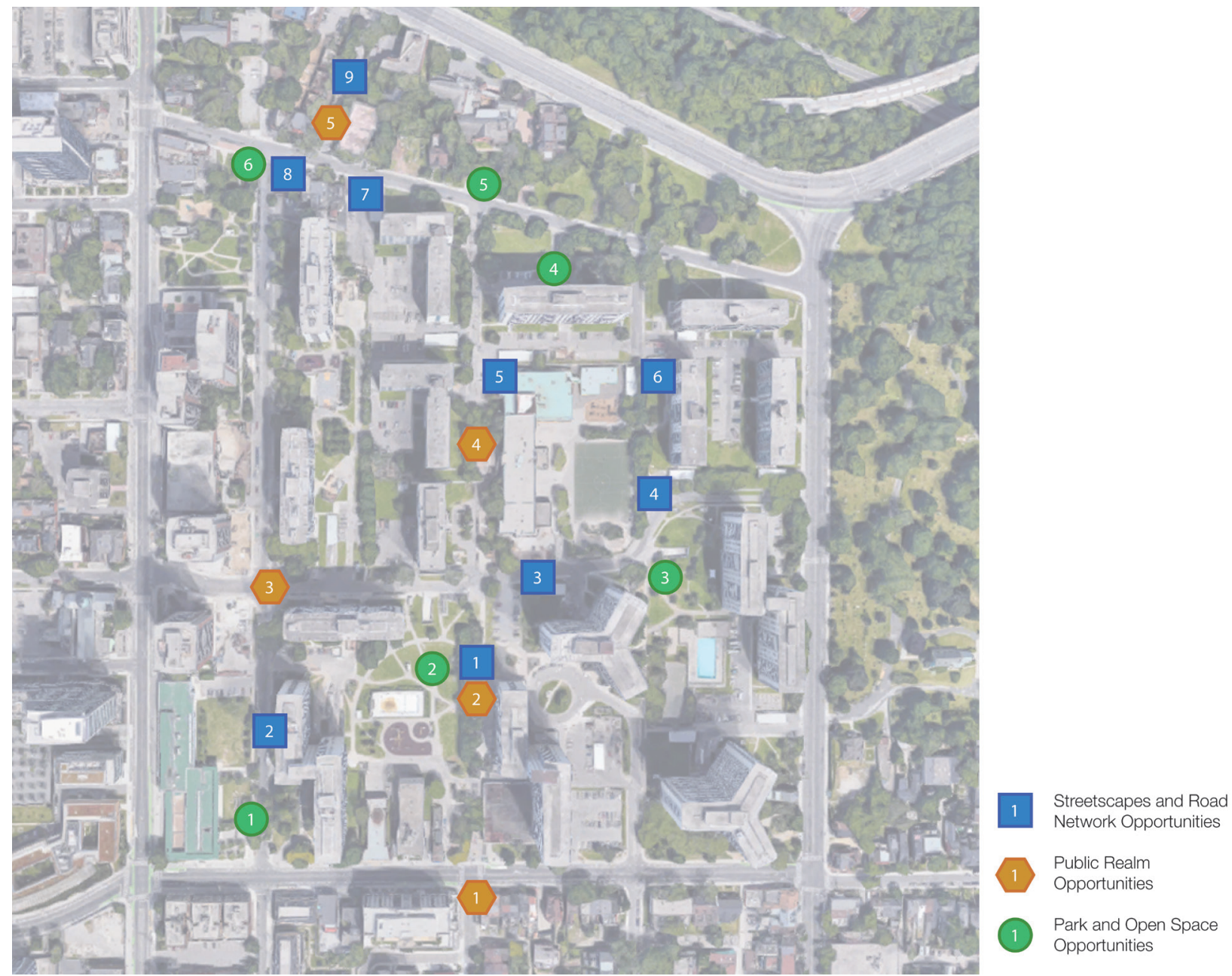

FIGURE 95

Neighbourhood opportunities diagram

\subsection{ANALYSIS AND INTEREST}

The public space in between these apartment buildings is arguably St. James Town's biggest challenge. The park areas adjacent to these towers are dysfunctional, cluttered with the remnants of an old, above-ground swimming pool and underutilized playgrounds, as can be seen in St. James Town. These towers were designed to sit within communal green space, leveraging the small size of apartment units as a means of encouraging outdoor public congregation and increased communal recreational activities. Furthermore, the neighbourhood's public realm severely lacks maintenance and desperately requires community advocacy and stewardship.

This analysis provides the foundation on which the design portion of this thesis project is built. This neighbourhood is of particular interest for several reasons. Firstly, its extreme density and large number of residents contrasted against its lack of amenities and public programming creates tremendous potential to invigorate the public realm. The extreme population density of the St. James Town community has caused widespread overcrowding in the area, and there are simply not enough resources to serve the large and culturally-diverse community. Secondly, there is a 


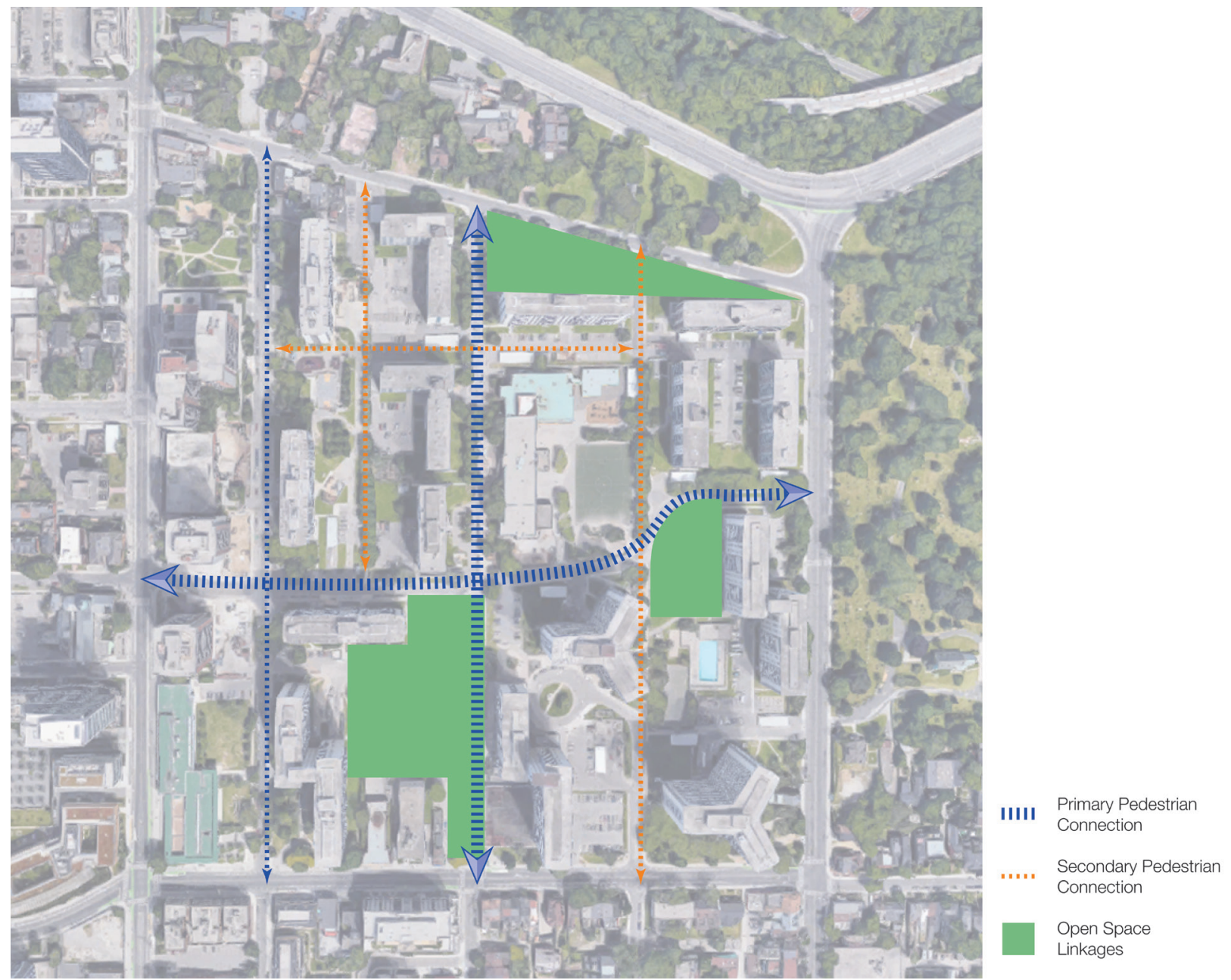

FIGURE 96

Neighbourhood connections and linkages diagram

lack of adequate public space and a well-defined civic center. While the towers are surrounded by open space, the majority of it is either concrete or poorly-designed public space. There is simply a lack of green space in the community. Based on research, it can be concluded that without adequate parks and general areas for the residents to engage in leisure activities, feelings of isolation and placelessness are unavoidable outcomes. Parks and green spaces, where neighbourhood residents can meet and engage in leisure and physical activities, are a vital part of any community (Gehl, 2011). It is an important factor in the physical and mental health of its residents, and also helps them feel more a part of their community. A lack of such spaces inevitably leads to a negative influence on the health of residents, both physically and mentally. Thirdly, its pedestrian realm currently fails to promote the walkable community that Le Corbusier originally envisioned. The neighbourhood has insufficient public seating, and its walkways and thoroughfares are malignant and in desperate need of rejuvenation. While there are numerous pathways throughout the neighbourhood, these paths tend to divide spaces. Furthermore, the lack of amenities in St. James Town make it a place to pass through rather than a destination. Lastly, its commercial storefronts are just as dilapidated, and require substantial renovations. The few storefronts in the neighbourhood are positioned off of Wellesley 


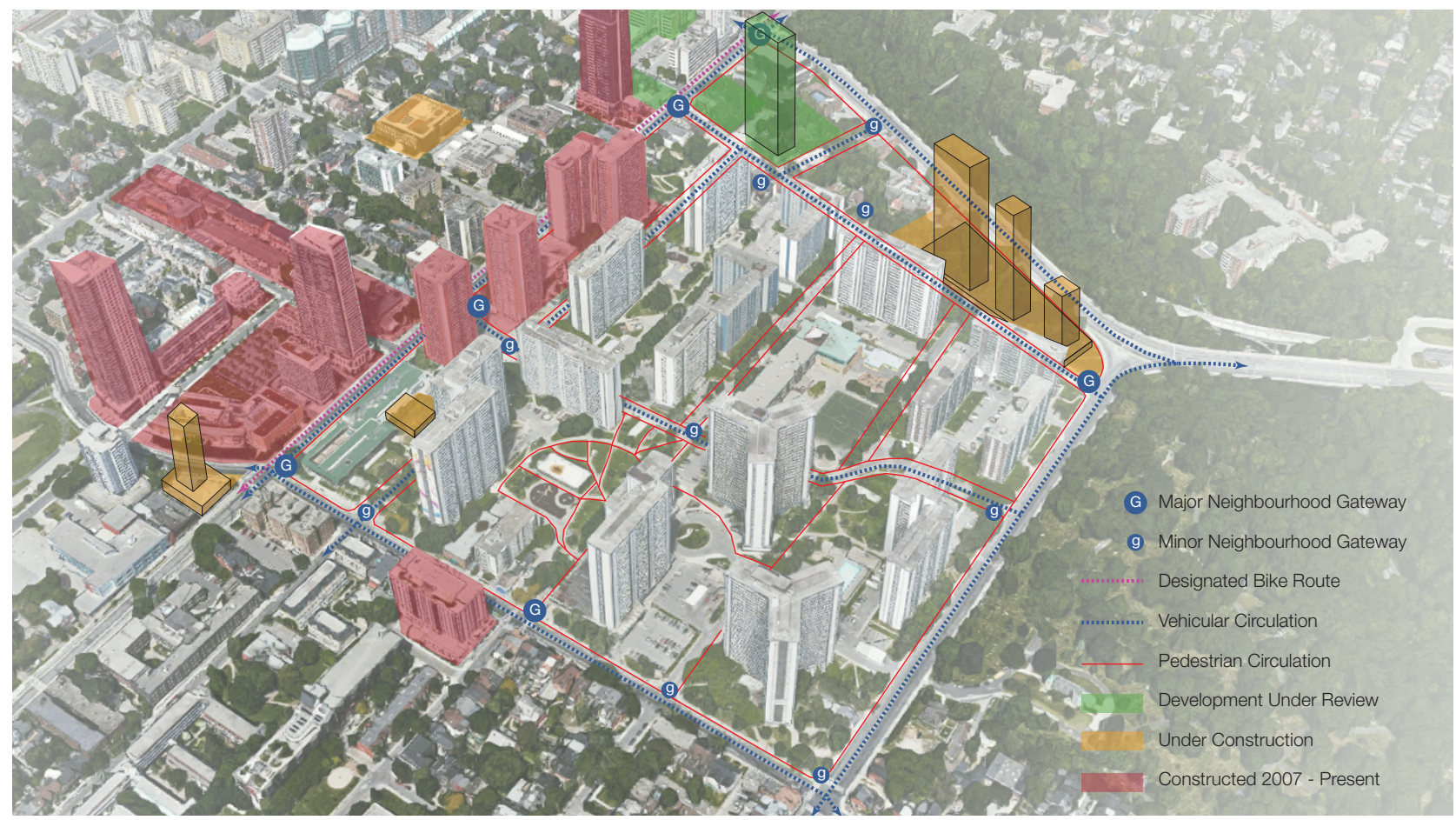

FIGURE 97

Overlayed mapping matrix

and require increased foot-traffic.

As existing apartment buildings in St. James Town are crowded, residents would greatly benefit from public services and recreational neighbourhood spaces. "The way the pool and the playground relate to our lives is the enjoyment time with friends and families. The apartments are too small to have everyone over, so we need to go outside," explained one resident. Green and open spaces where residents can engage in social and physical activities have been linked with improved physical and mental health as well as social integration. Lacking such spaces, the built environment in St. James Town can have negative influences on residents' health. It is unclear how the megadevelopment plan will affect these issues. Unfortunately, it might introduce more residents without first sufficiently addressing the existing community's needs (Barnes, 2011).
Through this analysis, several design challenges have been identified as opportunities to be addressed by this thesis:

- How can a Biophilic Design framework be implemented within a dense urban community?

- What enhancements would provide needed public amenities for a community with a currently inadequate public realm?

- How should a new building be designed such that it promotes health and wellbeing in a neighbourhood?

- How does one create invigorating development within an architecturallymundane neighbourhood? 


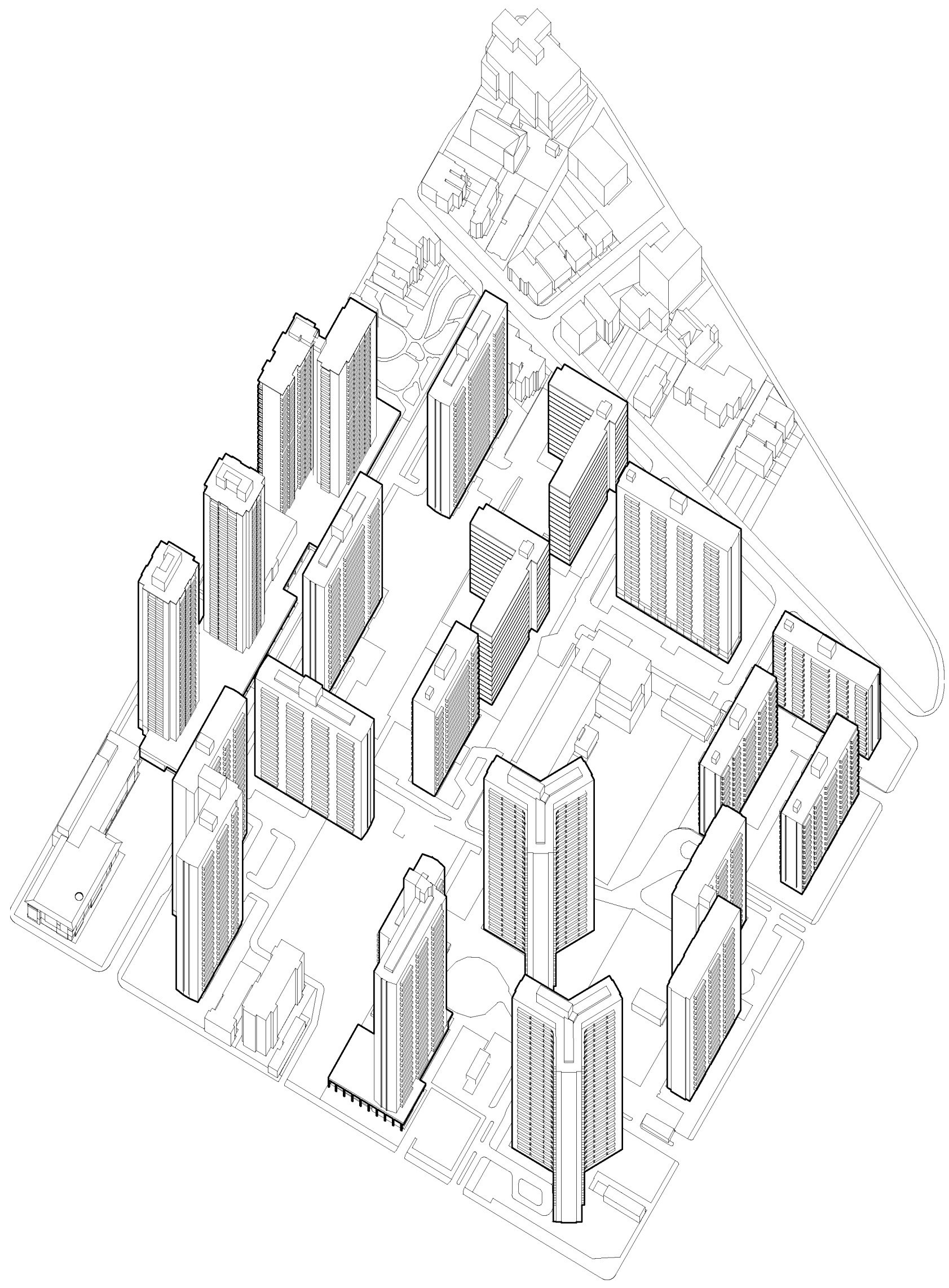

FIGURE 98

St. James Town Axo, highlighting its 19 high-rise apartment towers 


\section{DESIGN PROJECT PROPOSAL}

"What is the city but the people?"

- William Shakespeare

C reating a contemporary common for the St. James Town community has the capacity to contribute to the definition of its identity and character. As recent developments surround, and begin to occur within St. James Town, the social makeup of the neighbourhood will continue to diversify. The public realm currently fails to provide an adequate space for social and community congregation. This challenge of creating an identity for the common space will be exacerbated by the influx of new residents to the neighbourhood. St. James Town has the second highest renter population in all of Toronto, with $83.3 \%$ of its population currently renting property (TOcore, 2016). Additionally, $57.9 \%$ of its population has moved there within the last five years, with $23.7 \%$ moving in the last year alone, the third highest turnover rate in Toronto (TOcore, 2016). These statistics provide fundamental challenge to be addressed by the design portion of this thesis: how to design a public landscape park to create a sense of place for a community with such a short tenancy.

The St. James Town Common will provide variegated public spaces tailored to this dynamic community, rooted in a critical regionalism design strategy. It will take the form of a large civic park, providing urban green space off of a commercially-activated pedestrian promenade that connects Wellesley Street and St. James Avenue. Additionally, it will provide a platform for local commerce and entrepreneurship. Furthermore, the common will also function as an interactive landscape and playground for the neighbourhood. The ambition is to reinvigorate the public realm through redeveloping the existing commercial and recreational heart of the neighbourhood, ultimately enhancing place-based relationships in the community. 

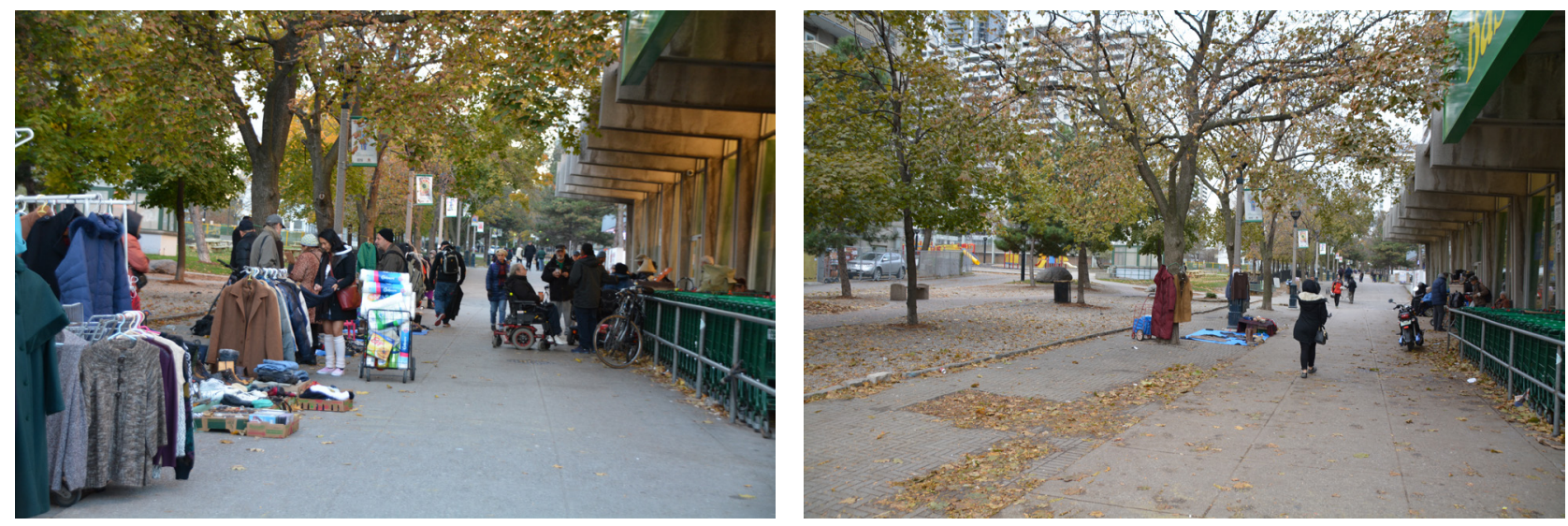

FIGURE 100 and 101

St. James Town daily flea market, Wellesley and Ontario Street, October 2017 (left) and November 2018 (right)

\subsection{DESIGN INSPIRATION}

Through numerous site visits, this pedestrian extension of Ontario Street was particularly unique. Residents have domesticated the sidewalk, subsequently invigorating the public realm. The location of merchants is based on the site's proximity to the pedestrian traffic, which is most substantial along Wellesley, outside of the Food Basics. Through this process, the community of St. James Town has begun to both define a sense of place, as well as identify the need for improved spaces for commerce. This analysis also identified a crucial struggle that the design of this thesis seeks to respond to. This can be seen in these images depicting the dwindling numbers
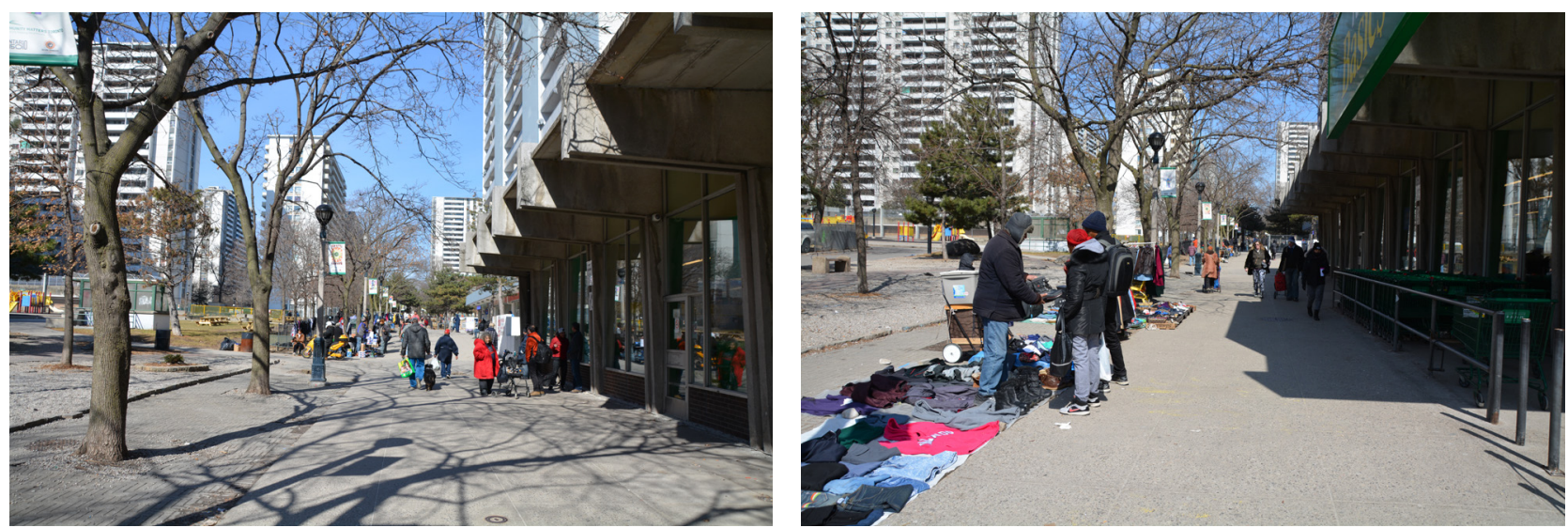

FIGURE 102 and 103

St. James Town residents daily flea market, Wellesley and Ontario Street, March 2018 (left) and April 2018 (right) of both merchants and market-goers as winter arrives and their resurgence upon the arrival of warmer weather. After completing an in-depth site analysis, this thesis began as an endeavour to establish an identity for the community, as it was determined that one was currently lacking. While there programmatically isn't a lot to do in St. James Town, this space had clearly been demarcated as the community hub, where residents could congregate. In addition to conversing in the park, local residents had established their domain over the sidewalk, converting public space into a makeshift commercial space. When the market was functioning, the public realm was invigorated - foot 


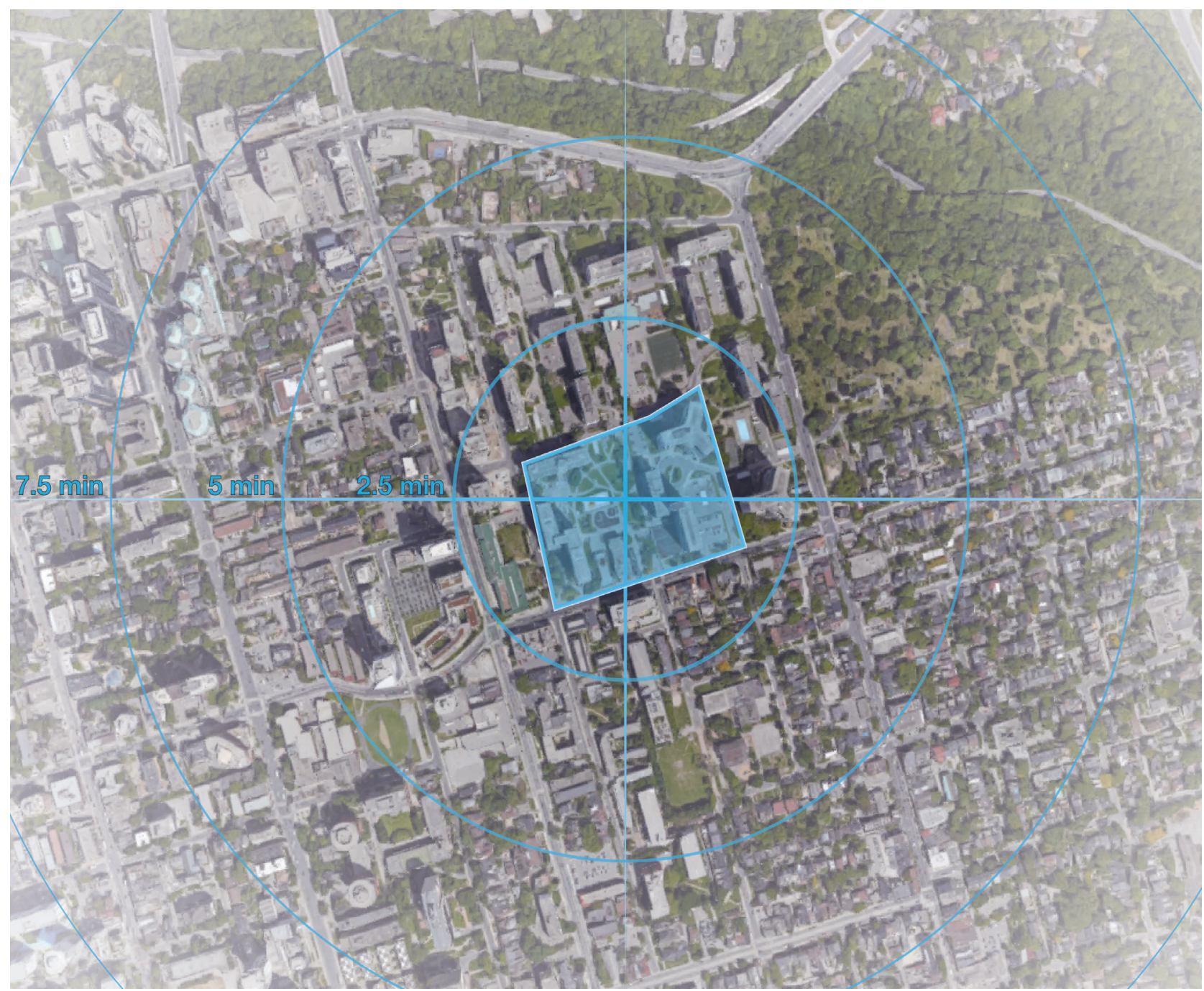

\section{FIGURE 104}

St. James Town Common extents and influence (walking radius)

traffic was increased, the promenade was animated with homemade and scavenged goods, and the level of social interaction dramatically increased, livening up the entire area. The challenge with this transformation, however, was that it depended on weather conditions. The series of images presented here demonstrate the pragmatic challenges of the market as the seasons change. Through numerous site visits, local residents expressed how this market had become not only their livelihood, but the heart of the community. As a result, it became the foundation upon which this thesis began.
As the area around St. James Town continues to see dramatic changes, it is important to establish that the development of this common is not intended just for the St. James community but for all residents nearby - it must serve a multi-cultural and economically diverse neighbourhood. For the purpose of this thesis, this outline functions as a secondary plan, identifying the extent of the influence of the common. 


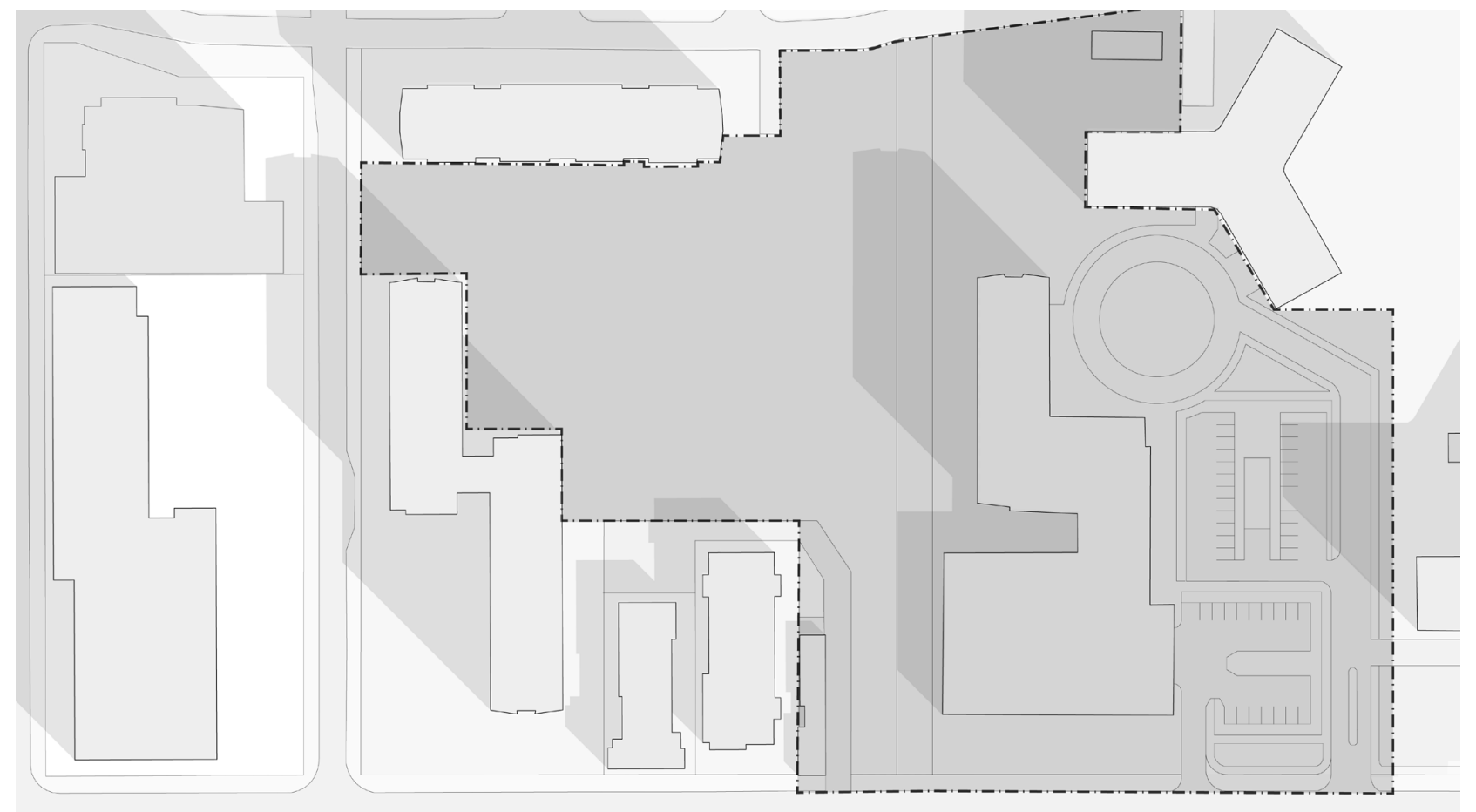

\section{FIGURE 105}

Site plan highlighting the extents of the scope

One of the primary focuses of the design is the fortification of the north-south circulation spine along the Ontario Street Pedestrian Promenade. By enhancing this axis, the intention is to improve both the vitality of the park that was experienced when the pedestrian market occurred, as well as increase its commercial activity.

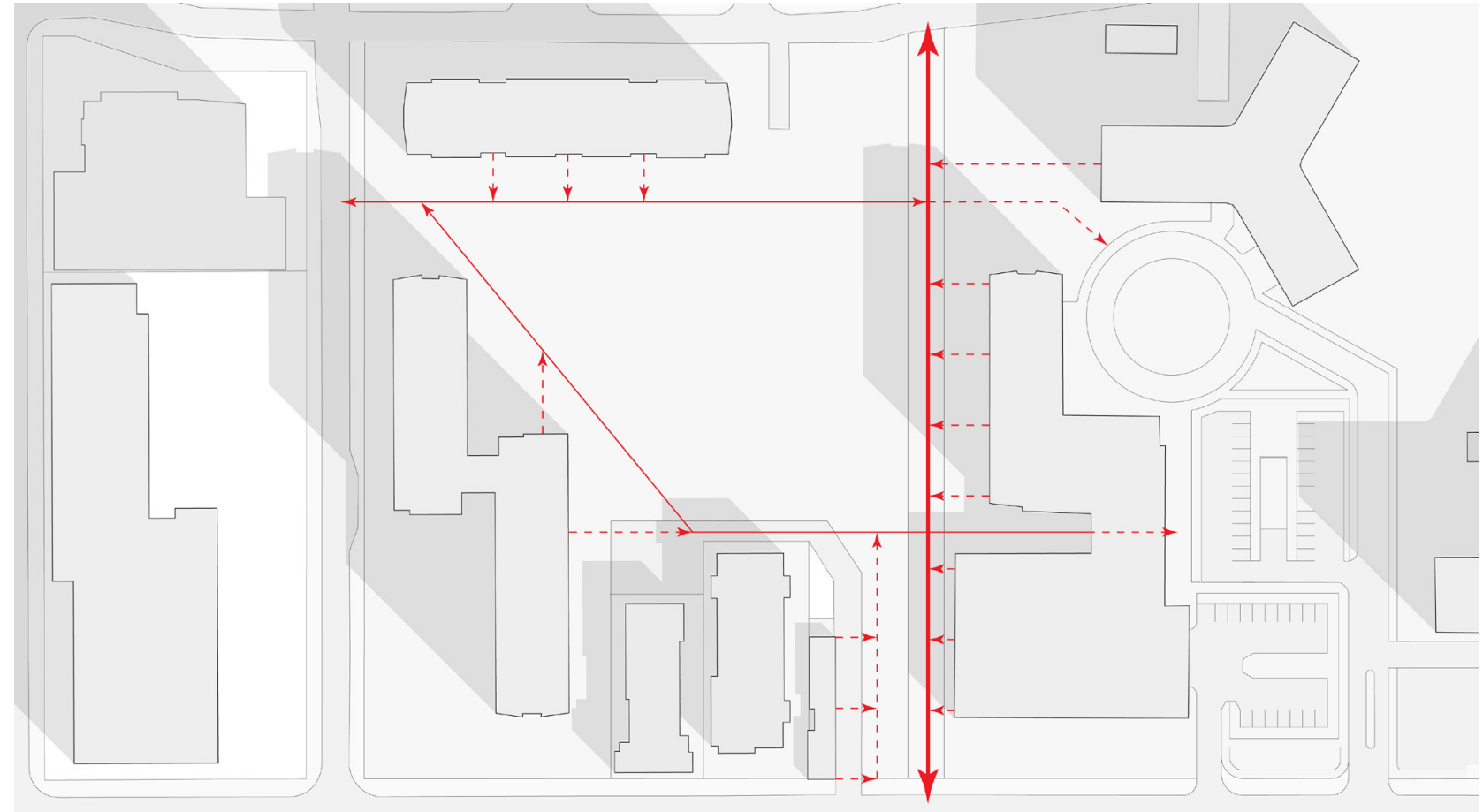

FIGURE 106

St. James Town Common primary circulation spine and ancillary paths 


\subsection{DEFINING THE SCOPE}

The public open space surrounding the existing St. James Town outdoor public pool is not operating to its capacity. There are numerous flaws with the existing public space:

- The pool has been closed since 2010

- The open public space around the pool lacks program and purpose

- The retail establishments are set back too far from the existing promenade

- The promenade lacks material expression, and is segregated from the open public space by fences

- Open space that is provided is disjointed by an excessive network of paths
These flaws form the foundation on which the design portion of this thesis develops from. The design of this thesis followed a three-step methodology Figures 106-109):

(1) 11 fundamental topophilic relationships were selected as the primary drivers of design.

(2) The scope of the design was established through an in-depth site analysis, reviewing the neighbourhood's community plan, and feedback provided by residents.

(3) Design elements were developed to address the challenges of the site, embodied in the established scope and topophilic relationships
Topophilic Relationships to Place

1. Geographic Connection to Place

2. Historic Connection to Place

3. Ecological Connection to Place

4. Cultural Connection to Place

5. Indigenous Materials

6. Landscape Orientation

7. Landscape Features that Define Building Form

8. Landscape Ecology

9. Integration of Culture and Ecology

10. Spirit of Place

11. Avoiding Placelessness

\section{Scope of the Design}

(a) Define Core of the Common with Distinct Public Realm Elements

(b) Customize Public Seating/Furniture to Define Extents of the Common

(c) Create a Signature St. James Town Landscape

(d) Enhance Connectivity Through Improved Circulation Networks

(e) Develop a Consistent Approach to Lighting

(f) Enhance Walkability and Primary Pedestrian Zones

(g) Integrate Existing Laneways/Pathways as Part of the Public Realm Network

(h) Improve Accessibility and Active Transportation Routes

(i) Provide Micro-Retail at Grade

(j) Create an Active and Transparent Ground Plane

(k) Reinforce Existing and Create New Visual and Pedestrian Axes

(I) Introduce Sustainable Materials

(m) Create New Zones and Opportunities for Public Art

\section{Design Elements}

(i) Expressive Canopy Structure

(ii) Pavilion Structure with Snack Shop Washrooms, and an Outdoor Kitchen

(iii) Pedestrian Promenade

(iv) Public/Private Vendors

(v) Furnishings and Amphitheatre Seating

(vi) Interactive Landscapes

(vii) Playground and Splash Pad

(viii) Enclosed Dog Park

(ix) Botanical Garden and Green House

(x) Paving and Hardscaping

(xi) Lighting

(xii) Public Art

(xiii) Identity and Way-Finding

(xiv) Cycling Path

(xv) Biophilic Parking Lot

FIGURE 107

Systematic integration of design methodology, design scope, and design elements 


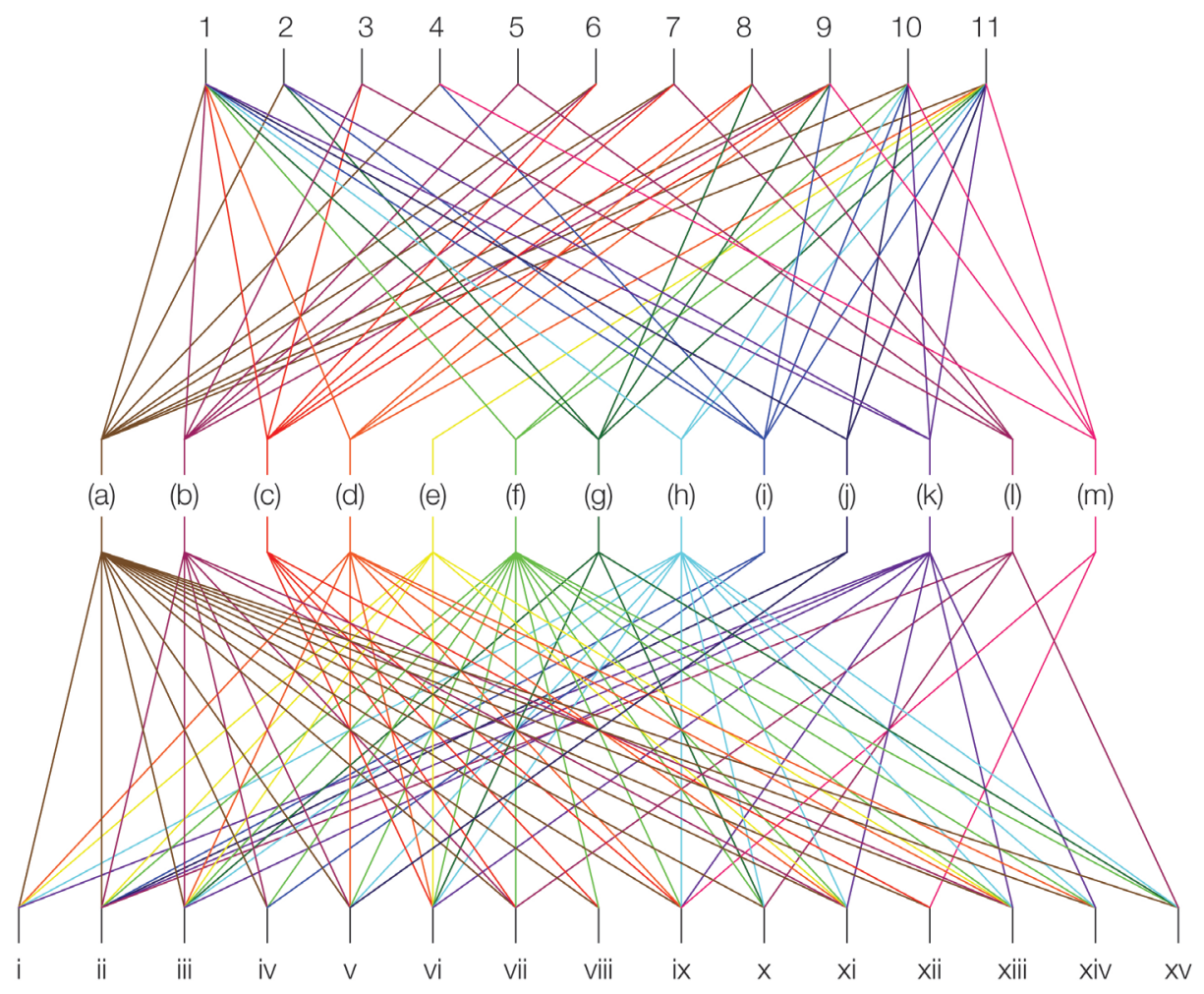

\section{FIGURE 108}

Design methodology, design scope, and design elements matrix

Topophilic design is defined by several key relationships that exist between people and their surrounding context. After establishing these 11 attributes of place-based relationships as the starting point, the scope of this project was defined through in-depth research, site observations, analysis, and resident testimony. Design elements were subsequently selected in order to address these programmatic requirements, while still responding to the initial place-based relationships.

The matrix depicted in Figure 108 maps this process. Each of the 13 scope elements respond to various topophilic relationships and are accomplished through numerous design elements. Figure 109 demonstrates a singular scope element. $(C)$ is the creation of a signature St. James Town Landscape. This responds to 8 of the topophilic relationships and is manifested in 5 design elements.
This thesis tackles the opportunities presented in St. James Town at the scale of the neighbourhood, building, and individual user. As a result, this intervention has an extensive area with numerous design elements, covering $20 \%$ of St. James Town. This culminates in a stratified and unified project, The St. James Town Common. These primary elements are (Figure :

- The pedestrian promenade

- The adjacent commercial hub

- The multi-purpose recreational field

- The splash pad and playground

- The elevated allotment gardens

- And the biophilic parking lot. 
c) Create a Signature St. James Town Landscape

1. Geographic Connection to Place

3. Ecological Connection to Place

5. Indigenous Materials

6. Landscape Orientation

7. Landscape Features that Define Building Form

8. Landscape Ecology

9. Integration of Culture and Ecology

10. Spirit of Place

vi. Interactive Landscapes

vii. Playground and Splash Pad

viii. Enclosed Dog Park

ix. Botanical Garden and Green House

xii Public Art

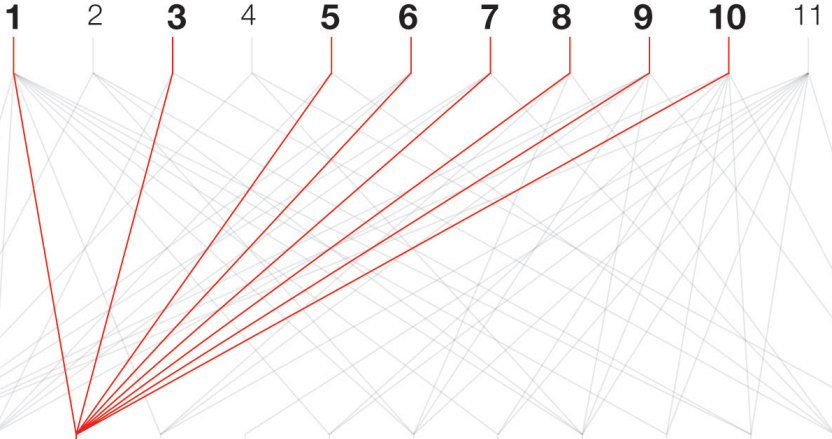
(a)
(b)
(c) (d)
(e) (f)
(g) (n)
(i)
(j) (k)
k) (l)
(m)

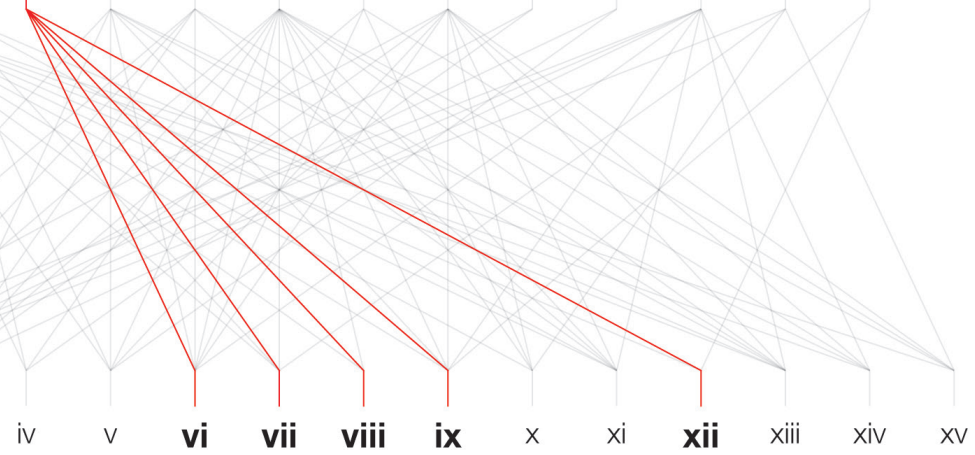

FIGURE 109

Design methodology, design scope, and design elements matrix

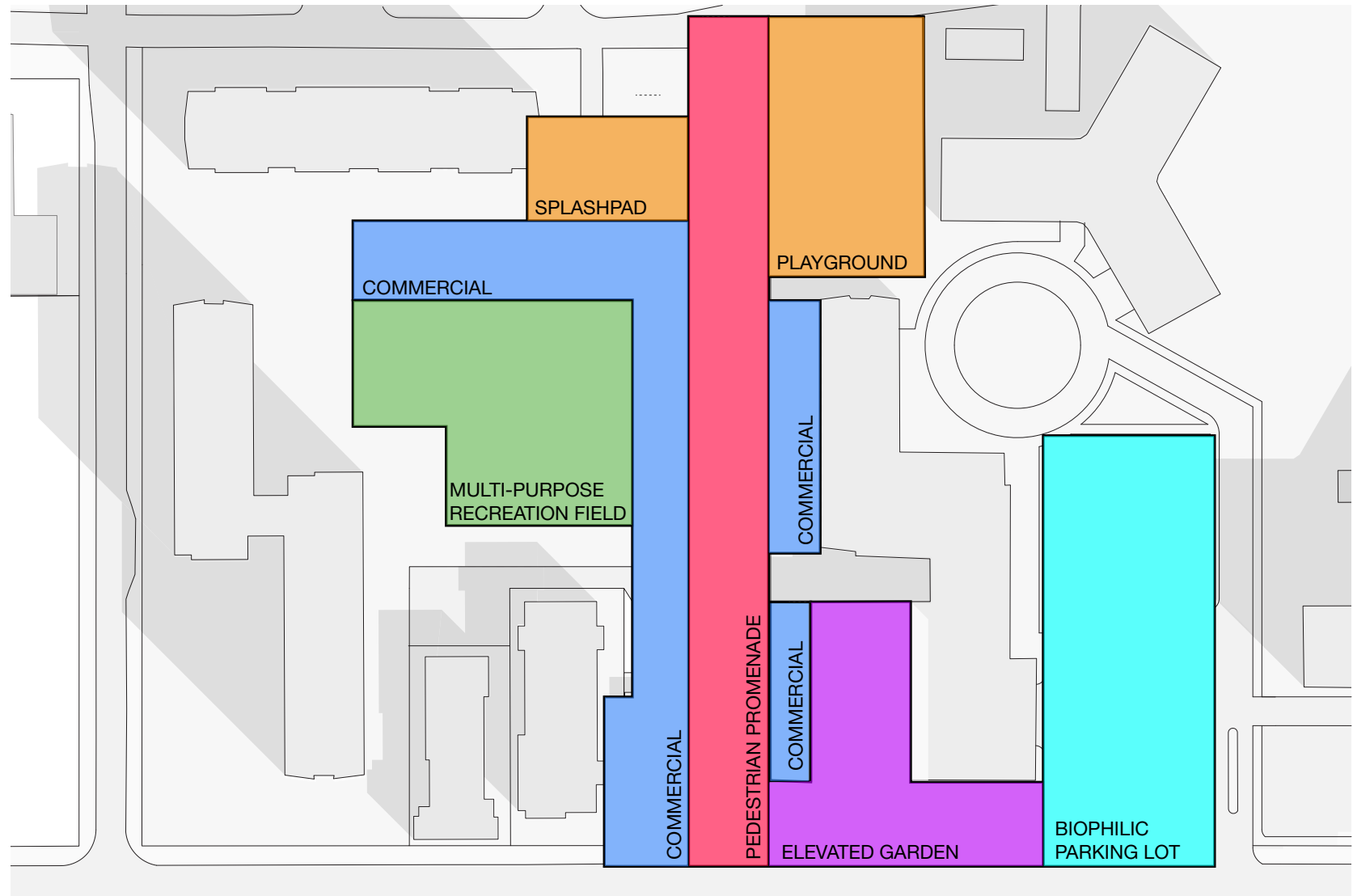

FIGURE 110

Program parti 


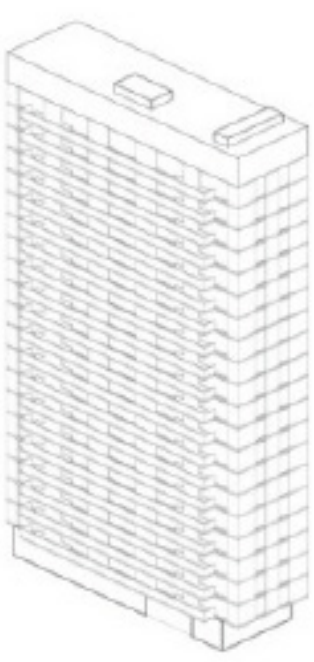

Bar Tower

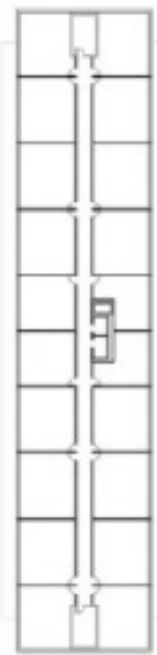

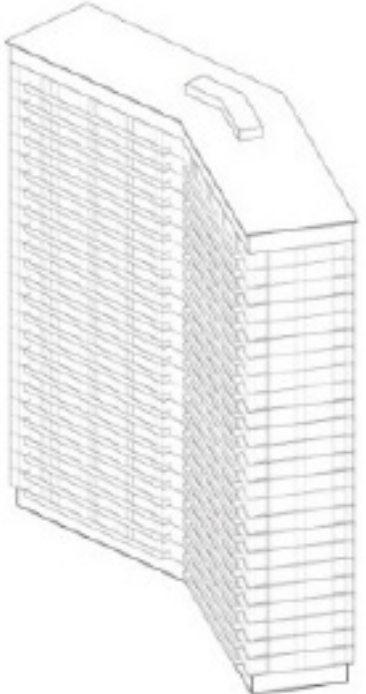

Articulated Tower

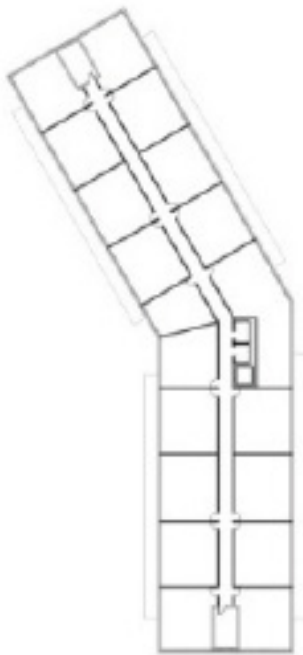

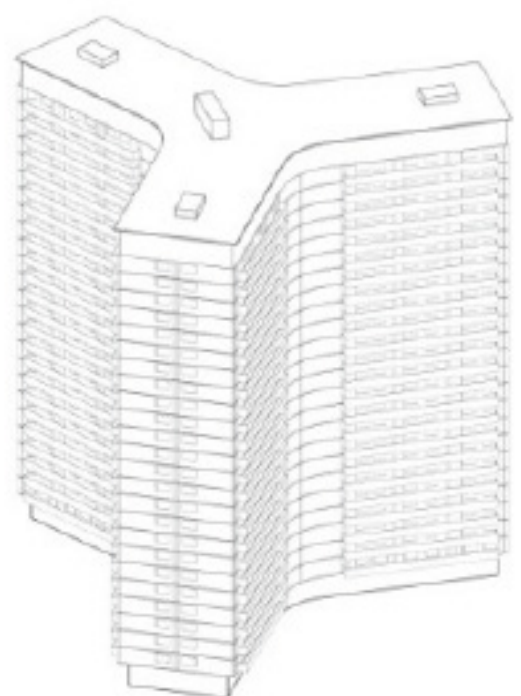

Y-Shaped Tower

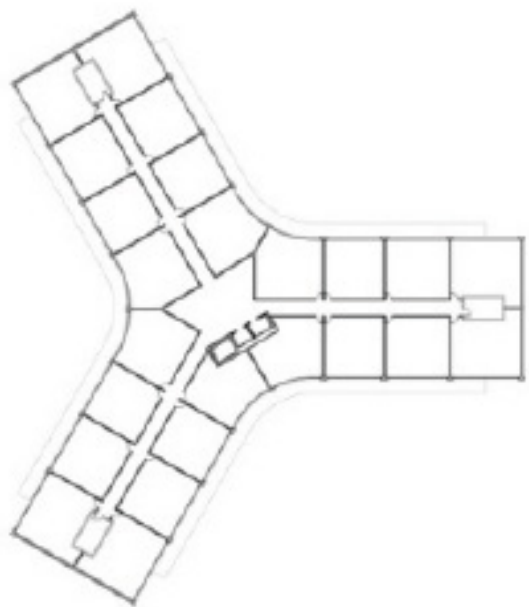

FIGURE 111

St. James Town typical tower blocks

\subsection{DESIGN ELEMENTS}

The scope established in Figures 108 is highlighted in Figure 110, which outlines the programmatic scope elements superimposed over the selected site (the extents of which are highlighted in Figure 105). Once the required design elements were established, biophilic and topophilic design principles began to inform design decisions. The first decision, which affected all of the design elements, was the selection of a base geometry unit.
Through analyzing the neighbourhood, the majority of the tower blocks are comprised of orthogonal geometries. This can be seen in the bar, articulated, and y-block apartment buildings typologies (Figure 111). Their geometry creates a very harsh and deliberate directionality that was undesirable for this thesis, as the intention is to create a freeflowing public space (Figure 112). While orthogonal geometries were too directional, using circular or curvilinear forms did the opposite - they provided 

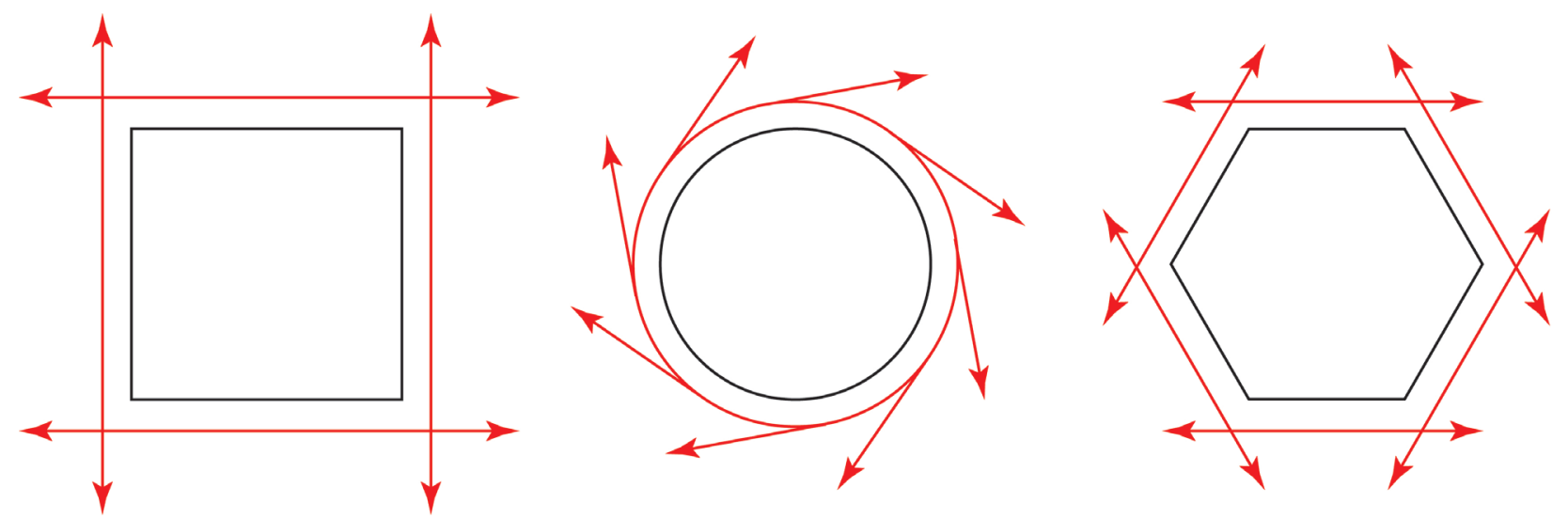

FIGURE 112

Base geometry selection and directionality diagram

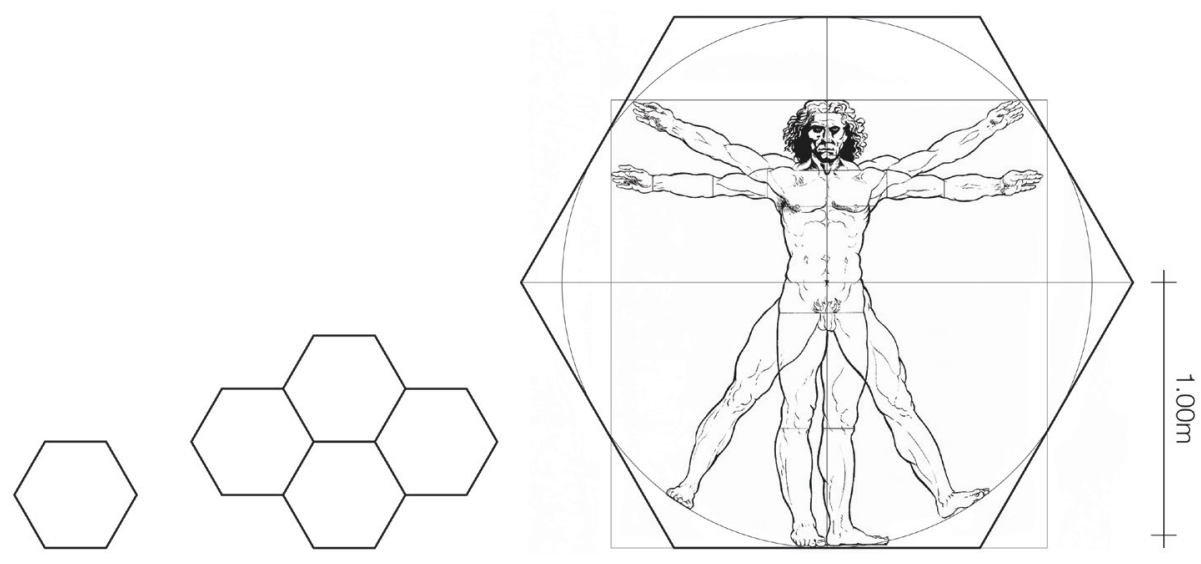

FIGURE 113

Sizing base geometry

virtually no directionally (Figure 112). As a result, the hexagon became the primary base geometry. The scale of this base unit was derived by utilizing the human body to define the size of a single module, with a radius of 1 metre, which can then be aggregated or scaled (Figure 113). The hexagon was incorporated as the starting point from that all design elements developed from.

Due to the size of the design intervention, which covers 4.5 hectares, a series of design elements were developed and then aggregated across the site (Figure 114). Expressive canopies were designed to demarcate the primary entrances, micro vendors drive pedestrian traffic, amphitheatre steps function as both a seating area, as well as provide access to the roof of the food basics, which is now elevated allotment gardens, and the pavilion frames the public gathering space and facilitates community activities.

Together, they create a holistic design that responds to the identified opportunities in St. James Town: the vitality of its pedestrian corridor experienced with increased foot traffic, the neighbourhood's park spaces' ability to provide interactive landscapes for learning and play, the large amount of open space that possesses the potential to form a civic centre and central recreation space, the community initiative to create impromptu spaces for commerce, and the re-purposing of existing spaces to become great public spaces. 


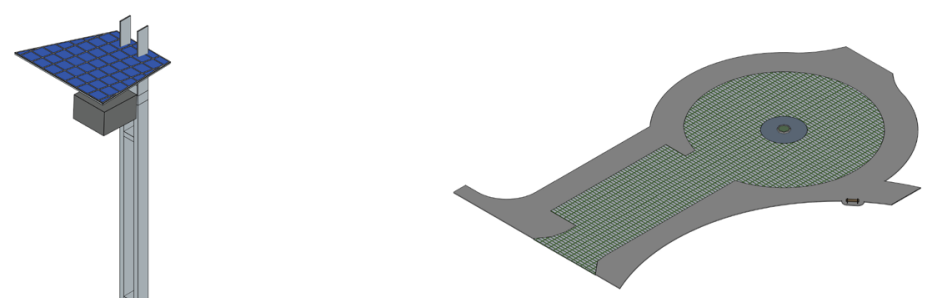

Grasscrete Roundabout

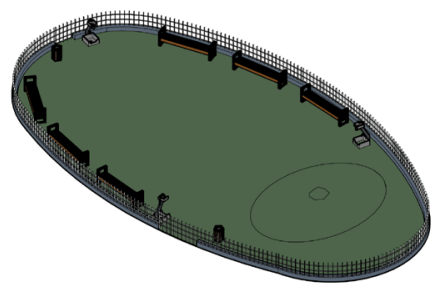

Dog Park

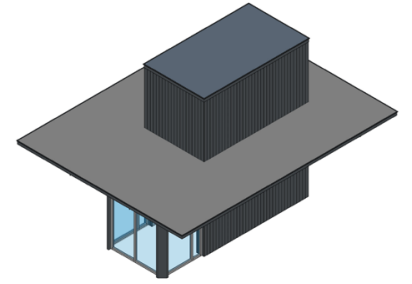

Elevator Entrance

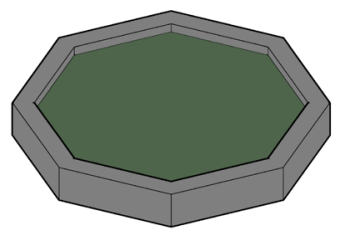

Planter

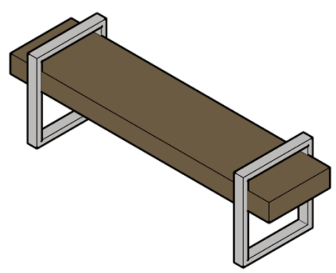

Bench

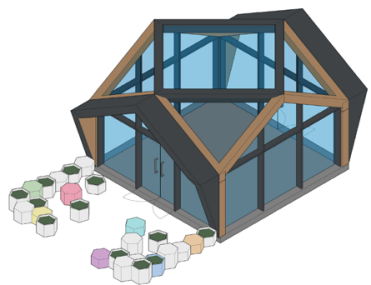

Single Vendor

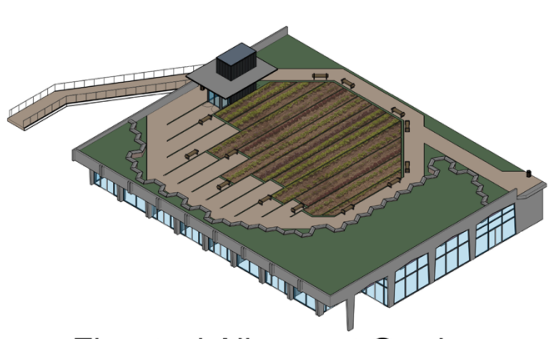

Elevated Allotment Garden

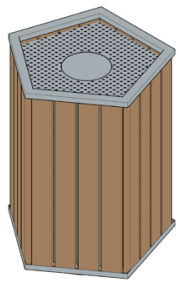

Trash Can

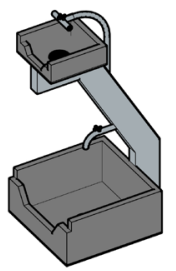

Dog Fountain

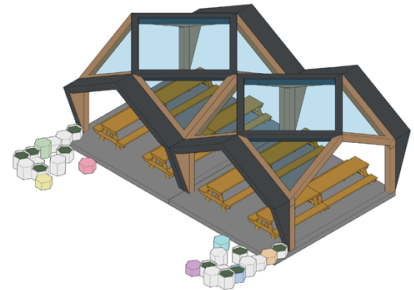

Open Pavilion

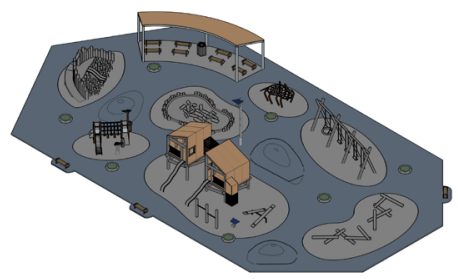

Playground

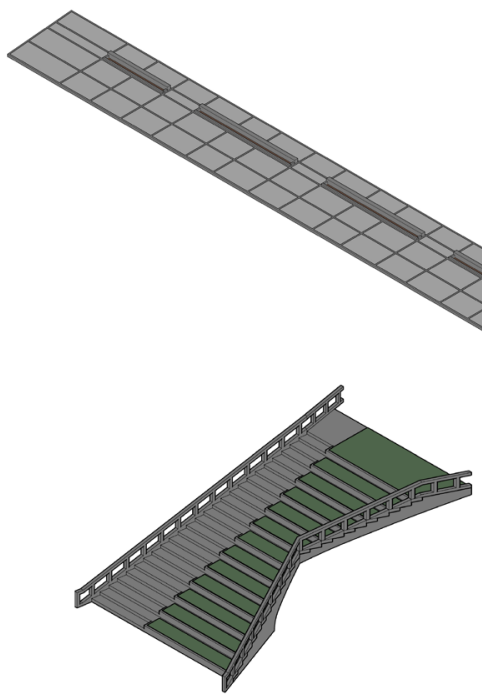

Promenade Amphitheatre

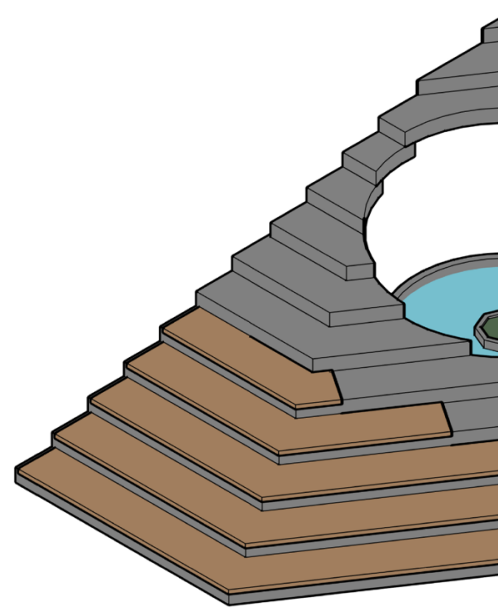

Wellesley

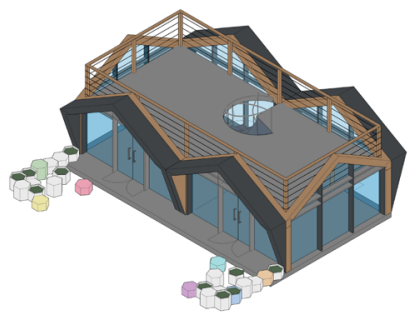

Double Vendor

FIGURE 114

Design elements axonometric 


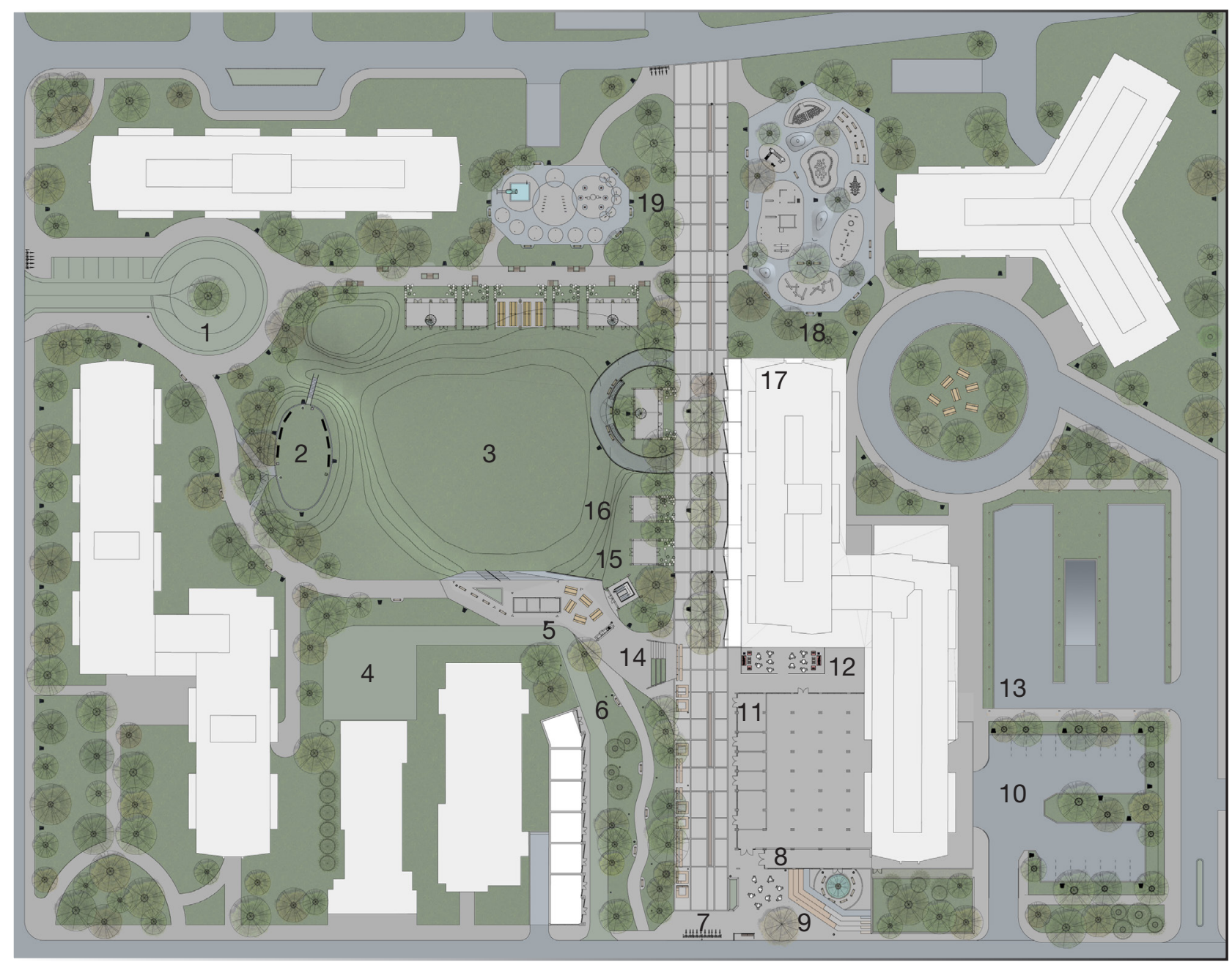

\section{FIGURE 115}

Ground Floor Plan

1. Revised western entrance, grasscrete roundabout

2. Elevated enclosed dog park

3. Multi-purpose open space

4. Revised service entrance, grasscrete

5. Snack shop and washroom pavilion with outdoor kitchen

6. Revised 224 Wellesley St. E with microbusiness vendors

7. Ontario Street Pedestrian Promenade

8. Cafe and patio

9. Amphitheatre steps
10. Biophilic parking lot and loading dock (South)

11. Revised 238 Wellesley St. E (Food Basics) with micro-business vendors

12. Restaurant patio

13. Biophilic parking lot (North)

14. Amphitheatre steps

15. Parking garage emergency exit

16. Micro-business vendor

17. Extended micro-business storefronts

18. Playground

19. Splash pad 


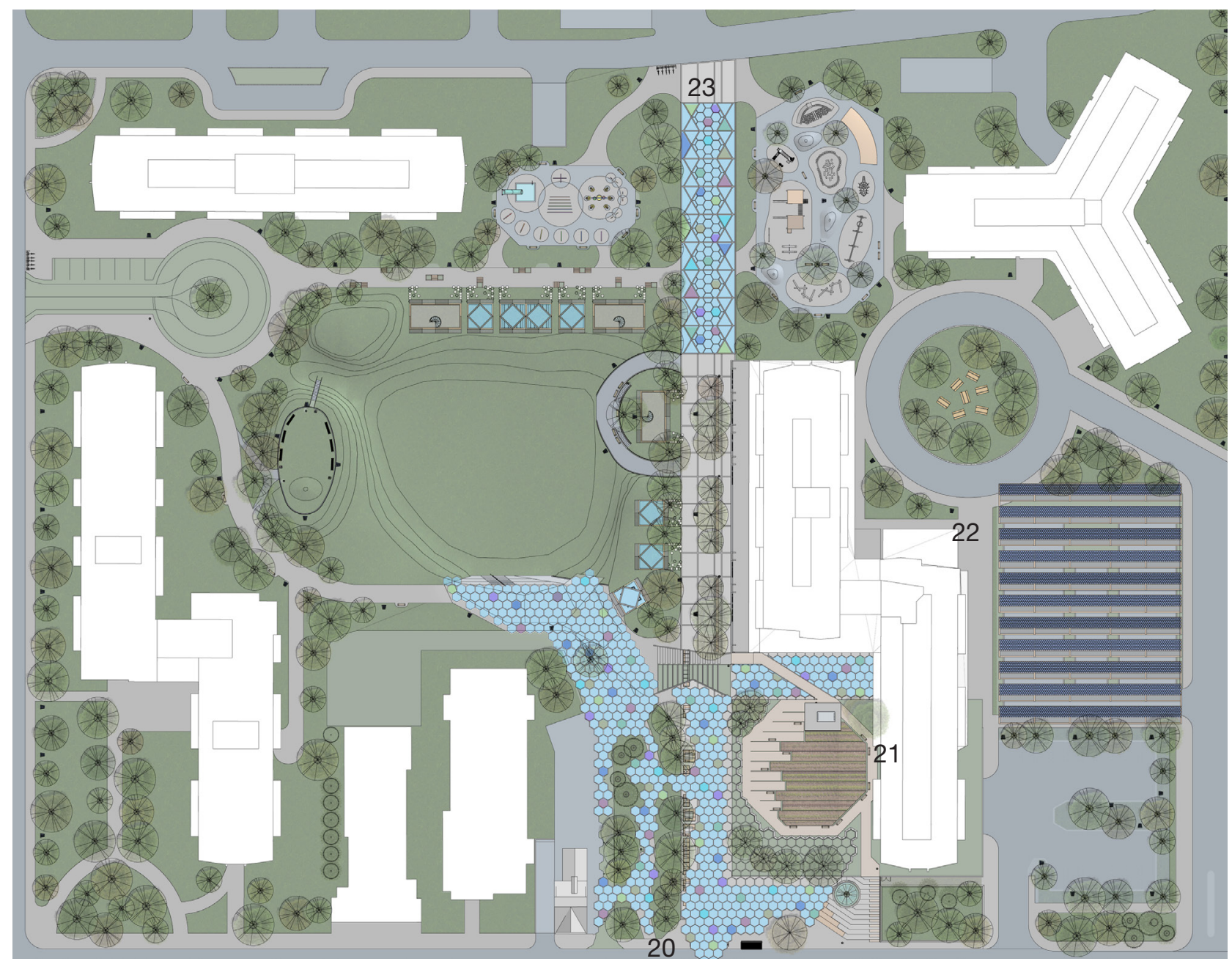

FIGURE 116

Site Plan

20. Hexagonal Wellesley St. E canopy

21. Elevated meadow and botanical garden

22. Heavy timber solar parking canopy

23. Hexagonal St. James Ave. canopy 


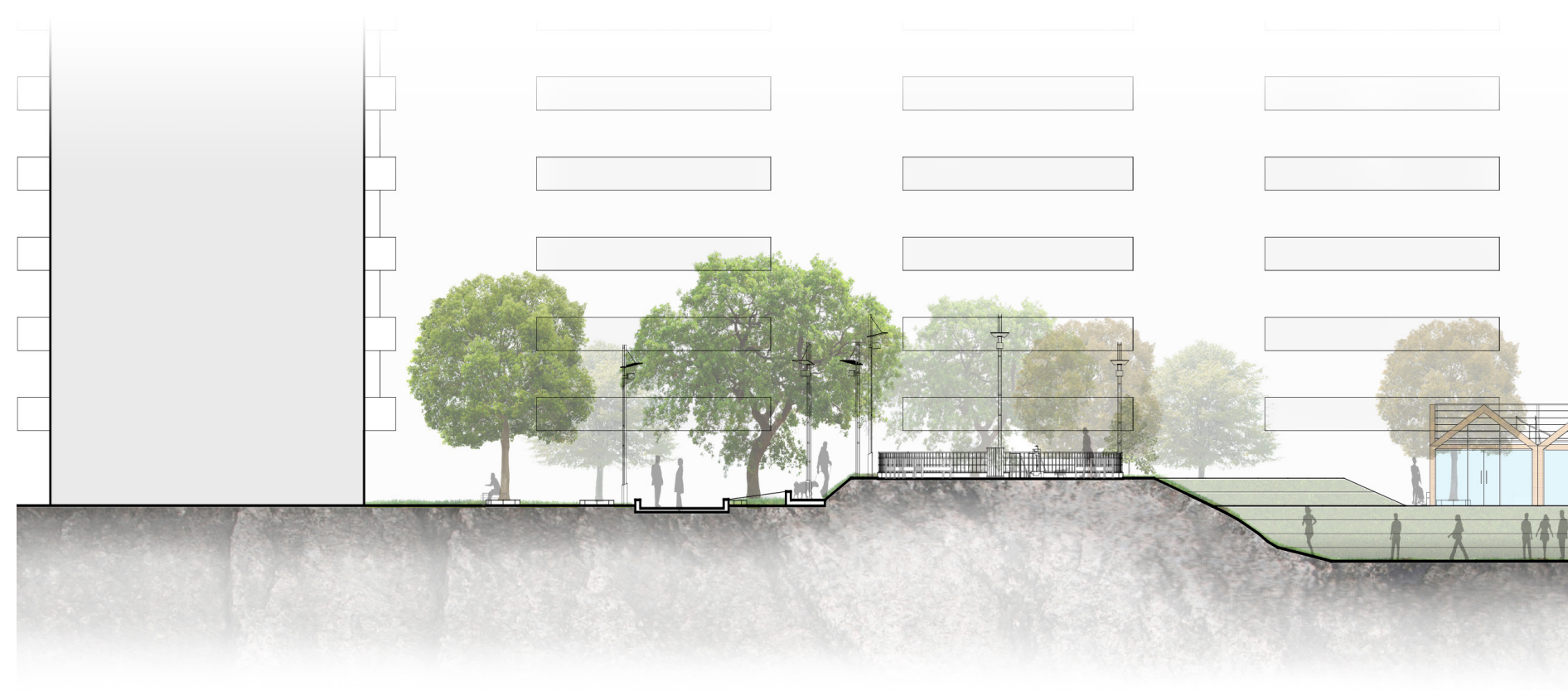

FIGURE 117

Site section through the Ontario Street Pedestrian Promenade and the large social gathering space

\subsection{DESIGNING THE PUBLIC REALM}

Key Design Elements

- Shade

- Tree and shrub selection

- Vegetation placement

- Protecting/preserving existing trees

- Hard- vs. soft-scaping

- Sand play
- Water play

- Gates and Fences

- Signage

- Lighting

- Pathways/circulation

- Material/colour selection

- Energy generation
Key Planning Considerations

- Existing ecological features

- A variety of planting techniques

- Efficient and purposeful maintenance protocols

- The use of sustainable construction practices
The best practices are organized under 11 interrelated sustainability themes and their associated goals, adapted from Waterfront Toronto:

1. Energy: Reduce levels of energy consumption and make greater use of low-impact renewable energy sources to meet energy demands.

2. Land-Use: Support sustainable community development through land-use planning.
3. Transportation: Make alternative transportation options such as walking, cycling and public transit, the natural choice for residents and visitors.

\section{Sustainable Buildings: Use architectural building systems that reduce negative environmental impacts, and provide high indoor air quality and exceptional comfort.}

5. Air Quality: Minimizing pollutant emissions helps improve air quality in the city 


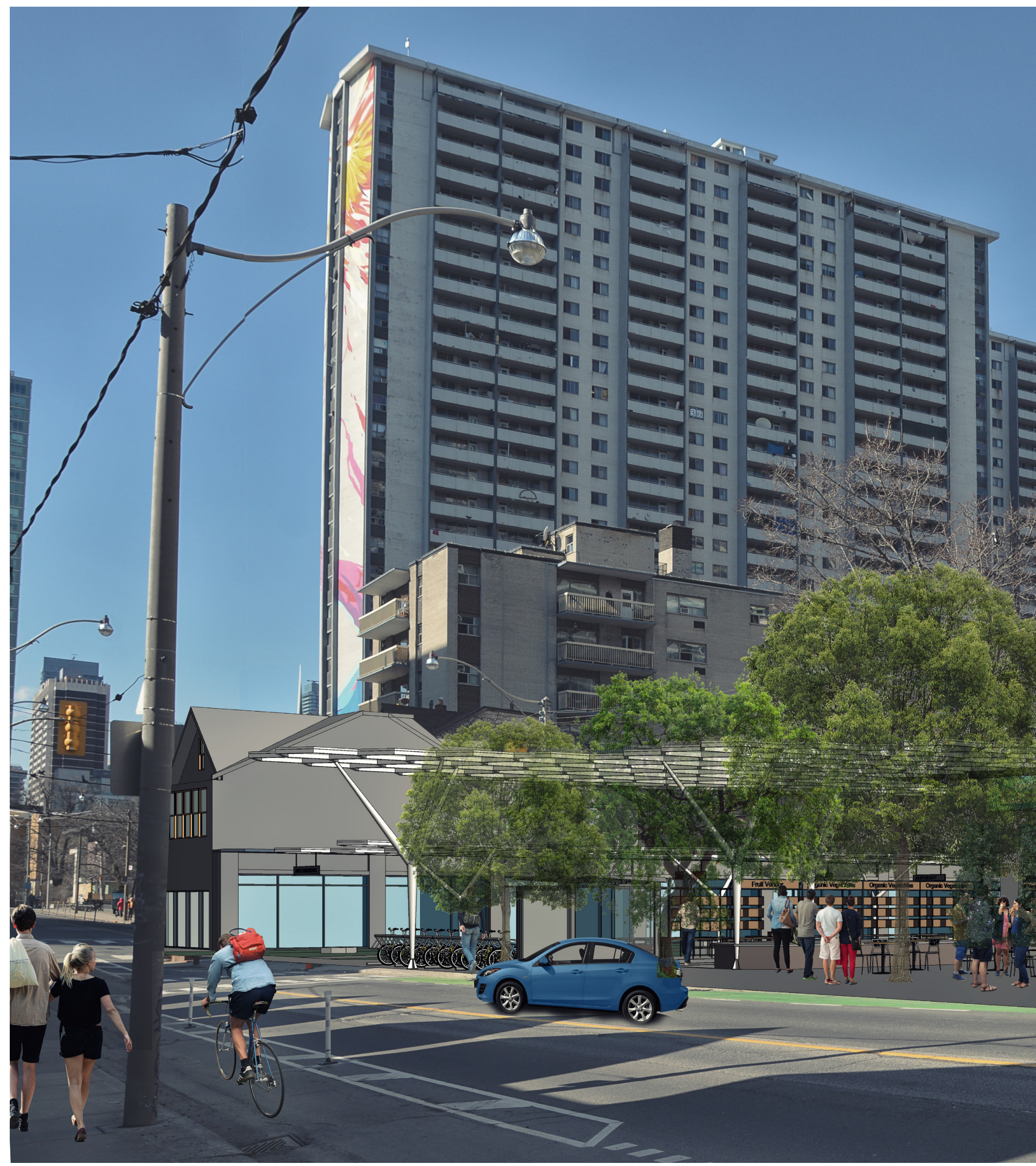

FIGURE 118

View from Wellesley St. looking north-west 


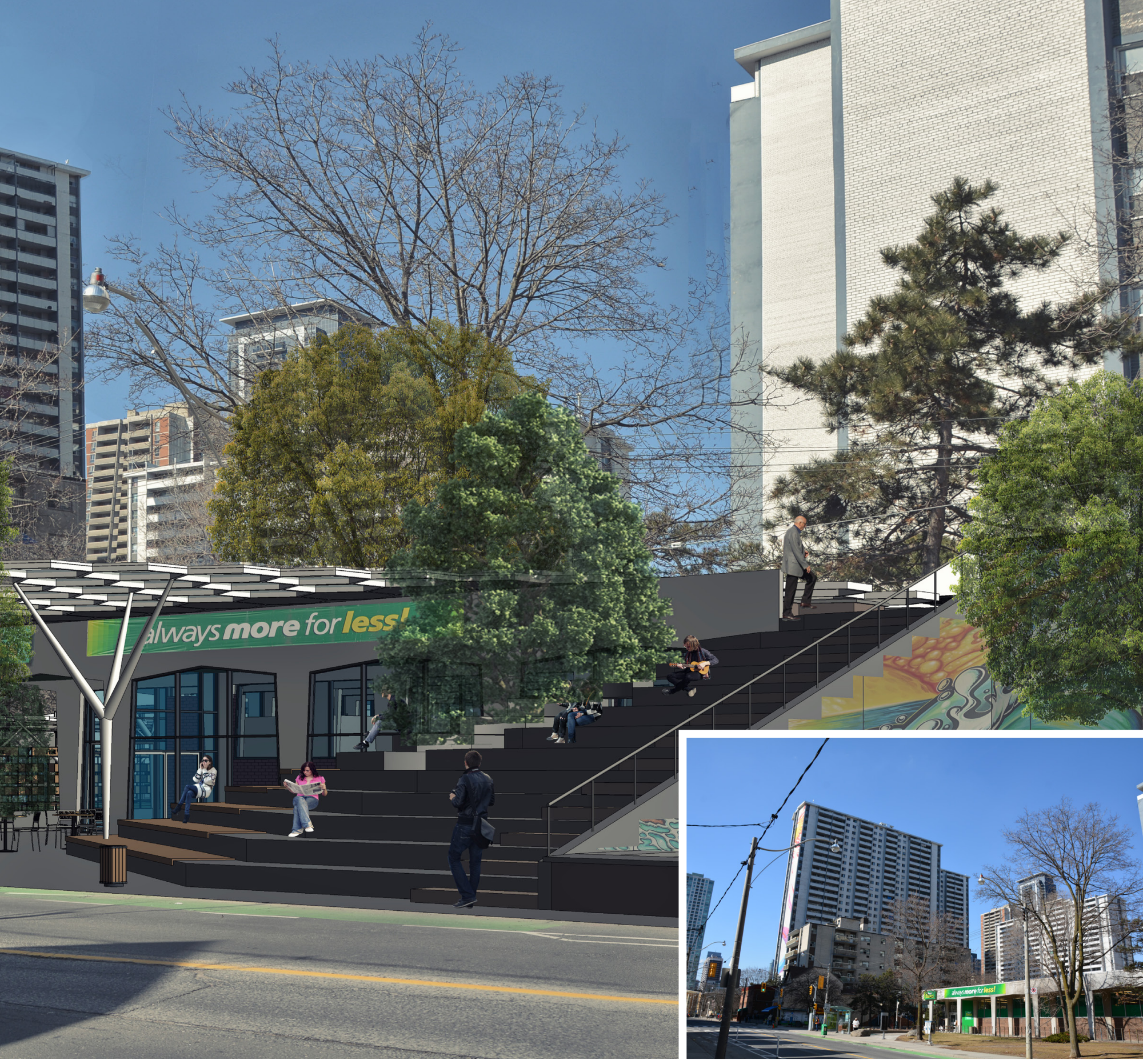

FIGURE 119

Existing conditions, looking north from Wellesley St. E. 


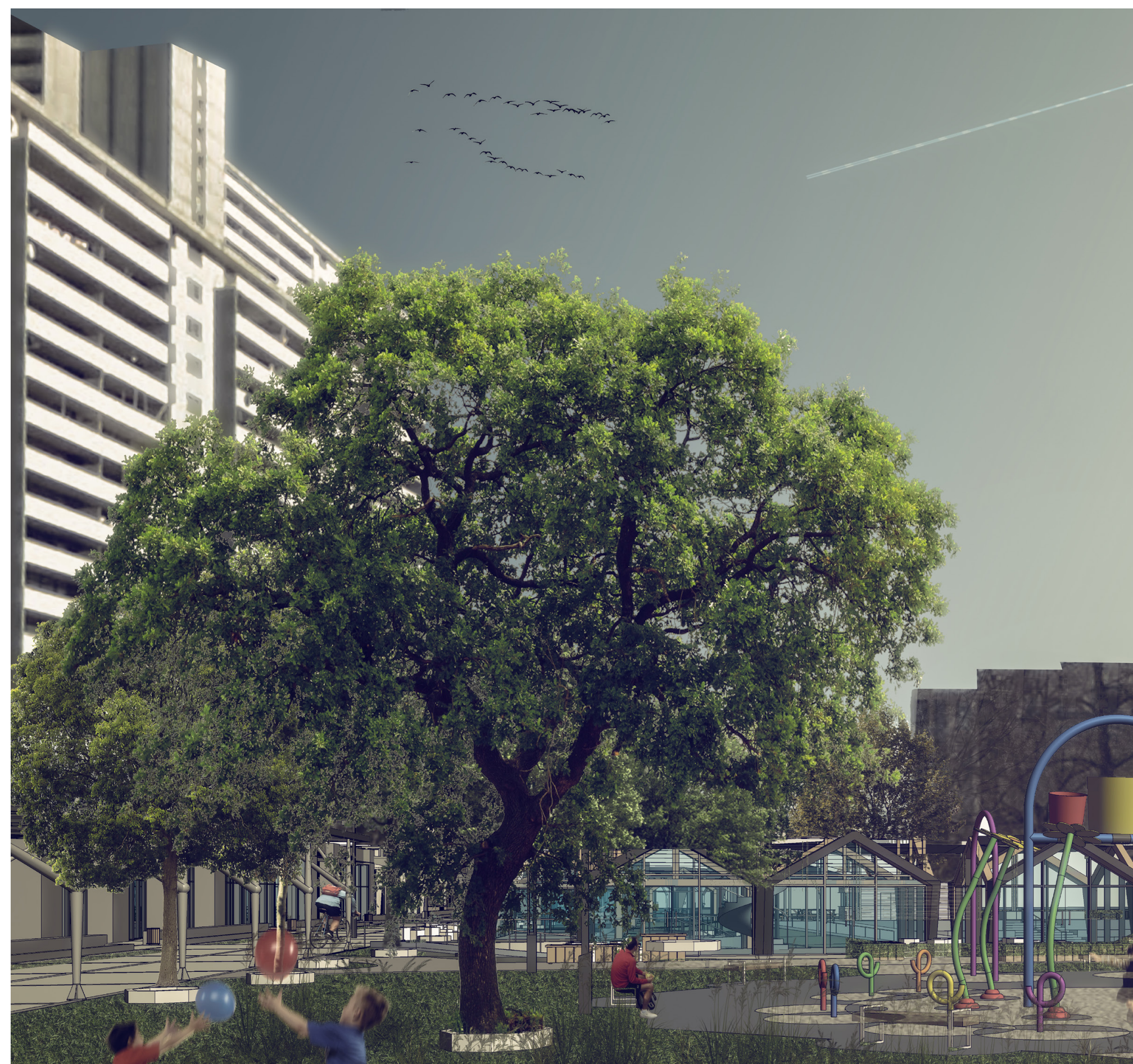

FIGURE 120

View from St. James Avenue looking south 


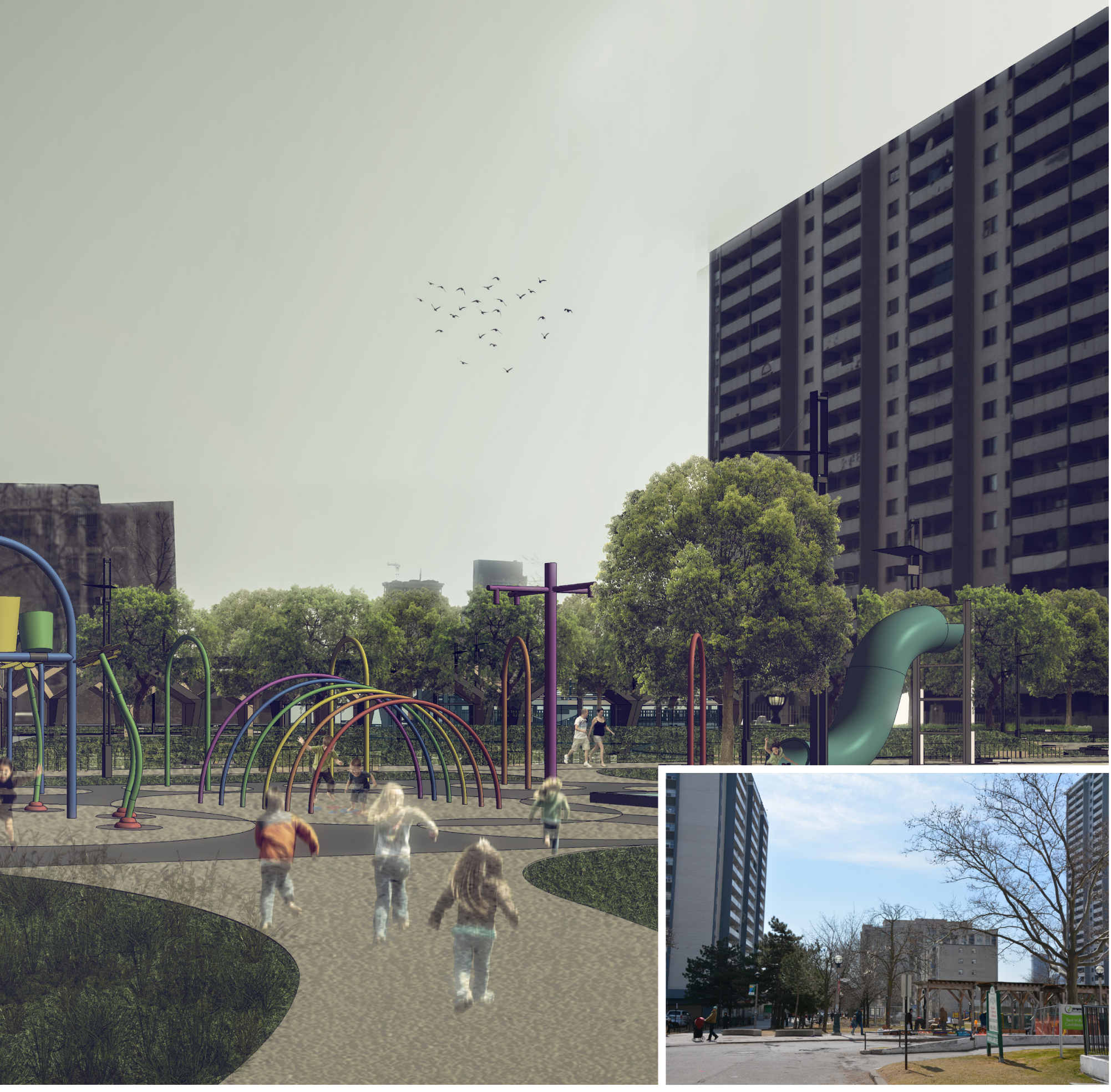

FIGURE 121

Existing conditions, looking south from St. James Avenue 


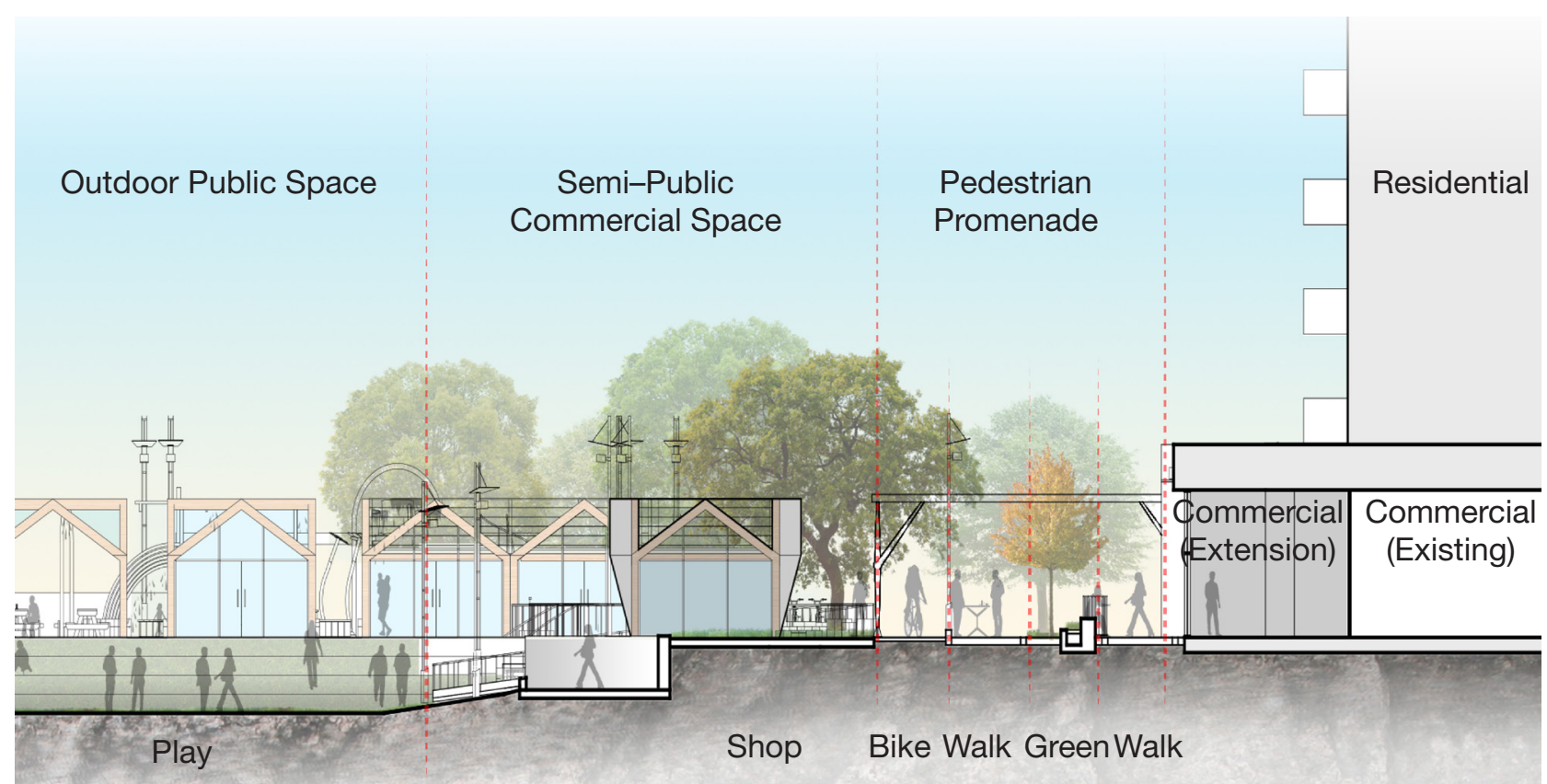

FIGURE 122

Public gradient section through the Ontario Street Pedestrian Promenade (OSPP)

\subsection{THE ONTARIO STREET PEDESTRIAN PROMENADE AND COMMERCIAL HUB}

Through an in-depth site analysis and numerous site visits, it is clear that one of the most fundamental challenges facing this urban space is creating reasons for people to stop. No matter the day of the week or time of day, the existing park was always bursting with life; however, there aren't enough reasons for people to stay. The numerous pedestrians that were using the space were merely just passing through. What's notable is that the majority of times when people did decide to stop while passing through the park was to visit the pedestrian market. This identifies both a pragmatic and design solution to getting people to stop within the park. The challenge lies in creating this effect all year round. While St. James Town was designed as a walkable community, the seasonal stagnation of it public realm does little to facilitate circulation beyond the Ontario Street Pedestrian Promenade.
In order to draw people into the centre of the St. James Town Common, the Ontario Street Pedestrian Promenade needs to be addressed, in addition to the storefronts which line it. The current commercial spaces north of the Food Basics are recessed back from the fairly busy circulation path, further diminishing their already-minimal street presence. Through introducing a civic park with strategically-placed vendors, in addition to redesigning the pedestrian promenade and realigning these storefronts with the edge of the promenade, the intention is to revitalize the public realm, and thus, the spirit of place (Figure 123 to 125).

When walking along Wellesley Street, pedestrians would first notice a large canopy structure, comprised of a hexagonal structure being 


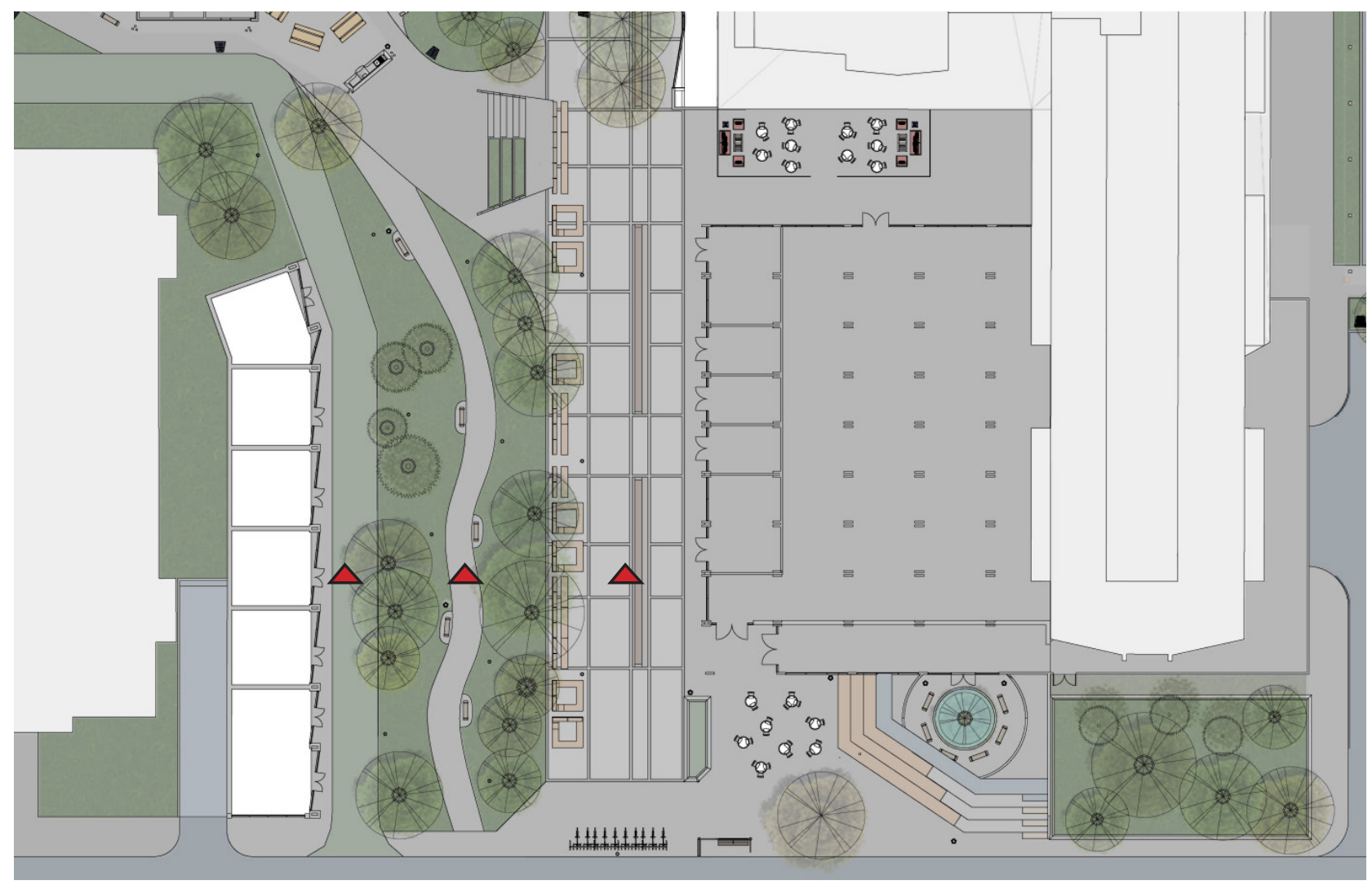

\section{FIGURE 123}

Ground plan highlighting mico-business vendors and cafe

supported by tree-like columns (Figure 118). This canopy projects out to engage the sidewalk, drawing the passersby into the park. Upon entering the common, users can elect to walk down one of three primary circulation paths. The first is along the hardscaped promenade (Figure 128). It is divided into a bike path, a commercial artery to allow existing merchants to continue to operate, a vegetation strip with bench seating, and the main walking path along the storefronts. The second walks down a trail whose path is dictated by the location of existing trees. The canopy overhead responds to the tree canopy, filling the voids between them. (Figure 130). The third lies along the renovated storefronts, where the canopy creates an arcade space over a former service road. The asphalt was replaced by a permeable paver that allows vegetation to grow in between, while still functioning as a service road when needed. The storefronts that were added adjacent to the service lane have a canted exterior wall, creating a colourful tab that acts as a means of way-finding and branding. (Figure 132). Together, these three paths function as anchors to draw pedestrians into the park and drive commercial activity (Figure 134).

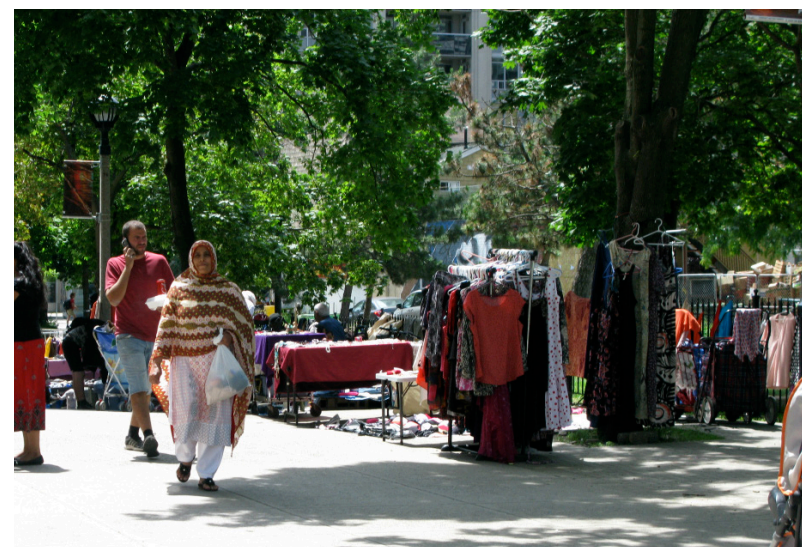

FIGURE 124

Existing conditions pedestrian promenade, August 2018 


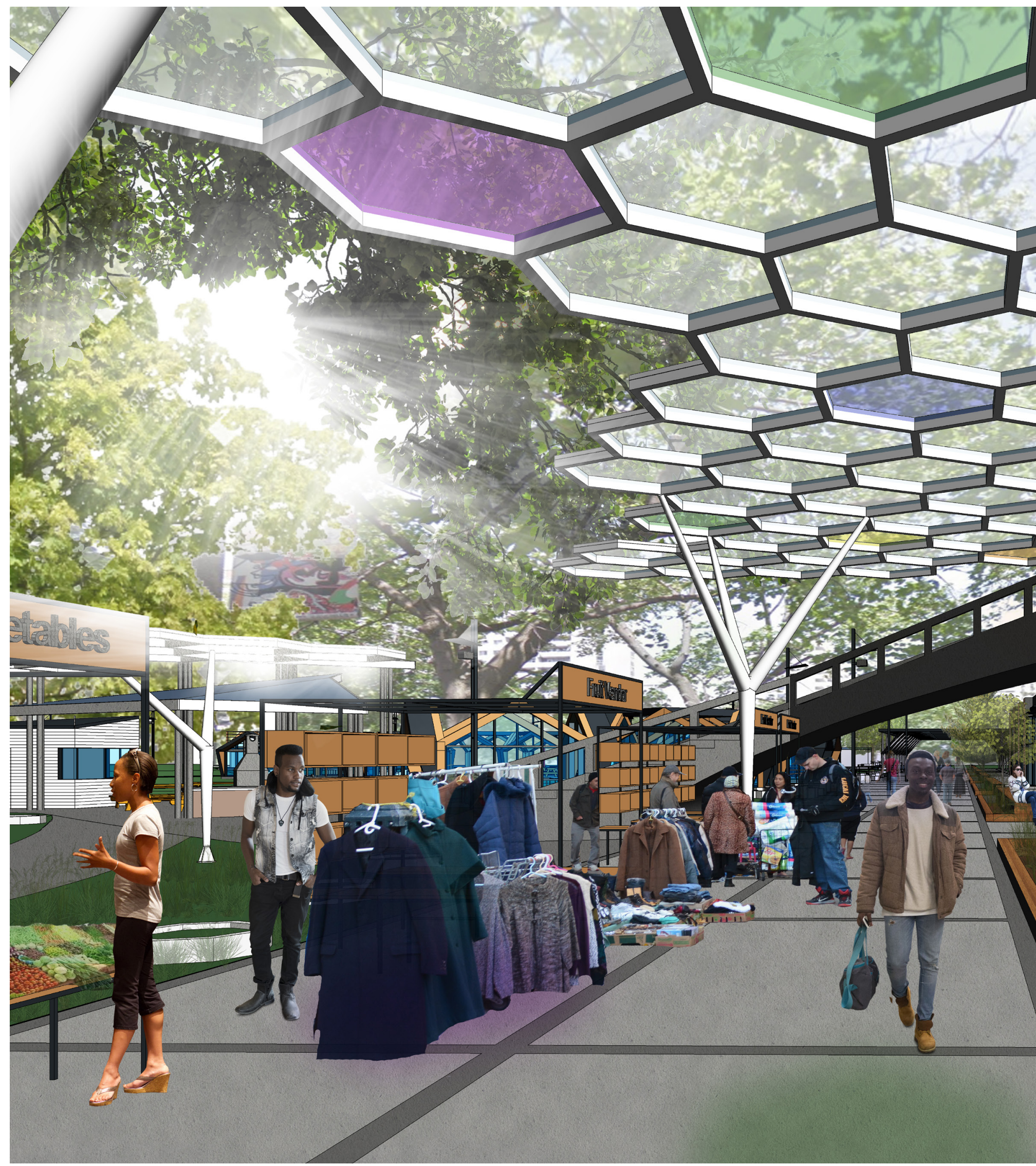

FIGURE 125

A perspectives looking north from the Ontario Street Pedestrian Promenade 


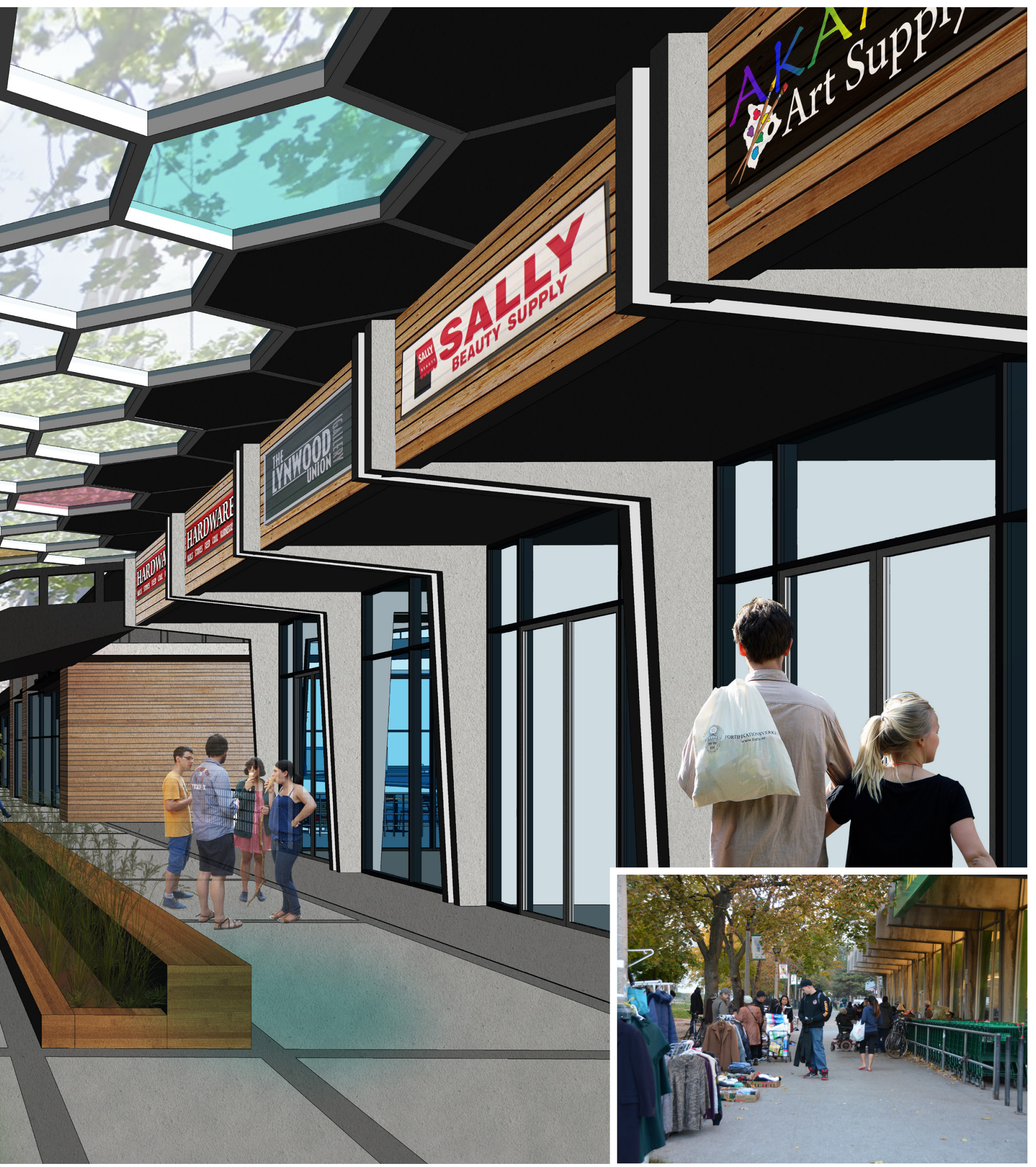

FIGURE 126

Existing conditions, looking north from the Ontario Street Pedestrian Promenade 


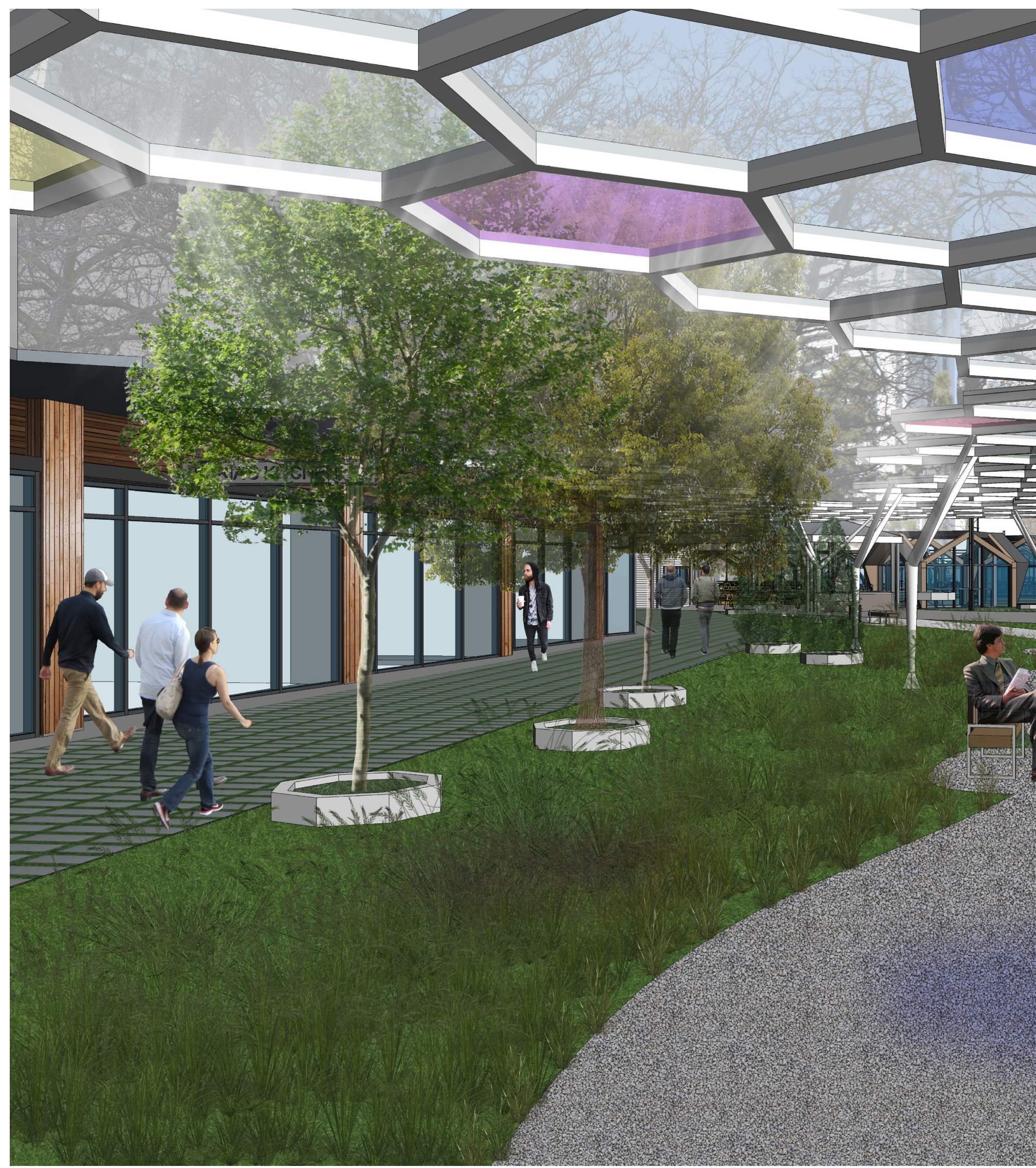

FIGURE 127

A perspective looking north from the vegetated forecourt and covered pathway 


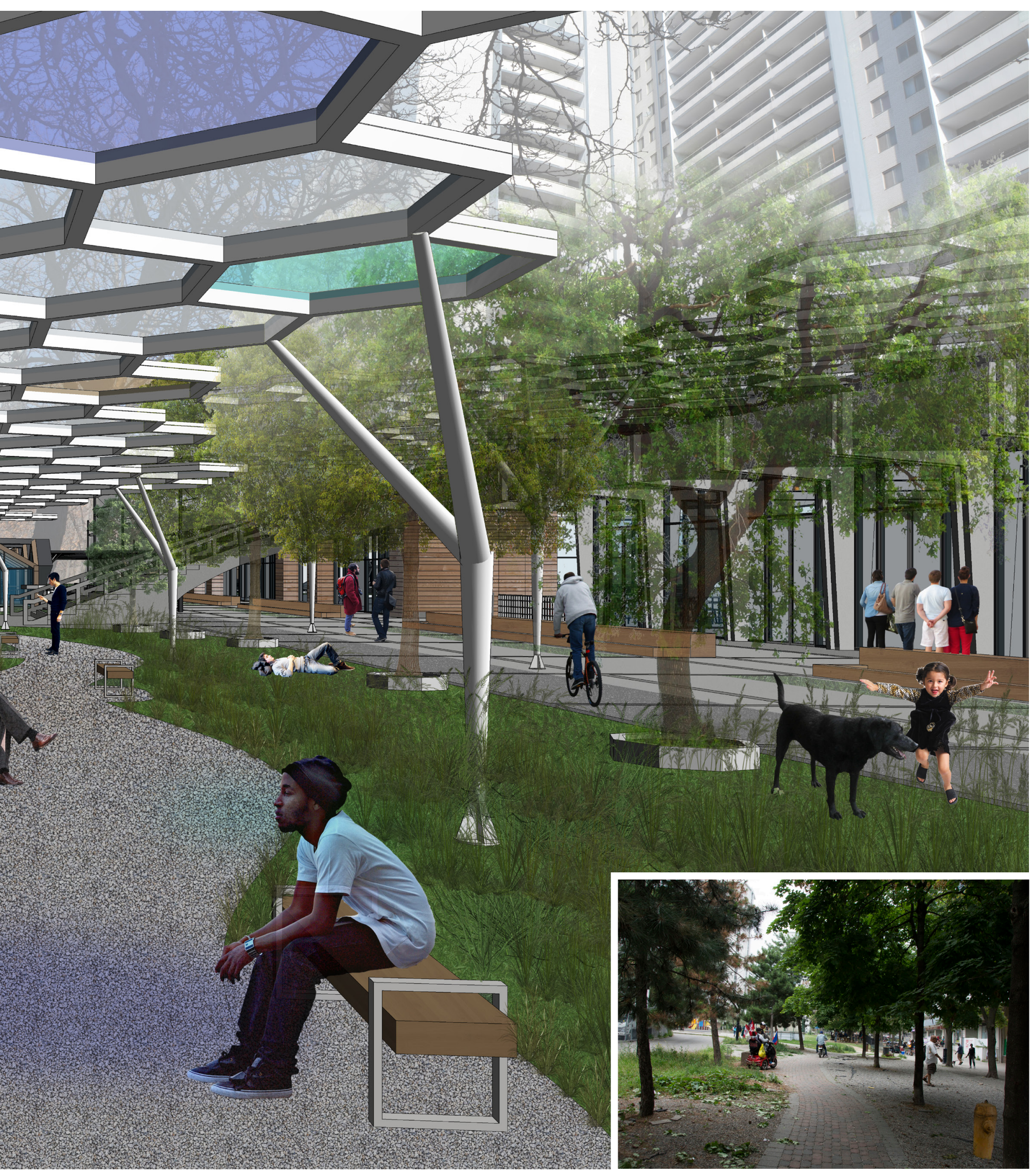

FIGURE 128

Existing conditions, looking north from the the vegetated forecourt 


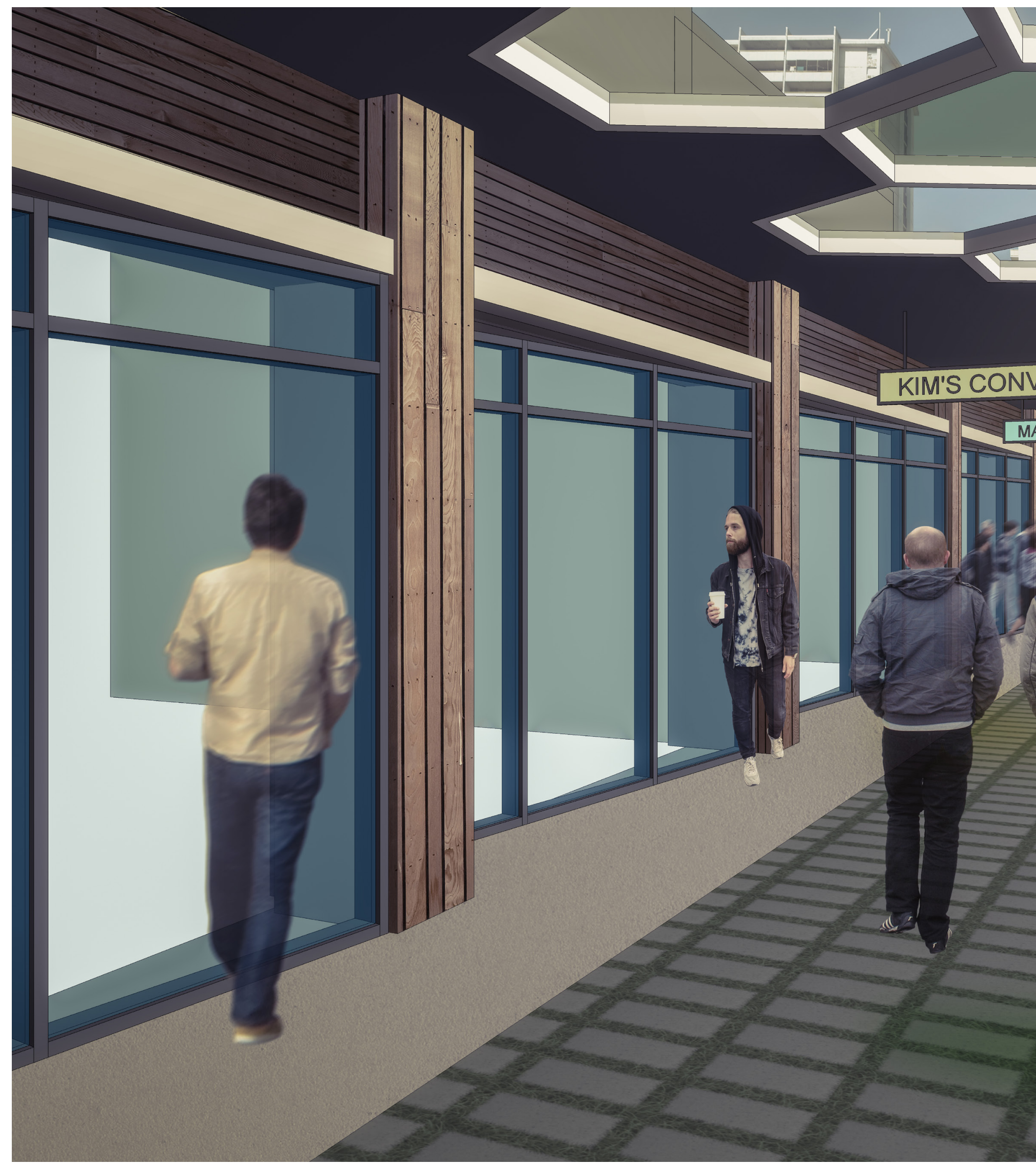

FIGURE 129

A perspective looking north from the revitalized storefronts 


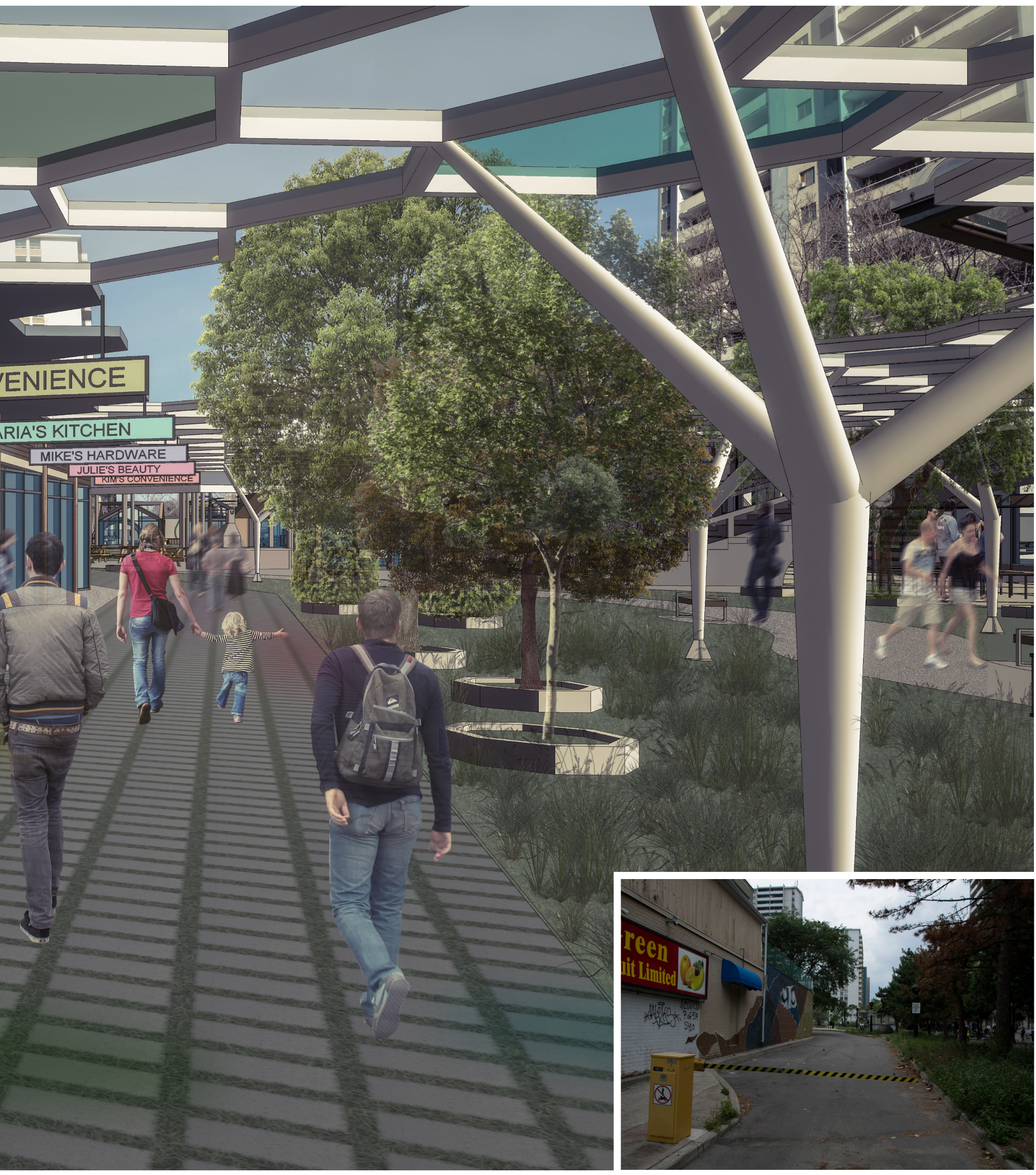

FIGURE 130

Existing conditions, looking north from the service road 


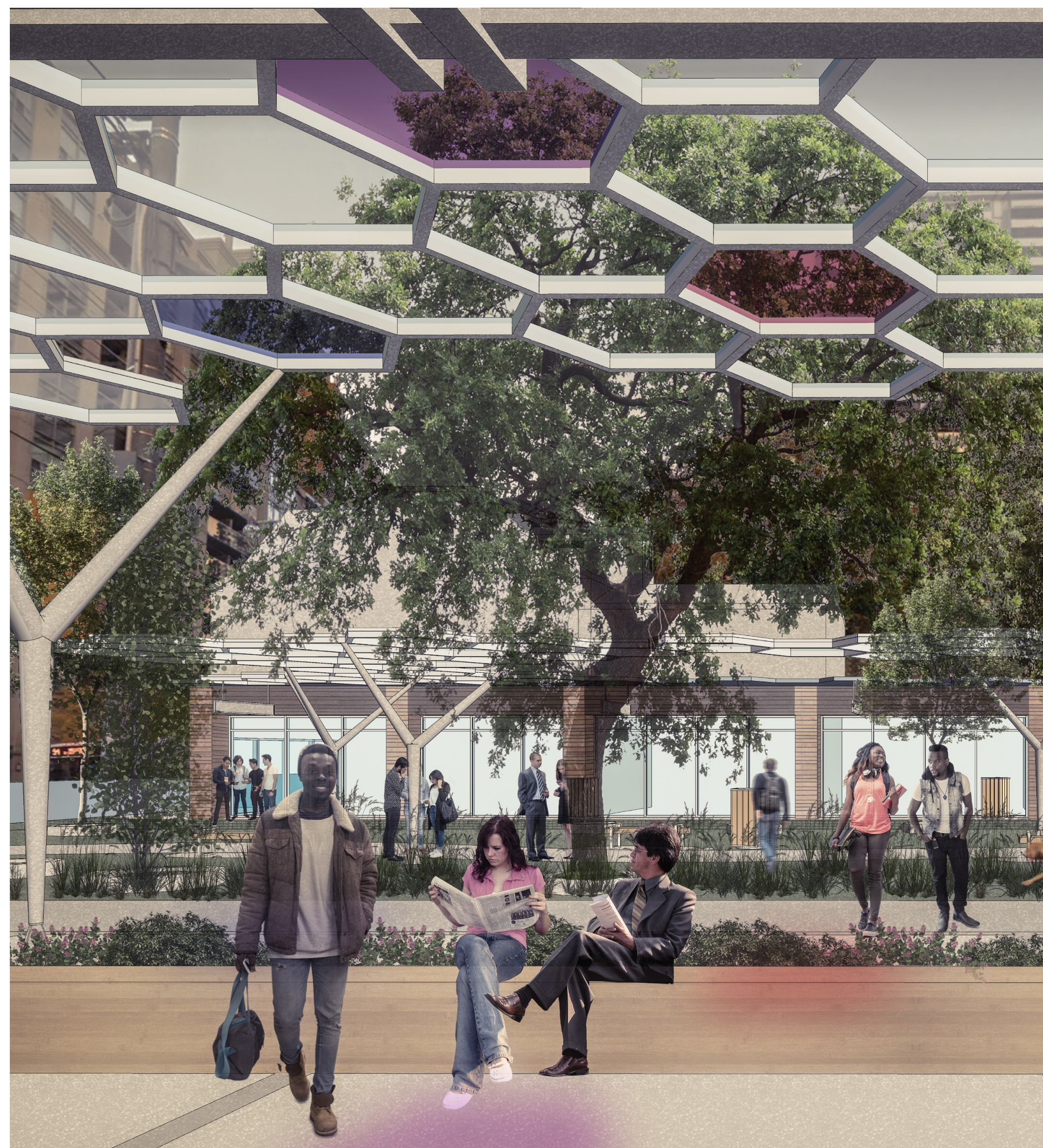

FIGURE 131

A perspective looking west from the Food Basics looking towards the renovated storefronts 


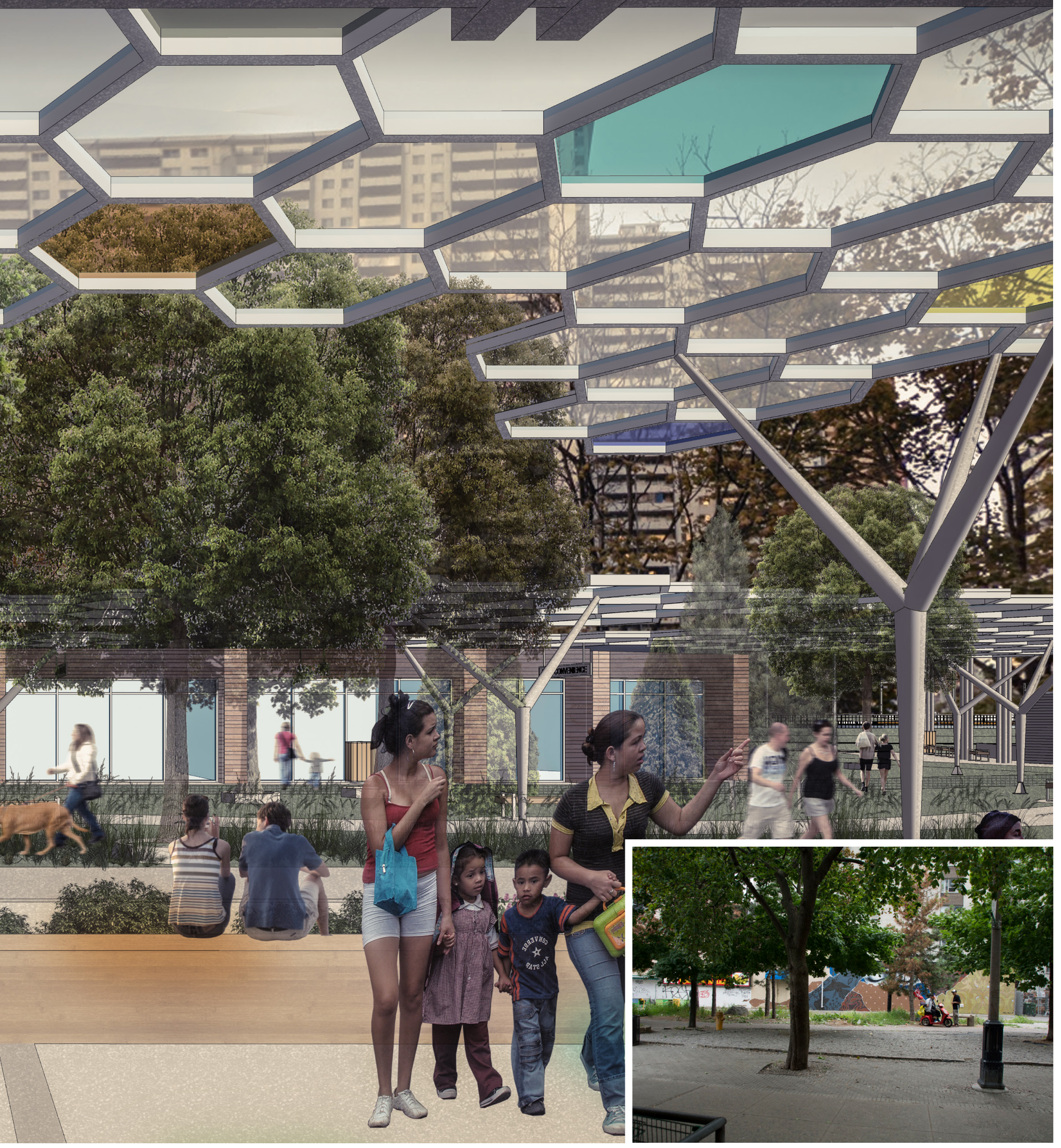

FIGURE 132

Existing conditions, looking west from the Food Basics 
The design of the market stalls focuses on facilitating community initiatives and commercial activities. They were designed to function in all weather conditions and are situated under the hexagonal canopy, extending the limited duration of the existing flea market to function all year round. The temporary market stalls are allocated for the existing merchants who currently form the flea market, and are located outside of the Food Basics. The single module has an area of 3 square metres and the double vendor is 6 square metres.

While the small market stalls serve the smallscale needs of individuals or groups beginning their commercial endeavours, larger vendors were also designed for more established commercial vendors. The single module vendor has an area of 30 square metres and the double module vendor has an area of 60 square meters. A consistent design aesthetic was utilized for their design, as well as a similar strategy was applied to the design of sheltered pavilions and the emergency exits from the existing parking garage below grade.

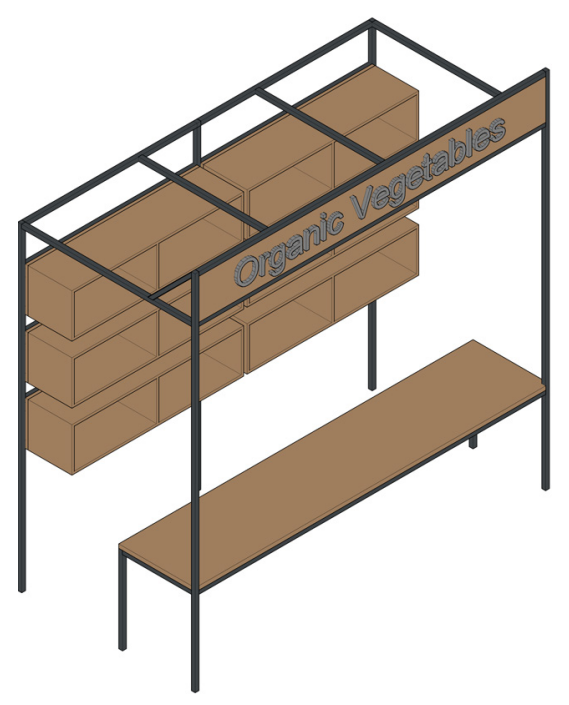

FIGURE 133

Single-module market stall
The intention is that all of these vendors will be operated through The St. James Town Community Corner (SJTCC), which provides the community with a fully-accessible set of offices, meeting spaces, program rooms, and community kitchen - all dedicated to local initiatives and services to benefit the neighborhood. It is a collaboration between residents, public and private funders, and service providers.

Community initiatives and public services are currently fundamental to the daily operation of the residents of St. James Town. As a result, individual vendors will have designated spaces for community initiatives to further supplement programs like the St. James Town Community Corner, which is in the adjacent tower to the West. The commercial spaces provided can triple the current operating capacity of the Community Corner, furthering the community outreach program's impact. As the land upon which this design is built is owned by the Toronto Community Housing Corporation, commercial activities are intended to be rooted in community initiatives and social justice.

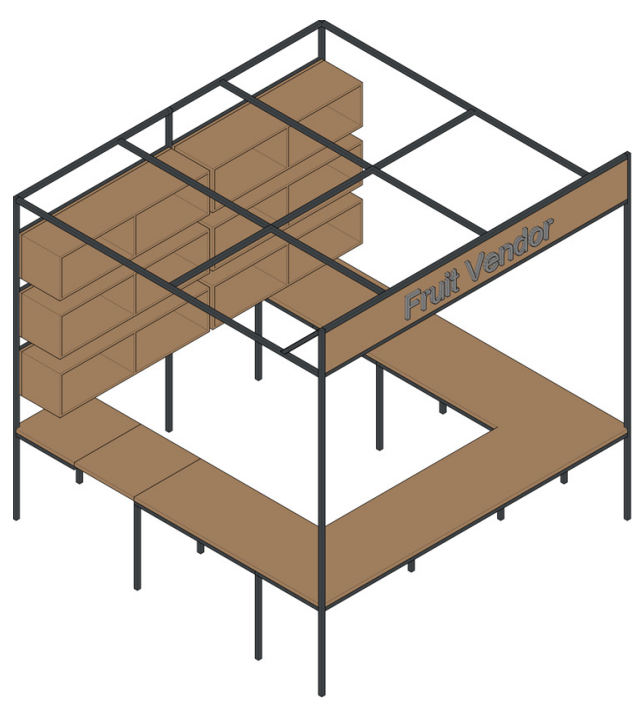

FIGURE 134

Double-module market stall 
After moving north through the first portion of the park, users are directed towards a large pavilion structure. The two levels of the pavilions' roof shelters an outdoor community kitchen as well as a snack shop and washroom structure. Ample seating is provided, overlooking the sunken meadows and wetlands below, which descends down just above the underground parking garage. In the middle, the pathway is cut out, leaving an opening for two trees, referencing the meaning of Toronto, in both the original Mohawk definition of: "where there are trees standing in the water," and its later interpretation as a "gathering place." The winding paths down to the lowest point are transformed in the winter time to become a skating loop, with the northern-sloped grassland functioning as a perfect hill for tobogganing. Following the pathway to the north or west, a series of interactive playgrounds are perched on top of large berms. These playgrounds are designed to be an extension of the landscape they rest upon, with the ground plane functioning as an additional stratified layer of play.

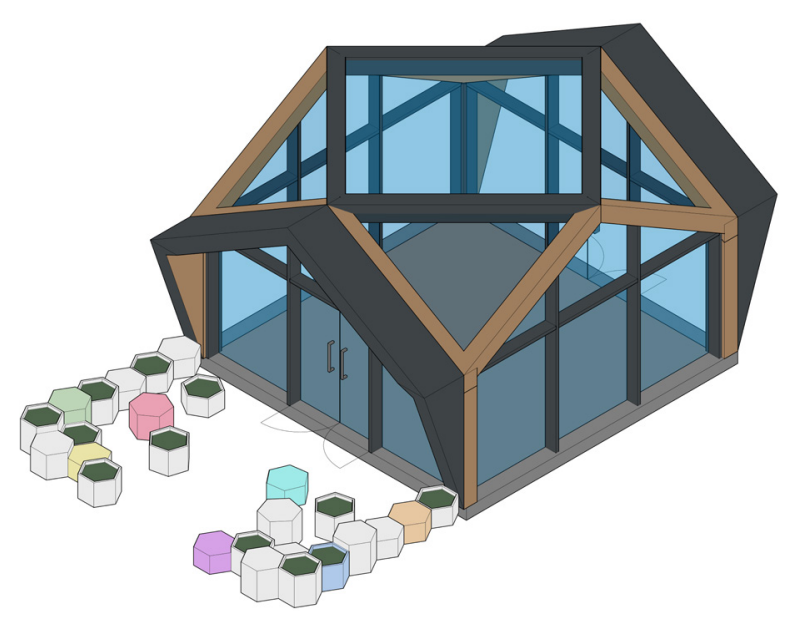

FIGURE 135

Single-module vendor with movable seats/planters

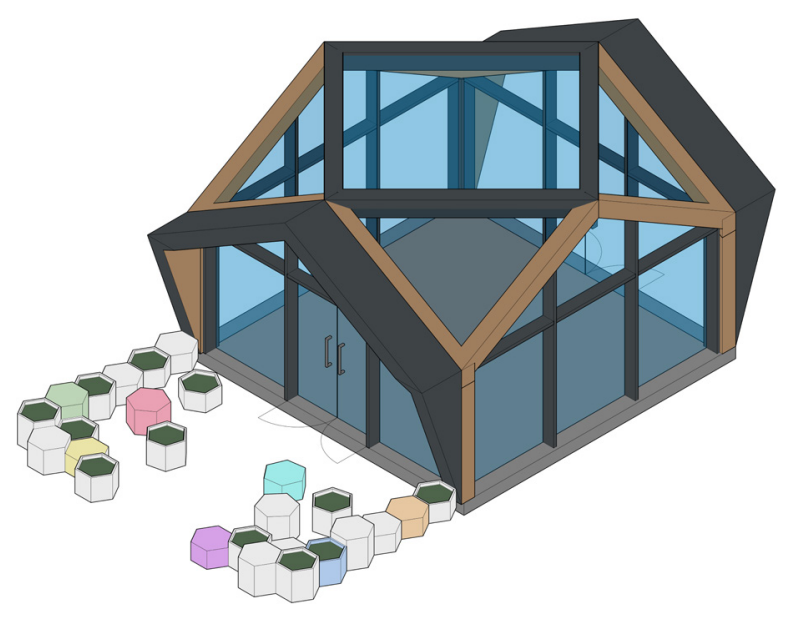

FIGURE 136

Parking lot emergency exit pavilon

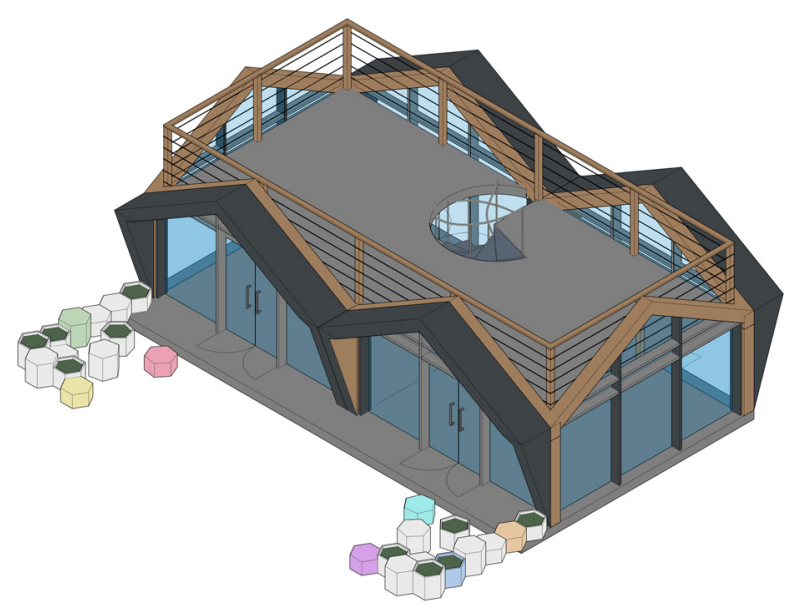

FIGURE 137

Double-module vendor with second storey outdoor space and movable seats/planters

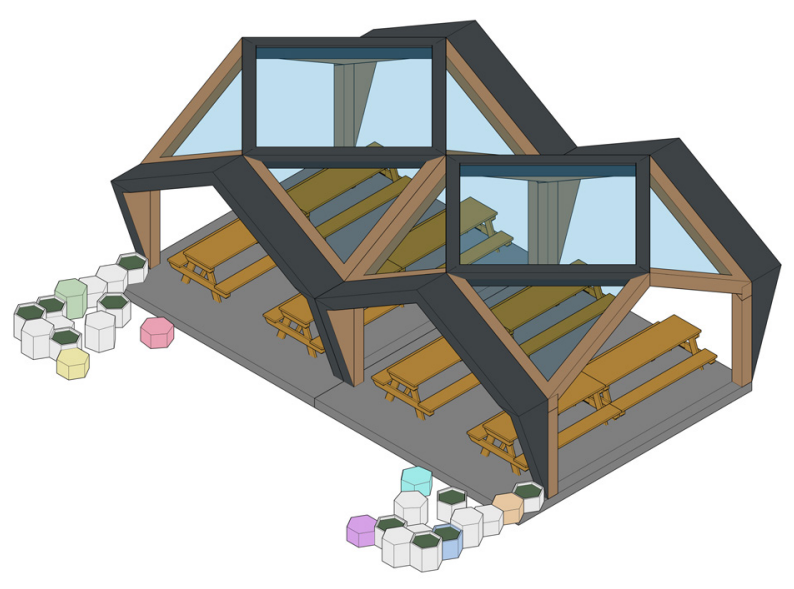

FIGURE 138

Double-module outdoor seating pavilion with movable seats/planters 


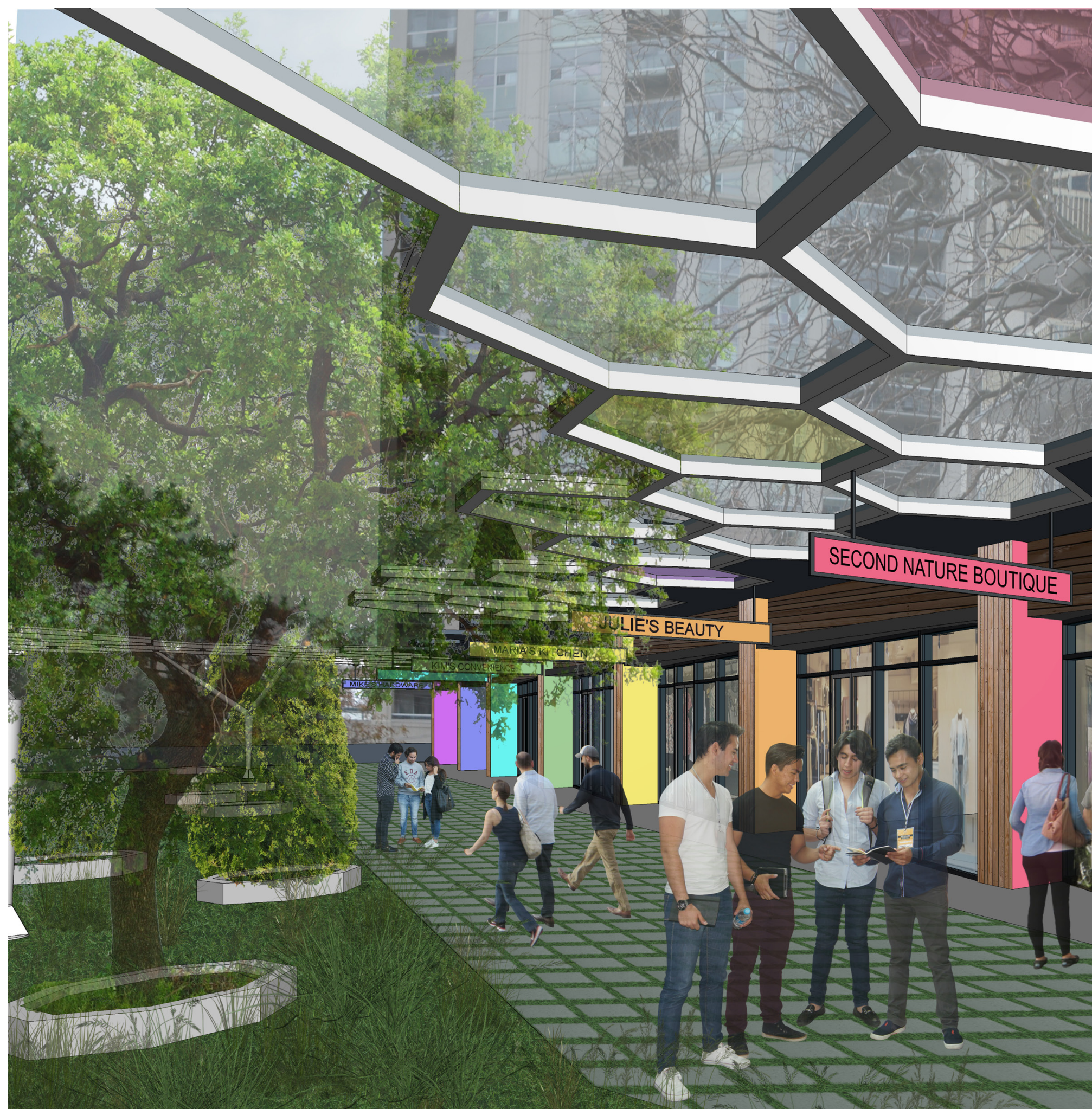

FIGURE 129

A perspective looking south from the service road towards the renovated storefronts 


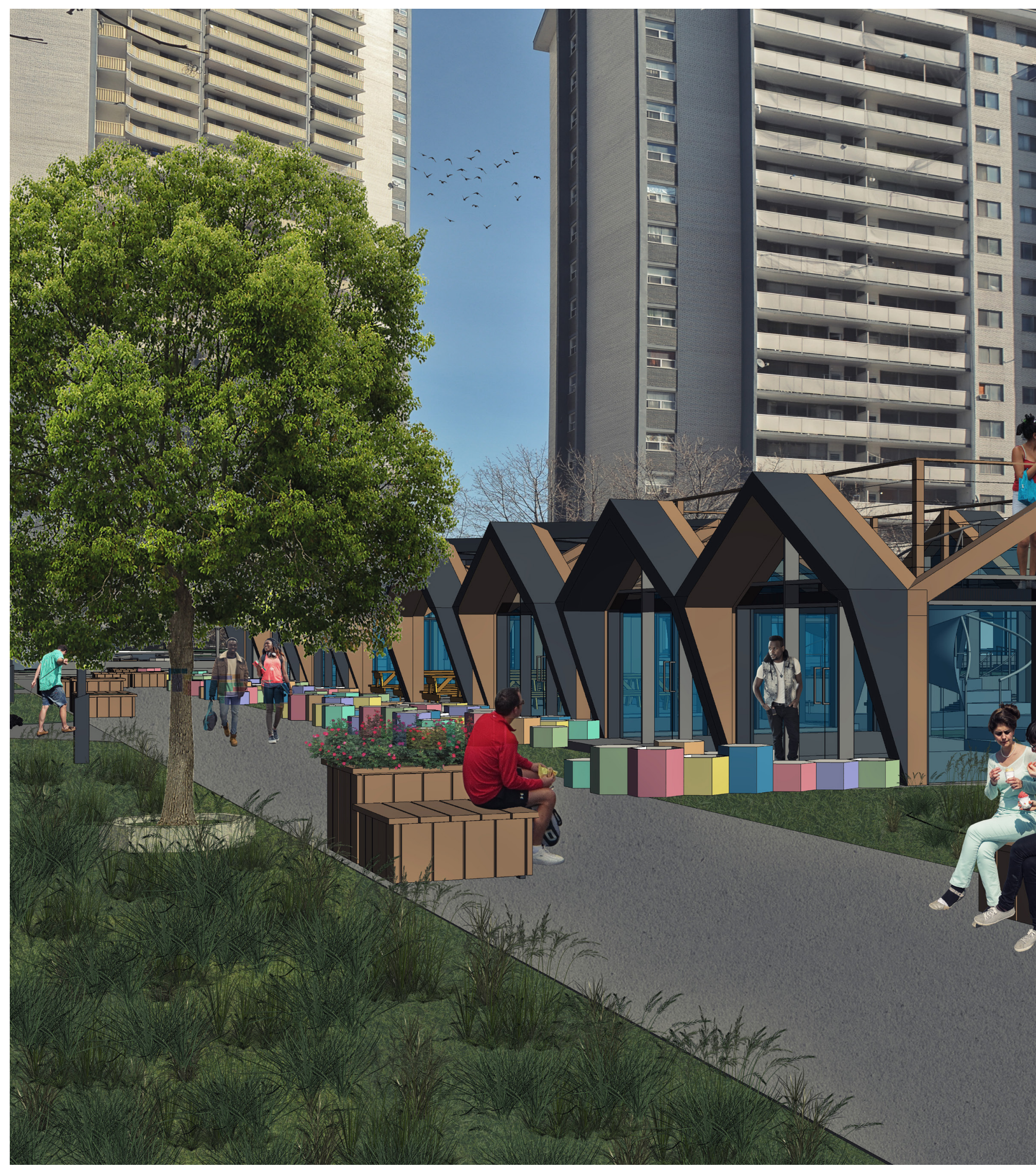

FIGURE 131

A perspective looking east along the new retail corridor, just north of the recreational field 


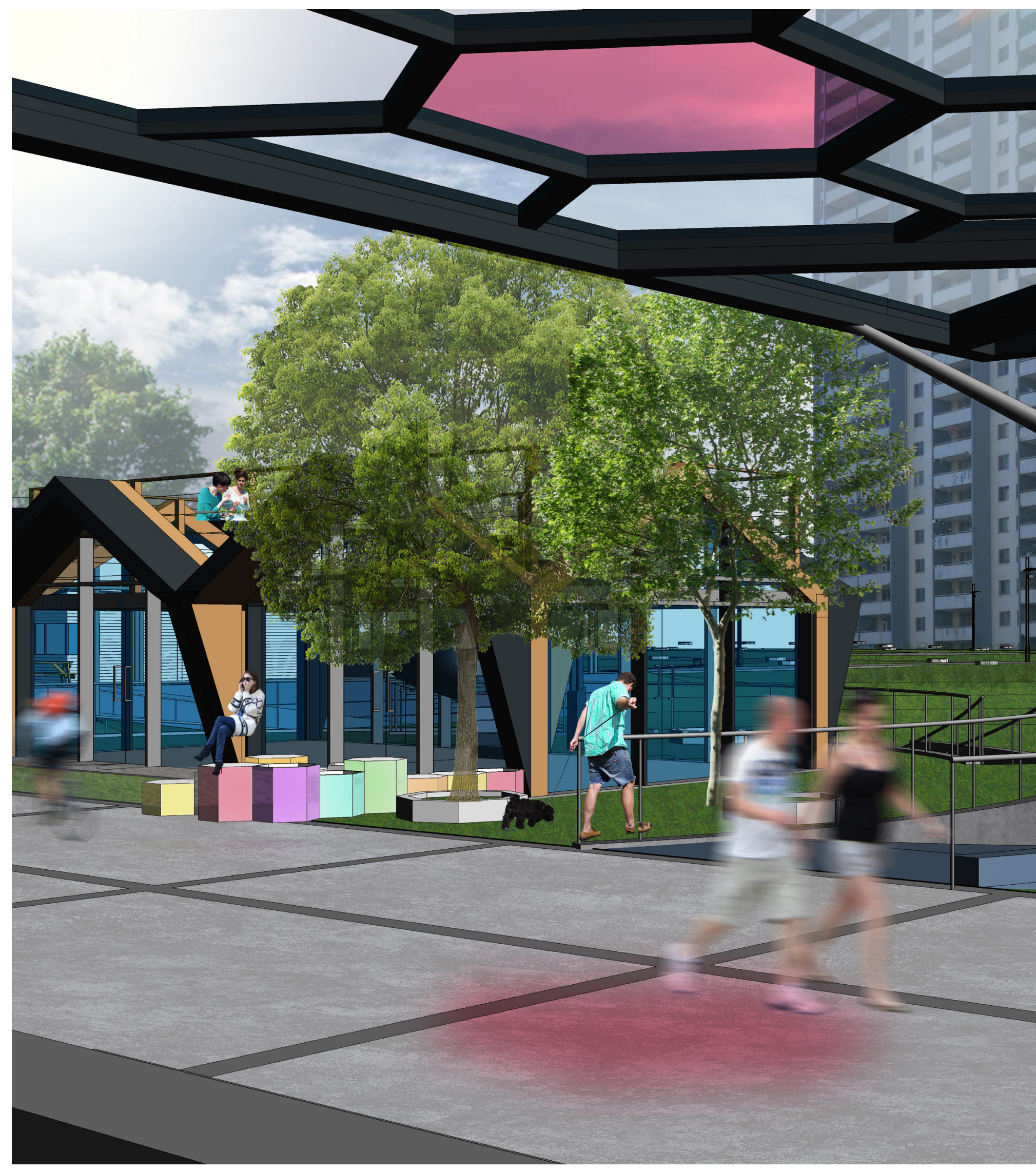

FIGURE 143

A perspective looking south-west, towards the new vendors with the recreational field in beyond 


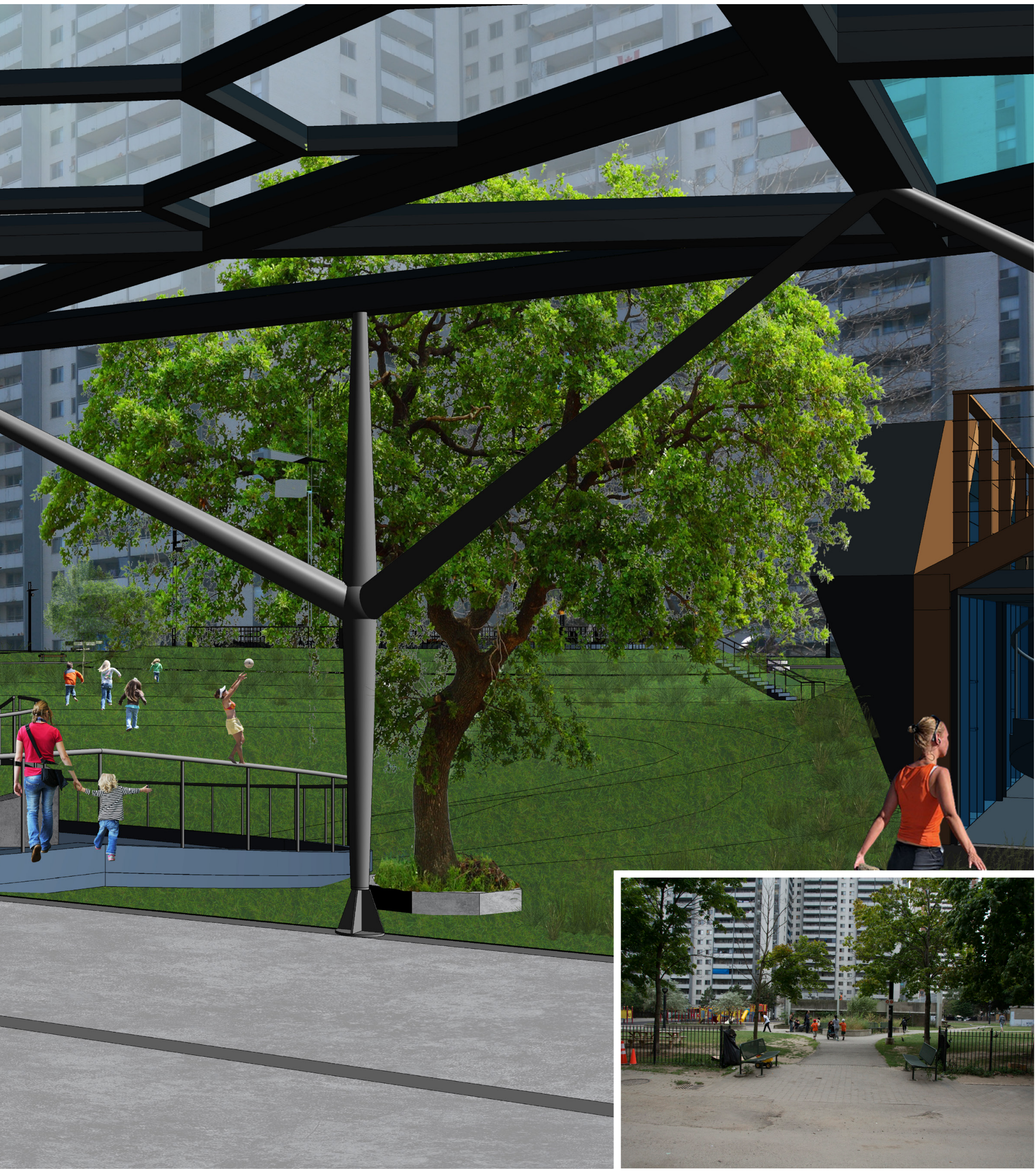

FIGURE 144

Existing conditions, looking south-west, towards the pool 


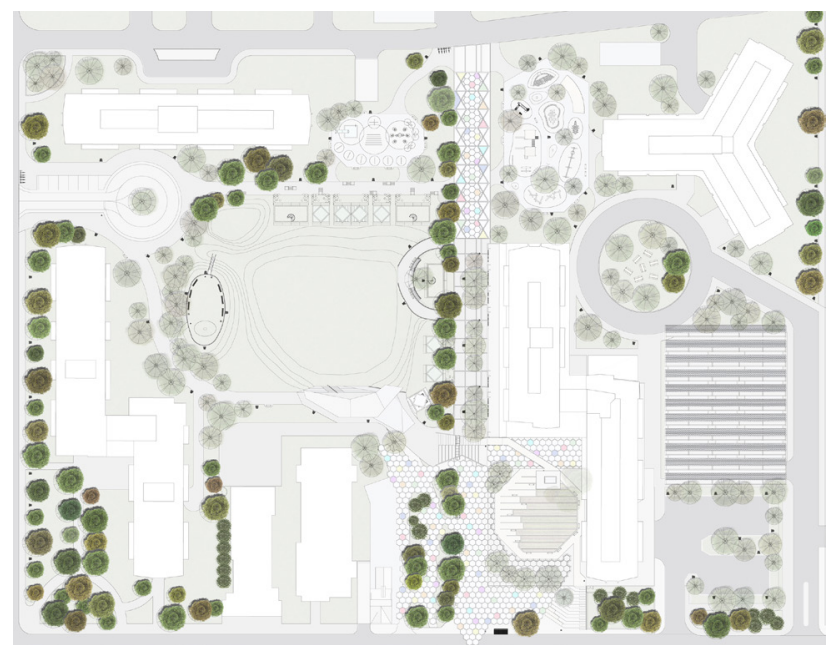

FIGURE 145

Existing Trees

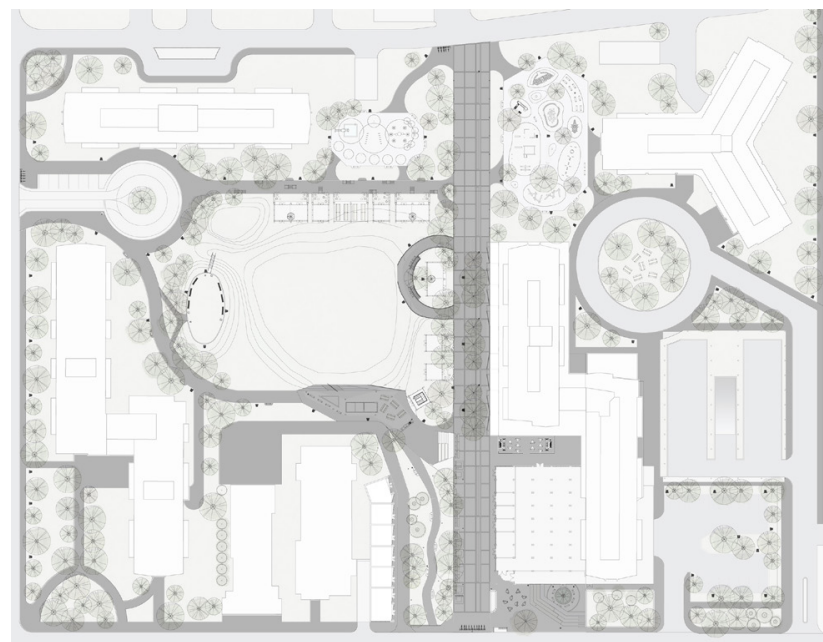

FIGURE 147

Pathways

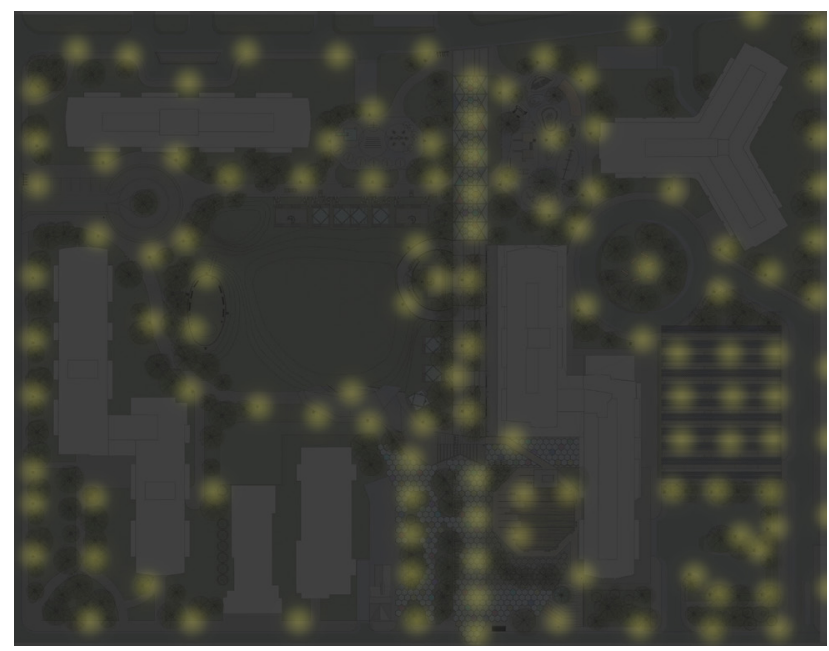

FIGURE 149

Lighting

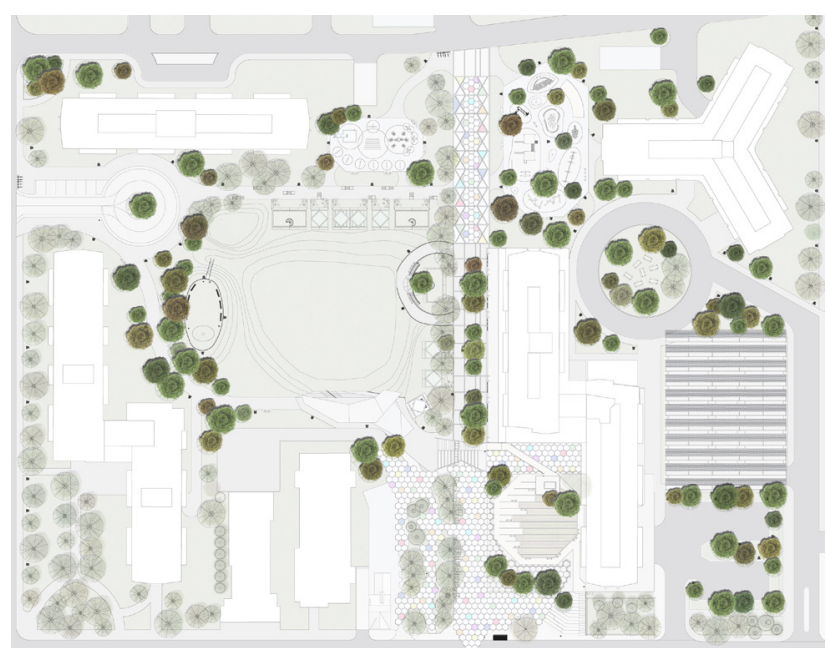

FIGURE 146

New Trees

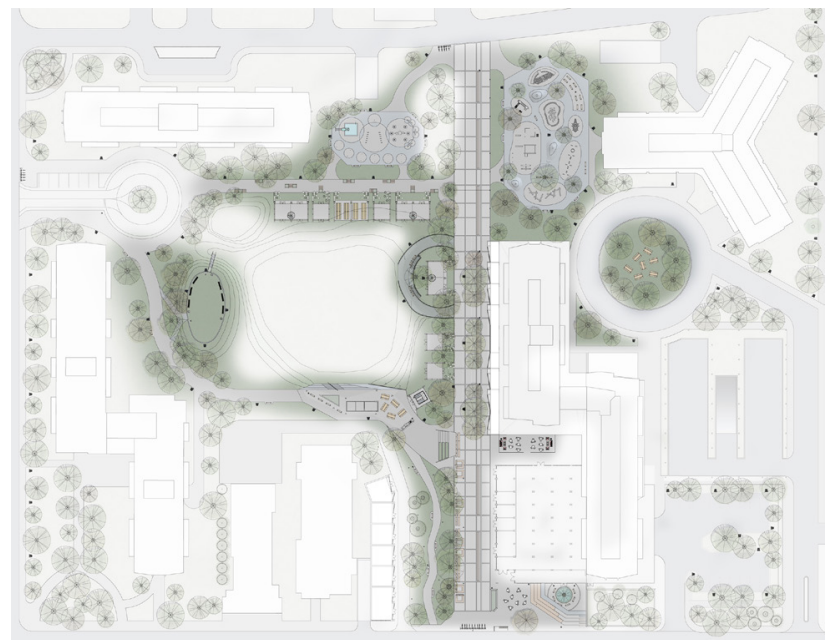

FIGURE 148

Furniture

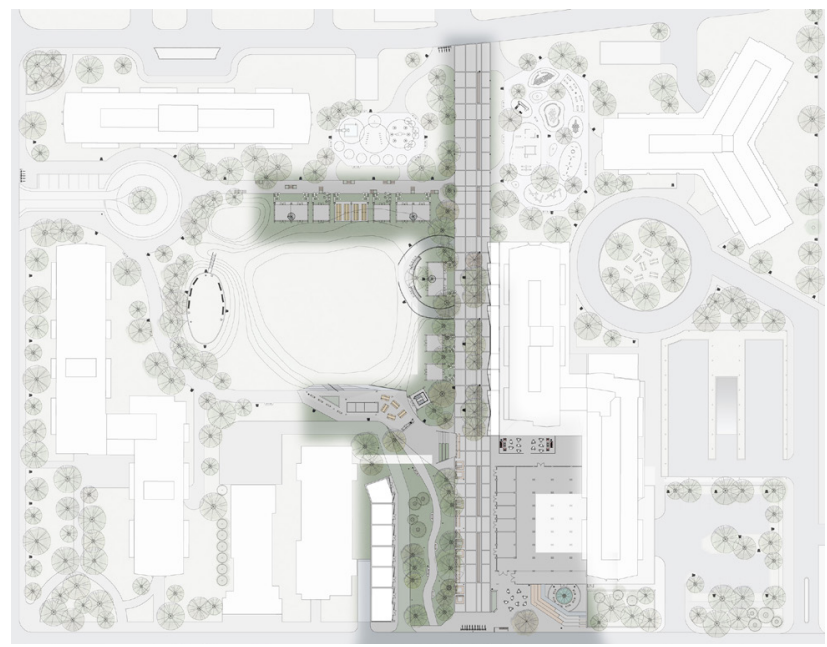

FIGURE 150

Vendors 
This series of mapping vignettes break down the site. Figure 144 highlights the existing trees. As this thesis is rooted in a biophilic design framework, all of the existing trees on the site were preserved. In addition to this, Figure 145 illustrates the additional vegetation added. Figure 146 shows the primary pathway networks that were designed to reinforce the primary north-south circulation spine, as well as additional secondary arteries. The parks extensive furniture is demarcated in Figure 147. These are most commonly bench fixtures, in addition to the picnic tables by the community kitchen and nestled within the roundabout in front of the Winnepeg tower. The addition of expressive solar-powered lights creates focal points along the path while improving the safety and security of the common at night, illustrated in Figure 148. Lastly, Figure 149 identifies the primary commercial hub in the common, lying most prominently along the Ontario Street Pedestrian Promenade in addition to the commercial corridor, which runs perpendicular to it.

Cutting through the promenade and adjacent spaces, the varying degree of public space can be seen (Figure 150). This creates a diverse collection of public and semi-public spaces in an attempt to establish a dynamic quality in the common. The public vs private divide is a concept this thesis constantly challenge. As a result, a commercial hub is established for the neighbourhood, augmenting the existing market. Facilitating a market that can function all year will provide a platform for residents to establish themselves, in addition to stimulating ancillary businesses in the region.

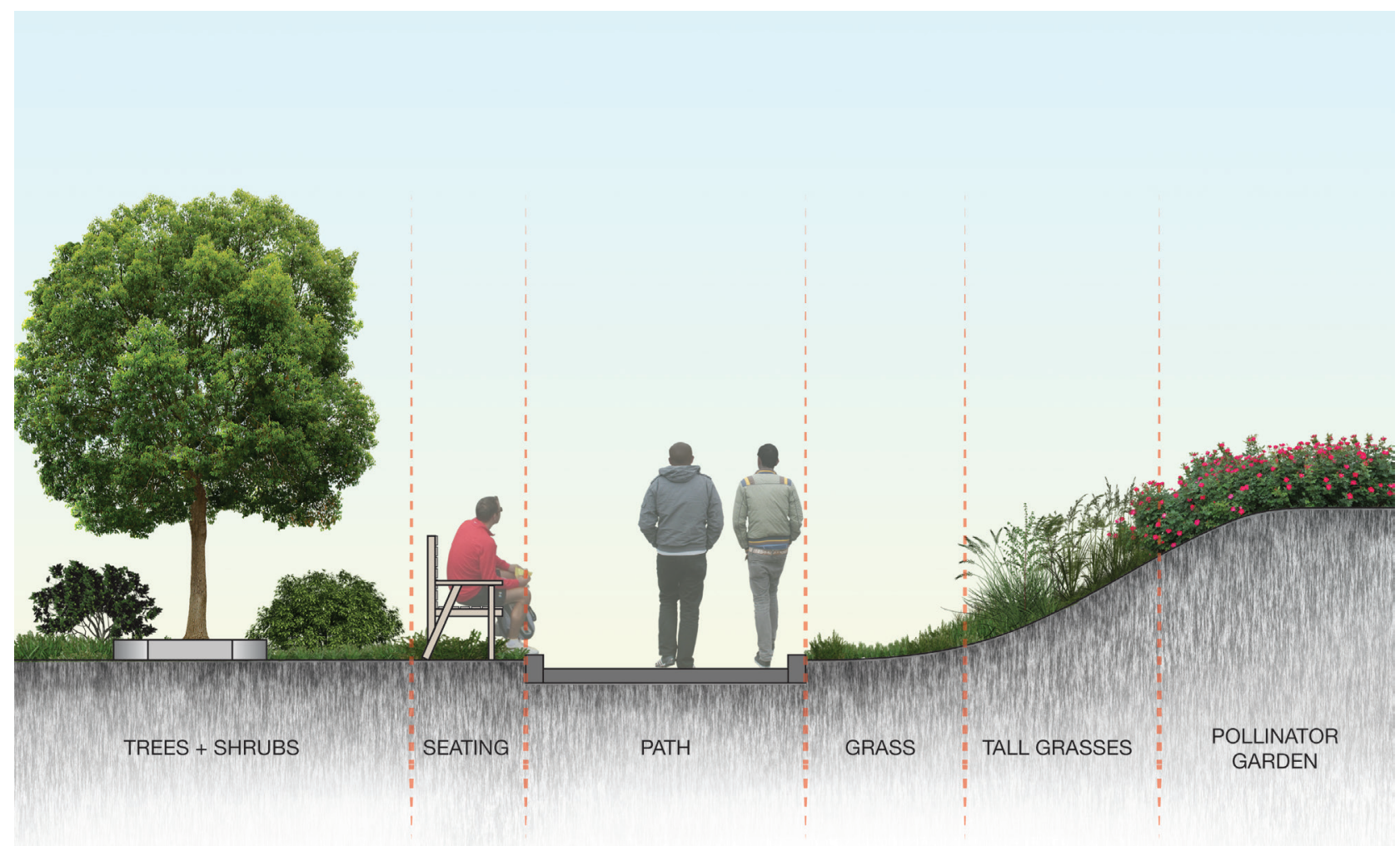

FIGURE 151

Typical section through pathway highlighting landscaping strategies 


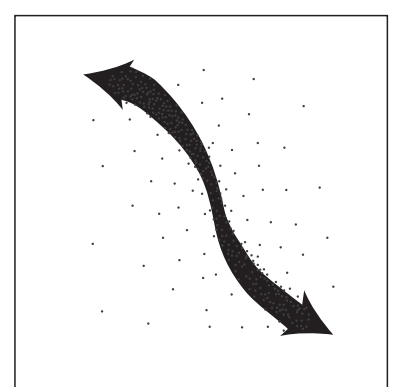

To Reduce

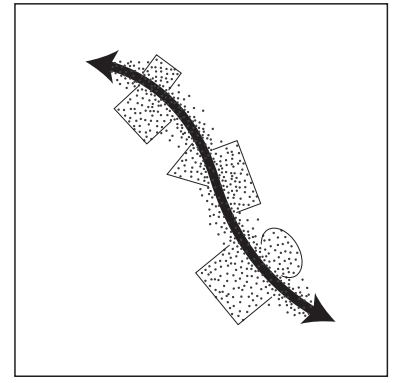

To Close In

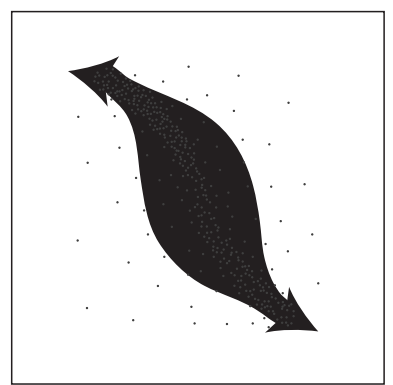

To Increase

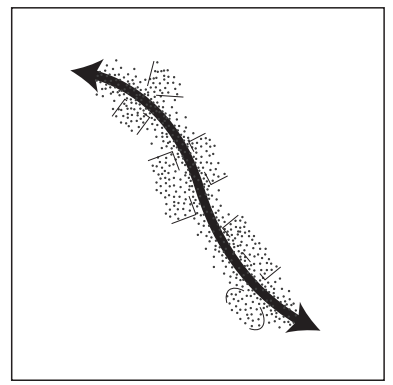

To Open Up

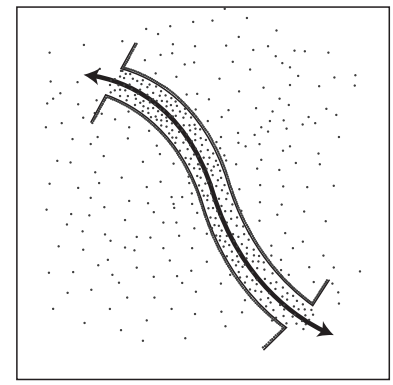

To Repel

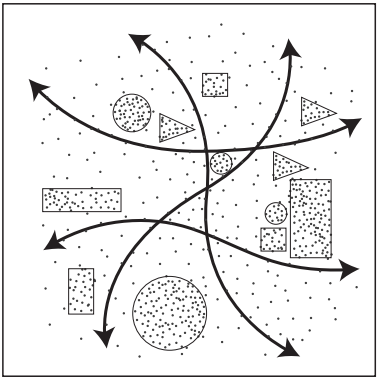

To Segregate

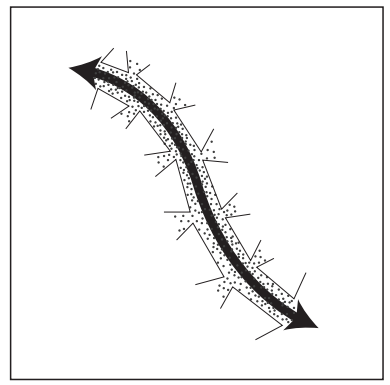

To Invite

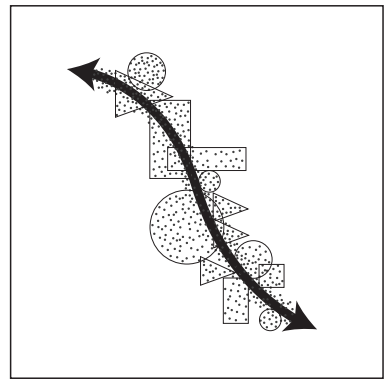

To Integrate

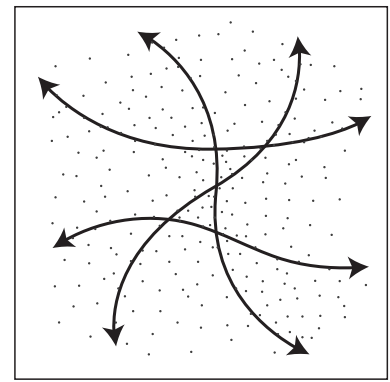

To Disperse

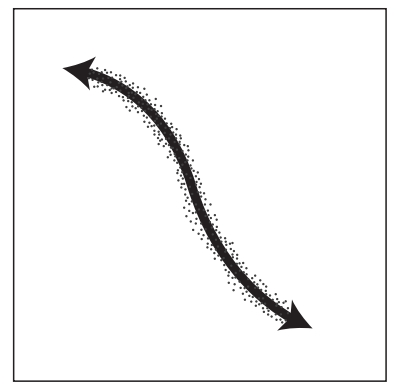

To Assemble

FIGURE 152

Jan Gehl's principles of fortifying public space

The movement of people through the common embraces Jan Gehl's principles of fortifying public space, which have been modified to suit the specific needs of the site and operation of the common.

"The establishment of a social structure and corresponding physical sturcutre with communal spacs at various levels permits movement from small groups and spaces toward larger ones and from the more private to the gradually more public spaces, giving a greater feeling of security and a stronger sense of belonging to the areas outside the private residence."

- $\quad$ Jan Gehl (2011, p. 59)
Gehl discusses how each of these five binary conditions play a vital role in the establishment of vibrant public spaces. He notes how they should not be viewed as positive or negative, rather, both conditions have certain contexts in which they are the more appropriate design response.

"The major function of the communal spaces is to provide the arena for life between buildings; the daily unplanned activities - pedestrian traffic, short stays, play, and simple social activities from where additional communal life can develop, as desired by residents."

- Jan Gehl (2011, p. 57) 


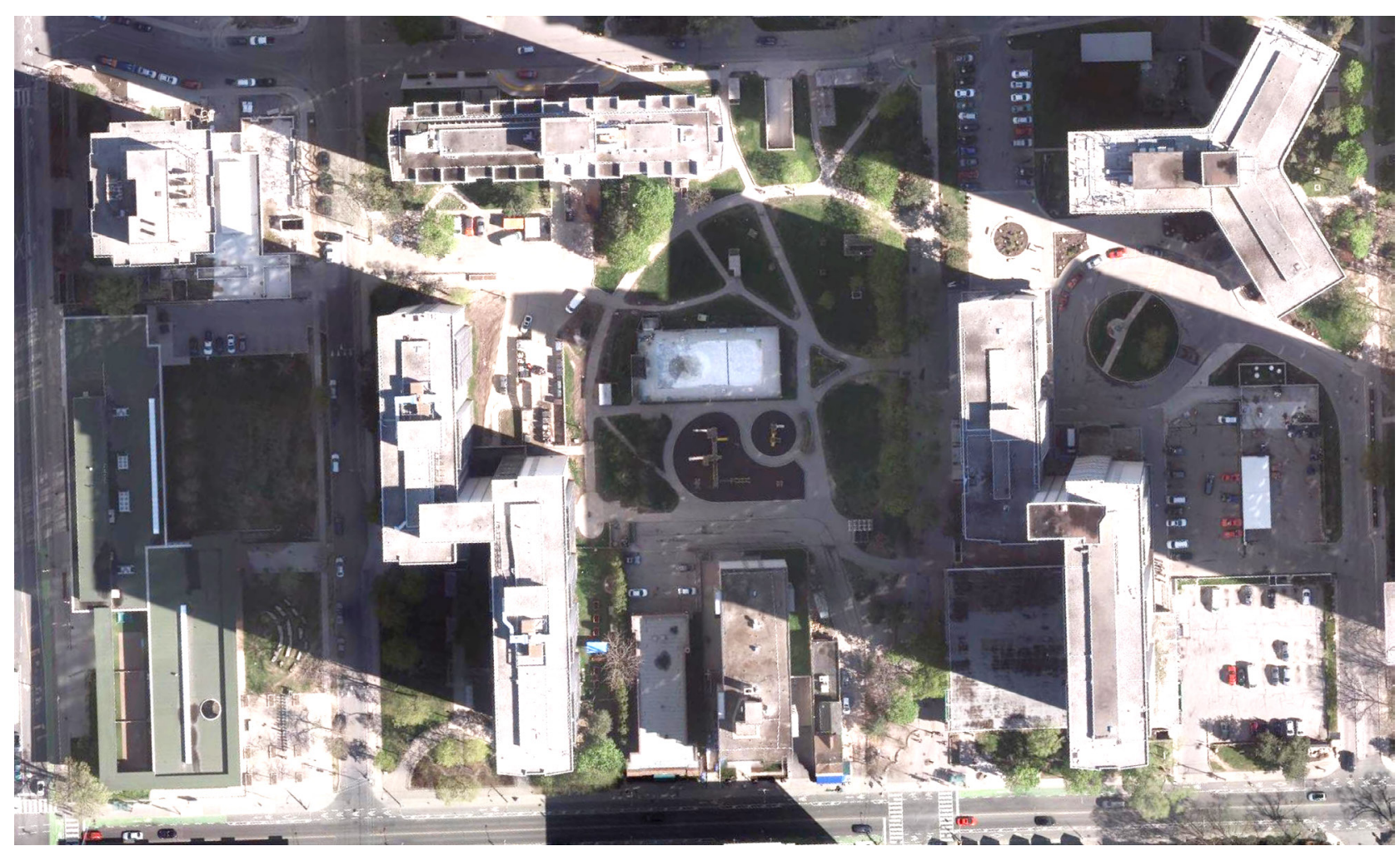

FIGURE 153

Aerial view of St. James Town's existing conditions

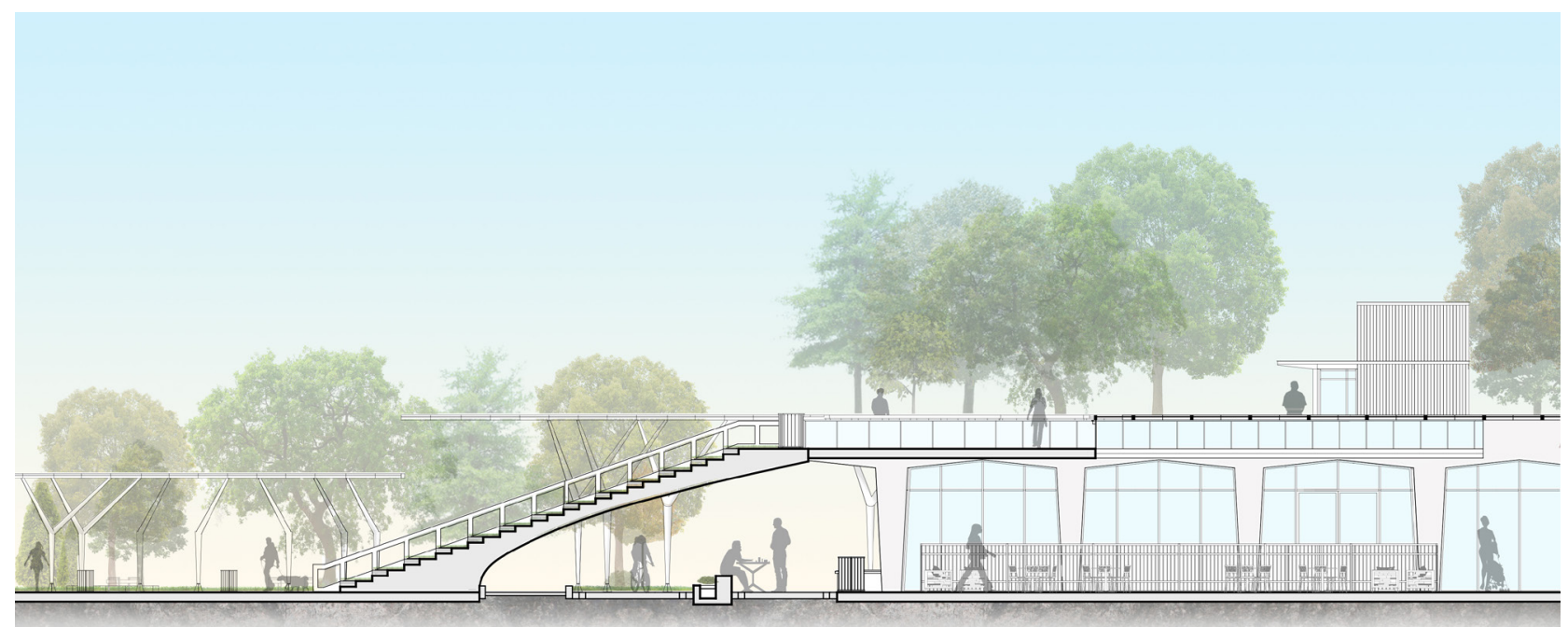

FIGURE 154

Section through the ampitheatre steps over the OSPP looking north 


\subsection{THE COMMONS - A PUBLIC MARKET}

The roof of the Food Basics is an extensive space that had tremendous potential. There are two amphitheatre steps that connect the ground plane to this elevated park space and serve as a vegetated seating area. They are located by the southern vegetated forecourt, adjacent to the Food Basics (Figures 129, 130, 132).

The arcade in front of the food basics was enclosed and turned into a café (Figure 131). This space is allocated for the St. James Town Community Café, a pop-up, pay-what-you-can café that was initiated in 2011 that has been looking for a permanent establishment. It features an outdoor seating area, centred around a water feature that mirrors the aperture in the amphitheatre steps (Figure 132).

The first structural bay of the Food Basics is going to be taken over by micro-vendors in order to better animate the promenade and connect to the pedestrian traffic along Wellesley. This is further enhanced by the renovation of the ground floor of the Sunny Green Fruit Vegetable Limited vendor into five new small shops (Figure 137). The current laneway which wraps around this store would be turned into a pedestrian path, replacing the harsh paving with a grasscrete path, a permeable paver which allows grass to grow between while allowing vehicles to traverse across it when needed. Additionally, several stand-alone vendors are strategically placed along the western edge of the promenade to drive pedestrians through the park.

As many of the residents of St. James Town are newly-landed immigrants, they require the infrastructure to support themselves; however, there is currently a lack of opportunity for residents to establish themselves within this community. While this is fundamentally a policy issue, residents have established their domain over the Ontario Street Pedestrian Promenade. Residents have turned this into a commercial hub, as they have domesticated the sidewalk. Their location is based on the proximity to the pedestrian traffic, which is most substantial along Wellesley Street, outside of the Food Basics. Through this process, the community of St. James Town has both defined a sense of place, as well as identified the need for improved spaces for commerce.

Community initiatives and public services are fundamental to the daily lives of St. James Town residents due to their marginalized nature. The majority of these initiatives focus on food, as a substantial number of residents rely on food banks for their daily supply of food. As a result, a fundamental component of the marketplace is the allocation of space for community supported agriculture. The allotment garden sits on top of the currently-empty Food Basics' roof. Access to this space is provided through amphitheatre seating which connects down to grade along Wellesley Street, which also projects over the Ontario Street Pedestrian Promenade. Elevator access from the northern portion of Food Basics is provided to maintain the accessible nature of the park. Beyond just producing food, the inclusion of a café in the existing Food Basics arcade, which faces Wellesley St. East, will further enhance community engagement. The St. James Town Community Café is a pop-up café that was initiated in 2011 , and has been looking for a permanent establishment. It is a pay-what-you-can community program that puts healthy food in the hands of the residents. 


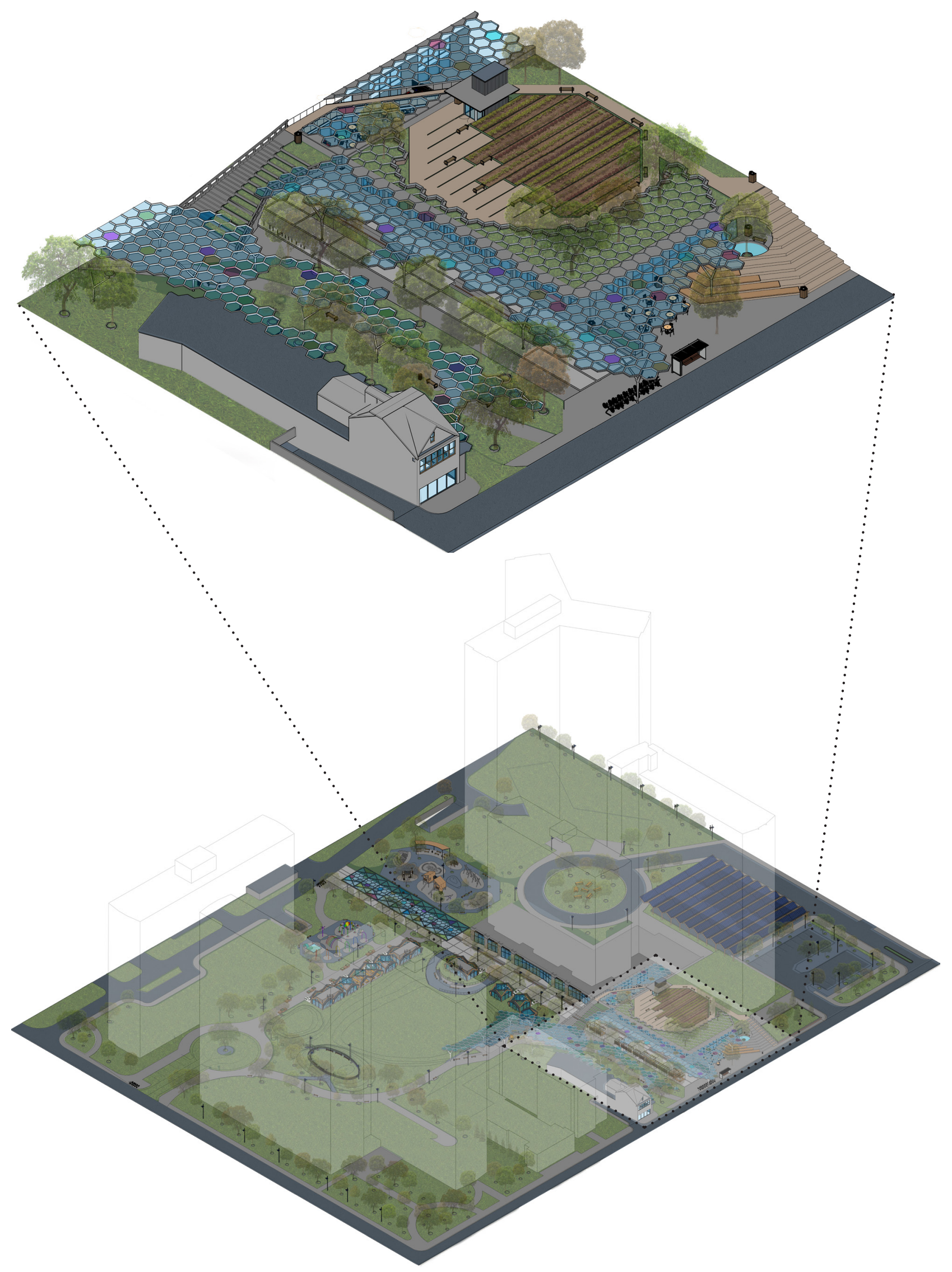

FIGURE 155

Overall Site Axo and blow-up of Wellesley frontage 


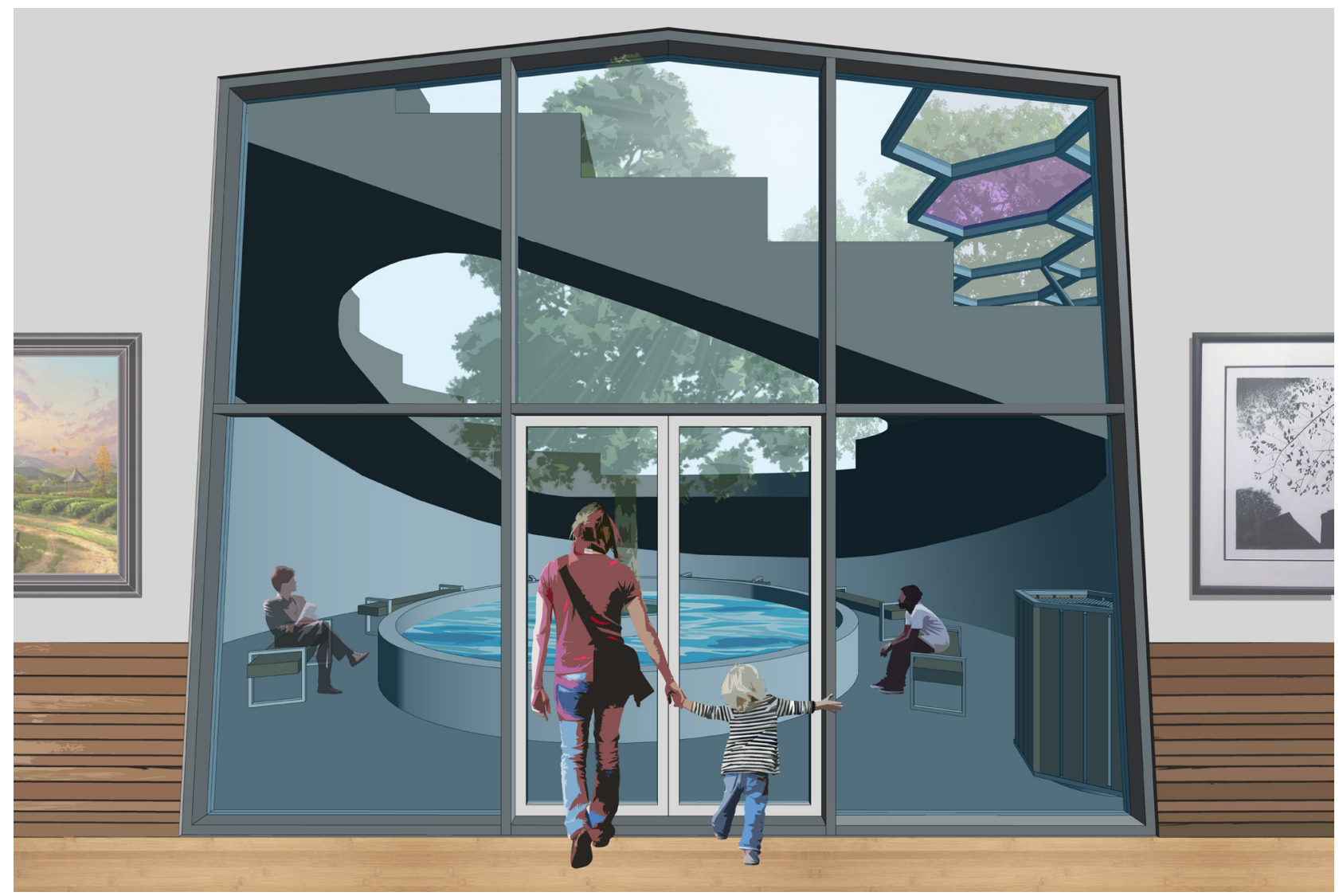

FIGURE 156

View from inside cafe looking south towards an outdoor seating area, Wellesley beyond

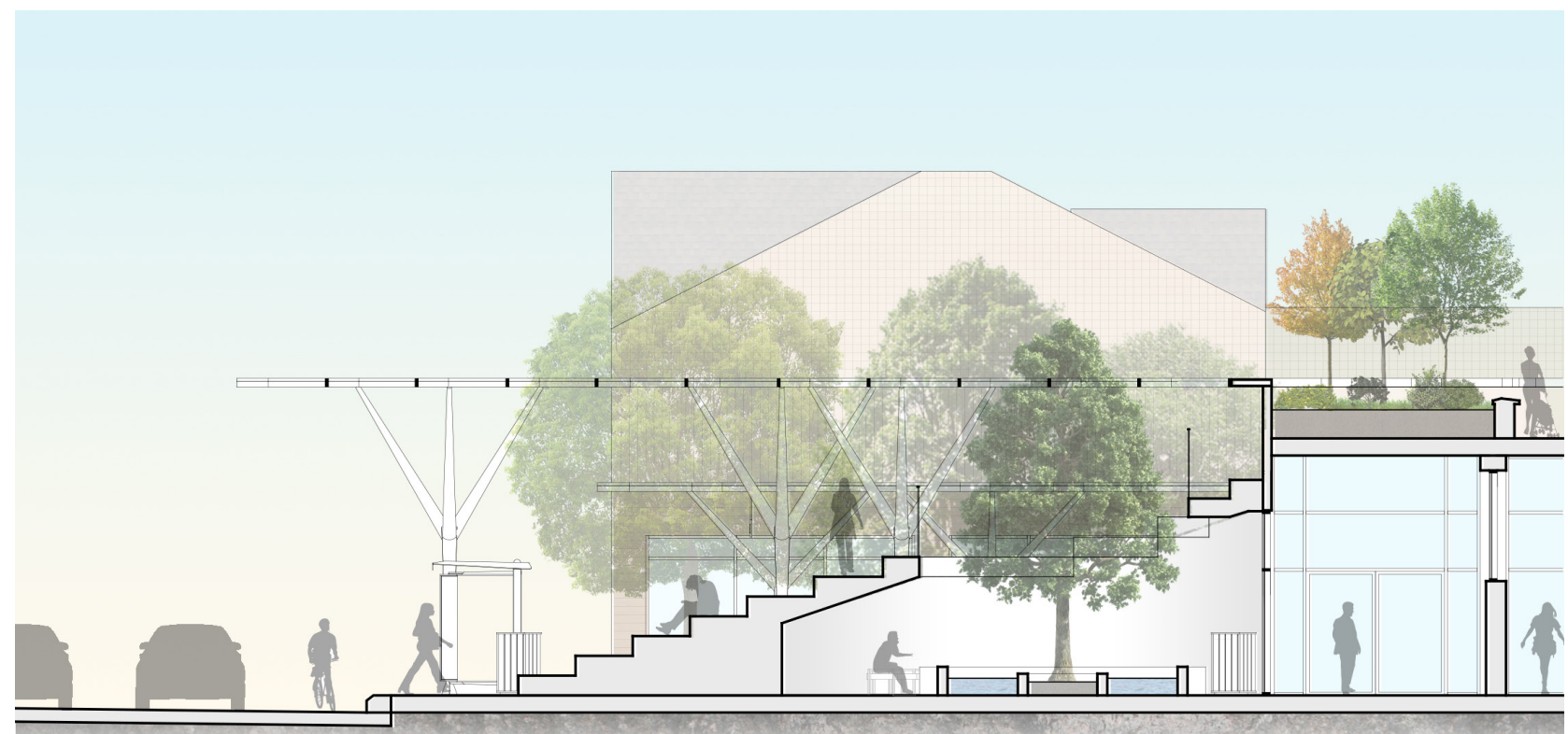

FIGURE 157

Section through Wellesley amphitheatre seating, cafe, and elevated allotment garden 


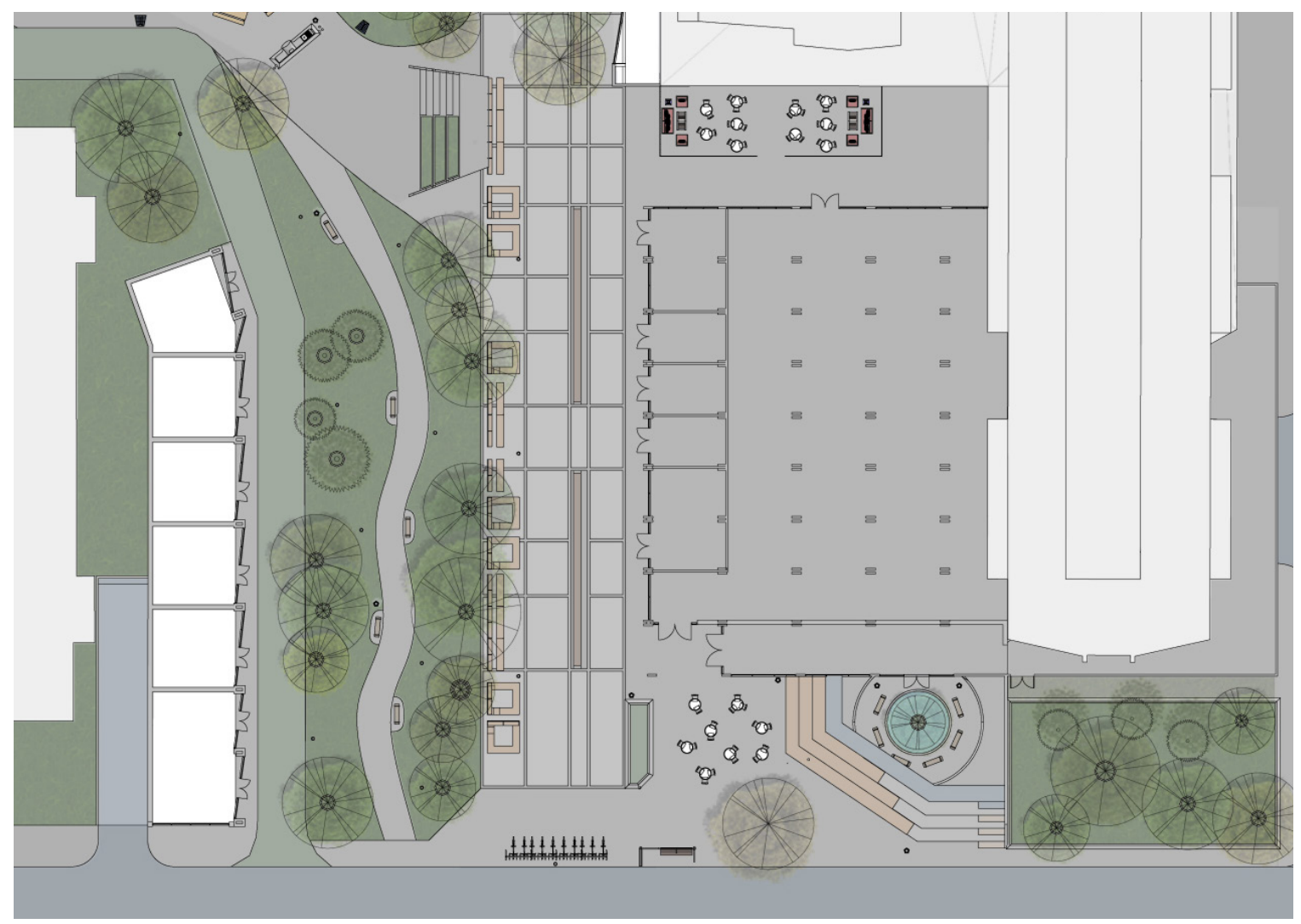

\section{FIGURE 158}

Ground plan highlighting mico-business vendors and cafe

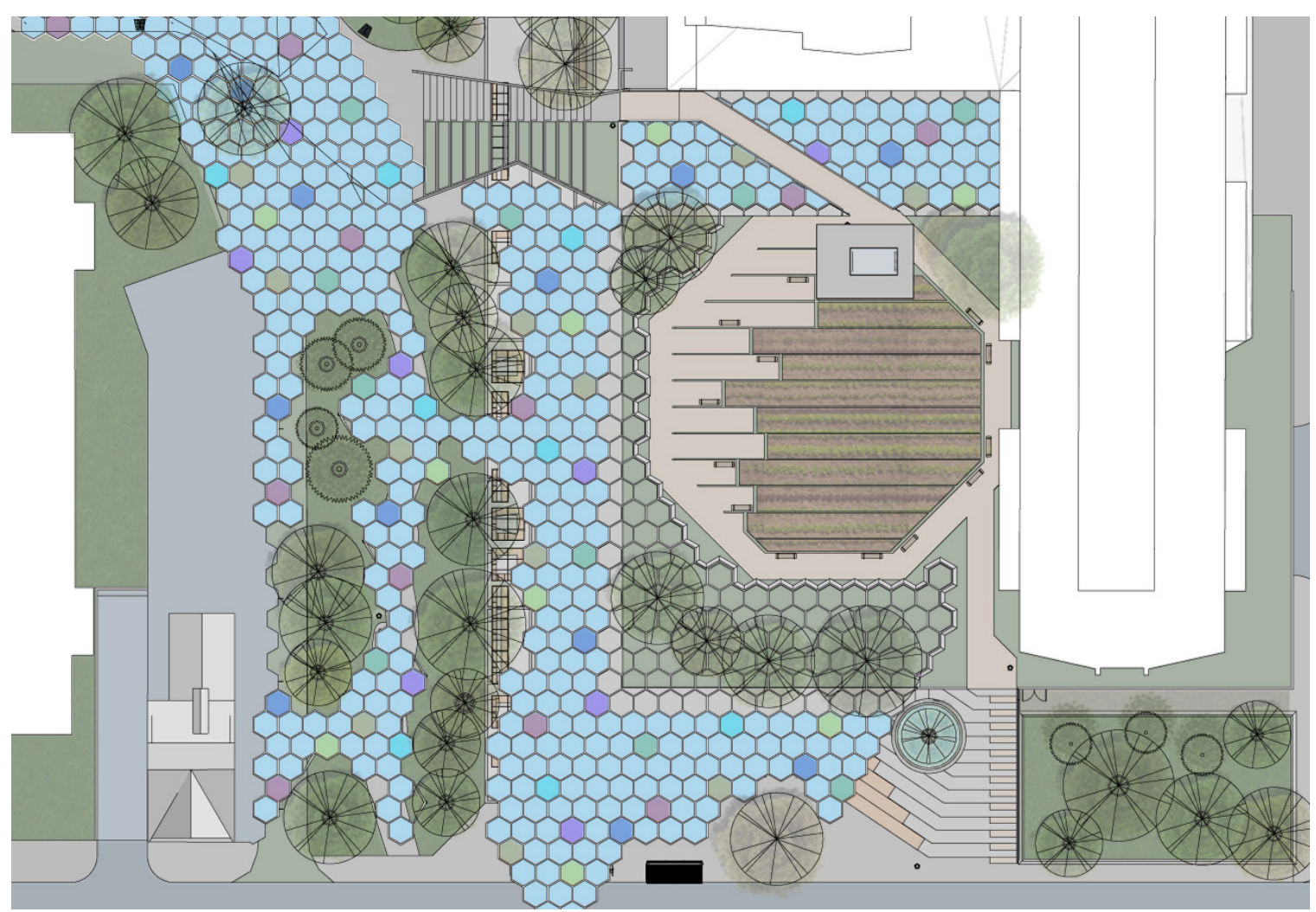

FIGURE 159

Site plan highlighting canopy and elevated allotment garden 


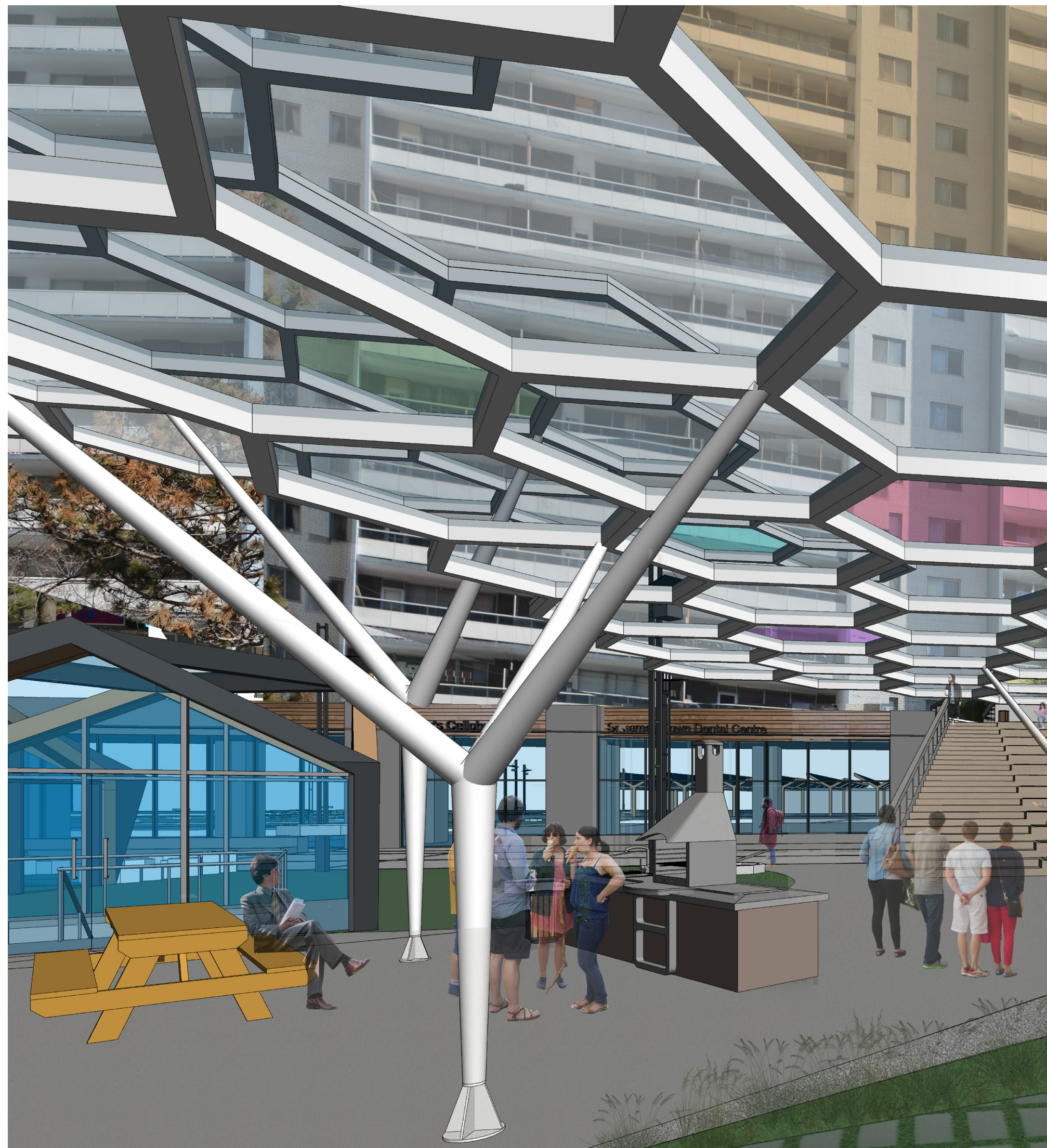

FIGURE 160

View from service road looking east towards the community kitchen, amphitheatre steps, and vegetated forecourt 


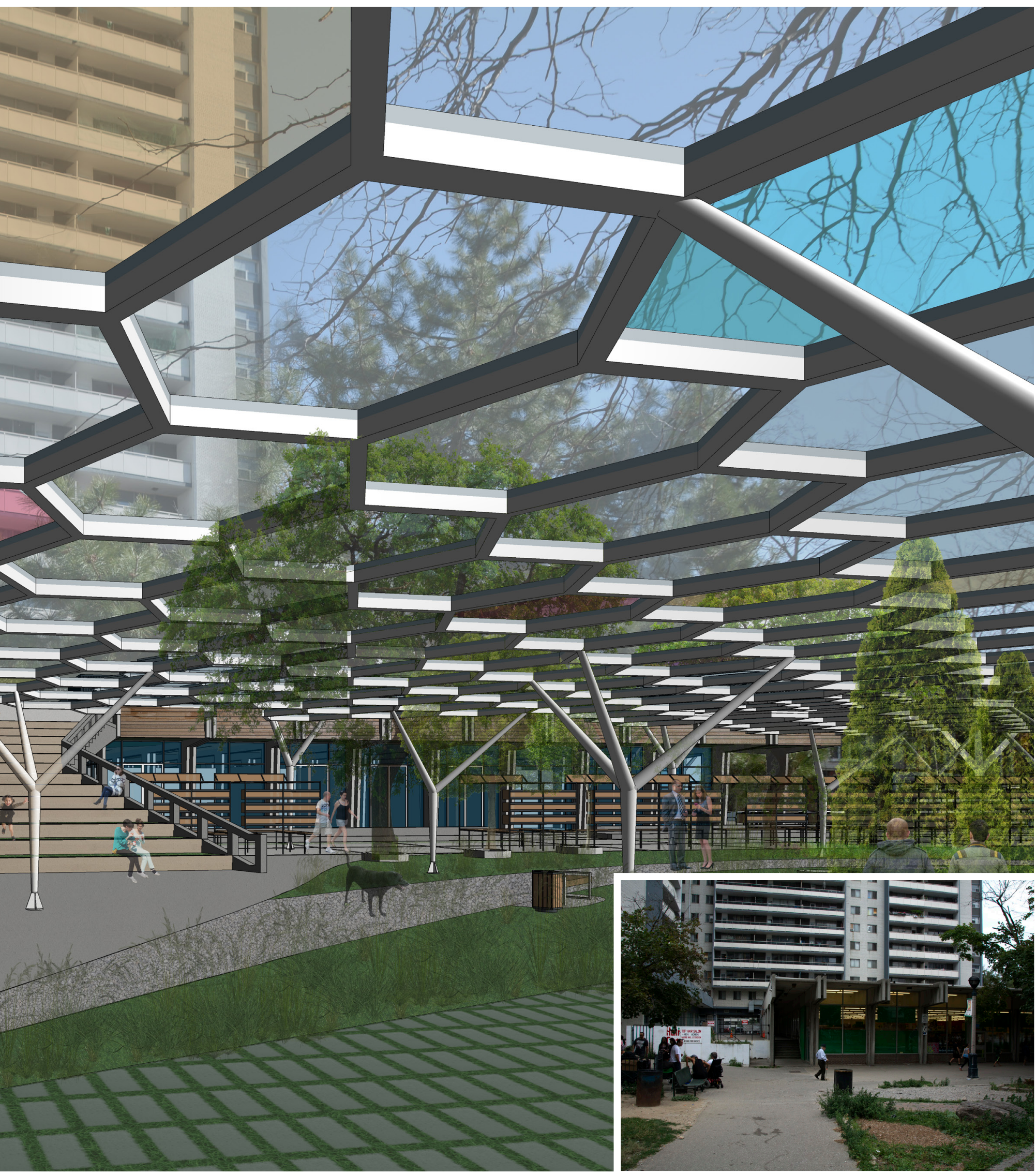

FIGURE 161

Existing conditions, looking north from the Ontario Street Pedestrian Promenade 


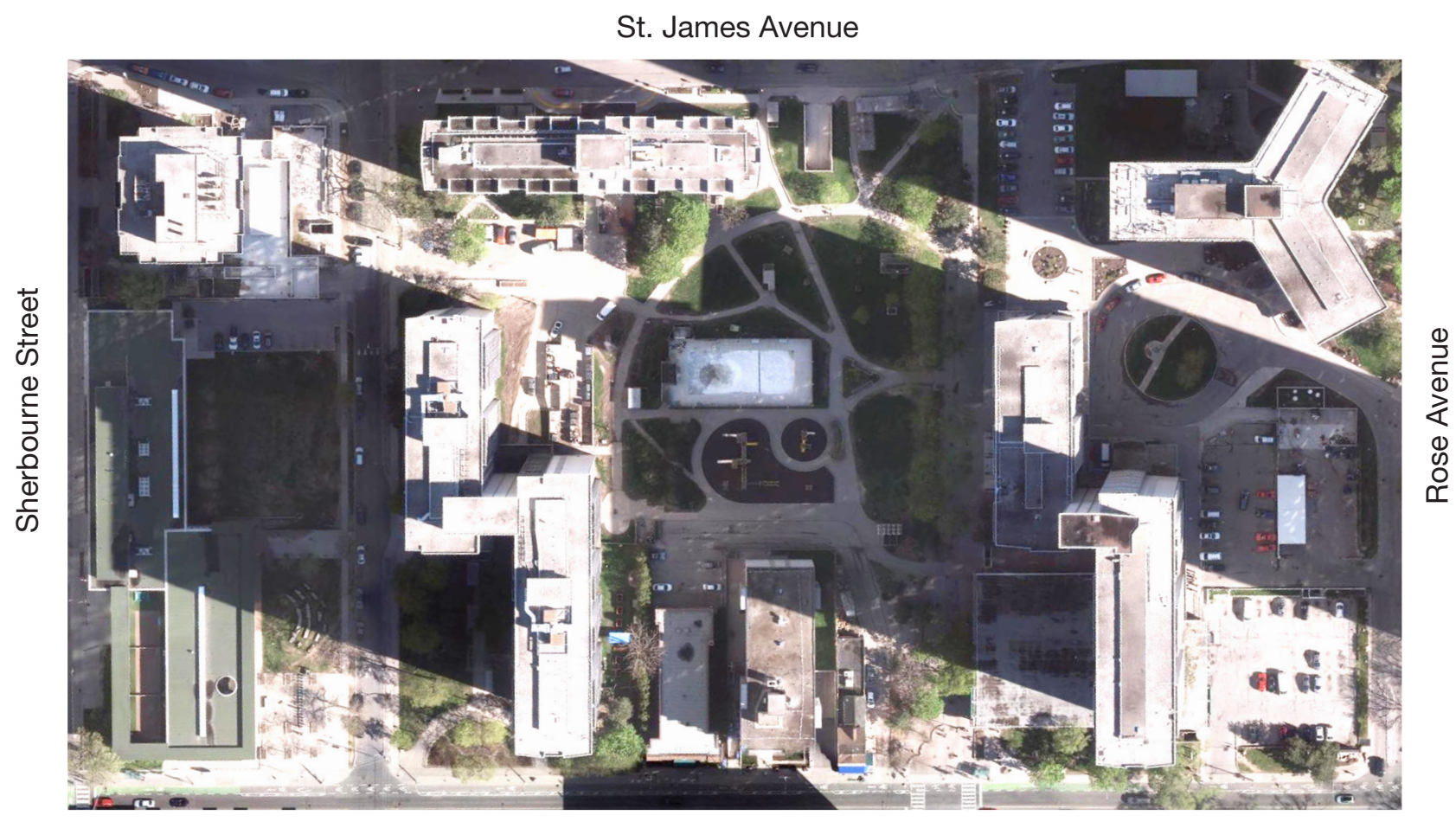

Wellesley Street East

FIGURE 162

Aerial View of St. James Town's existing conditions

The current state of the public space across from the pedestrian extension of Ontario Street, or the Ontario Street Pedestrian Promenade, is inadequate. Its numerous pathways transect the space, removing any opportunity for actual use (Figure 135). There is minimal seating, none of which is covered. Furthermore, there isn't anything to actually do in the space besides using the children's park, which is underutilized, in addition to being a mundane replica of every other children's playground structure in the neighbourhood. St. James Town requires a civic space; a public square where the community can unite. The creation of a gathering space would provide a place for recreation, while functioning as an extension of the community. The towers that comprise this dynamic neighbourhood were designed to sit within communal green space. This design leverages the small size of apartment units as a means of encouraging outdoor public congregation.
The existing gathering space had great potential but lacked an identity and a civic space for its residents to gather as it was transected by pathways and the large aboveground public pool. In response to this, a large, multi-purpose gathering space was designed to facilitate: sports, recreation, and leisure activities (Figure 138), winter activities (Figure 139), as well as can support community events and communal gatherings (Figure 140).

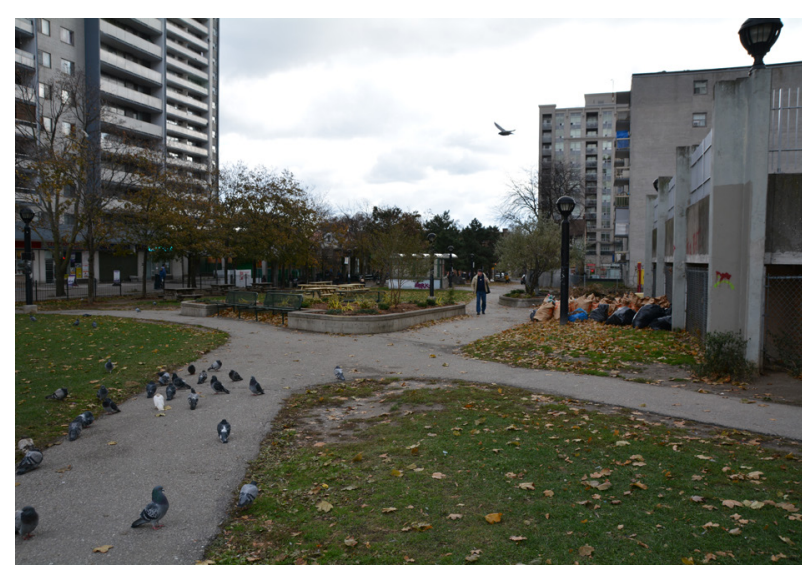

FIGURE 163

Image of transecting pathways, dividing the open space 


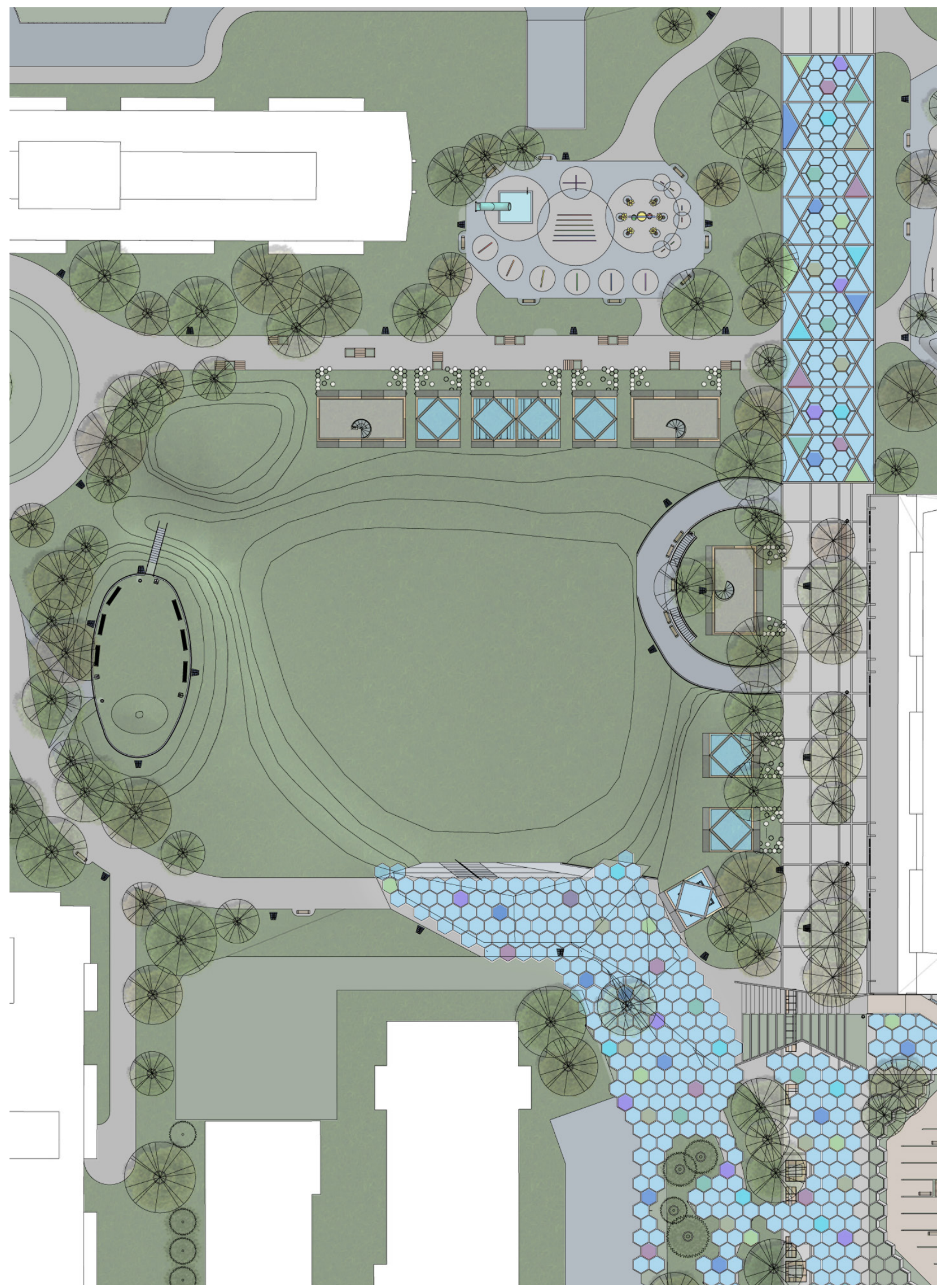

FIGURE 164

Site plan highlighting the large social gathering space, adjacent pavilion, enclosed dog park, and OSPP 


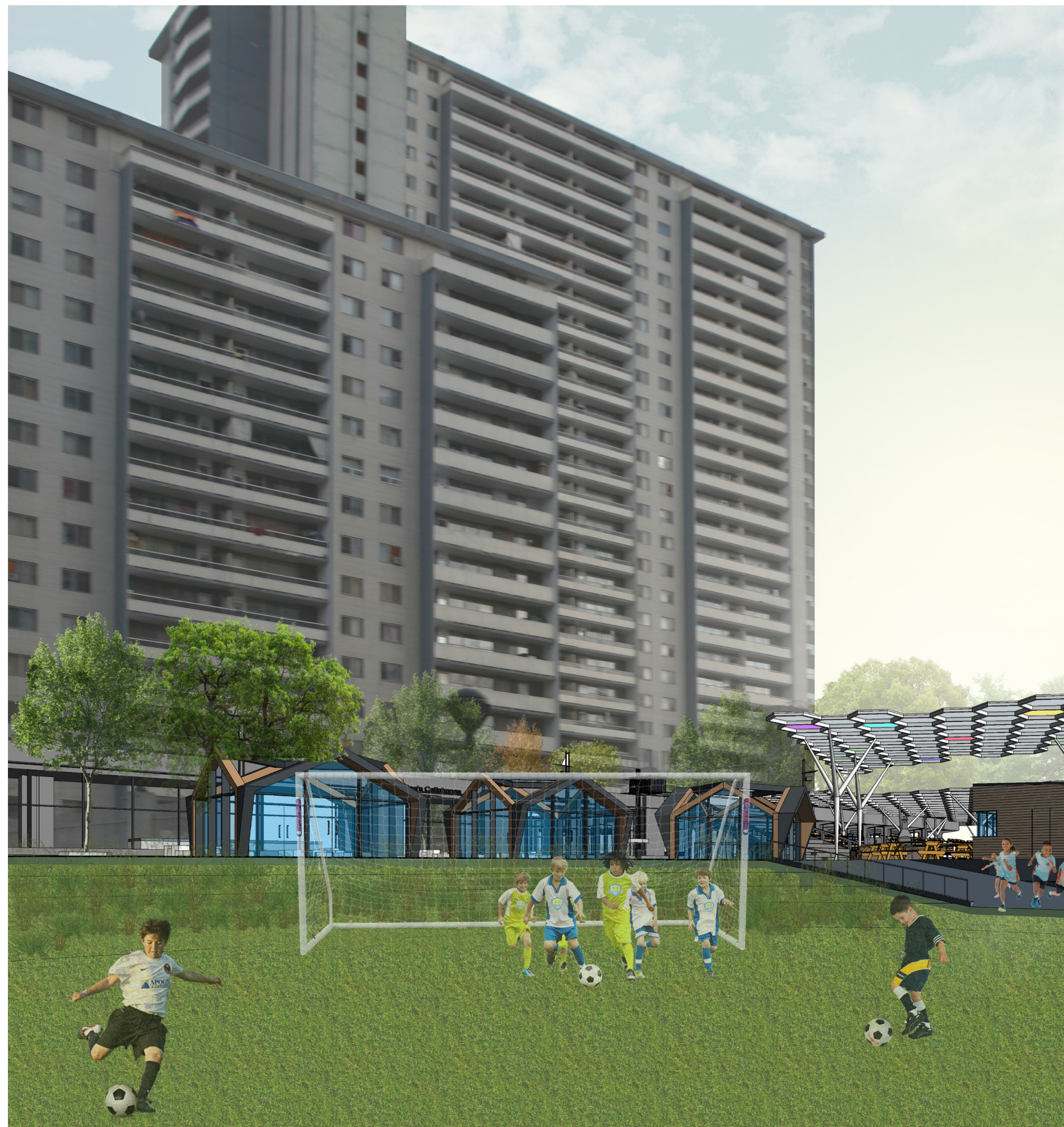

FIGURE 165

View from social gathering area looking southeast, rendered as a play field 


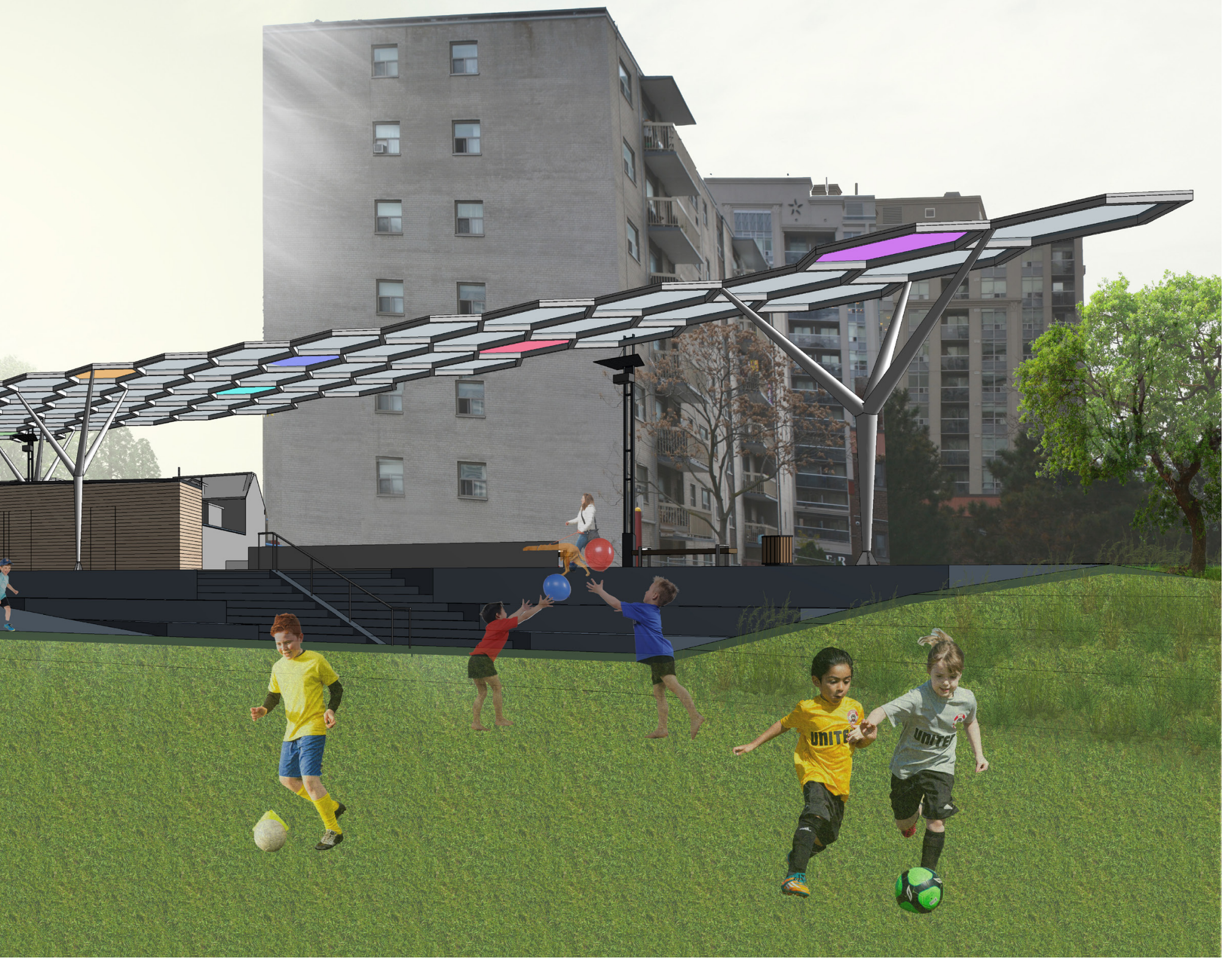




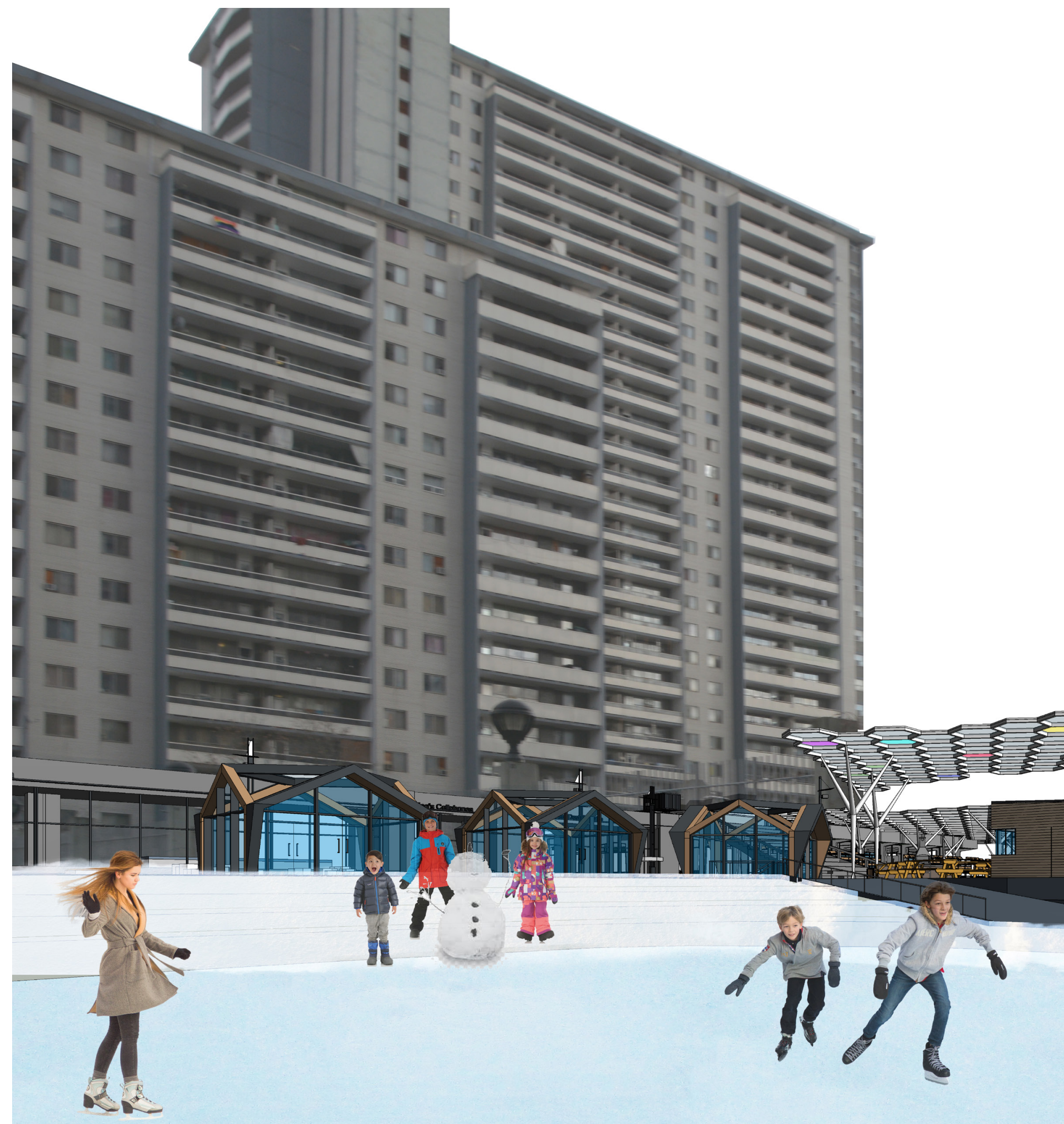

FIGURE 166

View from social gathering area looking southeast, rendered as a skating rink in the winter 


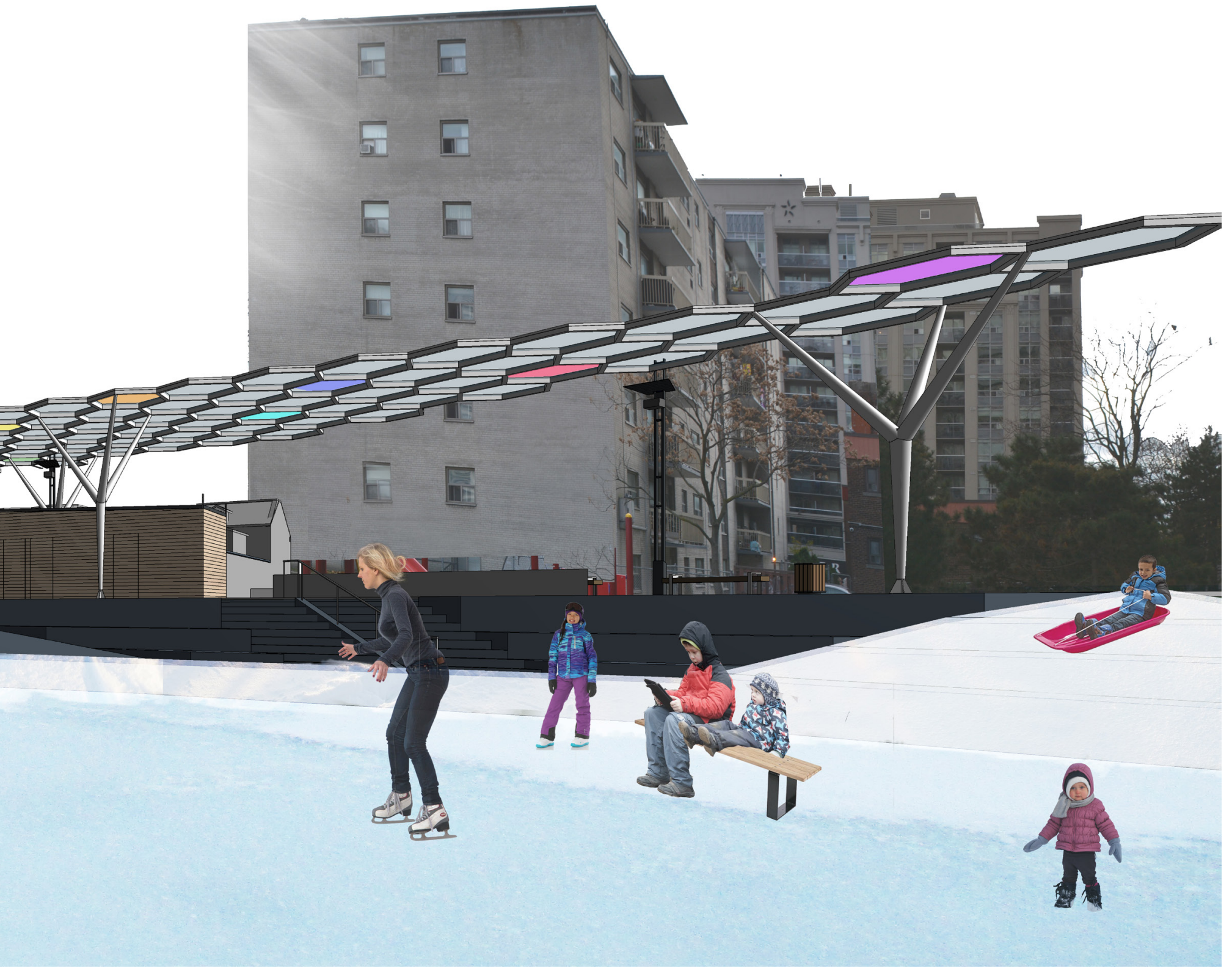




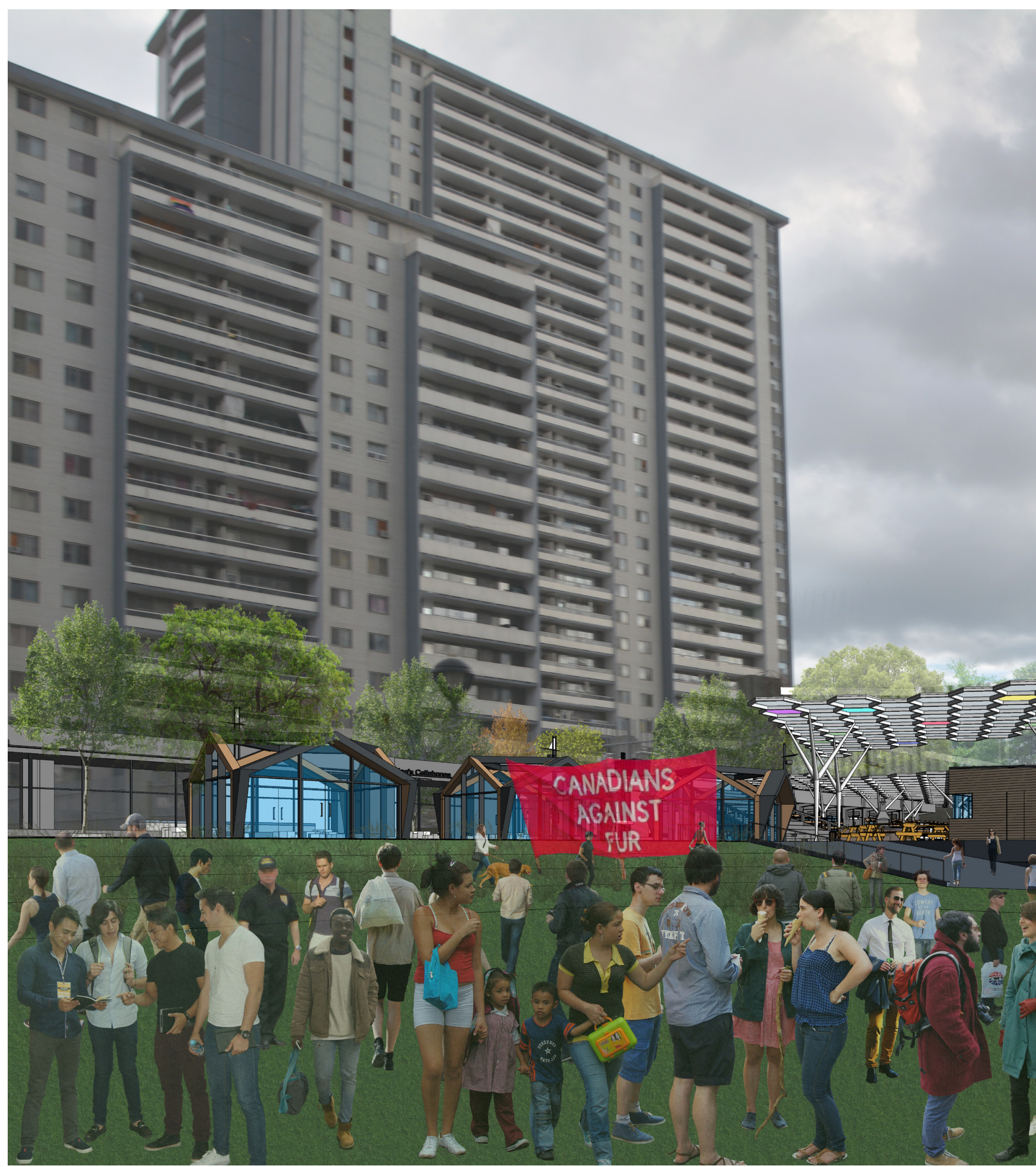

FIGURE 167

View from social gathering area looking southeast, rendered as a social gathering area for collective congregation 


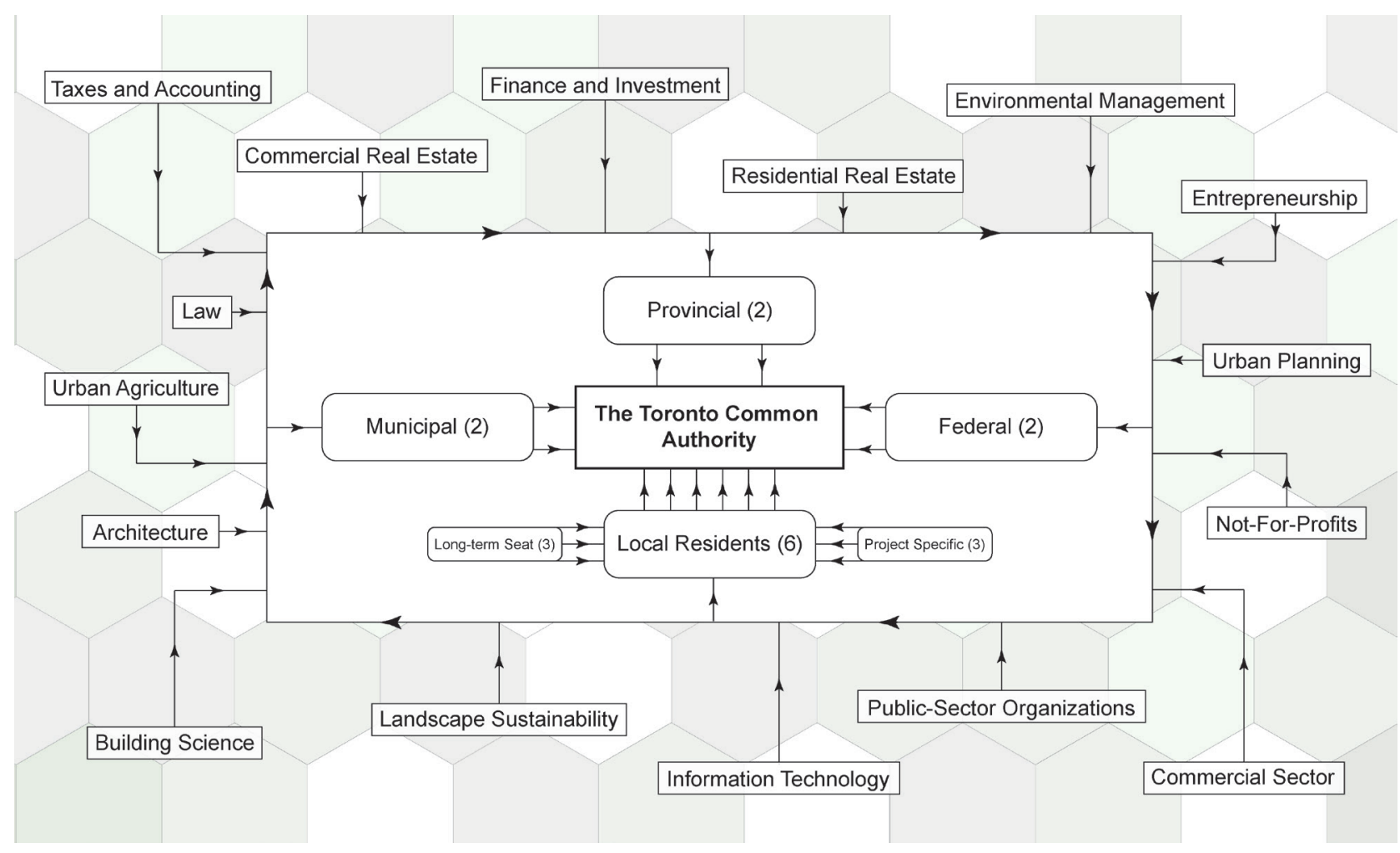

FIGURE 168

Proposed board structure of The Toronto Common Authority

\subsection{PUBLIC INFRASTRUCTURE}

One of the greatest successes of both Sherbourne Common and Corktown Common lies in their developer. By creating a public entity which operates under a semi-autonomous mandate, Waterfront Toronto is shielded from the bureaucracy of city politics. A similar methodology is intended for this project. The intention behind this thesis is to create a framework that can be applied for the redevelopment any Toronto park. As a result, the hypothetical developer of this project would be The Toronto Common Authority, a new public entity that would function as a public advocate and steward for Toronto's public space revitalization, modelled after Waterfront Toronto.
"Our priorities are simple. We put people first and reconnect them with the waterfront. We emphasize parks and public spaces, and we design in a way that's environmentally and economically sustainable."

- Waterfront Toronto (2018)

Similar to Waterfront Toronto, it would be established in concert between the Governments of Canada, Ontario, and the City of Toronto. It would be responsible for the creation of extraordinary public spaces in which to work, learn, and play. It would be managed by a similar Board of Directors, being comprised of two appointed representatives from each level of government, in addition to six community residents who are eager to take on an activist role. The Board would be responsible for electing a Chair, who would hold that position for a 4-year term. This would provide the Board with 


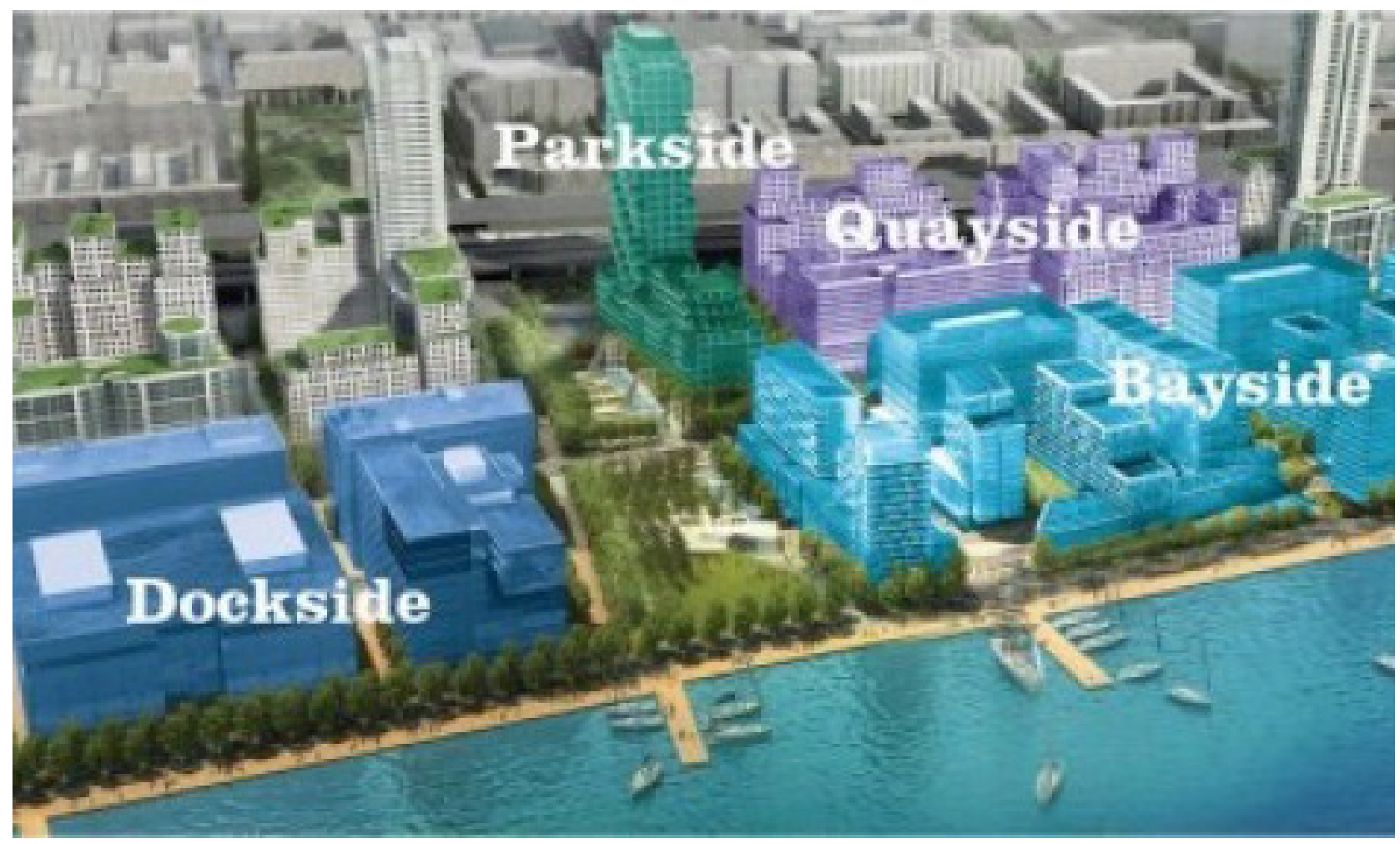

FIGURE 169

Waterfront Toronto's development projects along Toronto's waterfront

a diverse range of expertise, covering fields, such as: law, residential and commercial real estate, accounting and tax, investment and finance, environmental management, not-for-profit and public-sector organizations, public companies, entrepreneurship, urban planning and information technology.

The Board would meet at open meetings - open to the public to gather public opinion/input, consistent with the requirements for public meetings under the Ontario Municipal Act. This would also allow The Toronto Common Authority to engage the community in the revitalization of Toronto's public spaces, creating projects that are a more accurate reflection of Toronto's people.
In addition to being members of the Board, the twelve representatives would also assemble several key committees, responsible for:

- Finance, Audit \& Risk Management

- Investment and Real Estate

- Partnership

- Governance

- Human Resources \& Compensation

- Chairs

- Public and Government Engagement

- Design Review Panel

The intention behind this infrastructure is to insure the continued maintenance and successful operation of Toronto's parks and public realm, a critical shortcoming currently plaguing the city. 


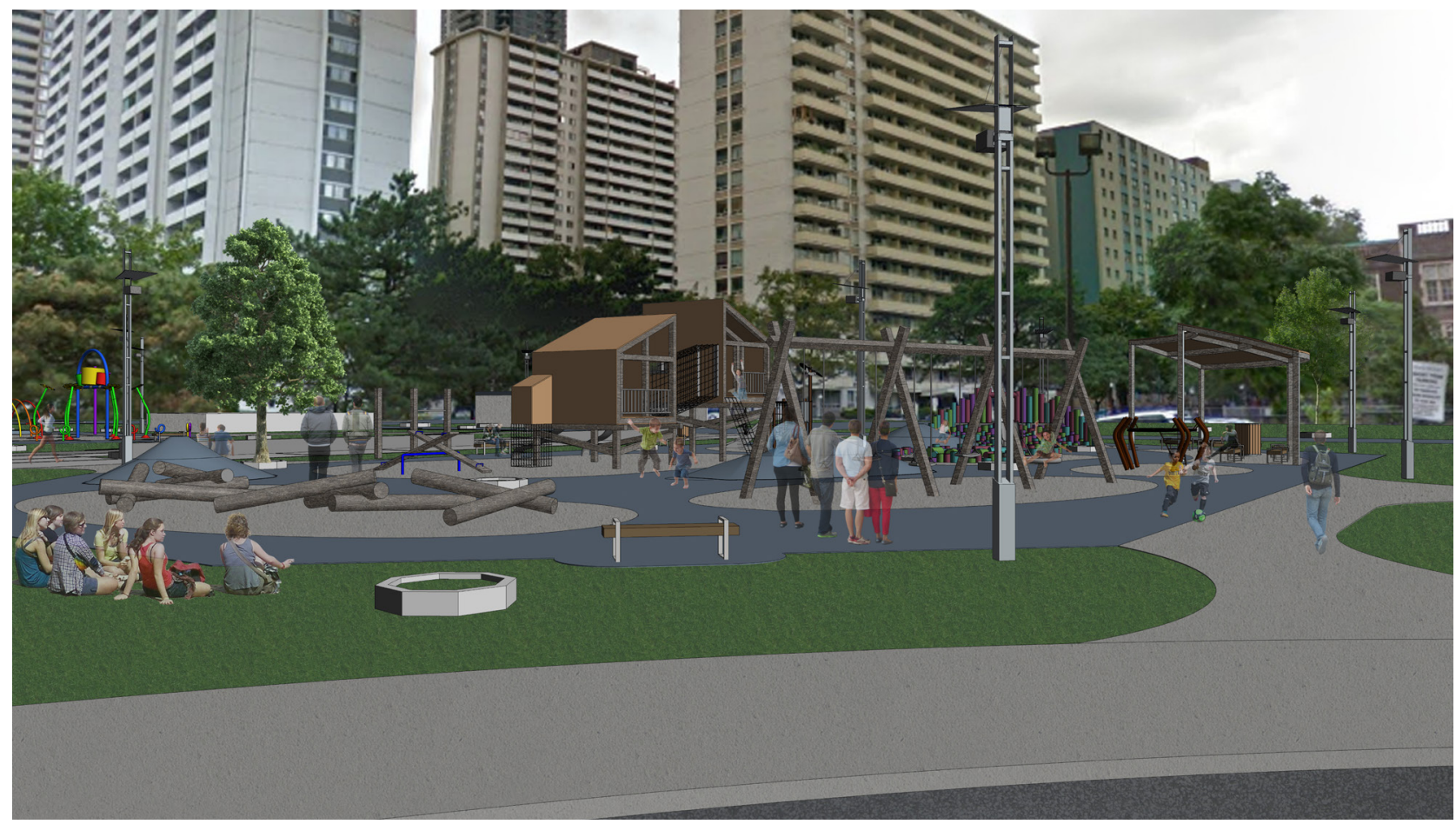

\section{FIGURE 170}

View of playground looking northwest

\subsection{PLAYGROUND DESIGN}

Key Design Considerations for Play-Learning Environments

- A diversity of spaces
o Flexible
o Playfulness
o Graduated challenges
o Scale

- Multi-purpose elements

o Elements which serve multiple purposes

o Use landscape to articulate spaces

o Moveable objects to create dynamic spaces

- Loose parts

o Child-sized furniture

o Creative accessories

o Provide loose parts that can be rearranged

- Community presence

o Respond to local ecology and community

- Seasonal presence

o Design for year-round use 


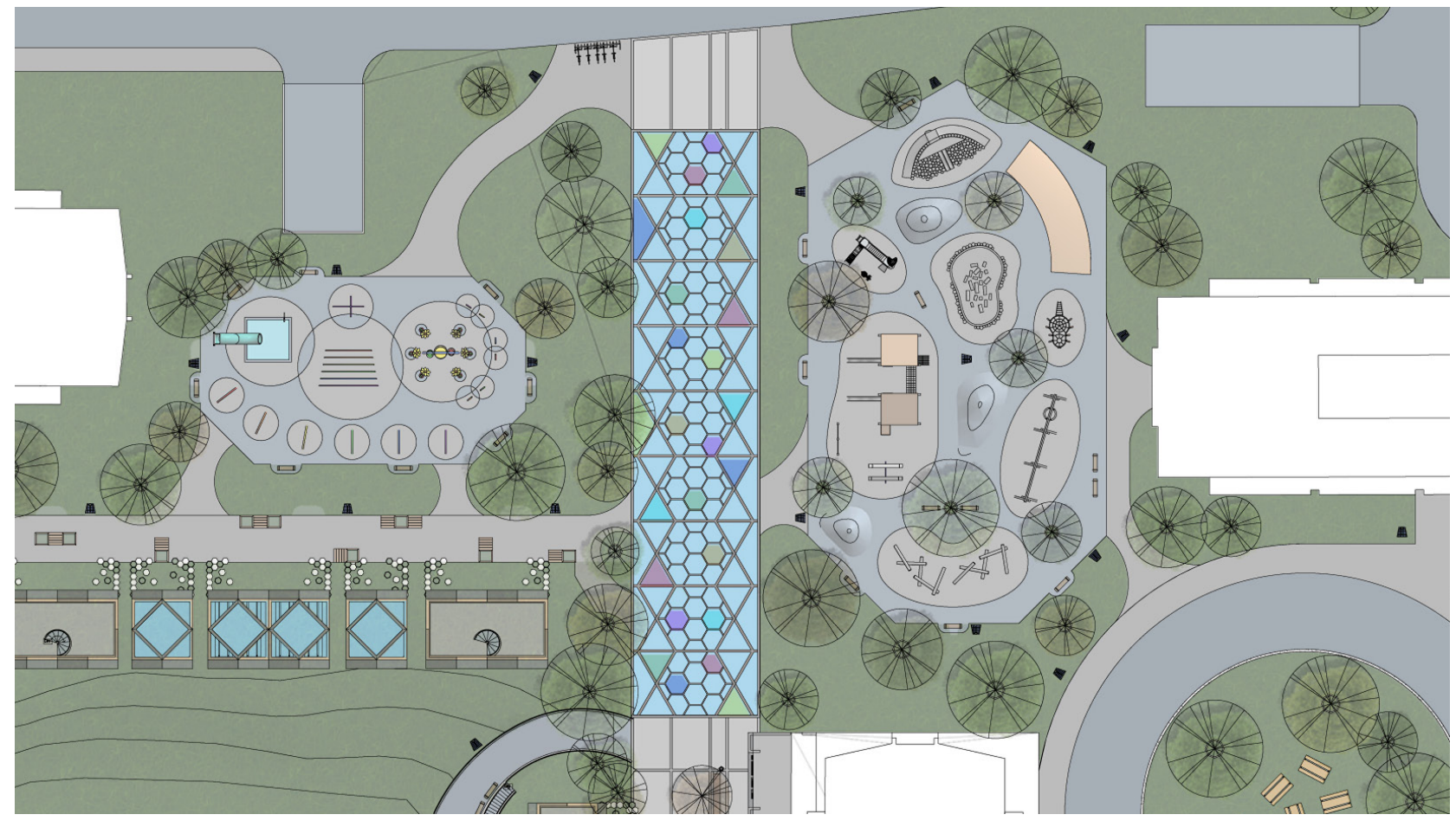

FIGURE 171

Site plan highlighting splash pad and playground

Principles for Planning Experiential-Learning Environments

- Meet children's developmental needs - physical, social, cognitive, and emotional

- $\quad$ Get people involved - adopt a participatory approach

- $\quad$ Appeal to children's senses - establish a code of aesthetics

- $\quad$ Make spaces safe and accessible

- $\quad$ Support inquiry and play-based learning

- $\quad$ Plan for maintenance

Developmental Goals

- $\quad$ Emotional development

- $\quad$ Physical development

- $\quad$ Social development

- $\quad$ Cognitive development

- $\quad$ Safeguard and improve children's health and well-being

- Increase the diversity of natural features and playground opportunities

- $\quad$ Enhance the use of the outdoors for inquiry and play-based learning 


\section{CONCLUSION}

$A$ s urban neighbourhoods are continuing to densify, the quality of the public realm in these cities and neighbourhoods becomes a fundamental issue. In an effort to enhance place-based relationships, improve social relations, and create an enhanced sense of community, this thesis proposes the notion of the contemporary common - a multi-faceted public space that functions as a unifying platform for social inclusion, collective culture, and civic inculcation. It is defined by four mobilizing principles: socio-spatial multiplicity, social solidarity, conviviality, and sustained maintenance. The enactment of these principles establishes a resilient public space, ultimately producing the following outcomes: evokes a sense of place, improves social negotiation, establishes civic formation, positively influences social justice, and creates social communion within its surrounding context. These principles and outcomes are solidified in response to the tragedy of the commons, which outlined the reasons for the decline/eradication of commonly held land in medieval England. The contemporary common, as a result, aims to improve social relations and develop a design capable of creating a sense of community within Toronto's dynamic and multi-cultural neighbourhoods. 
This proposed framework for the contemporary common is tested through the establishment of a community hub within St. James Town. The design of the St. James Town Common builds on the successful elements found within St. James Town and is a response to the opportunities in its public realm. It seeks to define the experience of place for its users, creating a unique architectural response to its diverse contextual influences. It also leverages landscape urbanism practices to develop a stratified approach to place-based design, rooting itself within the social and urban ecologies of the community. This stratified design implements a design framework that mandates the enhancement of the public realm through improving users' connection with nature within the modern built environment. Biophilic and topophilic design positively contribute to the retention of embodied energy, reduce stormwater runoff through permeable hardscaping, and most crucially, improve users' connection with their natural environment. By improving topophilic relationships, the ambition is to enhance the identity of the St. James Town neighbourhood and surrounding community.

Within the design portion of this thesis, increasing the vitality of the park is accomplished by fortifying the pedestrian promenade, increasing foot traffic from Wellesley Street to the south, and St. James Avenue to the north. In turn, this increased access creates greater opportunities for commercial activities, allowing existing businesses to continue to operate while facilitating the introduction of new micro-vendors. The resulting 1200 square metres of revitalized commercial space establishes St. James Town Common as the commercial hub for the neighbourhood. The multi-purpose recreation field functions as a social anchor for the neighbourhood, and is supported by the ancillary retail space, in addition to the dog park and pavilion. The splash pad and playground embrace natural materials to create an interface for play. Academic research, which established recreational environments that create opportunities for increased risk are beneficial for the development of children and adolescents, was pivotal to the design of the common's playground. The elevated allotment garden re-purposes the previously inaccessible roof of the Food Basics, converting into a community allotment garden. Lastly, the introduction of a solar canopy creates a biophilic parking lot, a term that would otherwise seem redundant.

As Kim Dovey states, places are "the frameworks of possibility within which our capacities are realized or not" (Dovey, 2008 , p. 19). The architecture of place defines our perspective of the world and our attachment to it. Rather than producing an architecture of iconography, the built world should develop the same kind of relationship that exists between humans and nature. In this way, by creating places that engage with their users, architecture can create agents of change, evoking 
stewardship and advocacy from its users. When this is accomplished, urban architecture has the capacity to withstand the influence of society, standing as a testament to the tenacity of the built form. While the design project explored a redevelopment of an existing park in St. James Town, the place-based approach to architecture can be applied to any public space in Toronto, most impactfully in situations of increased density, ensuring their longevity while improving the quality of Toronto's public realm.

Jan Gehl states, "First life, then spaces, then buildings - the other way around never works" (Gehl, 2011, p. 47). In the current age of developer-driven design, this thesis proposes a counter-directional approach to sustainability, focusing initially on the human dimension before the architectural. Through reacting to the social and cultural shifts of densifying urban neighbourhoods, the proposed architectural solution is provocative. By dissolving the traditional power structures that typically differentiate private and public space, in conjunction with the community-centred design that engages the surrounding neighbourhoods, the concept of the common can once again, firmly establish its righful domain in contemporary society.

In conclusion, this thesis presents a sound position on robust strategies for creating public landscapes for high-density urban neighbourhoods that promote social health, vitality, and well-being as fundamental elements. Moreover, this thesis ultimately reinforces the notion of architecture as a vital interface for successful community development, and a staunch proponent for long-term human sustenance.

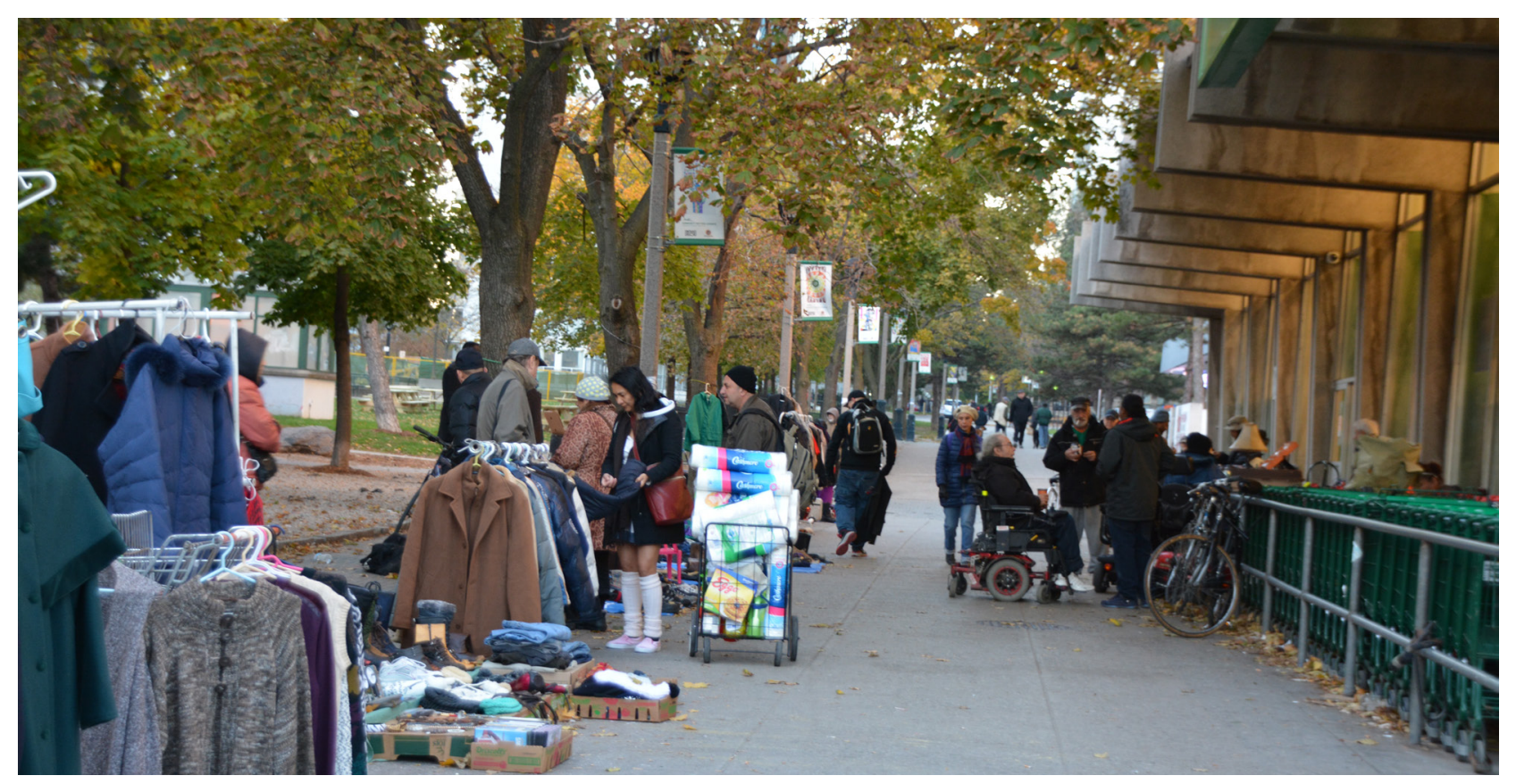

FIGURE 173

The public market that initiated this thesis investigation 

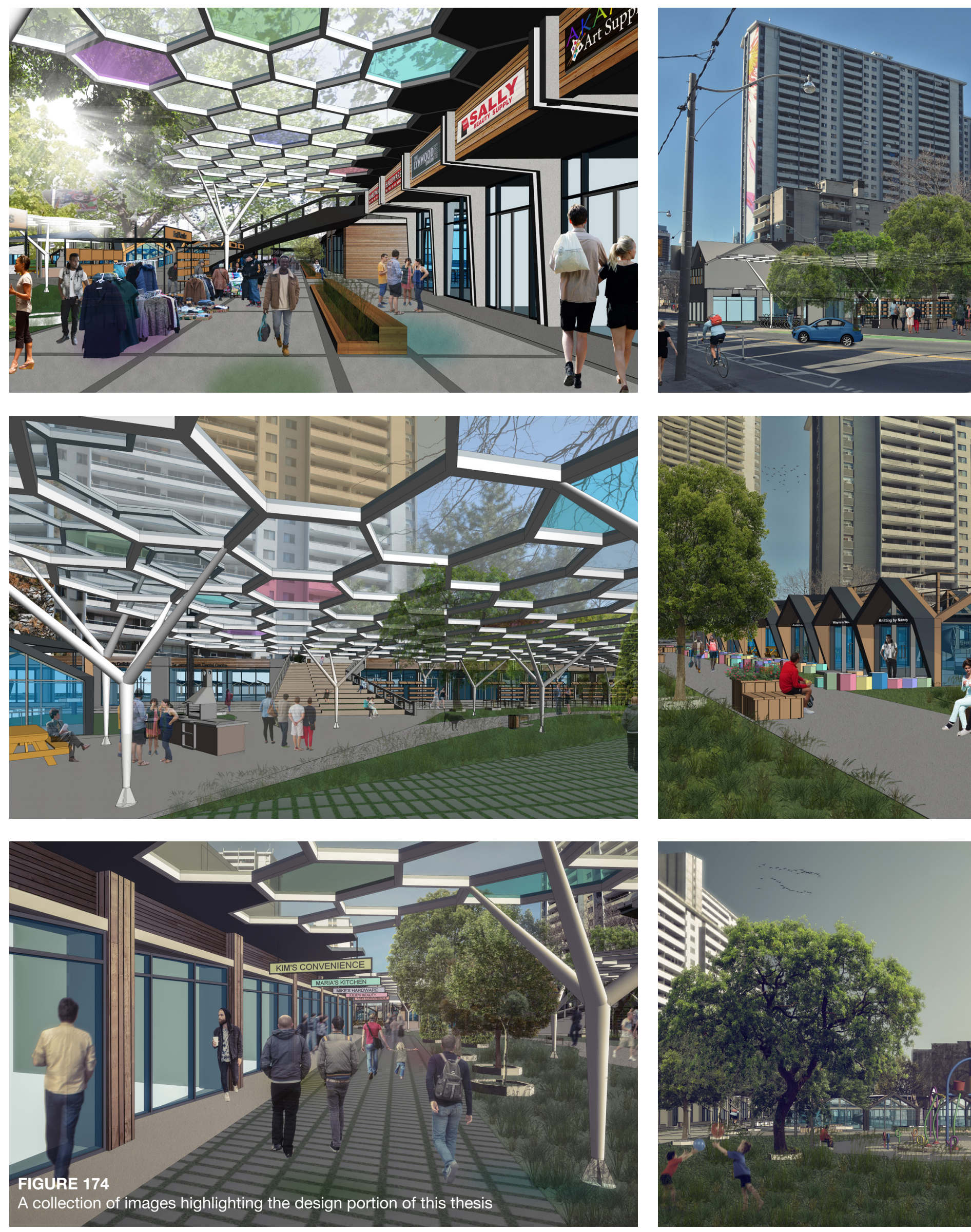

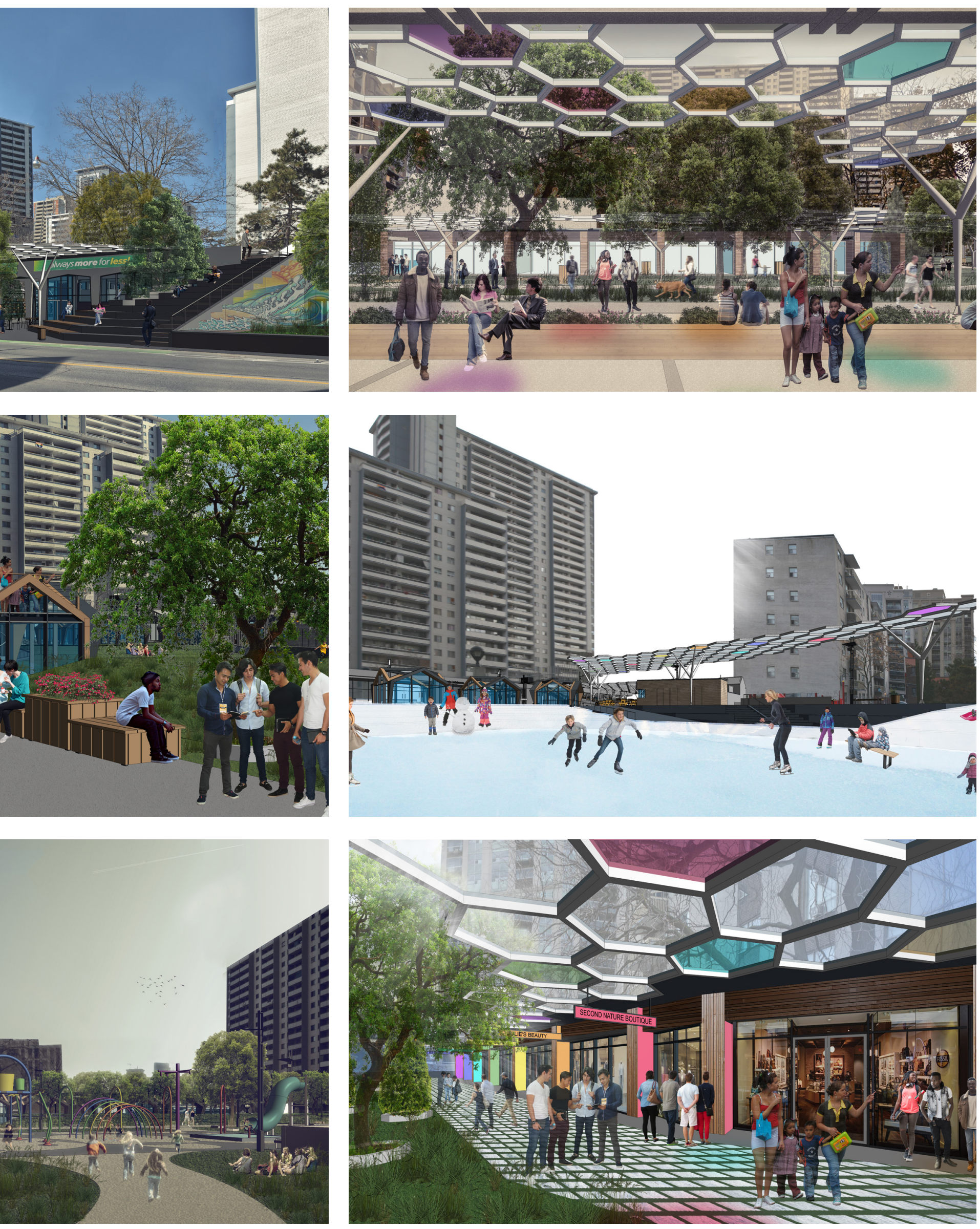


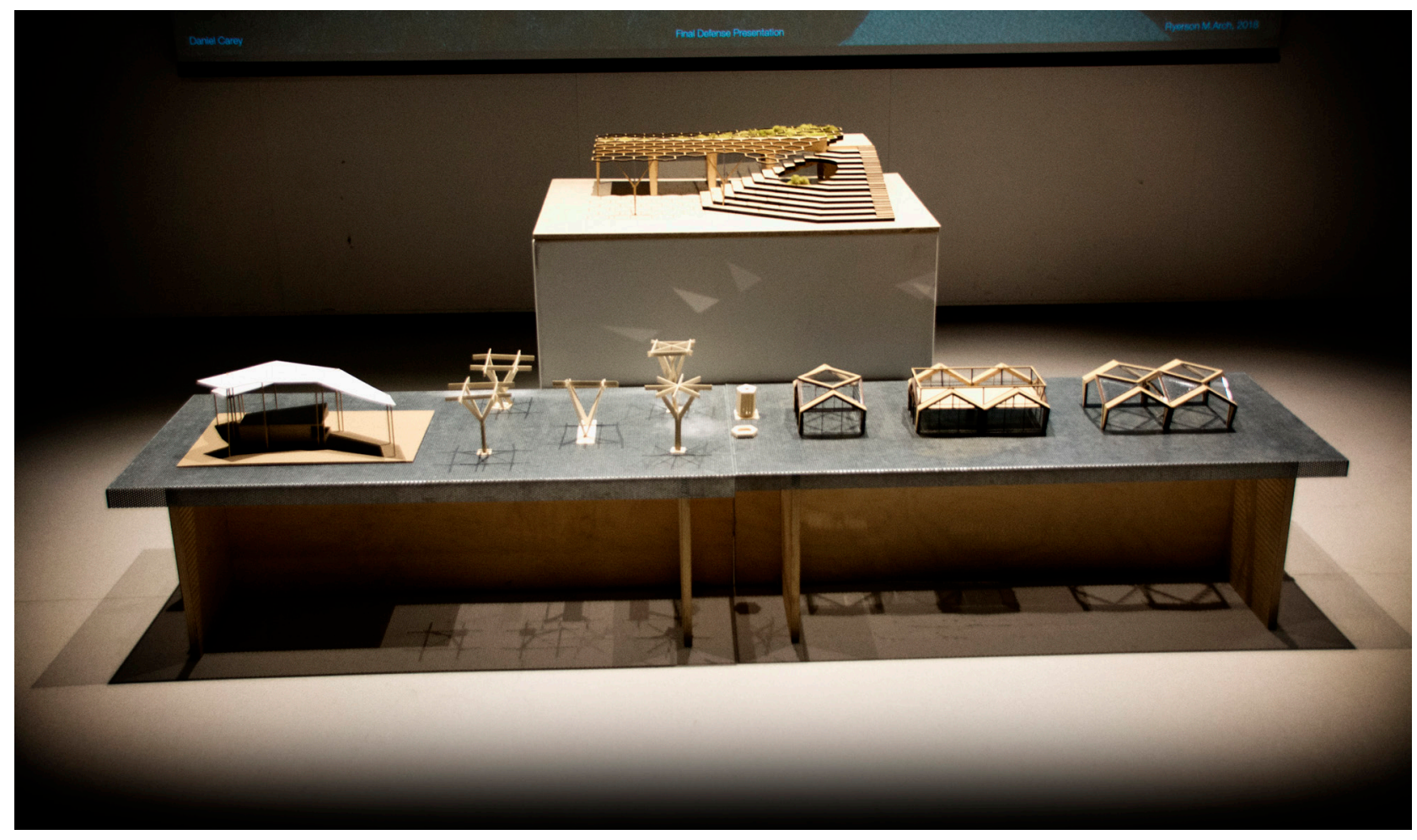

FIGURE A.1

Collection of thesis models

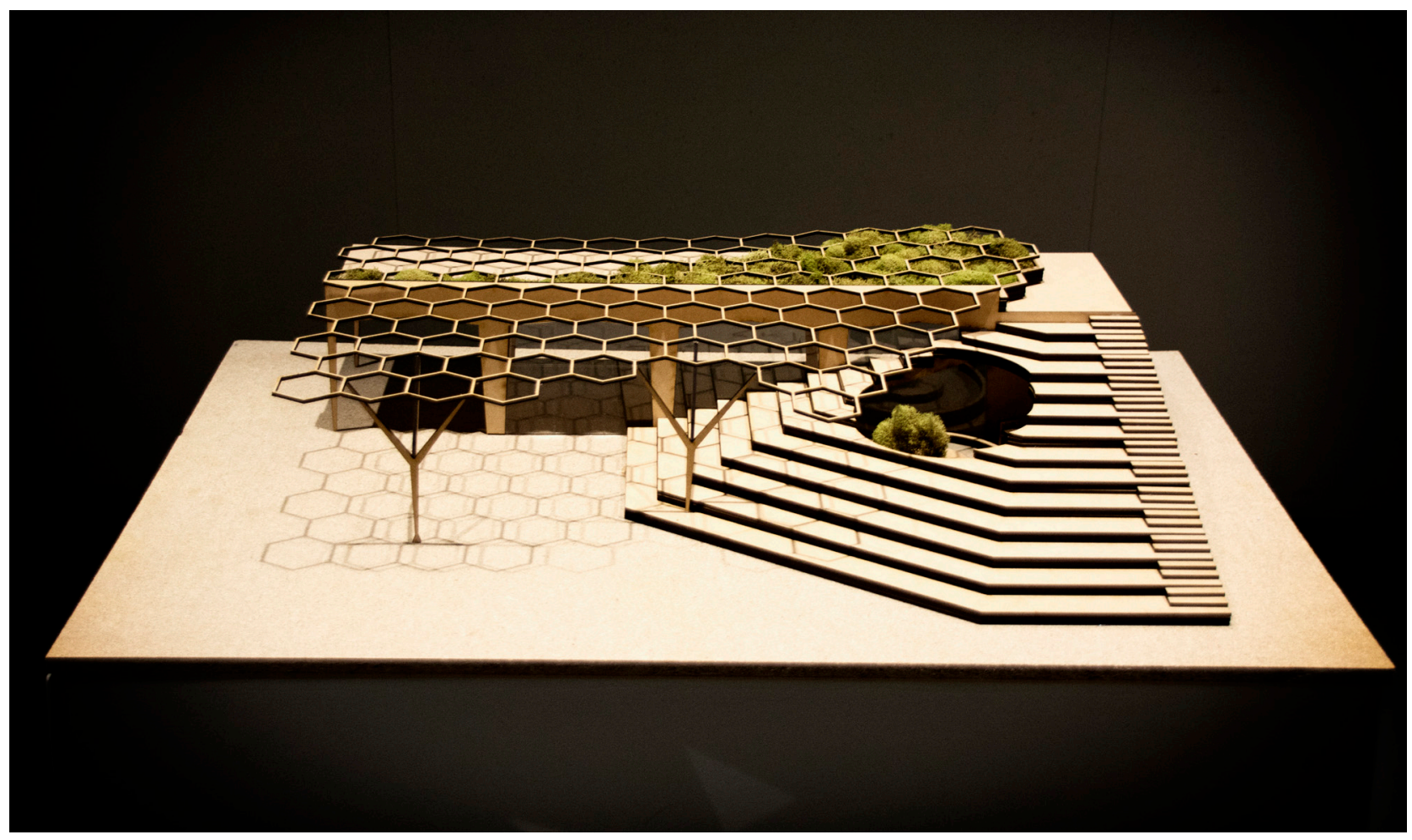

FIGURE A.2

1:50 model of the Wellesley St. E. amphitheatre steps, elevated allotment garden, and hexagonal canopy 


\section{APPEDNIX A: MODEL PHOTOS}

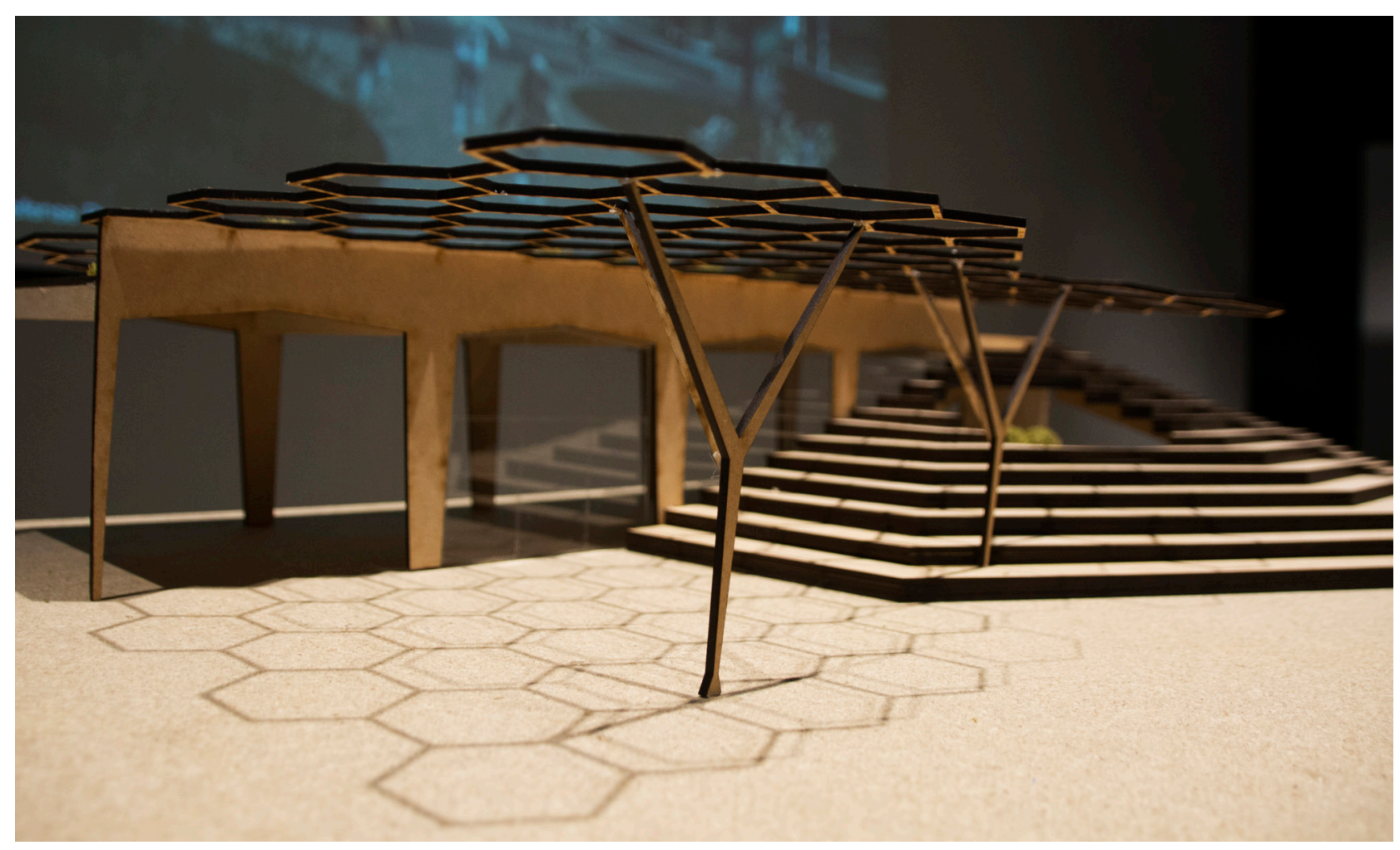

FIGURE A.3

Close-up image of the tree-like canopy support structure 


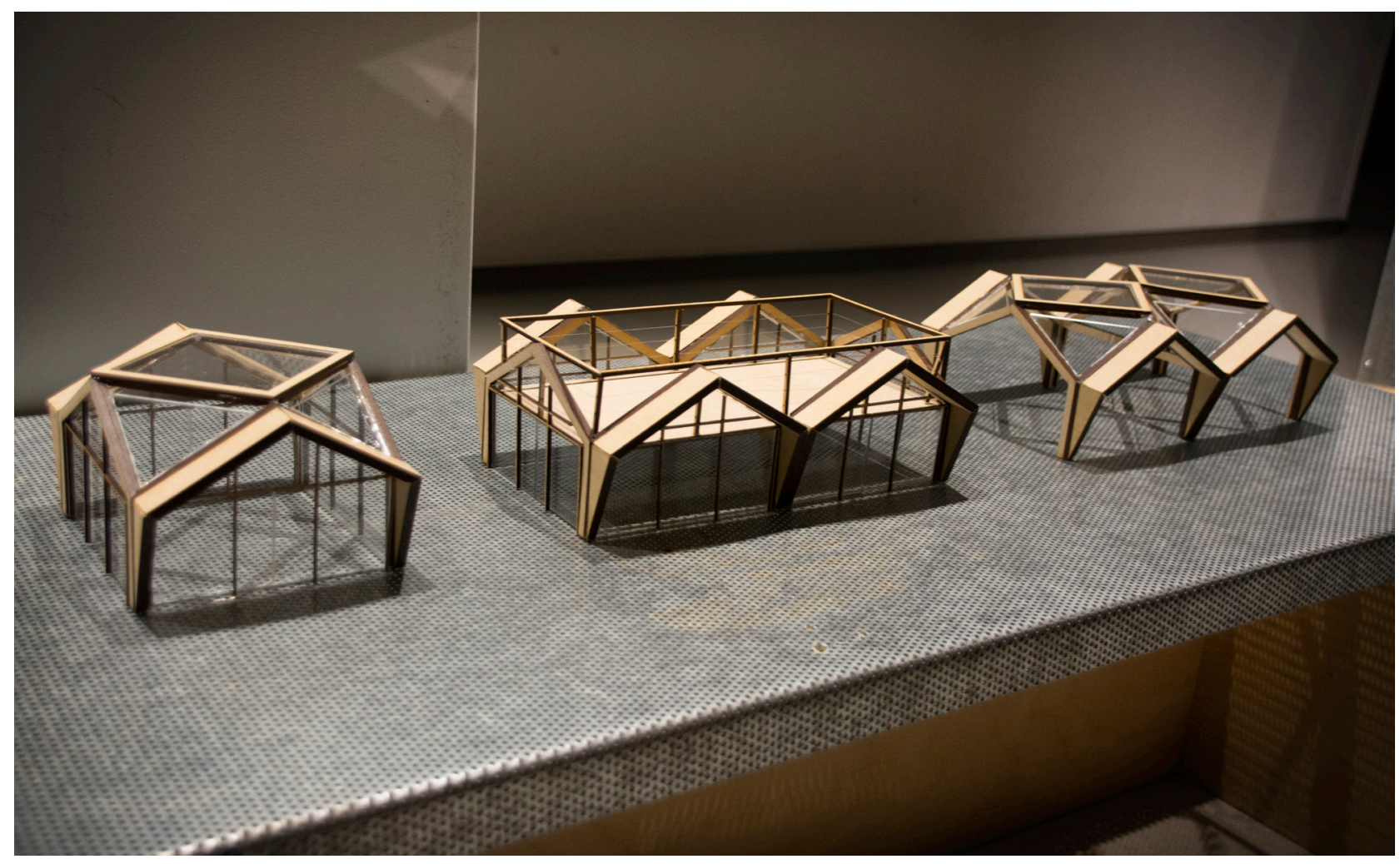

FIGURE A.4

A collection of 1:50 models of the various commercial vendors

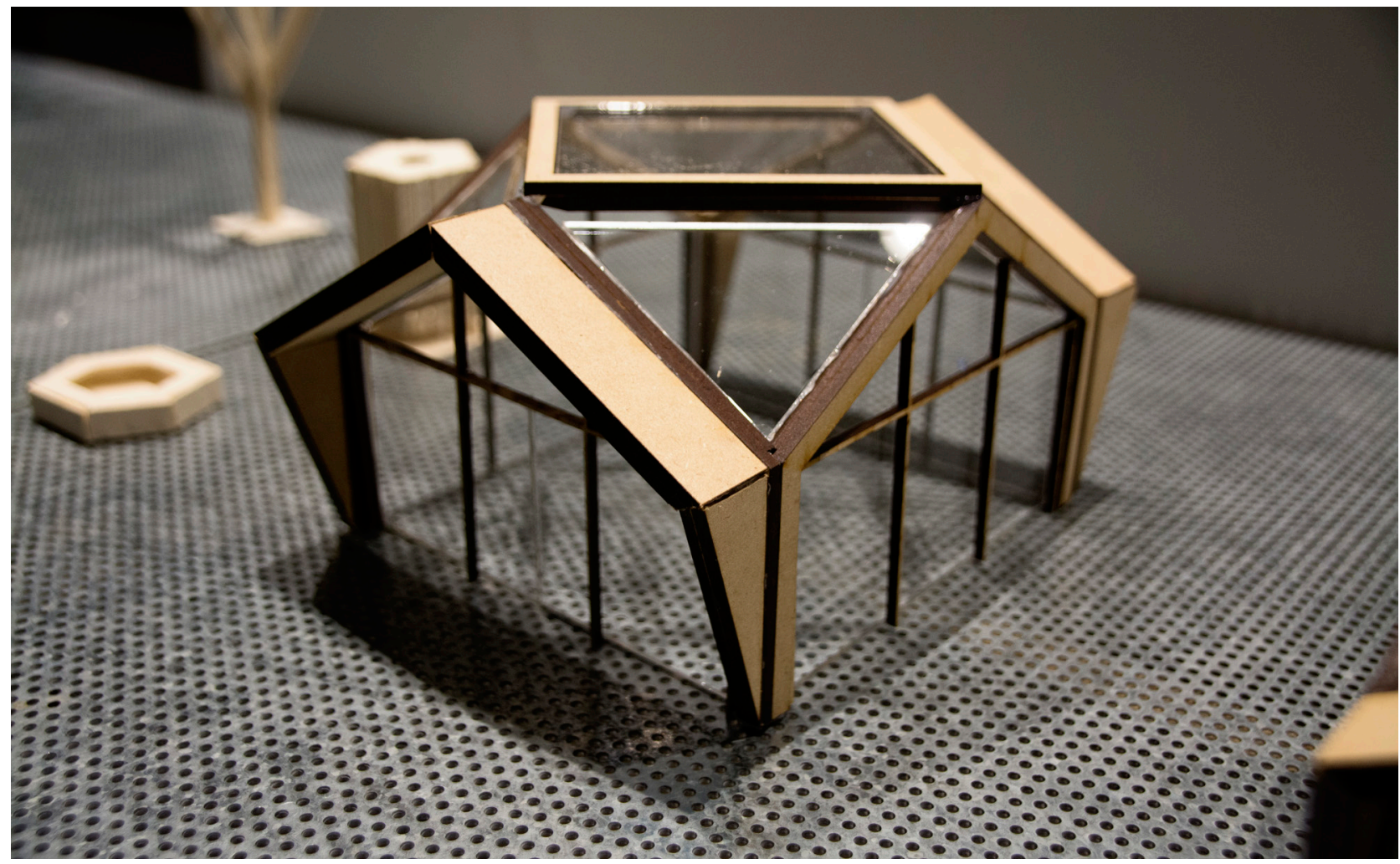

FIGURE A.5

1:50 model of the single-module commercial vendor 


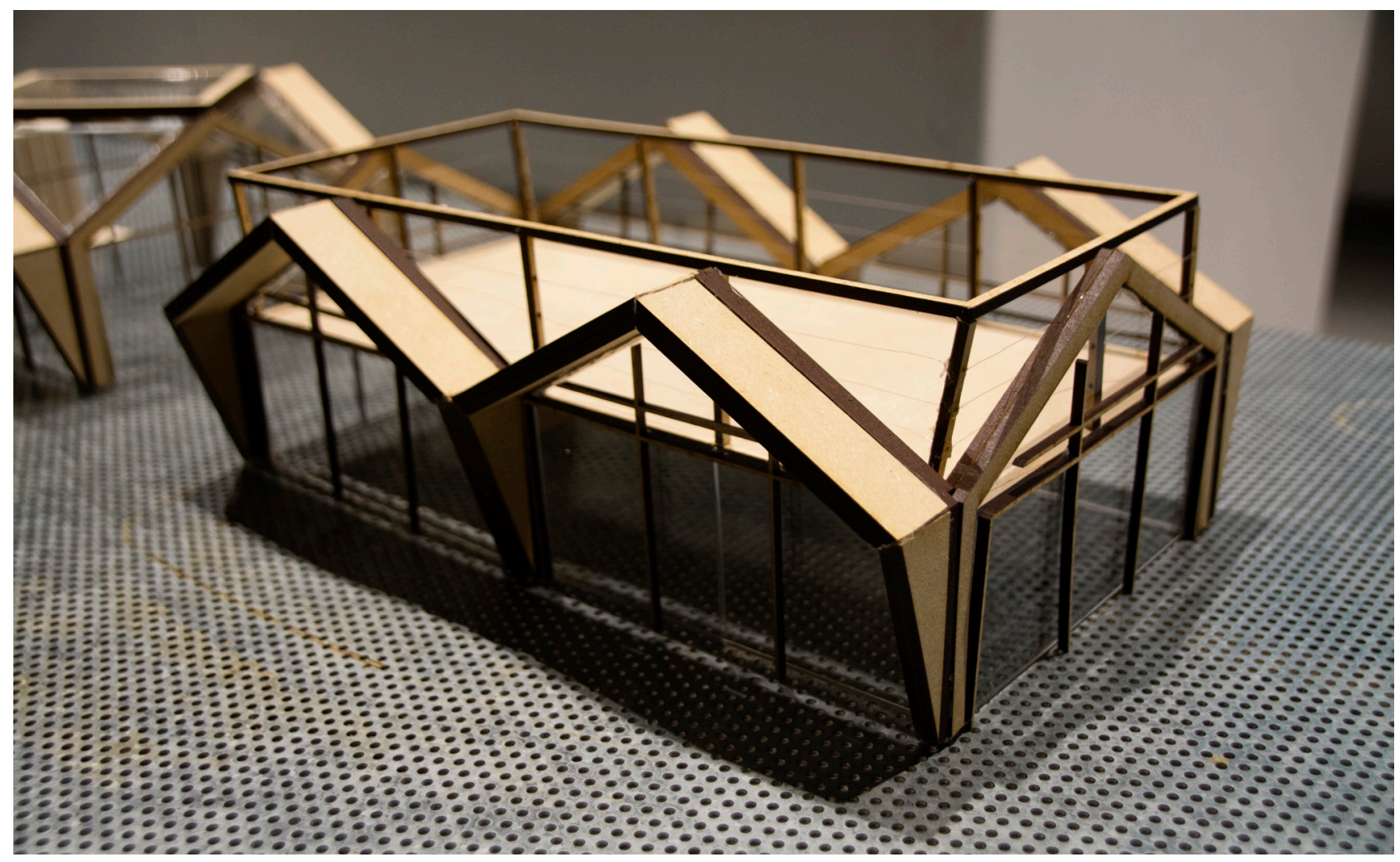

FIGURE A.6

1:50 model of the double-module commercial vendor with elevated patio space

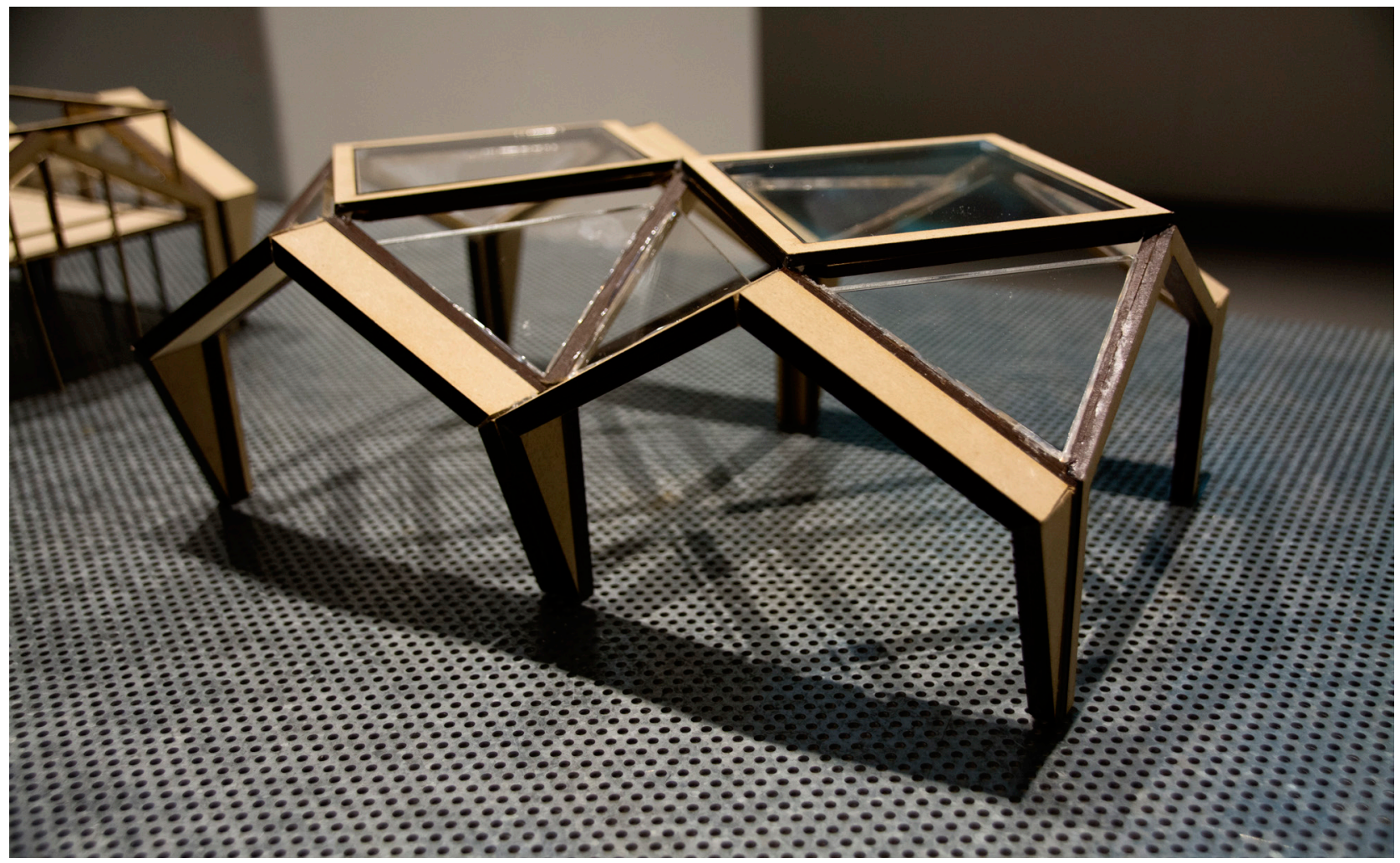

FIGURE A.7

1:50 model of the double-module outdoor seating pavilion 


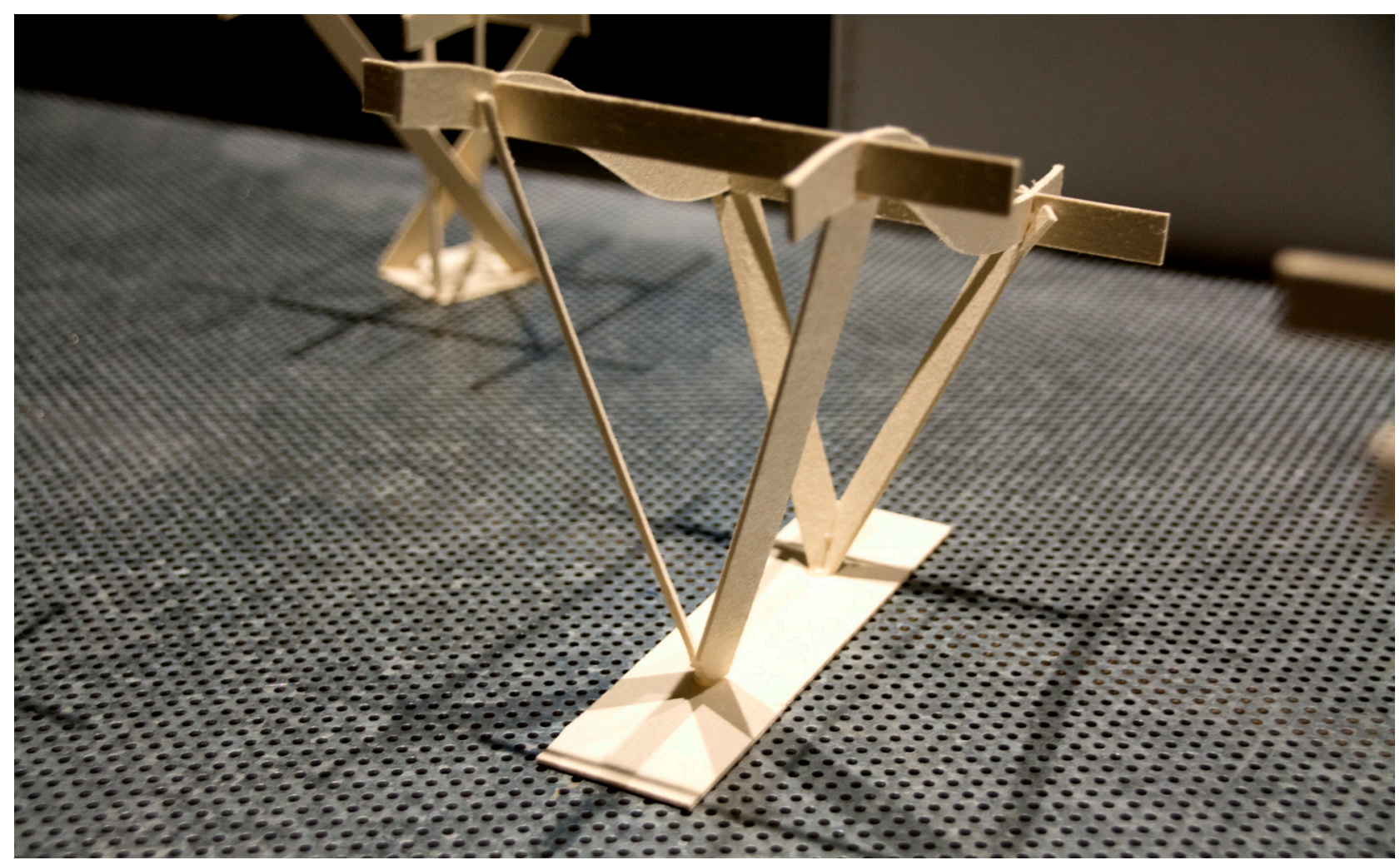

FIGURE A.8

1:50 model of experimental canopy support structures: the wave

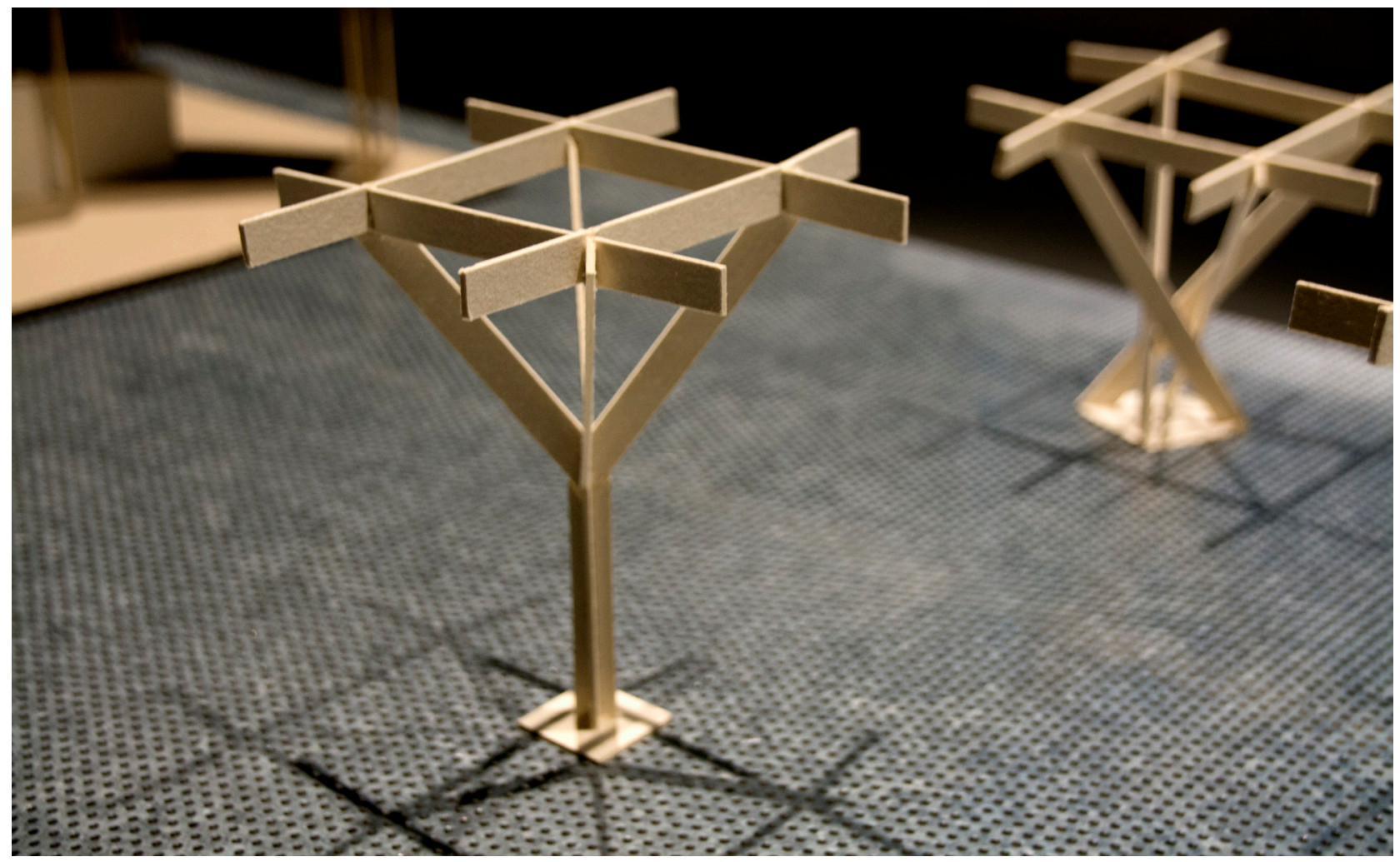

FIGURE A.9

1:50 model of experimental canopy support structures: the orthogonal tree-canopy 


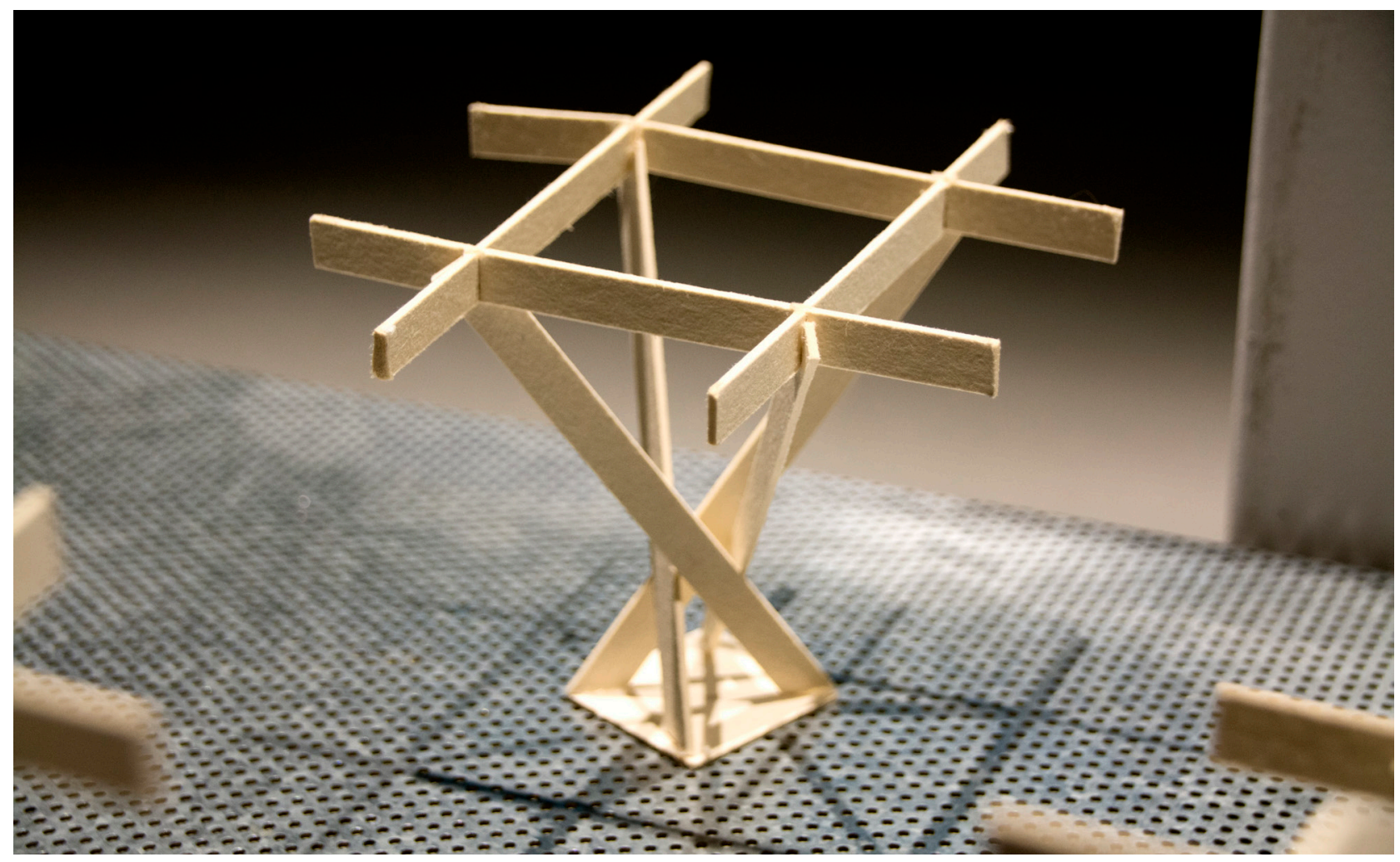

FIGURE A.10

1:50 model of experimental canopy support structures: the twisted tree

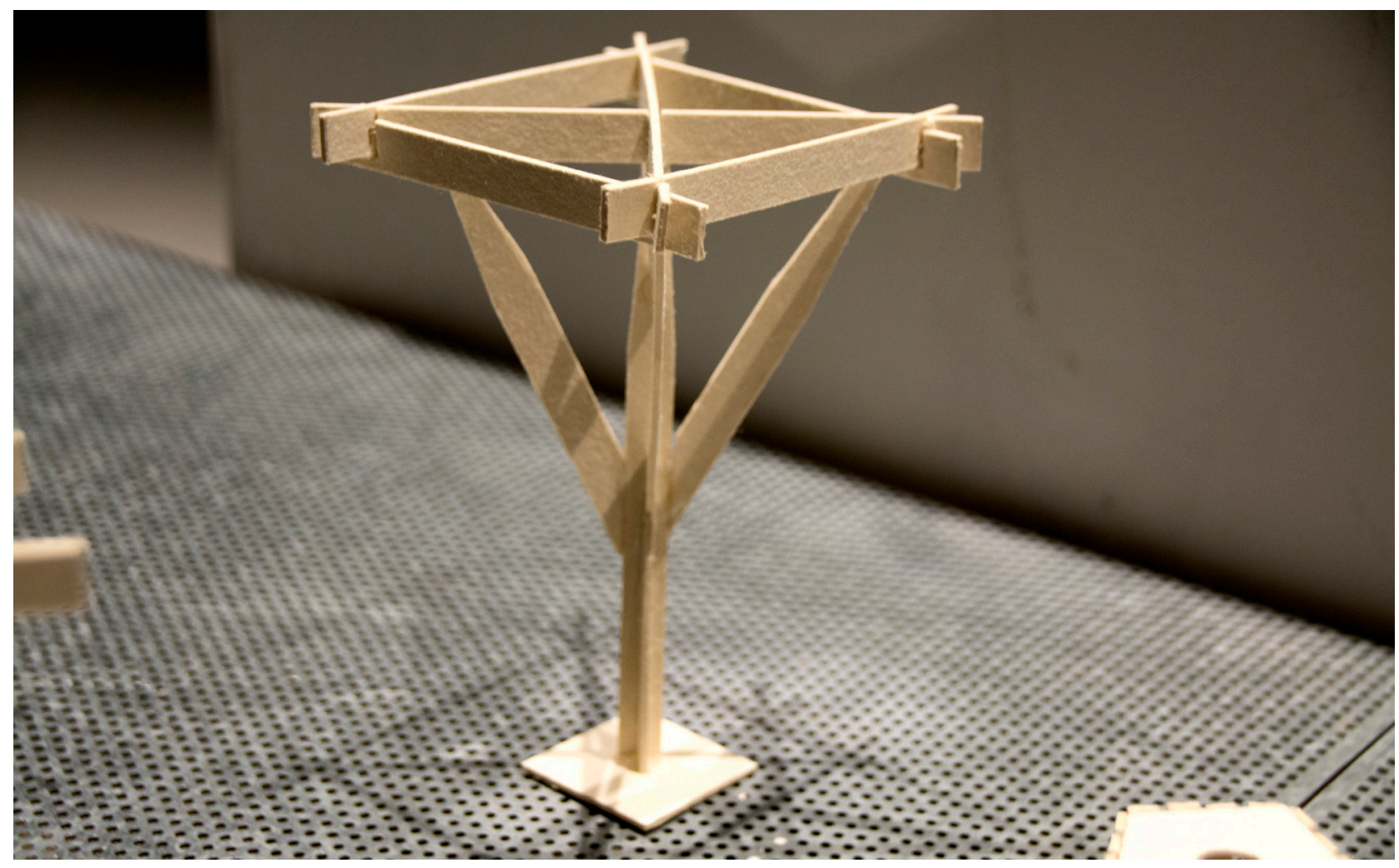

FIGURE A.11

1:50 model of experimental canopy support structures: the tapered tree 
Alexander, C., 1965. A City is Not a Tree. 50th Anniversary ed. New Orleans: Sustasis Press.

Amin, A., 2008. Collective Culture and Urban Public Space. City, 12(1), pp. 5-23.

ArchDaily, 2014. Markthal Rotterdam / MVRDV. [Online]

Available at: https://www.archdaily.com/553933/markthal-rotterdam-mvrdv

[Accessed 04 June 2018].

Barnes, S., 2011. Canada's densest neighbourhood, St. James Town, to possibly get new condos.

Wellesley Institute, 30 March.

Beatley, T., 2011. Biophilic Cities: Integrating Nature Into Urban Design and Planning. Washington : Island Press.

Beatley, T., 2016. Handbook of Biophilic City Planning \& Design. Washington: Island Press.

Beatley, T. \& Newman, P., 2013. Biophilic Cities are Sustainable. Resilient Cities. Sustainability, Volume 5, pp. 3328-3345.

Berry, B. \& Okulicz-Kozaryn, A., 2011. The Urban-Rural Happiness Gradient. Urban Geography, Volume 32, pp. 871-883.

Bianco, P. D., 2008. The spirit of place between the intangible and the tangible. Quebec City, ICOMOS Open Archive.

blogTO, 2013. Corktown Common sets the standard for Toronto parks. [Online] Available at: https://www.blogto.com/city/2013/08/corktown common sets the standard for toronto parks/

[Accessed 13 January 2018]. 


\section{BIBLIOGRAPHY}

Browning, W., Ryan, C. \& Clancy, J., 2014. 14 Patterns of Biophilic Design: Improving Health \& Well-being in the Built Environment. New York: Terrapin Bright Green LLC.

Byrd, H. \& Rasheed, E. O., 2016. The productivity paradox in green buildings. Sustainability, 8(4), pp. 347360.

Canada, S., 2011. NHS Profile, St. James Town. [Online]

Available at: http://www12.statcan.gc.ca/nhs-enm/2011/dp-pd/prof/index.cfm?Lang=E

[Accessed 10 October 2017].

Carr, S., Francis, M., Rivlin, L. G. \& Stone, A. M., 1993. Public Space. Cambridge: Cambridge University Press.

Caulfield, J. \& Peake, L., 1996. City Lives and City Forms: Critical Research and Canadian Urbanism.

Toronto: University of Toronto Press.

City Living, 2014. A History of St. James Town. [Online]

Available at: http://www.urbaneer.com/blog/a mini history on st. james town

[Accessed 13 January 2018].

City of Toronto, 2018. Nathan Phillips Square \& City Hall. [Online]

Available at: https://www.toronto.ca/services-payments/venues-facilities-bookings/booking-city-facilities/

city-squares/nathan-phillips-square/

[Accessed 08 January 2018].

Design Curial, 2014. MVRDV's Markthal. [Online]

Available at: http://www.designcurial.com/news/market-forces-4455805

[Accessed 04 June 2018]. 
Design Curial, 2014. MVRDV's Markthal, Rotterdam - Building Study. [Online]

Available at: http://www.designcurial.com/news/market-forces-4455805

[Accessed 12 June 2018].

Dovey, K., 2008. Framing Places: Mediating Power in Built Form. 2nd ed. London : Routledge.

Dubos, R., 1980. Wooing of the Earth. New York: Scribner.

Egorov, A. I., Mudu, P., Braubach, M. \& Martuzzi, M., 2016. Urban Green Spaces and Health: A Review of Evidence, Copenhagen: WHO Regional Office for Europe.

Evergreen, 2013. Landscape and Child Development - A Design Guide for Early Years-Kindergarten PlayLearning Environments, Toronto: Toronto District School Board.

Feireiss, K. \& Feireiss, L., 2009. Architecture of Change 2: Sustainability and Humanity in the Built Environment. Berlin: Die Gestalten Verlag.

Foucault, M., 1975. Discipline and Punish: The Birth of the Prison. New York: Random House.

Frampton, K., 1998. Towards a Critical Regionalism: Six Points for an Architecture of Resistance. New York, NY: New Press.

Fuller, R. A. et al., 2007. Psychological benefits of greenspace increase with biodiversity. Biology Letters, Volume 3, pp. 390-394.

Garrett, B. L., 2015. The privatisation of cities' public spaces is escalating. It is time to take a stand. The Guardian, 4 August.

Gehl, 2010. Cities for People. Copenhagen: Island Press.

Gehl, J., 2006. New City Life. Copenhagen: The Danish Architectural Press. 
Gehl, J., 2011. Life Between Buildings: Using Public Space. 6th ed. Washington: Island Press.

Gehl, J. \& Gemzie, L., 2004. Public Spaces, Public Life. Copenhagen: Danish Architectural Press.

Gehl, J. \& Svarre, B., 2013. How to Study Public Life. Copenhagen: Island Press.

Gillis, K. \& Gatersleben, B., 2015. A Review of Psychological Literature on the Health and Wellbeing Benefits of Biophilic Design. Buildings, 5(3), pp. 948-963.

Gore, A., 2013. The Future: Six Drivers of Global Change. New York, NY: Random House.

Gurung, M. M., 2014. Expanding Biophilic City Design Theory: A Study of Incorporating Nature Into The Urban Design Elements of Kathmandu. Penn State Electronic Theses and Dissertations for Graduate School.

Hardin, G., 1968. The Tragedy of the Commons. Science, 162(3859), pp. 1243-1248.

Harvey, D., 2011. The Future of the Commons. Radical History Review, Volume 109, pp. 101-107.

Hayes, D. J. \& Berman, M. G., 2015. Nature and the Environment: The Psychology of its Benefits and its Protection. Frontiers in Psychology, Volume 6, pp. 1804-1824.

Heerwagen, J. H., 2000. Green Buildings, Organizational Success, and Occupant Productivity. Building Research \& Information, 28(5), pp. 353-367.

Heerwagen, J. H., 2006. Investing In People: The Social Benefits of Sustainable Design. Sustainable Construction, pp. 19-22.

Henderson, K., Lock, K. \& Ellis, H., 2017. The Art of Building a Garden City: Designing New Communities for the 21st Century. Newcastle upon Tyne: RIBA Publishing.

Honig, B., 1993. Political theory and the displacement of politics. Ithaca: Cornell University Press. 
Howard, S. E., 1965. Garden Cities of To-Morrow. 2 ed. London: Faber.

Jacobs, J., 1961. The Death and Life of Great American Cities. New York: Random House Inc.

Kaplan, R. \& Kaplan, S., 1989. The Experience of Nature: A Psychological Perspective. Michigan :

Cambridge University Press.

Kaplan, R., Kaplan, S. \& Ryan, R., 1998. With people in mind: Design and management of everyday nature. Washington: Island Press.

Kaplan, S., 1995. The Restorative Benefits of Nature: Toward an Integrative Framework. Environmental Psychology, Volume 15, pp. 169-182.

Karmanov, D. \& Hamel, R., 2008. Assessing the restorative potential of contemporary urban environment(s): Beyond the nature versus urban dichotomy. Landscape and Urban Planning, Volume 86, pp. $115-125$.

Kellert, S., 2005. Building for Life: Designing and Understanding the Human-Nature Connection. Washington, DC: Island Press.

Kellert, S., 2016. Biophilic Urbanism: The Potential to Transform. Smart and Sustainable Built Environment, 5(1), pp. 4-8.

Kellert, S. R. \& Calabrese, E. F., 2015. The Practice of Biophilic Design. New Haven: Yale University Press. Kellert, S. R., Heerwagen, J. H. \& Mador, M. L., 2008. Biophilic Design: The Theory, Science, and Practice of Bringing Buildings to Life. New Jersey: John Wiley \& Sons.

Kellert, S. \& Wilson, E. O., 1993. The Biophilia Hypothesis. Washington: Island Press. 
Kesik, T. \& Saleff, I., 2009. Tower Renewal Guidelines - for the comprehensive retrofit of multi-unit residential buildings in cold climates, Toronto: Daniels Faculty of Architecture, Landscape, and Design.

Lynch, K., 1960. The Image of the City. Boston: MIT Press.

Massey, D., 1994. Space, Place, and Gender. Minneapolis: University of Minnesota Press.

Mendler, S., Odell, W. \& Lazarus, M. A., 2005. The HOK Guidebook to Sustainable Design. Hoboken, NJ: Wiley.

Monbiot, G., 2015. The Fortifying Commons. The Guardian, 15 December.

Mumford, L., 1938. The Culture of Cities. New York: Harcourt, Bruce, and Company. Musée Du Quai Branly Jacques Chirac, 2017. An Architecture For A Dream. [Online] Available at: http://www.quaibranly.fr/en/public-areas/an-architecture-for-a-dream/ [Accessed 129 2017].

Nieuwenhuis, M., Knight, C., Postmes, T. S. \& Haslam, A., 2014. The Relative Benefits of Green Versus Lean Office Space: Three Field Experiments. The Journal of Experimental Psychology: Applied, p. Advance Online Publication.

Nixon, R., 2001. Slow Violence and the Environmentalism of the Poor. Cambridge: Harvard University Press.

Noble, K., 2015. Parks in Crisis - Part 6: Are privately owned public spaces the answer to parks deficit?. Spacing Toronto, 21 April.

Norberg-Schulz, C., 1991. Genius Loci: Towards a Phenomenology of Architecture. New York, NY: Rizzoli. Ostrom, E., 2015. Governing the commons. Cambridge: Cambridge University Press. 
Ryan, C. O. et al., 2014. Biophilic Design Patterns: Emerging Nature-Based Parameters for Health and Well-Being in the Built Environment. International Journal of Architectural Research, 8(2), pp. 62-76.

Samueli School of Engineering - UCLA, 2014. Phase Change Composite Materials for Energy Efficient Building Envelopes. [Online]

Available at: https://www.seas.ucla.edu/ pilon/PCMlntro.html

[Accessed 3 July 2018].

Sharma, N., 2017. Private Parkettes Are No Substitute for Real Public Space. Torontoist, 21 August.

Snøhetta, 2017. Muttrah Fish Market. [Online]

Available at: https://snohetta.com/projects/359-muttrah-fish-market

[Accessed 14 June 2017].

Soderlund, J. \& Newman, P., 2015. Biophilic Architecture: A Review of the Rationale and Outcomes. AIMS Environmental Science, 2(4), pp. 950-969.

The United Nations Environment Programme - Sustainable Building and Climate Initiative, 2009. Buildings and climate change: A summary for decision-makers. [Online]

Available at: https://www.seas.ucla.edu/ pilon/PCMIntro.html

[Accessed 3 July 2018].

TOcore, 2016. TOcore Neighbourhood Population Profiles, Toronto: City of Toronto - City Planning Department.

Toronto Neighbourhood Guide, 2018. History of Yorkville. [Online]

Available at: http://www.torontoneighbourhoods.net/neighbourhoods/midtown/yorkville/history

[Accessed 13 January 2018]. 
Torrance, S., 2013. City of Toronto Guidelines for Biodiverse Green Roofs, Toronto: Toronto City Planning.

Tuan, Y.-F., 1974. Tophilia: A Study of Environment Perception, Attitudes, and Values. Toronto: Prentice-Hall Inc.

Tucker, P., Gilliland, J. \& Irwin, J. D., 2007. Splashpads, Swings, and Shade: Parents' Preferences for Neighbourhood Parks. Canadian Journal of Public Health, 98(3), pp. 198-202.

Urban Toronto, 2014. Corktown Common. [Online]

Available at: http://urbantoronto.ca/database/projects/corktown-common

[Accessed 13 January 2018].

Vogt, G., 2012. Miniature and Panorama. Baden: Lars Muller Publishers.

Weisman, A., 2007. The World Without Us. First ed. New York: St. Martin's Press.

Wheeler, S. M. \& Beatley, T., 2014. The Sustainable Urban Development Reader. Third ed. Abingdon: Routledge.

Wilson, E. O., 1986. Biophilia. Second ed. Cambridge: Harvard University Press.

Wilson, W. H., 1989. The City Beautiful Movement. Baltimore: The Johns Hopkins University Press. 
Anthropocene: A period of time which was initiated when humans began having a substantial impact on the Earth's land use, resources, ecosystems, biodiversity, climate, and geology

Biophilia Hypothesis: [Bio-] meaning life, [Philia] meaning love, the Biophilia hypothesis was developed by Edward O. Wilson in 1984. It is "the innately emotional affiliation of human beings to other living organisms" - E.O. Wilson. It is a movement towards developing healthy and productive habitats which extends the theory and practice of green building into a new dimension: human connection with architecture.

Biophilic Design: Design which focuses on aspects of the natural world which contributes to human health, productivity, and well-being.

Biophilic Urbanism: The systematic application of biophilic design interventions at an urban scale.

Commons: A social and political entity in which resources are publicly owned, shared, and protected.
Critical Regionalism: A place-based design movement that situates itself as an effort to counter the placelessness and lack of identity of contemporary urban environments.

Environmental Justice: the methodology of considering the lifecycle impacts of every design decision on the environment

Ephemeral: An architectural quality which encourages frequent yet momentary connections between users and design, most commonly achieved through materiality (tactility, colour, finish texture, material selection, etc.).

Genius Loci: The unique and distinctive atmosphere or spirit of place. It is comprised of the social, cultural, geographic, demographic, and environmental contexts which shape and define place.

Green Roof: An extension of an above grade roof, built on top of a human-made structure, that allows vegetation to grow in a growing medium and which is designed, constructed and maintained in accordance with the Toronto Green Roof Construction Standard. 


\section{LEXICON}

Key Performance Indicator (KPI): A metric representing an actual or perceived performance change, whether it be positive or negative. It is a dependent variable and may change in response to a change factor(s) which influence the metric being evaluated.

Nature: The biological realm; all living things. Can be substituted with Organic.

Natural: Products/resources of the Earth that have not been influenced by human interference - no longer in existence. As there is no longer any resources which are not affected through the Anthropocene, the term natural within this thesis is used interchangeably with nature to identify components of the biological realm.

Phenomenology: A systematic reflection on and study of the structures of consciousness and the phenomena that appear in acts of consciousness (Edmund Husserl).

Placelessness: The antithesis of place-based design. The resulting divorce of design from connection to the culture or ecology of place
Research+Design: The process of conducting research while designing, mediating between the two and relying on one another to inform each other. Includes digital, print, augmented, and virtual mediums for representation.

Resiliency: The capacity to withstand extreme forces of change through creating stronger connections between architecture and its users.

Resources: Biological and human-synthesized goods, technologies, knowledge and inventions which have established value in the market.

\section{Restorative Environmental Design: A two-} pronged approach to design which aims to be both a low-environmental-impact strategy which minimizes and mitigates adverse impacts on the natural environment as well as a positive environmental impact or biophilic design approach which fosters beneficial contact between people and nature in modern buildings and landscapes

Slow Violence: Issues which occur gradually and out of sight, a violence of destruction that is dispersed across time, an attritional violence that is not typically viewed as violence at all. 
Sustainability: The impact people and their behaviours have on the environment and subsequently designing in such a way to mitigate their footprint. While often criticized as trying to sustain the current unhealthy direction the world is on, it shall be understood that sustainability refers to a method/approach which minimizes the impacts people have on the environment.

\section{Topophilia [Topophilic Design and the Topophilic Dimension]: Place-based} relationships which successfully marry culture and ecology within a geographical context. It is rooted in human-nature; the need to establish territorial control.

Urban Agriculture: The commercial/private practice of cultivating and growing plants within an urban environment.

Vitality: The liveliness or energy which exists within a city.

Wellness: The active process of becoming aware of and making choices towards a healthy and fulfilling lifestyle; a dynamic process of change and growth. 
